\title{
UC-NRLF
}

.

하 24 bا 5 


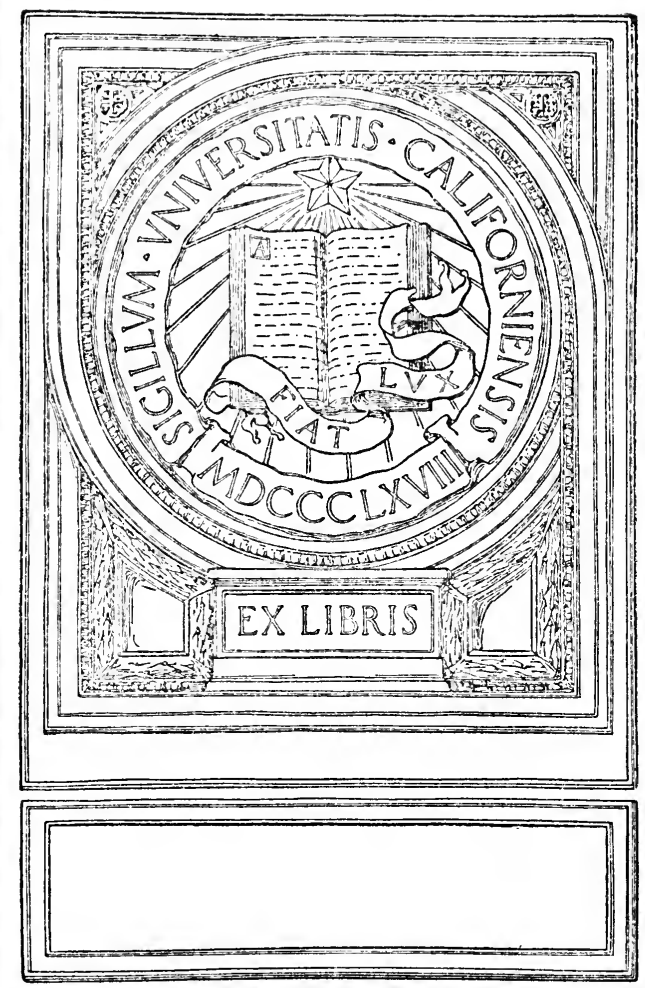




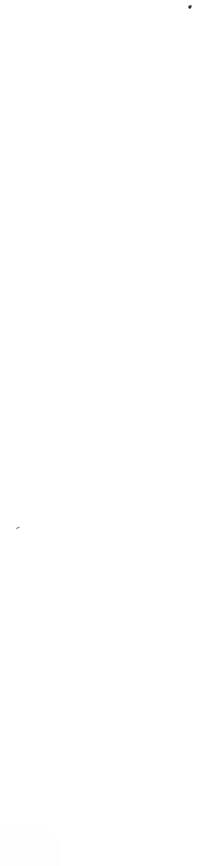



\section{METHODS OF MEASURING TEMPERATURE}




\title{
Griffin's Standard Scientific Text-Books.
}

\section{A TEXT-BOOK OF PHYSICS.}

\author{
By J. H. POYNTING, Sc.D., F.R.S.,
}

Professor of Physics, Birmingham University,

And Sir J. J. THOMSON, O.M., M.A., F.R.S.,

Professor of Experimental Physics in the University of Cambridge.
In Five Volumes.
Large $8 v o$.
Sold separately.

Introductory Volume. Fifth Edition, Revised. Fully Illustrated. 10 s. $6 d$. net.

\section{PROPERTIES O OF MATTER.}

CONTENTs.-Gravitation.-The Acceleration of Gravity.-Elasticity.-Stresses and Strains. -Torsion.-Bending of Rods.-Spiral Springs.-Collision.-Compressibility of Liquids.Pressures and Volumes of Gases.-Thermal Effects accompanying Strain.-Capillarity.Surface Tension.-Laplace's Theory of Capillarity.-Diffusion of Liquids.-Diffusion of Gases.-Viscosity of Liquids.-INDEX.

"We regard this book as quite indispensable not merely to teachers but to physicists of every grade above the lowest."-University Correspondent.

Volume II. Sixth Edition. Fully Illustrated. Price 8s.6d. net.

\section{SOUND.}

CoNTENTS. - The Nature of Sound and its chief Claracteristics. - The Velocity of Sound in Air and other Media.-Reflection and Refraction of Sound.-Frequency and Pitch of Notes.-Resonance and Forced Oscillations.-Analysis of Vibrations.-The Transverse Vibrations of Stretched Strings or Wires.-Pipes and other Air Cavities.-Rods.-Plates.Membranes.-Vibrations maintained by Heat.-Sensitive Flames and Jets.-Musical Sand. -The Superposition of Waves.-INDEX.

"The work ... may be recommended to anyone desirous of possessing an EASY UP-TO-D +TE STANDARD TREATISE On Acoustics."-Literature.

Volume III. Fourth Edition, Revised. Fully Illustrated. Price 15s. net.

\section{HEAT.}

CoNTENTS.-Temperature.-Expansion of Solids.-Liquids.-Gases.-Circulation and Convection.-Quantity of Heat; Specific Heat. - Conductivity.-Forms of Energy ; Conservation; Mechanical Equivalent of Heat.-The Kinetic Theory.-Change of State; Liquid, Vapour.-Critical Points.-Solids and Liquids.-Atmospheric Conditions.-Radiation.Theory of Exchanges.-Radiation and Temperature.-Thermodynamics.-Isothermal and Adiabatic Changes.-Thermodynamics of Changes of State, and Solutions.-Thermodynamics of Radiation.-INDEX.

"Well up-to-date, and extremely clear and exact throughout. . . As clear as it would be possible to make such a text-book."-Nature.

Volune IV. In Three Parts-Two Bound Volumes.

\section{ELECTRICITY AND MAGNETISM.}

Parts I. ANd II. In Cloth. Pp. i-xiv + 246. Price 10s. 6d. net. STATIC ELECTRICITY AND MAGNETISM.

Contents.-Common Phenomena.-Quantity of Electrification. - "Inverse Square" Sistems.-Electric Strain produced in a Field.-Force on a Small Charged Body in the Field.-Potential.-Energy in Electrifled Systems.-Measuring Potential and Capacity.Dielectric, Specific Inductive Capacity, Residual Effects.-Spec.Ind. Capacity and Refractive Index.-Stress in Dielectric.-Alteration in Dielectric under Strain.-Pyro- and Piezoelectricity.-Magnetic Actions.-Molecular Hypothesis of Magnets.-Magnets other than Iron.-Inverse Square Law. - Magnetic Fields. - Induced Jagnetism. - Permeability.Measurements of Susceptibility and Permeability.-Terrestrial Magnetism.-Magnetism and Light.-INDEX.

"The student of Physics has only to know of its existence and its authors in order to possess it."-Electrical Times.

Part III.-Is in the Press.

volume v. LIGHT-Is in Preparation.

London: CHARLES GRIFFiN \& Co., Ltd., Exeter St., Strand, W.C. 2. 


\title{
METHODS OF MEASURING TENPERATURE
}

BY

EZER GRRIFFITHS, D.Sc.

(FORMERLY FELLOW OF THE UNIVERSITY OF WALES)

ASSISTANT IN THE HEAT DEPT. OF THE NATIONAL PHYSICAL LABORATORY

\author{
WITH AN INTRODUCTION \\ BY
}

Principal E. H. GRIFFITHS, F.R.S.

WITH 81 ILLUSTRATIONS

LONDON

CHARLES GRIFFIN AND COMPANY LIMITED

EXETER STREET, STRAND, W.C. 2

1918

[All rights reserved] 


$$
\cos ^{2}
$$




\section{PREFACE}

'I'He present volume is written for those concerned with the measurement of temperature, whether in scientific investigations or in the control of industrial operations.

Attention has been devoted chiefly to the experimental basis of the methods in general use, the calibration of the instruments, and the precautions which must be observed in practice.

While the volume is complete. in itself, it is assumed that the reader is conversant with the fundamental principles of physics, and the aim has been to extend the general treatment given in standard text-books, such as those of Poynting and 'Thomson.

It was not deemed desirable to devote much space to descriptions of the constructional details of pyrometers, since the information is readily accessible in the catalogues of the manufacturers.

A connected account is given of the classical researches with the gas thermometer, which have established, in a concrete form, the absolute scale of temperature over the range $-200^{\circ}$ to $1550^{\circ} \mathrm{C}$. And it is well to remember that although the electrical and radiation methods enable "relative" measurements to be made with a high degree of precision, they are dependent on the gas thermometer work for their evaluation in terms of the fundamental scale of temperature.

In subsequent chapters the various types of pyrometers are dealt with individually, the theory underlying the method and the calibration of the instrument.

An attempt has been made to set out clearly the errors to which pyrometric observations are liable, when the conditions of use do not comply with those postulated by the theory upon which the design is based; particularly in the case of instruments of the "radiation" type.

The illustrations have been prepared by Mr. Edgar A. Griffiths, and the writer wishes to acknowledge his indebtedness to his brother for his contributions to the work.

The descriptions of the apparatus in use at the National Physical Laboratory have been inserted with the kind permission of the Director, Sir Richard Glazebrook. 



\section{INTRODUCTION}

'THE need of a monograph on the measurement of temperature must, I think, have been evident to every physicist, and it was a great pleasure to me to know that the difficult task of supplying this need was to be discharged by one so capable as Dr. Ezer Griffiths.

A perusal of Dr. Griffiths's book has made me realise how rapid our progress has been in recent times in this essential and hitherto somewhat neglected branch of physical measurement. Accurate measurement of temperature is the basis of nearly all accurate measurements in physics, and it is sad to reflect on the amount of valuable work which has had to be "scrapped" owing to lack of attention to this important matter. That unreliable instrument the mercury thermometer has in the past been used with little knowledge of its imperfections. We can best judge of the advances that have been made by recalling the conditions under which an observer had to work some thirty years ago. About 1888 I had the privilege of being called into consultation by Messrs. Heycock and Neville, who were engaged in an enquiry into the freezing-point of various metals as a basis for their investigations into the nature of certain alloys. We made a careful study of what we then regarded as the standard determinations of temperatures above the boiling-point of water. The discrepancies between the various observers were most startling. For example, the freezing-point of zinc ranged from $342^{\circ}$ to $450^{\circ}$; that of antimony varied by $100^{\circ}$; and at higher temperatures the data were unreliable. We ultimately decided for the purposes of standardisation to accept the following as authentic :-

The boiling-point of aniline

$\begin{array}{lll}" & , & \text { naphthalene } \\ " & " & \text { benzophenone } \\ " & " & \text { mercury } \\ & \text { sulphur }\end{array}$

[at $760 \mathrm{~mm}$.] $184 \cdot 41^{\circ}$ by Ramsay.

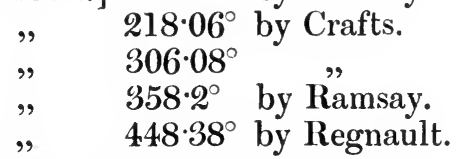

As is shown by Table VII., infra, we were fortunate in our selection, for, with the exception of sulphur, later determinations have led to but small modifications of the above numbers:

In 1891 I published * the results of the standardisation of platinum thermometers based on the above data. At the time when the observations were taken I was unacquainted with the admirable investigation by Professor Callendar $\uparrow$ into the relation between platinum and the air scales of temperature. In the autumn of $1889 \mathrm{I}$ for the first time 
became acquainted with this work. I then found that the upper portion of the curves obtained by me departed materially from the parabolic formula given by Callendar, although up to a temperature of something like $350^{\circ}$ we were in fair agreement. Consultation with Callendar led to the conclusion that either his formula did not hold with platinum thermometers constructed like mine, or that the value given by Regnault for the boiling-point of sulphur was too high. We, in consequence, joined forces and conducted under stringent conditions an enquiry into the true boiling-point of sulphur, the result being stated as follows: "the temperature by the normal air thermometer, at constant pressure, of the saturated vapour of sulphur boiling under standard pressure is $444.53^{\circ}$." Not only was the accuracy of Professor Callendar's conclusions thus established, but the results of both his and my own determinations were brought into close agreement. As shown by 'Table II. in Dr. Griffiths's work, various observers, both here and in the United States, have since redetermined the boiling-point of sulphur under varied conditions, and their investigations have but the more firmly established the conclusions we arrived at, and, as stated on page 8 infra, "the value $444.53^{\circ} \mathrm{C}$. is at the present time the generally accepted value of the boiling-point of sulphur on the thermodynamic scale." Many of the discrepancies between previous observers at higher temperatures are thus explained, for they were obtained by extrapolation from the value of sulphur obtained by Regnault, and as this was about $4^{\circ}$ too high, and as this error became rapidly magnified by extrapolation, it was evident that little value could be attached to the then accepted numbers at temperatures exceeding $500^{\circ}$.

Messrs. Heycock and Neville determined the freezing-point of such substances as gold, copper, silver, by means of thermometers standardised by the assumption of the parabolic formula and the above-determined boiling-point of sulphur; and when it is remembered that this meant the extrapolation over something like $600^{\circ}$, the agreement of their results (see 'Tables VII. and X., infra) with those obtained by subsequent observers is a convincing proof of the validity both of the parabolic formula up to a temperature of about $1100^{\circ} \mathrm{C}$. and of the sulphur boiling-point. I venture to say that the recent increase in the accuracy of measurement of high temperatures is in no small degree due to the investigations of Callendar and the confirmation of his conclusions, during the period 1887-1893, by the observers above referred to.

The chapters on the Thermocouple and Radiation pyrometers indicate how rapid has been the subsequent advance and also its importance for the purposes of industry.

If we consider the melting-point of palladium $\left(1549^{\circ} \mathrm{C}\right.$.) as satisfactorily determined, we may regard our methods of observation and our knowledge of the temperature scale about $1600^{\circ} \mathrm{C}$. as comparable both in facility and accuracy with our measurements some thirty years ago in the neighbourhood of $600^{\circ} \mathrm{C}$.

E. H. GRIFFI'THS. 


\section{CONTENTS}

\section{CHAP'TER I}

\section{THE FUNDAMENTAL SCALE OF TEMPERATURE}

The hydrogen gas scale between $0^{\circ}$ and $100^{\circ}$ C.: Chappuis' work-Comparison of the resistance thermometer with the air thermometer between $100^{\circ}$ and $600^{\circ} \mathrm{C}$. by Callendar-Determinations of the boiling-point of sulphur-The work of Day and Sosman with the high temperature gas thermometer: from $500^{\circ}$ to $1550^{\circ}$ C.-Henning's comparison of the platinum thermometer scale with the hydrogen gas thermometer down to $-200^{\circ}$ C.-The relation between the practical gas scale and the absolute thermodynamic scale-Standard tem. peratures for calibration purposes

Pp. 1-17

\section{CHAPTER II}

\section{THE MERCURIAL THERMOMETER}

Calibration and corrections of precision mercury thermometers-High temperature range mercury thermometers-Precautions necessary in accurate workThermometer glasses and their characteristics-Calibration of mercury thermometers by comparison in a molten salt bath

Pp. 18-29

\section{CHAP'TER III}

\section{THE RESISTANCE THERIMOMETER}

Siemens' work-Callendar and Griffiths' researches-Extrapolation of the scale of the platinum thermometer for the determination of high temperature freezingpoints-Construction of platinum thermometers-Resistance bridges for thermometric work: Siemens' three-lead bridge: Callendar and Griffiths' compensated lead bridge: Smith's difference bridge: Mueller's bridge-Precautions in working to eliminate various sources of error-Calibration of box coils and bridge wire-Standardisation of resistance thermometers-Types of sulphur boiling-point apparatus-Example of method of reducing platinum thermometer observations-Application of resistance thermometers in precision work at high temperatures-Industrial types of resistance pyrometers 


\section{CHAPTER IV}

\section{THE THERIMOCOUPLE}

Choice of metals for thermoelements-Potentiometers for thermoelectric work: simple circuit type; vernier type; deflectional type-Direct-reading temperature indicators-Insulation and mounting of thermocouples-Welding the wires-Notes on differential couples-Standardisation-Melting-points of metals and salts-Formulæ for the representation of temperature : e.m.f. relationship-Calibration of thermocouples by comparison with a standard couple

Pp. 59-80

\section{CHAPTER V}

\section{THE "FOURTH-POWER" LAW OF RADIATION AND TOTAL RADIATION PYROIMETERS}

Experimental proof of law-Work of Lummer and Pringsheim, Mendenhall and Forsythe-Féry total radiation pyrometer ; Foster's fixed focus pyrometer, etc. -Sources of error in practical forms of radiation pyrometers - Calibration under "black body" conditions

Pp. 81-97

\section{CHAP'TER VI}

\section{TOTAL RADIATION FROM OXIDE AND METALLIC SURFACES}

Emissivity of nickel oxide, iron oxide, molten copper, and copper oxide-Corrections to convert apparent temperatures to true temperatures

Pp. 98-105

\section{CHAPTER VII}

\section{THE DISTRIBUTION OF ENERGY IN THE SPECTRUM OF A "FULL RADIATOR" AND THE PRINCIPLES OF OPTICAL PYROMETRY}

Experimental work on the distribution of energy in the spectrum-Radiation laws :

Wien's, Planck's, and Rayleigh's-Variation with temperature of "total brightness "-Commercial forms of optical pyrometers : disappearing filament type and the polarising type-Theory and calibration of the instrumentsAbsorption devices-Determination of the " effective wave-length " transmitted by red glass-Extension of the scale of optical pyrometers above $1500^{\circ} \mathrm{C}$.Relative merits of the two types-Measurement of temperature in terms of total intrinsic brilliancy

Pp. 106-129 


\section{CHAPTER VIII}

\section{DISTRIBUTION OF ENERGY IN THE HEAT EMISSION SPECTRUM OF THE METALS}

Emissivity of iron, iron oxide, copper, copper oxide, nickel, gold, and silverCorrections to "apparent" temperatures taken with optical pyrometers

Pp. 130-144

\section{CHAPTER IX}

\section{HIGH TEMPERATURE MELTING-POINTS AND BOILING-POINTS}

Melting-points of refractory oxides-Metals of the platinum group-Tungsten and tantalum-The temperature of the positive crater of the electric arc and its dependence on external conditions-"Boiling-points" of the metals and the variation with pressure

Pp. 145-169

\section{APPENDIX}

TABLE XLV. Boiling-point of water at different pressures

P. 171

TABLE XI,VI. Boiling-point of sulphur at different pressures, and the corresponding values of the function $\left\{\left(\frac{t}{100}\right)^{2}-\left(\frac{t}{100}\right)\right\}$

P. 171

TABLE XLVII. Values of $t$ corresponding to platinum temperatures $(p t)$ over the range $-40^{\circ}$ to $1000^{\circ} \mathrm{C}$., assuming $\delta=1.50$

P. 172

TABLE XLVIII. The change in $t$ for a given small change of $\delta$

P. 173

INDEX

P. 175 



\section{CHAPTER I}

\section{THE FUNDAMENTAL SCALE OF TEMPERATURE}

The hydrogen gas scale between $0^{\circ}$ and $100^{\circ} \mathrm{C}$. : Chappuis' work-Comparison of the resistance thermometer with the air thermometer between $100^{\circ}$ and $600^{\circ} \mathrm{C}$. by Callendar-Determinations of the boiling-point of sulphur-The work of Day and Sosman with the high temperature gas thermometer : from $500^{\circ}$ to $1550^{\circ}$ C.- Henning's comparison of the platinum thermometer scale with the hydrogen gas thermometer down to $-200^{\circ} \mathrm{C}$. - The relation between the practical gas scale and the absolute thermodynamic scale-Standard temperatures for calibration purposes.

The scale of temperature.-In the early development of the science of temperature measurement the mercury in glass thermometer held undisputed sway as the fundamental standard; in time it was realised that a temperature scale based on the expansion of mercury relative to glass had serious limitations. 'The composition of the glass had a considerable influence on the resulting scale, and, moreover, the range of such instruments was extremely limited. These considerations led experimentalists like Regnault to prefer the scale of the gas thermometer as the standard of reference, with the mercury thermometer as a working standard, calibrated by reference to the gas scale.

Later the thermodynamical researches of Lord Kelvin showed that it was possible to formulate a scale of temperature which would be independent of the intrinsic properties of any particular substance and that it would be identical with the scale given by a "perfect gas."

A "perfect gas" is defined as one in which the expansion (which defines the temperature), whether under constant volume or pressure, would increase exactly in proportion to the quantity of heat required to produce it.*

Although none of the known gases are perfect in the sense contemplated by the above definition, the departure of such gases as hydrogen, helium, argon, oxygen, and nitrogen, under the conditions obtaining in gas thermometry, is small and, moreover, is amenable to calculation.

In passing, it may be remarked that the computed value of the correction increases with the temperature, and is of the order of about $1^{\circ}$ at $1100^{\circ} \mathrm{C}$. for air and nitrogen.

* A "perfect gas" may also be described as one which obeys Boyle's law, and one in which a free expansion, with no external work, would cause no change in temperature. 
METHOHS OY MEASURING TEMPERATURE

'The gas thermometer is never used directly in practical work for the measurement of temperatures, owing to the complications that would be involved. Consequently to realise the gas scale for practical work it is necessary to transfer the scale to auxiliary standards.

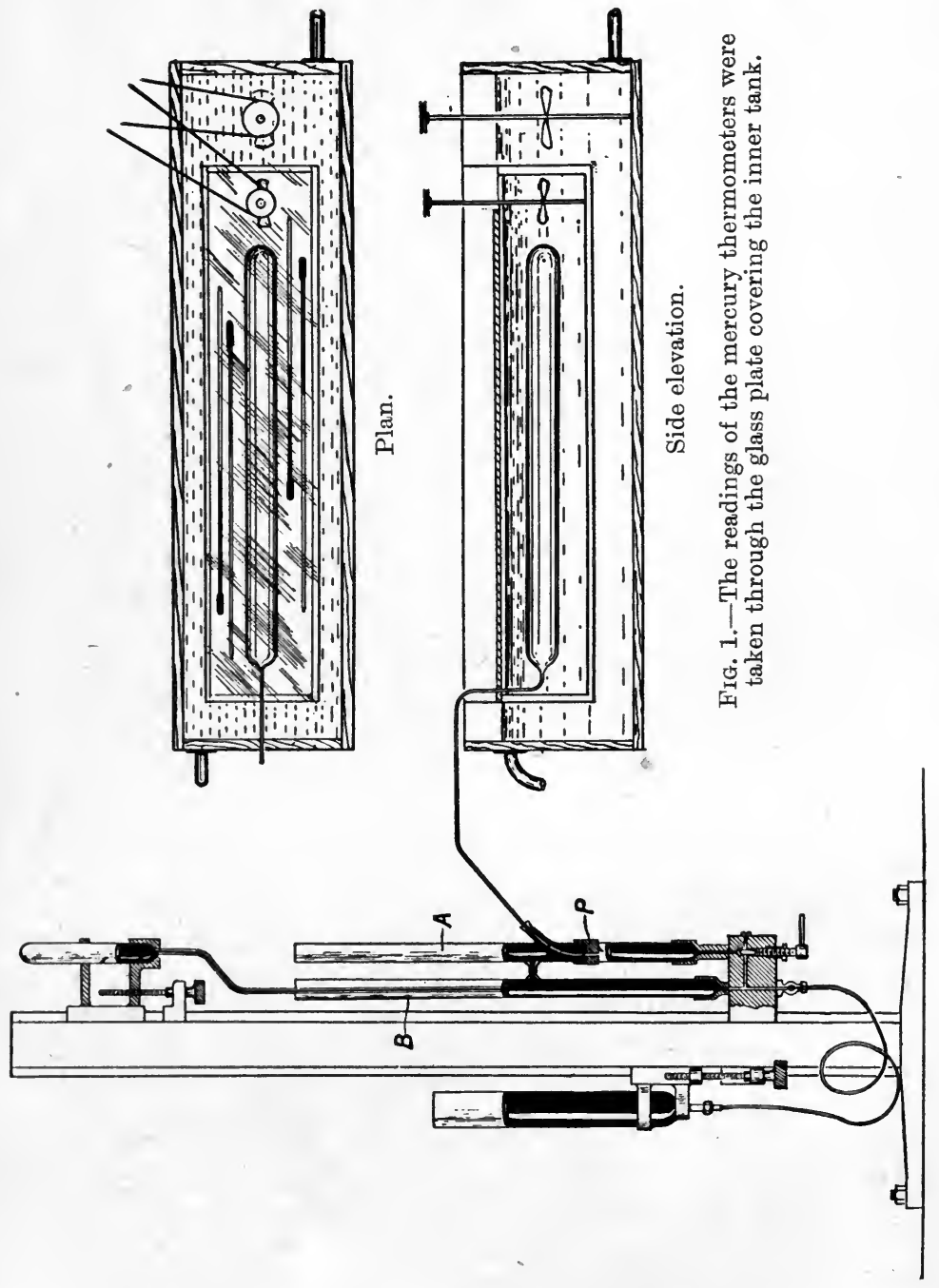

Such secondary standards may be mercury thermometers, thermocouples, or the melting-points or boiling-points of pure substances.

The scale from $0^{\circ}$ to $100^{\circ} \mathrm{C}$.--In 1884 Chappuis, at the Bureau International des Poids et Mesures, commenced an experimental investigation of the divergence of the scale of some "Verre Dur" 
mercury thermometers from that of the constant-volume hydrogen gas thermometer.

A careful comparative study was made of eight mercury thermometers by methods which are described in Chapter II., and the various corrections ascertained.

The accuracy of work was such that when the thermometers were directly compared in the same bath their observations agreed to $0.002^{\circ}$ - after the application of the corrections.

The next step was the determination of the divergence of this "Verre Dur" mercury thermometer scale from that of the gas thermometer.

The general features of the apparatus are shown in Fig. 1.

The bulb of the gas thermometer was of platinum-iridium alloy, $110 \mathrm{cms}$. long by $3.6 \mathrm{cms}$. in diameter, the bulb being connected to the manometer by a platinum capillary 1 metre in length and $0.7 \mathrm{~mm}$. in diameter. 'The end of the capillary was soldered to the plug (P), which was connected to the closed end of the manometer.

The barometer was inserted into the open limb and permitted the total pressure on the gas to be obtained from a single reading. The mercury in the tube A was in communication with that in B by way of the cross-tube. The function of the tube $\mathbf{A}$ was to enable the barometric height to be determined from observations of the difference in level in the same vertical line: the barometric height being required when standardising the instrument in steam.

The ice-point was obtained by surrounding the bulb with powdered ice, while the steam-point was determined with a horizontal type of hypsometer.

The apparatus employed in the comparison with the mercury thermometers is shown on the right in the diagram : the thermometers being laid alongside the gas thermometer bulb in a well-stirred water bath.

The coefficient of cubical expansion of the bulb was calculated from the value of the linear expansion, this being directly determined by measuring the length of the bulb at four temperatures.

Experiments were also made with the gases nitrogen and carbon dioxide, the initial pressure in each case being $1000 \mathrm{mms}$. of mercury.

Taking the hydrogen scale as standard of comparison, the divergences of the various scales from it are shown in 'Table $I$.

It will be observed that the maximum divergence in the case of the mercury "Verre Dur" thermometer is about $0 \cdot 107^{\circ}$ at $40^{\circ} \mathrm{C}$.; for the nitrogen gas thermometer $0.011^{\circ}$; and for the carbon dioxide thermometer $0.060^{\circ}$ at about $45^{\circ} \mathrm{C}$.

Calculation shows that the corrections necessary to convert readings on the hydrogen scale in the range $0^{\circ}$ to $100^{\circ}$ to the absolute thermodynamic are of the same order as the probable error of experiment in gas thermometer work. 
TABLE I.

\begin{tabular}{|c|c|c|c|}
\hline$t_{\mathrm{H}}{ }^{\circ} \mathrm{C}$. & ${ }_{\mathrm{N}}-t_{\mathrm{H}}{ }^{\circ} \mathrm{C}$. & $t_{\mathrm{CO}_{2}}{ }^{-t_{\mathrm{H}}{ }^{\circ} \mathrm{C} .}$ & $t_{\mathrm{Hg}-t_{\mathrm{H}}{ }^{\circ} \mathrm{C} .}$ \\
\hline & 0 & 0 & 0 \\
0 & +0.006 & +0.025 & +0.052 \\
10 & +0.010 & +0.043 & +0.085 \\
20 & +0.011 & +0.054 & +0.102 \\
30 & +0.011 & +0.059 & +0.107 \\
40 & +0.009 & +0.059 & +0.103 \\
50 & +0.005 & +0.053 & +0.090 \\
60 & +0.001 & +0.044 & +0.072 \\
70 & -0.002 & +0.031 & +0.050 \\
80 & -0.003 & +0.016 & +0.026 \\
90 & 0 & 0 & 0 \\
100 & & & \\
\hline
\end{tabular}

The negative values for $t_{\mathrm{N}}-t_{\mathrm{H}}$ at $80^{\circ}$ and $90^{\circ}$ are within the limits of experimental error, since an error of $0.01 \mathrm{~mm}$. in the pressure reading at $100^{\circ}$ would suffice to account for them.

The scale from $100^{\circ}$ to $600^{\circ} \mathrm{C}$.-Numerous investigations have been made concerning the gas scale over this range. At the present day it is generally accepted that the platinum resistance thermometer (standardised in ice, steam and sulphur vapour) will give a scale identical with that of the gas thermometer, to the same order of accuracy as that attainable in intercomparisons with the gas thermometer:

This important conclusion was arrived at by Callendar, who in 1887 made a direct determination of the resistance of a particular specimen of platinum wire at various temperatures up to $600^{\circ} \mathrm{C}$. The platinum spiral was sealed into the bulb of the air thermometer by means of which the temperature was obtained.

By this device, Callendar avoided one of the greatest experimental difficulties of that time in gas thermometry, viz. the maintenance by gas heating of a large enclosure at a constant and uniform temperature.

The apparatus is shown diagrammatically in Fig. 2. The gas thermometer was designed for both constant volume and constant pressure work.

Instead of the customary practice of confining the gas by a column of mercury a sulphuric acid gauge was employed, which increased the sensitivity seven-fold, and also eliminated capillary errors entailed by the use of a small-bore tube.

'This gauge is denoted by the letters FGHJK in the diagram. When the three-way tap $\mathrm{T}_{1}$ was turned in the middle of the acid column it prevented movement, whatever the variations of pressure.

The scale FG was adjusted so that when the end of the acid column stood at zero the pressure was the same in both limbs ( $\mathrm{F}$ and $\mathrm{K})$ of the gauge. To determine the pressure in terms of mercury corresponding to each reading of the scale $\mathbf{F G}$, the way AMN was cleared by drawing the mercury into $Q$; the tap $T_{3}$ turned off, $\boldsymbol{T}_{2}$ set in the position $(T)$, and $\mathrm{P}_{2}$ was connected to the open air through drying tubes, so that 
THE FUNDAMENTAL SCALE OF TEMPERA'TURE
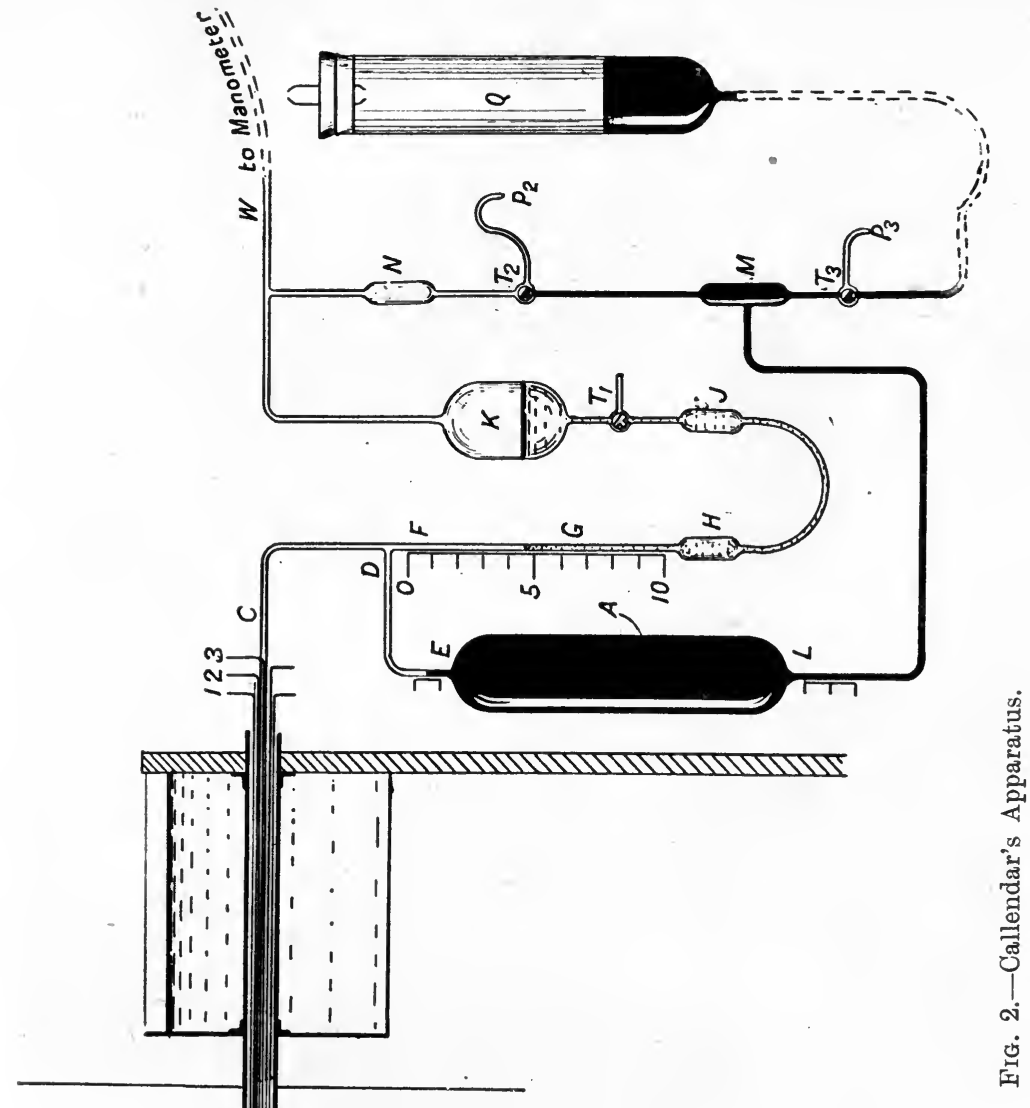
atmospheric pressure was communicated to the $\mathbf{F}$ limb of the $U$ gauge FG by way of $P_{2}$. Readings of the manometer and of the $U$ gauge were taken at various adjustments, from which the probable error of a single pressure observation and the pressure corrections were easily deduced; capillary effects being thus eliminated. In addition to the $\mathrm{U}$ gauge, there is another connection between the bulb capillary $\mathrm{C}$ and the manometer W by way of the bulbs AMN. These were filled with pure dry mercury, and were used for (1) work at constant pressure, (2) calibrating the bulb on the principle of the volumenometer, (3) as an open way through which the bulb could be filled with dry air.

Mercury could be withdrawn or added by means of the adjustable reservoir $Q$, or in weighed quantities by the tubes $\mathbf{P}_{2}, \mathbf{P}_{3}$ dipping into weighed beakers.

The bulb was dried and heated to a temperature of $400^{\circ}$ to $500^{\circ} \mathrm{C}$. $\mathrm{W}$ was connected to an exhaust pump and $\mathrm{P}_{2}$ with the dry air supply; then, by means of $\mathrm{T}_{2}$, the bulb could be connected alternately with either. After a series of such operations, mercury was re-admitted to fill $\mathrm{A}$, and the operation was then complete.

When using the instrument as a constant-pressure thermometer, mercury was allowed to run from $A$ into weighed beakers at $P_{3}$, until the sulphuric acid gauge indicated that the pressure in the bulb was at its original value. The scale FG gave the small variation of pressure, and the weight of mercury the expansion.

During each series of observations, the temperature of the bulb was maintained as steadily as possible.

The thermometer bulb was made from a piece of hard glass tubing ; the coefficient of cubical expansion being deduced from observations on a leugth of the same tubing as that from which the bulb was made. It was observed that the expansion was irregular, on account of the structural and hysteresis changes in the glass.

The resistance coil.-The platinum wire was 2 metres long by $0.013 \mathrm{~cm}$. diameter, wound in the form of a spiral. The resistance at room temperature was approximately $20 \mathrm{ohms}$. By the arrangement of double electrodes (shown in the diagram) the resistance of the lead wire outside the uniformly heated region could be allowed for.

One end of the coil was led out through the capillary connecting the bulb to the manometer (Fig. 3). A double lead of the same

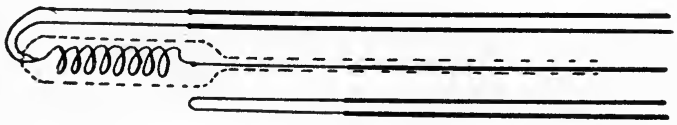

FIG. 3.

wire, and which was coated with the same hard glass to imitate it exactly, was laid alongside. 'The other double lead consisted of $10 \mathrm{cms}$. of fine platinum wire, to the mid-point of which the other end of the spiral was fused. The fine wires were bent double and fused 
through the glass, while the projecting ends were fused on to thick $(0.096 \mathrm{~cm}$.) platinum wires coated with hard glass and laid alongside the others.

The resistance of the leads was determined on each occasion, and the correction amounted to about 3 per cent. of the total resistance.

The experiments showed that to the degree of accuracy attainable in the observations (about $1^{\circ}$ ), the variation of resistance of platinum with temperature could be represented by a parabolic formula.

The subsequent investigations of Callendar and Griffiths showed that this was generally true for wires of varying degree of purity, when the appropriate values of the coefficients were inserted in the parabolic formula.

In a direct determination of the boiling-point of sulphur with the gas thermometer, they obtained the $444.53^{\circ} \mathrm{C}$., which was about $4^{\circ}$ lower than that previously obtained by Regnault.

Harker and Chappuis (1899), and later Holborn and Henning (1911), submitted the parabolic formula to a rigorous examination. Employing a liquid bath to obtain uniformity of temperature, they made a direct comparison of a number of platinum thermometers with the gas thermometer at various temperatures between $100^{\circ}$ and $500^{\circ} \mathrm{C}$., and found no divergence greater than the probable error of experiment.

While these researches proved conclusively the validity of the parabolic formula for the representation of the variation with temperature of the resistance of platinum, there still remained very considerable discrepancies between the various values ascribed to the boiling-point of sulphur on the gas scale.

This is a fixed point of importance in practical thermometry on account of its use in the standardisation of resistance thermometers. Since a determination of the resistance value in melting ice, steam, and the vapour of boiling sulphur under standard pressure is sufficient to determine the constants of the parabolic formula.

Determinations of the boiling-point of sulphur.-The value $448.38^{\circ} \mathrm{C}$. obtained by Regnault was found later to be nearly $4^{\circ}$ too high, doubtless on account of the superheating of the vapour in his form of apparatus.

In the course of their comparison of the resistance thermometer with the gas thermometer, Harker and Chappuis, and Holborn and Henning, made some determinations of the boiling-point of sulphur on the gas scale, employing the resistance thermometer as intermediary. Their values are indirect in so much that the gas thermometer was not directly employed to determine the temperature of the sulphur vapour, but are entitled to full weight, since the resistance thermometer was directly compared with the gas thermometer in salt baths at temperatures in the vicinity of the sulphur boiling-point.

Day and Sosman (1912) made a direct determination of the sulphur point, using a nitrogen-filled thermometer, whose bulb was of platinumrhodium alloy. It was of 205 c.cs. capacity, and the nitrogen was under an initial pressure of $500 \mathrm{mms}$. of mercury. 
Great precautions were taken to eliminate systematic errors. An aluminium shield surrounded the bulb in the sulphur tube, to prevent the condensed sulphur from lowering its temperature below the true boiling-point, and also to eliminate radiation loss to the walls of the tube.

The sulphur bath was electrically heated, and it was found that 35 per cent. variations in the current produced no variation in the observed boiling-point.

To ascertain whether the temperature of the walls of the tube had any influence in some of the experiments, the external jacket was heated until the temperature of the air gap was as high as that of the sulphur vapour within the tube. Provided the tube was full of vapour this produced no apparent change in the value obtained.

A direct comparison of the temperature given by this form of apparatus with that obtained in the Meyer tube form of sulphur boiling apparatus (Fig. 33) devised by Callendar and Griffiths, showed a systematic difference of but $0.04^{\circ}$.

The probable source of the divergences in the results obtained by various observers since the time of Regnault is uncertainty in the coefficient of cubical expansion of the bulb material.

Fused quart $z$ has the smallest coefficient of the materials available for the construction of the bulb of gas thermometers. Values obtained by Eumorfopoulos with a constant-pressure thermometer constructed of fused silica are given in 'Table II. below.

TABLE II.

Gas thermometer determinations of the boiling-point of sulphur since 1890 .

\begin{tabular}{|c|c|c|c|c|c|c|}
\hline Date. & Author. & Thermometer. & Gas. & $\begin{array}{c}\text { Pressure, } \\
\text { mmis. }\end{array}$ & $\begin{array}{l}\text { Original } \\
\text { figure. }\end{array}$ & $\begin{array}{l}\text { Thermo- } \\
\text { dynamic } \\
\text { scale. }\end{array}$ \\
\hline 1890 & Callendar \& Griffiths & Constant & Air & 760 & $444.53 \mathrm{C}$. & $44491 \mathrm{C}$. \\
\hline 1902 & Chappuis \& Harker & Constant & Nitrogen & 530 & $444 \cdot 70 \mathrm{C}$. & $444 \cdot 80 \mathrm{C}$. \\
\hline 1908 & Eumorfopoulos & Constant & Air & 760 & $444.55 \mathrm{C}$. & 444:๖3 C. \\
\hline 1911 & Holborn \& Henning. & $\begin{array}{l}\text { Constant } \\
\text { volume }\end{array}$ & $\begin{array}{l}\text { Hydrogen } \\
\text { Helium }\end{array}$ & $\left.\begin{array}{l}623 \\
612\end{array}\right\}$ & $444 \cdot 51 \mathrm{C}$ & $444.51 \mathrm{C}$. \\
\hline 1912 & Day \& Sosman & $\begin{array}{l}\text { Constant } \\
\text { volume }\end{array}$ & $\begin{array}{l}\text { Nitrogen } \\
\text { Nitrogen }\end{array}$ & $\begin{array}{l}625 \\
502\end{array}$ & $\begin{array}{l}444 \cdot 39 \mathrm{C} . \\
444 \cdot 45 \mathrm{C} .\end{array}$ & $444.55 \mathrm{C}$. \\
\hline
\end{tabular}

The value $444 \cdot 5_{3}{ }^{\circ} \mathrm{C}$. is, at the present time, the generally accepted value for the boiling-point of sulphur on the thermodynamic scale.

The scale from $500^{\circ}$ to $1500^{\circ}$ C.-Numerous investigations with the gas thermometer have been carried to high temperatures. The difficulties the early pioneers had to face were of a very real character, as a study of the memoirs of Princeps, Pouillet and Barus will show. 
Electric furnaces, homogeneous platinum alloy thermo-elements, and other refinements of the present day were unknown.

Amongst the earlier observers to make gas thermometer comparisons above $1100^{\circ} \mathrm{C}$. were Holborn and Wien, who, in 1895, carried the air thermometer scale to $1450^{\circ} \mathrm{C}$. They employed a very refractory porcelain bulb, and the thermocouple was enclosed within the bulb.

'The melting-point of nickel, as determined by the calibrated thermoelement, was found to be $1484^{\circ} \mathrm{C}$., a value exceeding that accepted at the present day. by $32^{\circ}$.

In 1906 Holborn and Valentiner made gas thermometer comparisons up to $1680^{\circ} \mathrm{C}$. 'The bulb was made of pure iridium, and was only 50 c.cs. in capacity. The greatest practical difficulty was the lack of uniformity in the temperature over the bulb, and variations amounting to $60^{\circ}$ occurred along its length.

'The iridium, being volatile at these temperatures, had a very destructive effect on the thermocouples used as intermediary for transferring the scale.

'The melting-point of palladium was found to be $1575^{\circ} \mathrm{C}$., a value $25^{\circ}$ higher than Day and Sosman's recent value.

In 1911 Day and Sosman published an account of an investigation which had been going on for seven years at the Carnegie Institution. Reference must be made to the original paper for a detailed account of the apparatus; here it will suffice to refer to the salient features.

The thermometer was of the constant-volume type filled with nitrogen, the bulb being of about 200 c.cs. capacity. Both bulb and capillary tube were made of a platinum-rhodium alloy, the choice of which was determined by considerations of rigidity at high temperatures and possible contamination of the thermocouples exposed with the bulb in the furnace.

The expansion-coefficient of the bulb was deduced from experiments on the linear expansion of a bar of the same composition.

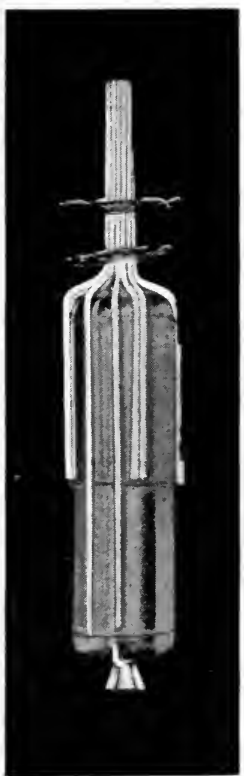

FIG. 4.-Day and Sosman's gas thermometer bulb with thermo - elements in position.

To diminish the danger of deformation of the bulb at high temperatures, the furnace was enclosed in a gas-tight shell, in which the pressure was adjusted at each temperature until equal to that within the bulb.

A section of the furnace and internal arrangements is given in Fig. 5 . For the highest temperatures the heating coil was made in three sections, internally wound.

The current through each coil was separately adjusted, so as to produce as uniform a temperature distribution as possible over the space occupied by the thermometer. 
Internal windings* have disadvantages from the point of view of uniformity, but are inevitable where temperatures up to $1550^{\circ} \mathrm{C}$. are required with platinum windings.

The distribution of temperature over the bulb was obtained by binding a number of pure platinum wires to different points of the bulb and insulating by means of Marquardt capillary tubing. The platinumrhodium walls of the bulb formed the other element of each couple.

A number of independent platinum-platinum 10 per cent. rhodium

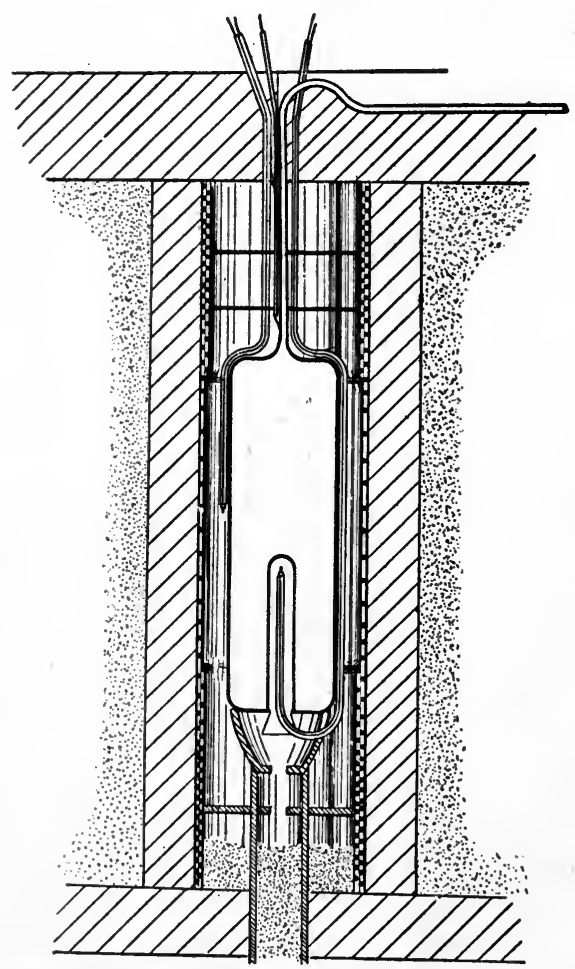

Fig. 5.-Section of Day and Sosman's furnace and gas thermometer bulb.

couples were also inserted in the furnace, one of which was placed in the re-entrant $\uparrow$ tube of the bulb as illustrated in Fig. 5 .

Owing to the impossibility of insulating the thermo-elements completely from the heating circuit at high temperatures, alternating current had to be employed for heating.

* For the same conditions of insulation, etc., an internal temperature $200^{\circ}$ higher can be obtained with the heating coil within instead of over the outside of the porcelain

+ The re-entrant tube for bringing the couple to the centre of the bulb was first employed by Barus in 1889, when using a rotating gas muffle around the thermometer to produce uniform temperature conditions. 
THE FUNDAMENTAL SCALE OF TEMPERATURE 11

The results of the work are embodied in the following melting- and freezing-point determinations of metals and salts of stated purity :-

TABLE III.

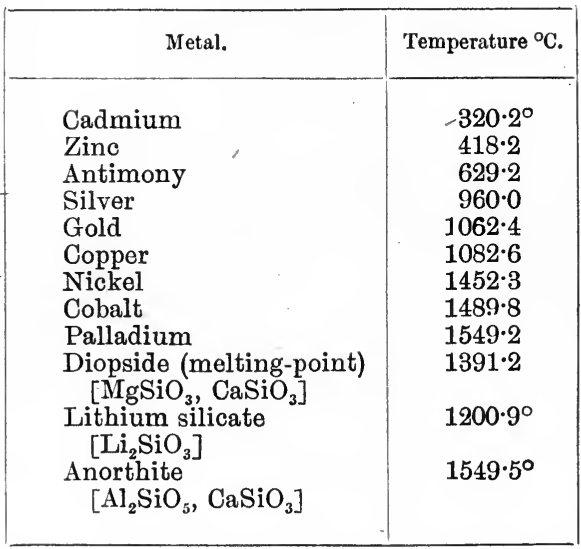

Note.-The salt melting-points are reproducible to probably $1^{\circ}$.

Although the investigation was carried out with great thoroughness, the low temperature portion of the scale, as represented by the freezingpoints of cadmium and zinc, is inconsistent with the work of several observers on the sulphur-point. The difference is considerably greater than the probable error of experiment in this region, and is of the order of $1^{\circ}$.

This fact led Day and Sosman to repeat some of their work at various temperatures up to $600^{\circ} \mathrm{C}$., employing the same gas thermometer immersed in a well-stirred salt bath. The revision confirmed the fact that their previous values were too low by about $1^{\circ}$, and this they explain by stating that an integration of the temperature over the bulb in an electric furnace gives a slightly higher value for the mean temperature than the true value, as obtained in a well-stirred salt bath. 'They further point out that their apparatus was primarily designed for high temperature work, where the use of a salt bath is not at present a practicable proposition.

Since the values at higher temperatures obtained by various observers differ by several degrees, it is impossible to ascertain whether the above error is systematic throughout the range. Above $1000^{\circ} \mathrm{C}$. the values given by Day and Sosman have been tacitly accepted by most workers as a basis for high temperature measurements.

Range $0^{\circ}$ to $-200^{\circ} \mathrm{C}$.-Holborn and Wien in 1901 extended their previous comparison between the gas and platinum thermometers between $0^{\circ}$ and $500^{\circ} \mathrm{C}$., by making comparisons at $-78^{\circ} \mathrm{C}$. and $-190^{\circ} \mathrm{C}$, temperatures obtainable by the use of solid $\mathrm{CO}_{2}$ and liquid air. The coil of the platinum thermometer was enclosed within the bulb of the gas thermometer, so as to minimise the error due to the slowly varying 
temperature. 'They found that the parabolic formula obtained by standardising in ice, steam and sulphur vapour represented the gas scale between $-78^{\circ}$ and $500^{\circ} \mathrm{C}$., but below $-78 \mathrm{C}$., deviated; the divergence amounting to $2.3^{\circ}$ at $-190^{\circ} \mathrm{C}$., the platinum thermometer reading too low.

Travers and Gwyer, in 1905, made comparisons at the same two temperatures with improved apparatus of greater sensitivity. They found the departure of the platinum thermometer at $-190^{\circ} \mathrm{C}$. to be $2.23^{\circ}$, a value in close agreement with that of Holborn and Wien.

Henning, in 1913, carried out a detailed investigation over the range $0^{\circ}$ to $-200^{\circ} \mathrm{C}$. 'The comparison was effected between the hydrogen gas thermometer and a number of platinum thermometers constructed of wire of varying degrees of purity. The lowest temperatures were obtained by means of liquid air baths, while the intermediate points wcre obtained in a bath of alcohol or petroleum ether cooled by liquid air.

His experiments showed that the parabolic formula was not valid below $-40^{\circ} \mathrm{C}$., and, moreover, that platinum thermometers constructed of wires of varying purity were not consistent, but gave results differing by as much as half a degree when immersed in the same bath.

He found, however, that the scales of two different thermometers could be connected over this range by a formula involving only one constant, and that the constant could be determined by a comparison of the thermometers at a single temperature.

'Thus, if platinum temperatures * $p t^{\prime}$ and $p t$ are deduced from observations with two thermometers compared at the same temperature, the following empirical relationship holds good:-

$$
p t^{\prime}-p t=c p t(p t-100)
$$

'The constant $c$ may be obtained by a comparison of the two thermometers at one low temperature, as, for example, in a liquid air bath.

Although the above formula would appear to require for its evaluation the use of a standard platinum thermometer, whose scale has been directly compared with the gas thermometer, it is possible to utilise Henning's data by making the assumption that his gas thermometer would give the accepted value $-182 \cdot 9_{5}^{\circ} \mathrm{C}$. for the boiling-point of oxygen.

The curve in Fig. 6 is plotted from data given by Henning for his standard thermometer, having $a=0.0039150$ and $\delta=1.484$.

Hence, if a platinum thermometer has to be calibrated down to low temperatures, it is only necessary to determine the resistance in ice, steam, sulphur vapour, and boiling oxygen.

The departure of the scale at the oxygen-point can then be compared with Henning's value at $t=-182 \cdot 9_{5}^{\circ} \mathrm{C}$.

In 'Table IV. the values of $a, \delta$ and $c$ are given for the various platinum thermometers tested, and it will be observed that there is 
THE FUNDAMENTAL SCALE OF TEMPERA'TURE 13 no obvious connection between $c$ and the $\delta$ of the parabolic formula (see Chap. III.).

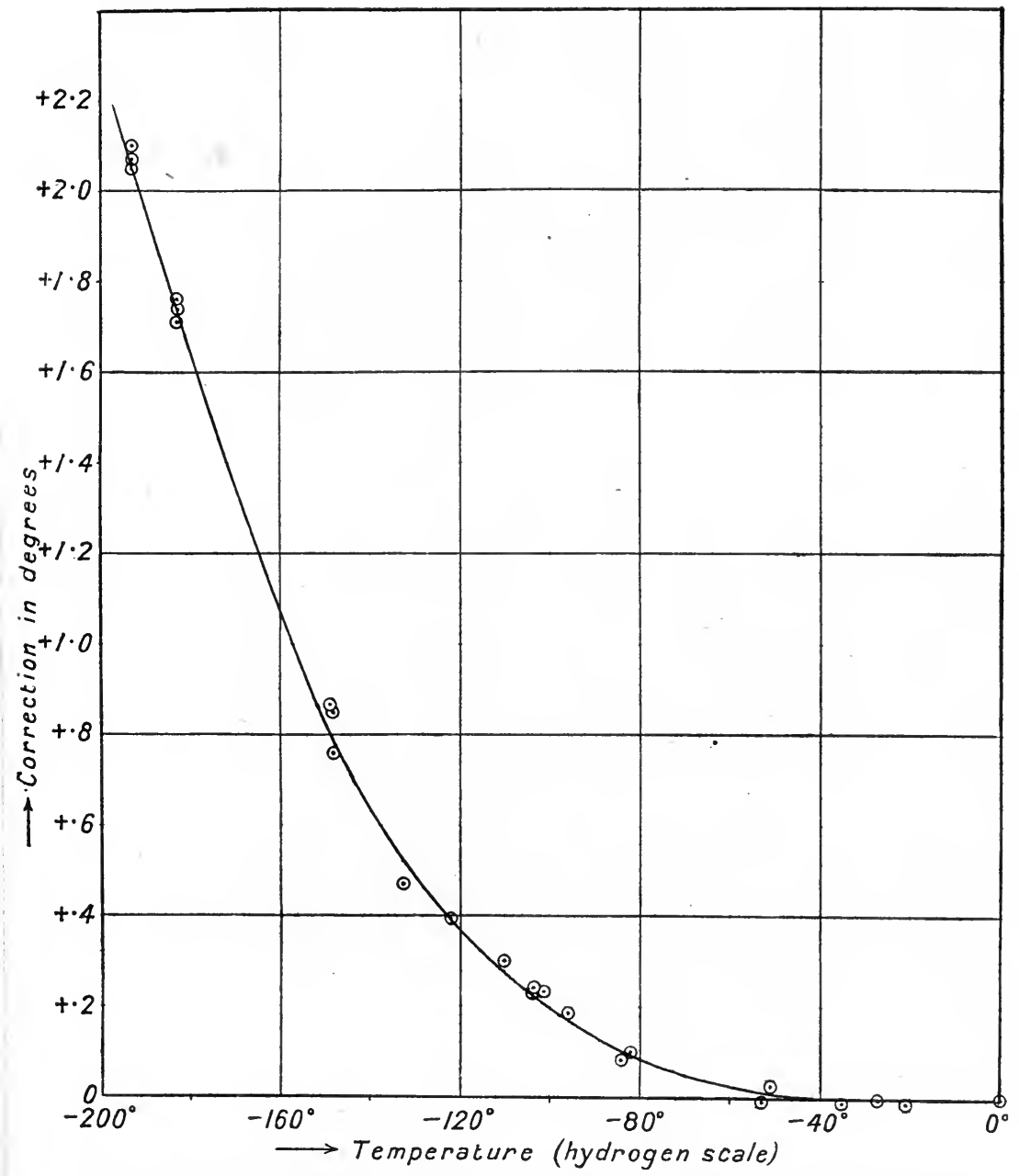

FIG. 6.-Curve plotted from Henning's data for his standard thermometer.

TABLE IV.

\begin{tabular}{|c|c|c|}
\hline 100a. & $\delta$. & $c \times 10^{5}$ \\
\hline 0.38624 & 1.510 & -0.68 \\
0.38874 & 1.492 & +0.09 \\
0.39131 & 1.491 & +0.06 \\
0.39132 & 1.491 & +0.11 \\
0.39150 & 1.484 & 0 \\
0.39134 & .1 .486 & -0.10 \\
0.39143 & 1.482 & +0.10 \\
\hline
\end{tabular}


Choice of gas for use in gas thermometers, and the relation between the practical gas scale and the absolute thermodynamic scale of temperature. - Since the thermodynamic scale of temperature is the ultimate standard of reference, it is desirable to choose as gas to be employed in the thermometer that one which approaches nearest the "ideal gas."

In practice it has not always been possible to do this. Hydrogen, which has a very small correction to bring its scale to the thermodynamic, has been found to be entirely satisfactory up to temperatures of about $400^{\circ} \mathrm{C}$. At higher temperatures the ready diffusivity of hydrogen through platinum and its alloys has necessitated recourse being made to nitrogen, which has been employed up to $1600^{\circ} \mathrm{C}$.

'The discovery of the monatomic gases, helium, argon, and neon, with no chemical affinity, has placed at the disposal of gas thermometer workers elements which approach the "ideal gas" nearer than hydrogen or nitrogen. Helium also possesses the very valuable characteristic of an extremely low liquefaction-point, and for work at low temperatures it is now coming into general use. At higher temperatures it readily diffuses through quartz and glass, consequently argon will probably be employed for this part of the range in future.

Corrections to thermodynamic scale.-Hydrogen, nitrogen, and air approximate fairly closely to the "ideal gas" over the range in which they obey Boyle's law.

The corrections necessary to convert the practical gas scale to the thermodynamic scale can be calculated from certain physical properties of the gas. The method of calculation is complicated by the necessity of employing indirect methods, owing to the lack of the requisite data.

To determine the departure of a real gas from the ideal state a knowledge of two quantities is necessary: (1) the departure of the product $p v$ from a constant value under isothermal conditions of change ; (2) the value of $\lambda$, the amount of heat that must be added to unit mass of gas during a free expansion, in which its volume is increased by unity, to keep its temperature constant.

Both these quantities are small and difficult to measure directly with the necessary degree of accuracy.

Kelvin first realised the need of experimental data to permit of the calculation of the corrections to the practical gas scale, in order that it might be expressed in terms of the thermodynamic scale.

In collaboration with Joule he devised in 1850 the "porous plug" experiments. In these experiments a gas is caused to flow steadily through a porous plug; and the change in temperature is measured. The difference in temperature obtained depends upon both of the quantities referred to above, and consequently the reduction of the observations to give the desired corrections is a matter of some difficulty.

The problem has been attacked from "different standpoints by Kelvin, Rose-Innes, Callendar, Berthelot, and Buckingham.

The order of agreement between the results will be seen by a study of Table $\mathbf{V}$. 
TABLE V.

Corrections to the constant pressure ( $p=1000 \mathrm{mms}$ ) hydrogen scale between $0^{\circ}$ and $100^{\circ} \mathrm{C}$. : the values to be subtracted from the observed temperatures.

\begin{tabular}{|c|c|c|c|c|c|c|}
\hline $\begin{array}{l}\mathrm{I} . \\
t^{\circ} \mathrm{C} .\end{array}$ & $\begin{array}{l}\text { II. } \\
\text { Roce Innes } \\
\text { (1901). }\end{array}$ & \multicolumn{2}{|c|}{$\begin{array}{c}\text { Callendar } \\
\text { (1903). }\end{array}$} & $\begin{array}{l}\text { V. } \\
\text { D. Berthelot. }\end{array}$ & \multicolumn{2}{|c|}{ Buckingham. } \\
\hline 20 & 0.0024 & $0 \cdot 0025$ & 0.0013 & 0.0008 & $0 \cdot 0026$ & 0.0023 \\
\hline 40 & $0 \cdot 0033$ & 0.0035 & 0.0018 & 0.0010 & $0 \cdot \cos 7$ & 0.0032 \\
\hline 60 & 0.0031 & 0.0033 & 0.0016 & 0.0009 & 0.0037 & 0.0032 \\
\hline 80 & 0.0019 & 0.0020 & 0.0010 & 0.0005 & 0.0024 & 0.0022 \\
\hline
\end{tabular}

The data in columns II., III., VI., and VII. have been obtained by calculation based on the value of the Joule-Kelvin effect and are in agreement. On the other hand, data in columns IV. and V. have been obtained by general consideration of the equation of state of the gas, without the use of the Joule-Kelvin effect. The latter values are apparently only $\frac{1}{2}$ or $\frac{1}{4}$ the mean of the others and are not so reliable.

Outside the range $0^{\circ}$ to $100^{\circ} \mathrm{C}$., extrapolation of data determined within this range has to be resorted to.

Table VI. summarises the corrections to the gas scales which are in use at the present day.

\section{TABLE VI.}

Corrections to thermodynamic scale $\theta_{0}=273 \cdot 10^{\circ} \mathrm{C}$.

\begin{tabular}{|c|c|c|c|c|c|c|}
\hline $\begin{array}{c}\text { Temp. } \\
\text { Centigrade. }\end{array}$ & \multicolumn{2}{|c|}{ Constant pressure $=76 \mathrm{cms.}$} & \multicolumn{2}{|c|}{ Constant volume $p_{0}=100 \mathrm{cms.}$} \\
\cline { 2 - 6 } & Helium. & Hydrogen. & Nitrogen. & Helium. & Hydrogen. & Nitrogen. \\
\cline { 2 - 7 } & & & & & & \\
-250 & - & - & - & +0.02 & - & - \\
-200 & +0.10 & +0.26 & - & +0.01 & +0.06 & - \\
-100 & +0.03 & +0.03 & +0.33 & 0.000 & +0.014 & +0.07 \\
-50 & +0.009 & +0.004 & +0.09 & 0.000 & +0.004 & +0.02 \\
+25 & -0.002 & -0.002 & -0.013 & 0.000 & 0.000 & -0.006 \\
+50 & -0.002 & -0.003 & -0.017 & 0.000 & 0.000 & -0.006 \\
+75 & -0.002 & -0.002 & -0.012 & 0.000 & 0.000 & -0.004 \\
+150 & +0.005 & +0.003 & +0.04 & 0.000 & +0.001 & +0.01 \\
+200 & +0.01 & +0.01 & +0.10 & 0.000 & +0.002 & +0.04 \\
+450 & +0.07 & +0.04 & +0.50 & 0.00 & +0.01 & +0.15 \\
+1000 & +0.24 & +0.01 & +1.7 & - & +0.04 & +0.70 \\
+1500 & - & - & +3.0 & - & - & +1.3 \\
\hline
\end{tabular}

Standard temperatures in the range covered by gas thermometer experiments.-The vast amount of labour expended on gas thermometer observations, briefly sketched in the preceding pages, has resulted in the fixing, with some degree of certainty, of a series of 
standard temperatures which may form the basis of a common scale of temperature.

Table VII. summarises the most probable values of a series of standard temperatures, according to recent research.

Most of the substances are easily obtained of the requisite purity. But in the case of benzophenone and oxygen special attention must be given to the purity of the samples employed.

'The appropriate method of utilising these fixed points for the calibration of auxiliary standards is given with the description of these particular instruments.

TABLE VII.

Standard temperatures.

(Thermodynamic scale.)

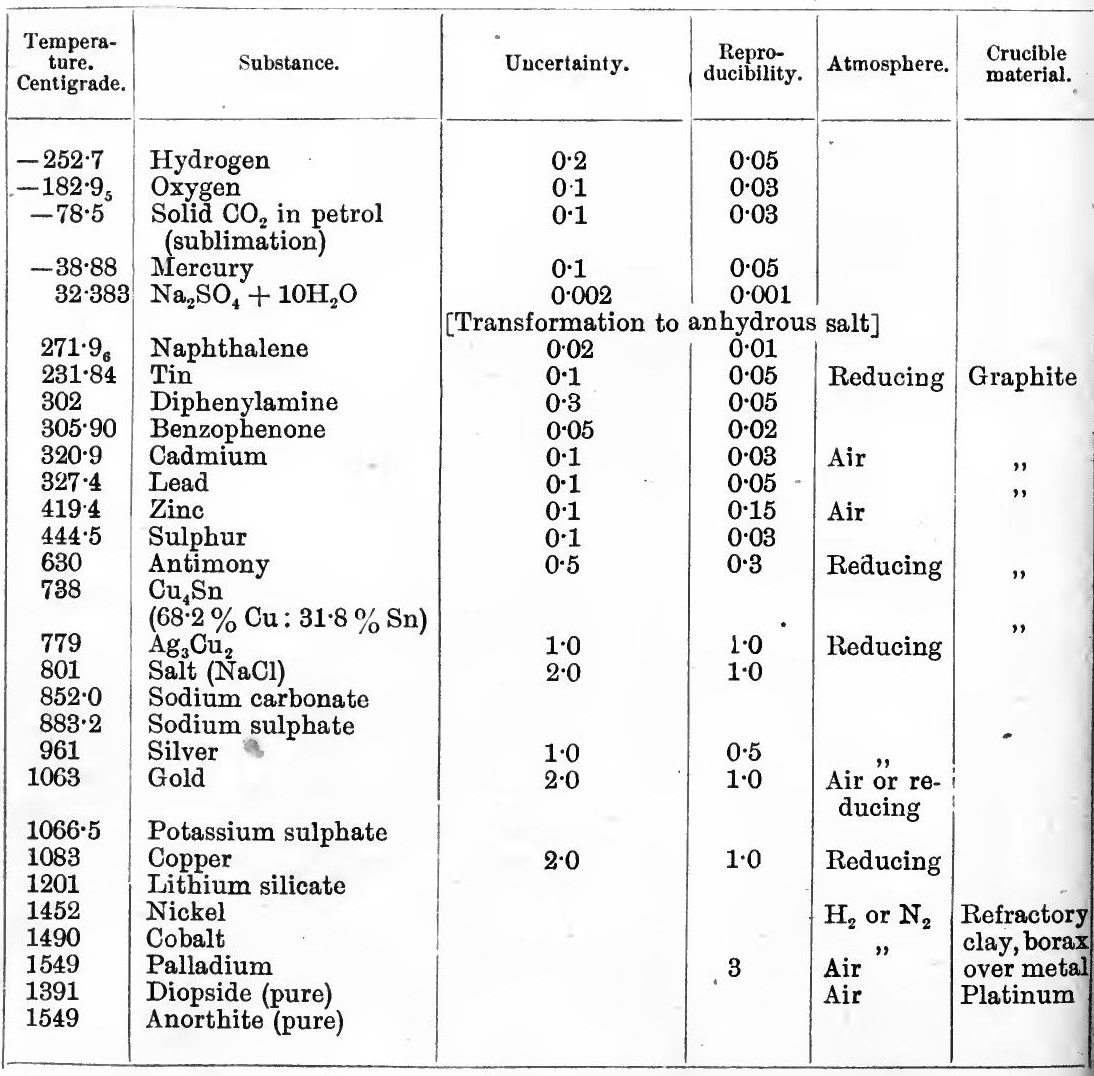

The estimates of the limits of the uncertainty in the absolute values and of the reproducibility are due to Burgess. 


\section{REFERENCES TO CHAP'TER 1 .}

\section{Range $0^{\circ}$ to $100^{\circ} \mathrm{C}$.}

Chappuis, Travaux et Mémoires du Bureau International des Poids et Mesures, vol. vi. (1888).

"The Expansion of Gases by Heat," Harper's Scientific Memoirs, No. XIV., edited by Randall. (Contains quotations from historical memoirs on the subject.)

\section{Range $100^{\circ}$ to $600^{\circ} \mathrm{C}$.}

Callendar, Phil. Trans. Roy. Soc. (1887).

Harker and Chappuis, Phil. Trans. Roy. Soc. (1899).

Holborn and Henning, Ann. d. Phys., 35, p. 761 (1911).

Callendar and Griffiths, Phil. Trans., A. 82, 119 (1891).

\section{Sulphur Boiling-point}

Regnault, Mémoires l'Académiè des Sciences, vol. xxvi. Collected works, Relation des Experiences," 3 vols. Pub. Libraire de Firmin Didot Frères, Paris (1862).

Day and Sosman, Am. Jl. Sci., 33, p. 517 (1912); Jl. Wash. Acàd. Sci., 2, p. $167(1912)$.

Eumorfopoulos, Proc. Roy. Soc., 81, p. 339 (1908); 83, p. 106 (1910).

\section{Range $500^{\circ}$ to $1550^{\circ} \mathrm{C}$.}

1 Holborn and Wien, Wied. Ann., 47, p. 107 (1892).

Holborn and Valentiner, Sitzungsber. Berl. Akad., pp. 811-817 (1906); Ann. d. Phys. (4), 22, pp. 1-48 (1907).

Jaquerod and Perrot, Arch. d. Sci. Phys. et Nat. d. Genève (4), 20, pp. 28-58, I28-158, 454, 506-529 (1905).

Holborn and Day, Am. Journ. Sci. (4), 8, pp. 165-193; Wied. Ann., 68, p. 817 (1899).

'Day and Sosman, Am. Journ. Sci., 29, p. 93 (1910); Reprint 157, Carnegie Instit. of Washington (1911);Am. Journ. Sci., 33, p. 517 (1912); Jl. Wash. Acad. Sci., 2, p. 167 (1912).

Jacquerod and Wassmer, Jl. Chim. Phy., 2, p. 52 (1904).

Waidner and Burgess, Bull. Bur. Stds., 6, p. 149 (1910); ibid., T, p. 1 (1910).

Holborn and Henning, Ann.d. Phys., 35, p. 761 (1911).

Dickinson and Mueller, Jl. Wash. Acad. Sci., 2, p. 176 (1912).

Range $0^{\circ}$ to $-200^{\circ} \mathrm{C}$.

Holborn and Wien, Wied. Ann., 59, p. 213 (1896); ibid., 6, p. 242 (1901).

Travers and Gwyer, Proc. Roy. Soc., 74, p. 528 (1905).

Henning, Ann. der Physik., 40, p. 635 (1913) ; ibid., p. 1064 (1913).

\section{Correction to Thermodynamic Scale.}

Kelvin, Math. and Phys. Papers, vol. i., p. 100 (1848).

Joule Thomson, Phil. Trans., 143, p. 357 (1853); ibid., 144, p. 321 (1854); ibid., 152, p. 579 (1862).

Weinstein, Trav. et Mem. Bur. Int., vol. vi.

Callendar, Phil. Mag. (6), 5, p. 48 (1903).

D. Berthelot, Trav. et Mem. Bur. Int., 13 (1903).

Buckingham, Bull. Bur. Stds., 3, p. 237 (1907).

Lehfeldt, Phil. Mag., No. 275, April, 1898.

Rose-Innes, Phil. Mag. (6), 2, p. 130 (1901).

K. Onnes and Braak, Leiden Comm., 97b, $102 b$ (1907).

"The Free Expansion of Gases," Harper's Scientific Memoirs, edited Ames.

\section{Supplementary References.}

G. K. Burgess, The Present Status of the Temperature Scale, Eighth Int. Cong. of Applied Chemistry, vol. xxii., p. 53.

Barus, Researches on Thermometry, Bull. No. 54, U.S.A. Geol. Survey, 1889.

Griffiths and Schotield, "Pyrometer Standardisation," Trans. Faraday Society (1917). 


\section{CHAP'TER II}

\section{THE MERCURIAL THERMOIMETER}

Calibration and corrections of precision mercury thermometers-High temperature range mercury thermometers-Precautions necessary in accurate work--Thermometer glasses and their characteristics-Calibration of mercury thermometers by comparison in a molten salt bath.

THE simplicity of the mercury in glass thermometer and the convenience of a direct reading temperature scale have led to the very general use of this type of pyrometer, and the peculiarities of the instrument have received much study during the past half-century.

The result of this accumulation of experience has been to show that, where extreme accuracy is desired, the simplicity of the instrument is more apparent than real, and that a well-designed resistance thermometer outfit easily surpasses it in sensibility, besides being free from "zero depression," which is the inherent failing of the mercury in glass thermometer.

The range $0^{\circ}$ to $100^{\circ} \mathrm{C}$. with the mercury thermometer.In the fundamental interval $0^{\circ}$ to $100^{\circ} \mathrm{C}$. the mercury thermometer received very careful study at the International Bureau of Weights and Measures at Sèvres, and it was shown that by adopting suitable precautions it was possible to reproduce the temperature scale to better than $0.005^{\circ}$ in this interval. The standard thermometers of the Bureau were of "Verre dur" glass, since this glass had the smallest zero depression of the then known glasses. This thermal hysteresis manifests itself in troublesome changes of the zero after exposure to higher temperatures and in slowness in settling to equilibrium when maintained at a definite temperature.

The mercury thermometer was graduated to give a temperature scale of its own; the degree being defined as one-hundredth of the volume of the stem contained between the readings, at the meltingpoint of ice, and the steam-point of water under standard conditions.

The object of Chappuis' work, previously described, was to obtain the relation between this scale and that of the international hydrogen scale in which the degree Centigrade is defined as one-hundredth part of the change in pressure of a constant volume of hydrogen gas, when its temperature is changed between that of melting pure ice and that of

* The difference in the ice-point reading taken after a long time at $0^{\circ} \mathrm{C}$. and that immediately after exposure to a temperature of $100^{\circ} \mathrm{C}$. 
steam from boiling pure water at normal pressure, the initial pressure of the gas at $0^{\circ}$ being $1000 \mathrm{mms}$. of mercury.

Sources of error in mercury thermometers. - Since it is impossible to construct a thermometer to comply with the ideal conditions contemplated above, it is necessary to calibrate each mercury thermometer and determine corrections for the following :-

1. The variations in the calibre of the capillary bore.

2. The variation in the fundamental interval from $100^{\circ} \mathrm{C}$.

3. The influence of the variations in the external pressure on the bulb from standard atmospheric pressure.

4. Effect of the internal pressure on the volume of the bulb due to the height of the column of mercury above the centre of the bulb.

5. Changes in the zero or "ice-point" reading.

It is the standard practice in work of the highest precision to determine the reading in melting ice immediately after each observation taken by the thermometer.

When the above corrections have been ascertained, it is then possible to express its readings in terms of the international gas scale.

The Bureau of Weights and Measures has supplied to the various national laboratories standards whose corrections have been determined, and which have also been compared with the four "Verre dur" thermometers by which the normal hydrogen scale is preserved at the Bureau. So that it is now possible to obtain the corrections necessary to reduce the readings of any thermometer to the international hydrogen scale by a direct comparison with one of these. 'This procedure is to be recommended, as it is questionable whether the calibration method of obtaining the corrections of a thermometer is defensible on the score of precision or of economy of time. The determination of the absolute corrections of a thermometer at a large number of points by direct comparison in a well-stirred bath requires less time than the determination of the relative corrections by calibration at a few points. Moreover, the user is at the mercy of the thermometer-maker as to whether the composition of the glass is identical with that of "Verre dur" or other standard glass.

The calibration of a standard mercury thermometer.The procedure followed in the work of calibrating a primary standard is of interest in the light it throws on the peculiarities of mercury thermometers and in showing the care and attention which must be bestowed on the instrument if readings of great accuracy are desired.

The preliminary step is to remove all strains set up in the glass during manufacture by a thorough annealing. This is effected by a prolonged exposure to a temperature higher than that to which it is proposed to submit the thermometer in actual use.

One result of this annealing is to a produce a very considerable rise in the zero-point.

1. Calibration of the bore.-The graduations on the stem are supposed to be equidistant: The standard practice is to break off mercury columns approximately $10^{\circ}, 20^{\circ} \ldots 90^{\circ}$ in length and measure 
the excess length of these columns over the corresponding spaces at successive points along the scale.

The method of reducing the data to obtain the bore corrections need not be described here.*

2. Determination of the fundamental interval. (a) Steampoint.-The type of hypsometer employed at the International Bureau is shown in Fig. \%. The steam jacket is capable of rotation from the

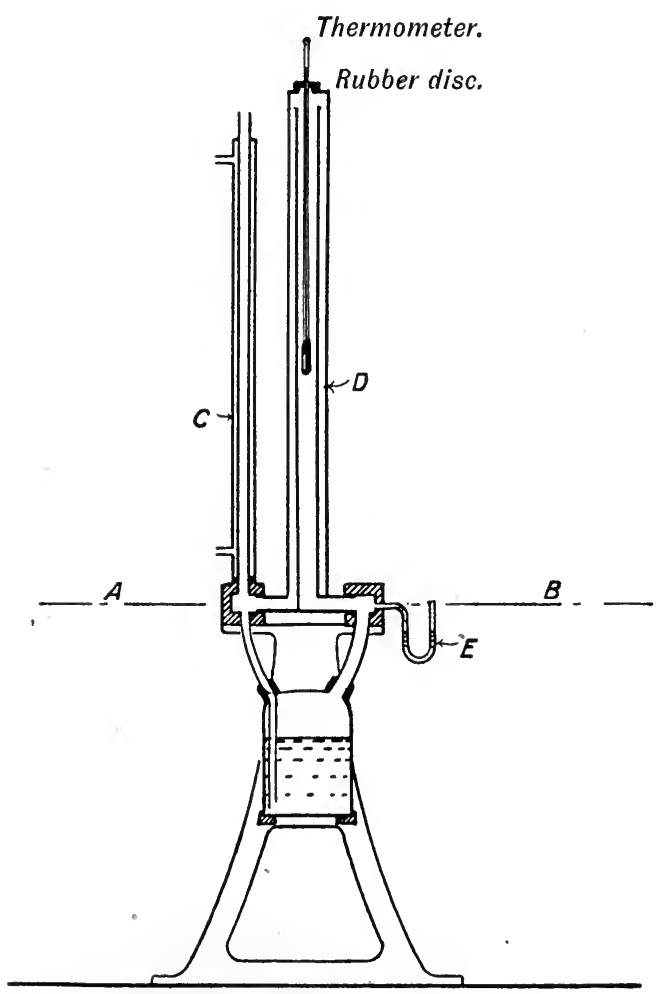

FIG. 7.-Hypsometer employed at the International Bureau.

$\mathrm{A}, \mathrm{B}$, axis of rotation; C, condenser ; D, steam jacket ; E, water manometer.

horizontal to the vertical position, so that readings may be taken in both positions.

The thermometer is inserted in the hypsometer with a few tenths of a degree projecting for reading. A thin rubber disc-is better than a cork for closing the mouth, since it permits of the steam heating practically the whole of the mercury column.

* The arithmetical artifices employed in the reduction of the observations by the method of least squares is described in Traite Practique de la Thermometrie de Précision, Guillaume. Also in a paper entitled An Example in Thermometry, by A. S. Cole and E. L. Durgan. Minor contributions, Physical Review, vol. iv. p. 207 (1897). 
A U-tube water manometer is fixed to the steam jacket, so that the excess pressure within the apparatus may be added to that of the barometric pressure.*

Alternate barometer and thermometer readings are taken.

Even at temperatures as low as $100^{\circ} \mathrm{C}$, a slight distillation of the mercury will take place from the top of the column to the cooler region above; some observers have eliminated this by mounting a small glass bell jar over the hypsometer, so that the thermometer is entirely enclosed in the steam. Others have overcome this difficulty by passing hot air over the emergent end.

Readings are taken with the hypsometer in both the vertical and the horizontal positions, as this determines the internal pressure coefficient.

The observations are taken first in the horizontal position, then in the vertical ; this sequence avoids the possibility of distilled mercury joining with the column, since the reading is lower in the vertical than in the horizontal position.

This procedure, however, has one disadvantage, in so much as the meniscus in the vertical position is a falling one. $\dagger$

The difficulty may be overcome by withdrawing the thermometer a few centimetres, so as to slightly cool the stem; on replacement the meniscus will be a rising one.

(b) Ice-point.-A convenient form of ice-point apparatus is shown in Fig 8.

Finely powdered ice is employed, saturated with distilled water, the water being drawn off until the surface whitens. 'The ice-point is determined as soon as possible after withdrawal from the hypsometer. Usually a period of two or three minutes must elapse before the thermometer can be safely inserted into the ice. Since the zero

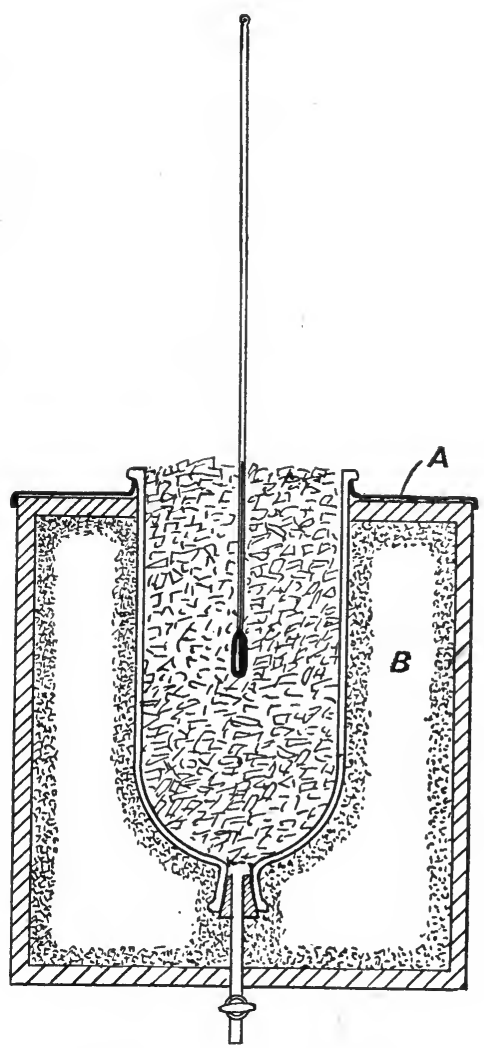

FIG. 8.-Ice.point apparatus. A, lead sheet; B, cork dust. begins to rise after its temporary depression, at the rate of about $0.001^{\circ}$ per minute, it is necessary in work of the highest precision to allow the same interval of time to elapse between the withdrawal from the higher temperature bath and the determination of the ice-point.

* The boiling-point of water at various pressures is given in Table XLVII. (Appendix).

+ Readings with a receding column are not reliable owing to "stiction." 
In order to obtain a rising meniscus at the ice-point, a super cooler has been proposed, consisting of a test-tube containing mercury inserted into a freezing mixture. By this means it would be possible to cool the bulb a few degrees below $0^{\circ}$ before inserting into the ice bath.

The temporary depression of the zero after heating to higher temperatures has been exhaustively studied by several observers for "Verre dur" thermometers.

It has been found that the depression can be approximately calculated from the expression-

$$
Z_{0}-Z_{t}=0.000930 t+0.00000130 t^{2}
$$

where $Z_{0}$ is the ice reading corresponding to long-continued exposure at $0^{\circ}$.

$Z_{t}$ is the ice-point reading corresponding to the temperature $t$.

It will be observed that the depression for $t=100^{\circ} \mathrm{C}$. is $0 \cdot 11^{\circ}$.

When it is not practicable to determine the ice-point after each temperature observation, values calculated from the above formula (or one determined for the particular thermometer) may be used to reduce the observations to true temperatures.

The variable zero of the mercury in the glass thermometer is probably its greatest defect, and it is interesting to note that experiments with fused quartz have shown that this material is greatly superior to glass in respect of zero-keeping properties.

3. External pressure coefficient.-The thermometer is enclosed in a glass tube containing sufficient mercury to cover the bulb, and the remainder of the tube is filled with glycerine.

Observations are then taken in a bath, whose temperature is rising slowly, the pressure within the tube being varied by connecting it alternately to an exhausted receiver and to the atmosphere. Water is sometimes recommended instead of glycerine, since the heating and cooling of the liquid produced by variations of pressure is less for water than for glycerine. 'The effect of this heating or cooling of the liquid is to give too high a value for the pressure coefficient. 'The error due to this cause, however, is less than $0^{\circ} 001^{\circ}$ at $100^{\circ} \mathrm{C}$.

Defining the external pressure coefficient as : "The change of reading in scale degrees produced by a change in pressure of 1 millimetre of mercury," the order of magnitude of this coefficient for a Tonnelot thermometer is 0.0001 . So that the correction for external pressure changes is generally negligible in magnitude.

The internal pressure coefficient is readily calculated from the two readings in steam, the external pressure coefficient and the dimensions of the thermometer.

If the thermometer is always used in the same position as when calibrated, the internal pressure correction need not be considered.

Water bath for the intercomparison of mercury thermometers. - For the rapid calibration of mercury thermometers by comparison with a standard or a resistance thermometer, the type of 
water bath illustrated in Fig. 9 has been developed at the National Physical Laboratory.

It consists of two parallel vertical tubes joined by cross connections above and below.

The thermometers are placed in one vertical limb, while the rotary stirrer and heaters are fixed in the other. To reduce the heat loss from

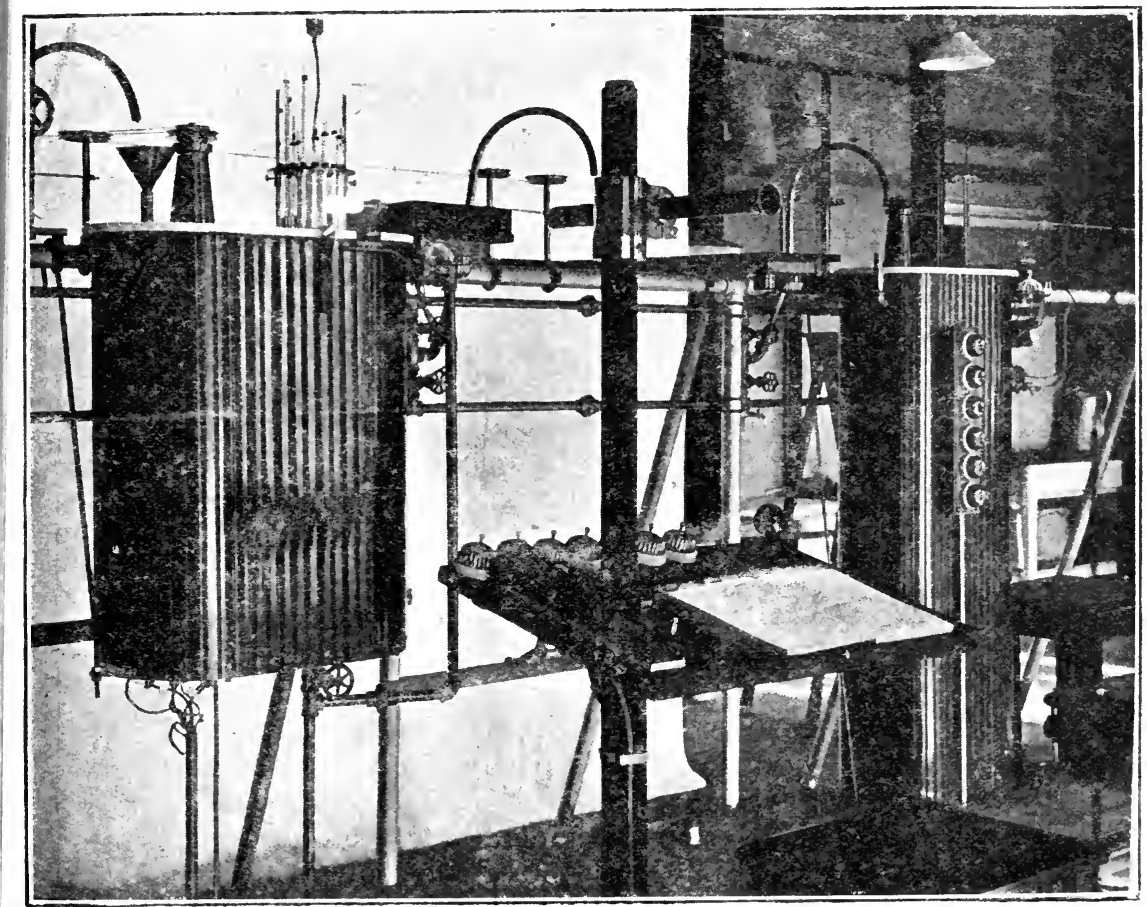

FIG. 9.-Water bath for the comparison of mercury thermometers.

The electrical connections to the heater units will be observed in the bottom left-hand corner.

the sides the bath is insulated with granulated cork enclosed in wooden lagging.

The heating is effected by a number of resistance units of the type shown in Fig. 10, which illustrates the internal construction of a double unit wound ready for insertion into an envelope of thin sheet copper.

Two plain sheets of mica (not shown) are fastened over the faces of the unit to insulate it from the metal walls of its container.

The copper envelopes are soldered to a brass plate closing the end of the limb containing the stirrer and project up into the stream of water.

The units are designed for working off the 100 volt supply circuit, and are each of 400 watts capacity. 
Generally six units are provided for each bath and are contained in three separate pockets. Variations in the energy supply are obtained by means of seven two-way lamp switches with an intermediate "off" position.

The six resistance units are connected in series, and from

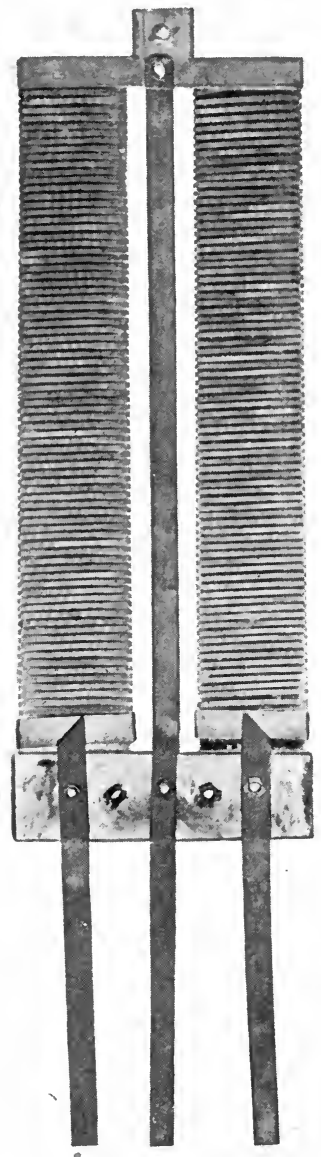

Fra. 10.-Heater element for water bath. them are led seven connections to the neutral points of the switches. The upper and lower contacts of each switch are connected respectively to the positive and negative poles of the 100-volt supply circuit.

By this arrangement, permitting series and parallel combination of the units, the energy can be varied from 60 to 2400 watts without the use of any series resistance. To obtain still smaller heating energies a sliding resistance of 100 ohms is connected in series with the first unit.

It might be remarked that the life of a suitably proportioned unit has been found to be about 500 kilowatt hours.

High temperature mercurial thermometers. - By employing a hard glass and filling the upper part of the stem with gas under sufficient pressure to prevent distillation, or boiling of the mercury, it is possible to measure temperatures as high as $500^{\circ} \mathrm{C}$. But to determine temperatures absolutely to within $1^{\circ}$ at $450^{\circ} \mathrm{C}$. demands considerable care to eliminate the various sources of error to which these instruments are subject.

Borosilicate glass $59^{\prime \prime \prime}$ is generally employed for the construction of highrange thermometers with the divisions engraved directly on the stem. Generally there is an auxiliary bulb, or reservoir, at the top, which is "large " in proportion to the volume of the bore of the stem itself; its volume usually being 20 times that of the internal volume above $0^{\circ}$.

'This bulb is filled with gas-nitrogen or carbon dioxide"under sufficient pressure to prevent boiling of the mercury at the highest temperature at which the thermometer is intended to be used.

Fra. 11.-High-range thermometer.

$\mathrm{A}$, bulb to take expansion from $0^{\circ}$ to $100^{\circ}$; $\mathrm{B}$, auxiliary bulb; $\mathrm{C}$, narrow bore tube filled with shellac or fusible metal. 
The pressures necessary are-

2 atmospheres for a maximum temperature of $400^{\circ} \mathrm{C}$.

20

60

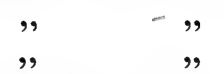

,

$550^{\circ} \mathrm{C}$.

$750^{\circ} \mathrm{C}$.

To seal off the thermometer under pressure a little shellac or fusible metal is placed in the narrow bore tube above the auxiliary bulb, and before sealing off this is heated until it flows down, sealing up the tube while still under pressure. The external pressure may then be removed and the glass tube sealed off above in the usual way.

Occasionally high-range thermometers are made by fusing off the capillary containing gas at atmospheric pressure with the mercury standing at some low point.

Evidently, if the length of the capillary is properly chosen, the mercury, on rising, will compress the contained gas, increasing the pressure sufficiently to prevent boiling at all temperatures on the scale. This method is not so satisfactory as the oprevious one, since the internal pressure increases rapidly as the temperature rises, depressing the readings of the thermometer. This depression of the zero is not constant for different instruments, owing to the difficulty of duplicating the conditions.

The scale of high-range thermometers generally have about $30^{\circ}$ divisions engraved at the ice-point, $10^{\circ}$ below and $20^{\circ}$ above, the same at the $100^{\circ}$ point, the two points being separated by a small reservoir to shorten the length of the stem. Then the graduation proceeds in single degrees over the higher portion of the range.

In others the reservoir takes up the expansion from $0^{\circ}$ to $200^{\circ} \mathrm{C}$.

The graduations at $0^{\circ}$ are essential for keeping a check on the behaviour of the instrument by frequent ice-point readings.

If the scale of a borosilicate glass thermometer were obtained by extrapolation of the hundred degrees between ice and steam, it would differ considerably from the gas scale as the data in Table VIII. shows :-

TABLE VIII.

\begin{tabular}{|c|c|c|c|}
\hline $\begin{array}{c}\text { Gas thermometer } \\
\text { scale. } \\
{ }^{\circ} \mathrm{C} .\end{array}$ & $\begin{array}{c}\text { Mercury thermo- } \\
\text { meter borosilicate } \\
\text { glass scale. } \\
{ }^{\circ} \mathrm{C} .\end{array}$ & $\begin{array}{c}\text { Gas thermometer } \\
\text { scale. } \\
{ }^{\circ} \mathrm{C} .\end{array}$ & $\begin{array}{c}\text { Mercury thermo- } \\
\text { meter borosilicate } \\
\text { glass scale. } \\
\text { o } \mathrm{C} .\end{array}$ \\
\hline 0 & 0 & 375 & \\
\hline 100 & 100 & 400 & $385 \cdot 4$ \\
200 & $200 \cdot 7$ & 425 & $412 \cdot 3$ \\
300 & $304 \cdot 1$ & 450 & $440 \cdot 7$ \\
325 & $330 \cdot 9$ & 475 & $469 \cdot 1$ \\
350 & $358 \cdot 1$ & 500 & $498 \cdot 0$ \\
\hline
\end{tabular}

It is interesting to note that under similar conditions a thermometer of Jena $16^{\prime \prime \prime}$ glass would read $301 \cdot 96^{\circ} \mathrm{C}$. for a gas thermometer temperature of $300^{\circ} \mathrm{C}$., so that the scale of the mercury "Verre dur" glass 
thermometer approximates more nearly to that of the gas thermometer than that of borosilicate glass. This, however, is of no importance, since at the present day the scales are never obtained by extrapolation.

Salt baths for comparisons at higher temperatures. Generally the scales of instruments which are to serve as standards are pointed off by comparing the thermometer with a resistance thermometer in oil and nitrate baths.

Fig. 12 illustrates a form of salt bath suitable for comparisons between $200^{\circ}$ and $600^{\circ} \mathrm{C}$.

The salt mixture consists of about equal proportions of sodium and potassium nitrates. It is important not to expose any joints or brazing

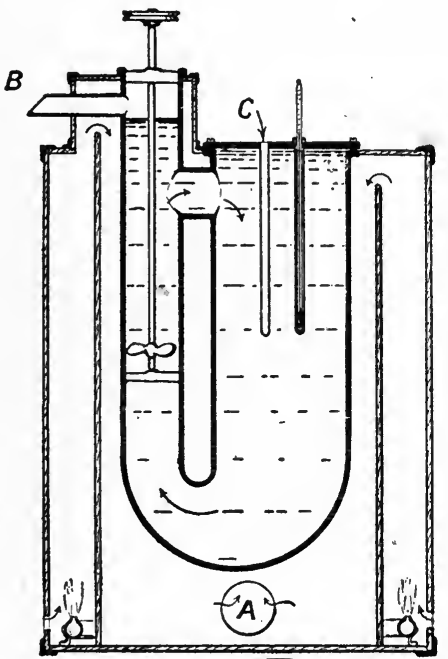

Fig. 12.-Salt bath for comparisons of thermometers between $200^{\circ}$ and $600^{\circ} \mathrm{C}$.

A, flue pipe; $B$, overflow and filler tube; C, steel tube (thin-walled) screwed into top of bath.

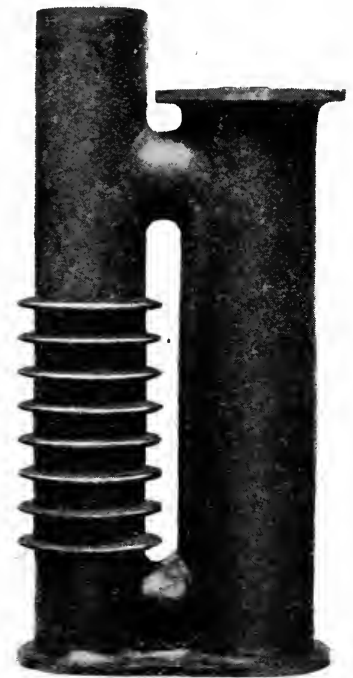

Fig. 13.-Cast-iron container for molten salt bath.

to the action of the molten nitrate; the only satisfactory mode of construction is to employ castings or oxyacetylene welded steel parts. bath.

Fig. 13 is a photograph of a cast-iron container for a molten salt

The hot gases should be so directed as to come in contact with the upper part of the bath first. This ensures that the frozen salt melts from the top downwards, and thus avoid the severe strains which would be set up should the bottom be first heated.

Changes in high-range thermometers. - When a thermometer is new and has not been submitted to any annealing, considerable changes of zero take place, due to the strains set up in the glass in manufacture and to thermal hysteresis. A high-range thermometer 
is of course subject to the same changes as a low-range one, only they appear in a more aggravated form.

(1) Permanent changes.-There occurs a permanent contraction of the bulb and stem, rendering all the readings higher than the original values. This contraction takes place more rapidly if the temperature is raised. In the case of a thermometer maintained at room temperature the changes will extend over years. They can, however, be brought speedily to conclusion by subjecting the thermometer for a period of 4 to 10 days to a temperature higher than that which it will be required to measure in practice and by following this treatment with a slow cooling extending over a period of 3 to 6 days. 'The result of this annealing, or artificial ageing, is to produce a rise of the zero of the order of $30^{\circ}$ when the thermometer has been subjected to a maximum temperature of about $450^{\circ} \mathrm{C}$.

(2) Temporary changes.-All thermometers, when heated, show changes which are temporary in character and the magnitude of the changes depend on the temperature and the composition of the glass.

If the zero of a thermometer is determined immediately after it has been exposed to high temperature, it will be found to be depressed below the value obtained, when the thermometer has been at room temperature for a long period. For a top temperature of $400^{\circ}$ to $500^{\circ} \mathrm{C}$. the depression of the zero may amount to $1^{\circ}$. Consequently, in work of precision, it is the custom to determine the zero as frequently as possible by ice-bath operations.

While an absolute accuracy of $1^{\circ}$ at high temperatures is about the best obtainable with mercury thermometers, to secure this it is necessary to observe some additional precautions to those already described in connection with low-range thermometers.

Some additional precautions.-1. Prolonged exposure of the thermómeter to high temperatures should be avoided. Distillation of the mercury from the top of the column to the colder portion of the stem invariably occurs to some extent, and it is impossible to join up the minute globules. The effect of such distillation can be obseived on the zero point reading.

2. The thermometer should be immersed in the hot region to as near the top of the column as the conditions permit. Emergent stem corrections are, at the best, but makeshifts, and at high temperatures their magnitude is apt to become serious even with a small emergence. For example, a thermometer was tested at a temperature of $450^{\circ} \mathrm{C}$., with about $14^{\circ}$ of the column (corresponding to the length of $11 \mathrm{mms}$.) emergent; the reading was $1^{\circ}$ low in consequence.

The emergent stem correction is usually calculated by the formula-

$$
\text { Correction }=0 \cdot 00016(T-t) n
$$

where $T=$ temperature of bath,

$$
\begin{aligned}
t & =\text { " } \\
n & =\text { number of degrees exposed. }
\end{aligned}
$$

Where the conditions of the experiment necessitate an emergent 
column, it is advisable to calibrate the thermometer under precisely similar conditions.

Thermometer glass. - The composition of the glass is a matter of considerable importance in thermometer construction. Unsatisfactory glasses show thermal hysteresis of large magnitude.

Weber, as far back as 1883 , proved that the best results were obtained with a pure potassium glass containing large percentages of silicon and calcium, and that the presence of both $\mathrm{K}_{2} \mathrm{O}$ and $\mathrm{Na}_{2} \mathrm{O}$ together was objectionable.

The glass selected by the International Bureau is known as "Verre dur"; it is a lead-free glass, containing about 11 per cent. of the oxide of sodium $\left(\mathrm{Na}_{2} \mathrm{O}\right)$ and only a trace of $\mathrm{K}_{2} \mathrm{O}(0.3$ to 0.4 . per cent.); the chief constituents being silica 72 per cent. and lime 14 per cent. At that time "Verre dur" was probably the best obtainable, but in recent years glasses surpassing "Verre dur" have been introduced and the betterclass thermometers nowadays are made of Jena $16^{\prime \prime \prime}$ glass.

For high-temperature work borosilicate glass $59^{\prime \prime \prime}$ is in general use, since this glass does not soften until quite high temperatures are attained.

Its chemical composition is given in the table below --

TABLE IX.

Composition of $59^{\prime \prime \prime}$ Glass.

\begin{tabular}{|l|cc|}
\hline & & \\
$\mathrm{SiO}_{2}$ & 72 per cent. \\
$\mathrm{Al}_{2} \mathrm{O}_{3}$ & 5 &, \\
$\mathrm{Na}_{2} \mathrm{O}$ & 11 &, \\
$\mathrm{~B}_{2} \mathrm{O}_{3}$ & 12 &, \\
$\mathrm{Mn}_{2} \mathrm{O}_{3}$ & 0.05 & $"$, \\
\hline
\end{tabular}

Sometimes $\mathrm{K}_{2} \mathrm{O}$ is present to the extent of about $1 \frac{1}{2}$ per cent. Such glass is of course inferior in properties to one free from both $\mathrm{Na}_{2} \mathrm{O}$ and $\mathrm{K}_{2} \mathrm{O}$ together.

The zero depressions after heating to $100^{\circ} \mathrm{C}$. are quite small.

For "Verre dur" about $0 \cdot 10^{\circ}$.

$\begin{array}{lll}\text { Jena } 16^{\prime \prime \prime} & 0.08 \text {. } \\ \text { Borosilicate } 59^{\prime \prime \prime} & 0.03 \text {. }\end{array}$

Although it was originally stipulated that "Verre dur" should be free from lead, this requirement has not always been complied with. Glasses of broken "Verre dur" thermometers analysed at the N. P. L. were found to contain quite appreciable amounts of lead.*

Apart from the difficulty of obtaining glasses of the correct chemical composition, it has been observed that thermometers made out of the same ingot of glass will differ in behaviour 'due to slight differences of chemical composition in various parts of the ingot and even the working of the bulbs in the blowpipe slightly affects the composition of the glass. 
Unless the thermometer receives the most thorough annealing, the strains set up during the construction will exert a noticeable influence on the temperature scale obtained.

Fused silica possesses most of the qualities desired in a thermometer envelope, except for the practical difficulty of engraving clean sharp lines for the graduations.

\section{REFERENCES TO CHAPTER II.}

\section{Low range mercury thermometer calibration.}

Benoit, Trav. et Mém. du Bur. Int. des Poids et Mes., 2, p. c. 35 (1883).

Broch, lbid., 5, p. 3 (1886).

Chappuis, Ibid. (1888).

Guillaume, Traité Pratique de la Thermométve de Précision (1889). Gauthier Villars.

Pernet, Jaeger \& Gumlich, Wiss. Abhandl. der Phys. Tech. Reichsanstalt, 1 (1894).

Grützmacher, Ibid., 3, p. 256 (1900).

Report of Committee of British Association, p. 145 (1882).

Waidner and Dickinson, Bull. Bur. Stds., vol. iii. p. 68 (1907).

Comparison with gas and resistance thermometers.

Chappuis, Ibid. (1888).

W. S. Day, Phys. Rev., 6, p. 193 (1898) ; Phil. Mag., 46, p. 1 (1898).

Waidner and Mallory, Ibid., 8, p. 193 (1899); Phil. Mag., 48, p. 1 (1899).

Griffiths, Report B.A., p. 130, 1890 ; Appendix IV., 16th Report B.A., 1889 ; or " B.A. Reports on Electrical Standards," p. 411 (Cam. Univ. Press).

Balfour Stewart, Phil. Trans. Roy. Soc., 153, p. 425 (1863).

Chree, Phil. Mag., 43, p. 225 (1898).

Harker, Proc. Roy. Soc. A., 78, p. 225 (1906).

Comparison at higher temperatures.

Grützmacher, Wied. Ann., 68, p. 769 (1899).

'Thiesen, Scheel. und Sell, Wiss. Abhandl. der Phys. Tech-Reichsanstalt, 2, p. 1-71 (1895).

Zeitschr. für Inst., 15, p. 433 (1895).

Mahlke, Wied. Ann, 53, p. 965 (1894).

Scheel, Wied. Ann., vol. 58, p. 168 (1896).

Lemke, Zeitschr. für Inst., 19, p. 33 (1899).

Influence of glass on behaviour and effect of annealing.

Mahlke, Zeitschr. für Inst., 15, p. 178 (1895).

Grützmacher, Zeitschr. für Inst., 15, p. 250 (1895).

Wiebe \& Böttcher, Zeitschr. für Inst., 10, p. 245 (1890).

H. C. Dickinsòn, Bull. Bur. Stds., 2, p. 189 (1906).

Person. C. R., 19, p. 1314 (1844).

Kohlrausch, Pogg. Ann. Phys., 127, p. 4 (1866).

Crafts, C. R., 91, p. 291, 370, 413 (1880); Ibid., 94, p. 1298 (1882).

Pernet, C.R., 91, p. 471 (1880).

Weber, Ber. K. Akad. der Wiss., 13, p. 1233 (1883).

Wiebe, Zeitschr. für Inst., 6, p. 167 (1886); Ibid., 8, p. 373 (1898)；10, p. 207 (1890).

For Jena glass consult “Jena Glass," by Hovestadt, trans. by Everett (1902).

(This book contains a résumé of the work done on thermometer glass.) 


\section{CHAPTER III}

\section{THE RESISTANCE THERMOMETER}

Siemens' work-Callendar and Griffiths' researches-Extrapolation of the scale of the platinum thermometer for the determination of high temperature freezingpoints--Construction of platinum thermometers-Resistance bridges for thermometric work : Siemens' three-lead bridge : Callendar and Griffiths' compensated lead bridge : Smith's difference bridge : Mueller's bridge-Precautions in working to eliminate various sources of error-Calibration of box coils and bridge wire-Standardisation of resistance thermometers-Types of sulphur boilingpoint apparatus-Example of method of reducing platinum thermometer observations-Application of resistance thermometers in precision work at high temperatures-Industrial types of resistance pyrometers.

The resistance thermometer.-The foundation of a method for the measurement of temperature based on the change of resistance of platinum is due to Sir William Siemens, who in 1871 constructed a practical form of pyrometer on this principle. He also devised an ingenious form of resistance bridge, with the object of eliminating uncertainties due to change in the resistance of the leads, consequent on variations in the depth of immersion of the pyrometer stem in the hot region.

'The constructional details of the early Siemens pyrometers were unsatisfactory. 'The platinum wire was wound on a pipeclay cylinder and enclosed in a tube of wrought iron.

A committee of the British Association, appointed in 1872-3 to test these pyrometers, made an unfavourable report on their permanency, and for some years this method of temperature measurement fell into disuse. Prof. A. W. Williamson, chairman of the B.A. committee, suggested that the changes in the resistance of the platinum were due to the reducing atmosphere produced by the highly heated iron casing, which would cause the platinum to combine with a trace of the reduced silicon taken from the pipeclay cylinder.

Analysis proved the truth of this theory and pointed to the desirability of an oxidising or neutral atmosphere around the platinum wire.

Siemens showed that a sheath of platinum eliminated this trouble and Fig. 14 illustrates his improved type of pyrometer.

His method of calibrating the pyrometer for high temperature work is open to criticism in the light of present-day knowledge.

Up to $350^{\circ} \mathrm{C}$. he calibrated it against an (unstudied) mercury thermometer, and at higher temperatures employed a calorimetric method. 
The relation between the resistance and temperature was expressed by the formula $r=a^{r} \mathrm{~T}^{2}+\beta \mathrm{T}+\gamma$, where $a, \beta, \gamma$ are constants.

Siemens arrived at this general formula from considerations of a mechanical model of the atom, in .which he assumed that " the resistance a metallic body offers to the passage of an electric impulse from atom to atom is directly proportional to the velocity of the vibrations which represent its heat."

'The work of Callendar in 1887 has already been referred to in Chap. 1.

'To the joint work of Callendar and Griffiths we owe the modern resistance thermometer and bridge, an instrument unequalled among pyrometric devices for precision and reliability. Callendar introduced nomenclature which has since come into general use.

'The platinum temperature $p t$ is defined as .

$$
p t=\frac{\mathbf{R}_{t}-\mathbf{R}_{0}}{\mathbf{R}_{1}-\mathbf{R}_{0}} \times 100
$$

where $R_{0}$ is the resistance at $0^{\circ} \mathrm{C}$.

$$
\begin{array}{lll}
\mathrm{R}_{1} & , \quad " & 100^{\circ} \mathrm{C} . \\
\mathrm{R}_{t} \quad " & t^{\circ} \mathrm{C} . .
\end{array}
$$

The quantity $\mathbf{R}_{1}-\mathbf{R}_{0}$ is generally referred to as the "Fundamental Interval" (F.I.) of the thermometer.

He showed that the difference between the true temperature $(t)$, as measured by the air thermometer, and the platinum temperature $p t$ was represented by a parabolic formula-

$$
t-p t \equiv d=\delta\left\{\left(\frac{t}{100}\right)^{2}-\frac{t}{100}\right\}
$$

where $\delta$ is the coefficient for that

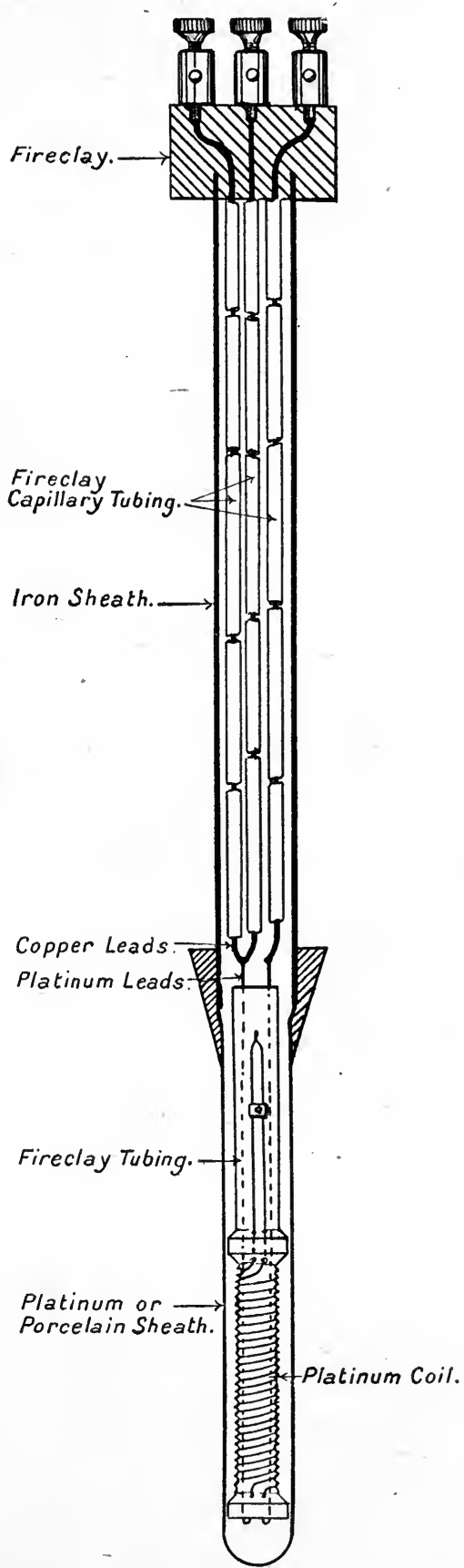

FIG. 14.-Siemens' improved pyrometer. 
particular sample of wire and whose numerical value is about $1 \cdot 5$.

The subsequent work of Callendar and Griffiths proved that the parabolic formula, with appropriate values of the coefficients, held generally for the representation of the variation of resistance of platinum with temperature over the range $0^{\circ}$ to $600^{\circ} \mathrm{C}$.

The type of thermometer finally adopted by them had a platinum coil wound on a mica rack with leads of heavy platinum wire.

A similar pair of wires to the leads, in the form

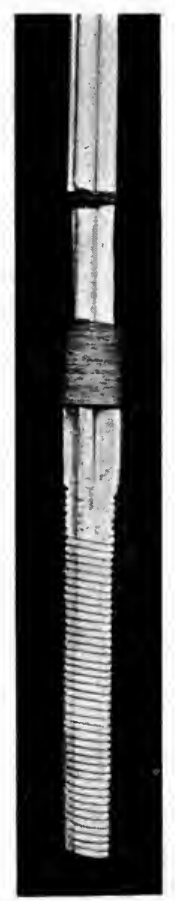

FIG. 15.-Complete platinum resistance thermometer coil. of a loop, were laid alongside. This loop was connected in the opposite arm of the bridge so as to compensate for the resistance of the leads to the coil at all temperatures.

Fig 16 illustrates the connections of the bridge.

Extrapolation of the scale of the platinum thermometer for the determination of high temperature melting-points.-The work of Heycock and Neville immediately followed that of their colleagues Callendar and Griffiths, and was primarily directed towards the determination of the freezing-points of metals and their alloys.

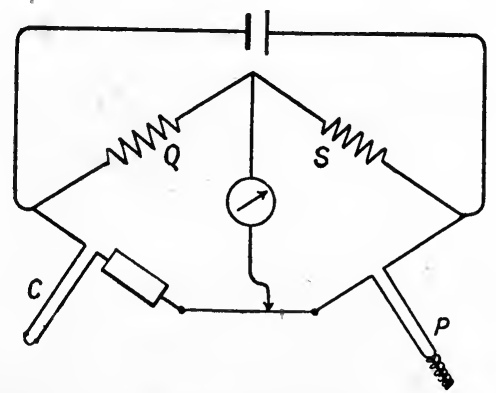

Fig. 16.-Diagram of bridge connections.

$\mathrm{Q}, \mathrm{S}$, equal ratio arms. C, compensatory loop, the lower end is joined by tine wire to produce same conducting effect as in the leads to coil. $P$, platinum coil and leads.

To measure temperatures in the vicinity of $1000^{\circ} \mathrm{C}$., it was necessary to extrapolate the parabolic formula over a range of $400^{\circ} \mathrm{C}$., since at that time there were no reliable determinations of the melting-points of metals in terms of the gas scale.

For example, gold, a metal obtainable in a state of high purity, had, according to Barus, a freezing-point value of $1093^{\circ} \mathrm{C}$. This was determined by means of a platinum vs. platinum-iridium couple calibrated in terms of a gas thermometer. Holborn and Wien, at the same time (1892) and employing an almost identical method, obtained the value $1072^{\circ} \mathrm{C}$., a discrepancy of $21^{\circ}$. 
Heycock and Neville investigated the freezing-point of gold among those of other metals, and their work showed that it gave a sharp, well-defined transition point which renders it an excellent "fixed point" for calibration purposes.

Employing thermometers constructed of wire of various degrees of purity and reducing the observations by the parabolic formula, they obtained the values given in 'Table $\mathrm{X}$.

TABLE X.

Freezing-point of gold. Purity $99.95 \%$.

\begin{tabular}{|c|c|c|c|c|}
\hline $\begin{array}{c}\text { Thermometer } \\
\text { number. }\end{array}$ & $\begin{array}{c}\text { Platinum, } \\
\text { Temperature }{ }^{\circ} \mathrm{C} .\end{array}$ & $\delta$ & $\begin{array}{c}d=t-p t \\
{ }^{\circ} \mathrm{C} .\end{array}$ & $t^{\circ} \mathrm{C}$. \\
\cline { 1 - 2 } 13 & $908 \cdot 7$ & $1 \cdot 500$ & $153 \cdot 2$ & $1061 \cdot 9$ \\
\cline { 2 - 3 } 15 & $852 \cdot 9$ & $2 \cdot 040$ & $208 \cdot 3$ & $1061 \cdot 2$ \\
18 & $900 \cdot 7$ & $1 \cdot 574$ & $180 \cdot 7$ & $1061 \cdot 4$ \\
$13 \mathrm{~A}$ & $903 \cdot 3$ & $1 \cdot 553$ & $158 \cdot 6$ & $1061 \cdot 9$ \\
14 & $907 \cdot 7$ & 1.511 & $154 \cdot 3$ & $1062 \cdot 0$ \\
\hline
\end{tabular}

Weighted mean $1061 \cdot 7^{\circ}$

This value for the freezing-point of gold is in close agreement with the recent determination of Day and Sosman, $1062 \cdot 4^{\circ} \mathrm{C}$.

A comparison of the most reliable recent determinations of the freezing-points of the metals, expressed on the gas thermometer scale, with those obtained previously by Heycock and Neville proves conclusively that the resistance thermometer standardised at $0^{\circ}, 100^{\circ}$ and $444.5^{\circ} \mathrm{C}$, will give temperatures identical with the gas scale up to $1080^{\circ} \mathrm{C}$., within the limits of experimental error to which the gas thermometer scale is known.

This is further confirmed by several direct comparisons between the resistance thermometer and the gas thermometer over the same range.

Influence of the purity of the platinum.-A fairly accurate idea of the purity of the platinum wire may be formed from a consideration of its coefficients of resistance. The purest specimens give values of $a$ (the mean coefficient between $0^{\circ}$ and $100^{\circ} \mathrm{C}$.) as high as 0.00389 and $\delta$ about 1.50 or slightly less. Impure wire on the other hand may give values of $a$ only 60 per cent. of the above and of $\delta$ 's up to 1.6.

The parabolic formula has been found to hold rigorously when the purity does not vary very far from the first named values. When a thermometer is constructed of impure wire it is generally found that the zero will not remain constant after exposure to high temperatures and consequently the reliability of the instrument is impaired.

Since only a small quantity of the material is required it is advisable to wind the coil of the purest platinum obtainable. 'The heavy wire leads may be of commercially pure wire.

For work up to temperatures of $500^{\circ} \mathrm{C}$. silver leads are quite satisfactory, provided an intermediate piece of platinum is introduced between 
the fine wires and the silver, so as to avoid the risk of contamination in the autogenous welding.

Above $600^{\circ} \mathrm{C}$. the volatilisation of the silver causes contanination of the platinum coil and also deterioration of the insulation of the mica rack.

Construction of platinum thermometers. - Fig. 14 represents the original type of high temperature resistance thermometer. Its chief defect is the considerable lag in its indications.

Fig. 17 illustrates an hermetically sealed type of thermometer designed by Dr. E. H. Griffiths for laboratory work of high precision. By sealing the sheath it is possible to eliminate any possibility of moisture condensing on the mica and impairing the insulation. Insulation troubles are frequent in high resistance thermometers unless precautions are taken to prevent access of moist air.

Other types of heads are shown on the thermometers in Figs. 32 and 34.

Of the various insulating materials hitherto investigated for high temperature work, good quality mica has proved to be the most satisfactory for thermometer construction.

Exposure to a temperature of about $1000^{\circ} \mathrm{C}$. causes dehydration of the mica, which in consequence becomes silvery white and brittle. If reasonable care is taken it is quite satisfactory in this condition.

Resistance thermometers for calorimetric work.-For calorimetric work it is desirable to have a sensitive thermometer of small lag, so that its indications at any instant are a true measure of the temperature of the liquid.

Thermometers of the type illustrated in Fig. 17 are satisfactory provided the coil is made as light as possible and the sheath of very thin glass.

With the object of reducing the thermometer lag to a minimum, Dickinson and Mueller have developed the type of thermometer illustrated in Figs. 18 and 19.

The mode of construction is described by them as follows :-

Coil.-The coil is of the purest platinum wire $0 \cdot 1 \mathrm{~mm}$. in diameter, a length of about 2.2 metres being wound in a flat bifilar coil about $8 \mathrm{cms}$. long and $7 . \mathrm{mms}$. broad, on one end of a mica strip, which is about $18 \mathrm{~cm}$. long and $0.2 \mathrm{~mm}$. thick. The turns of wire are held in place by notches in the sides of the mica strip and are spaced

FIG. 17.--Hermetically sealed thermometer for high precision work. 
about 14 turns to the centimetre. The coil is insulated from the surrounding sheath by strips of mica somewhat wider and thinner than that on which the coil is wound.

Before winding, the wire is annealed by heating to a high temperature, $1000^{\circ}$ to $1200^{\circ} \mathrm{C}$. by passing an electric current through it. After

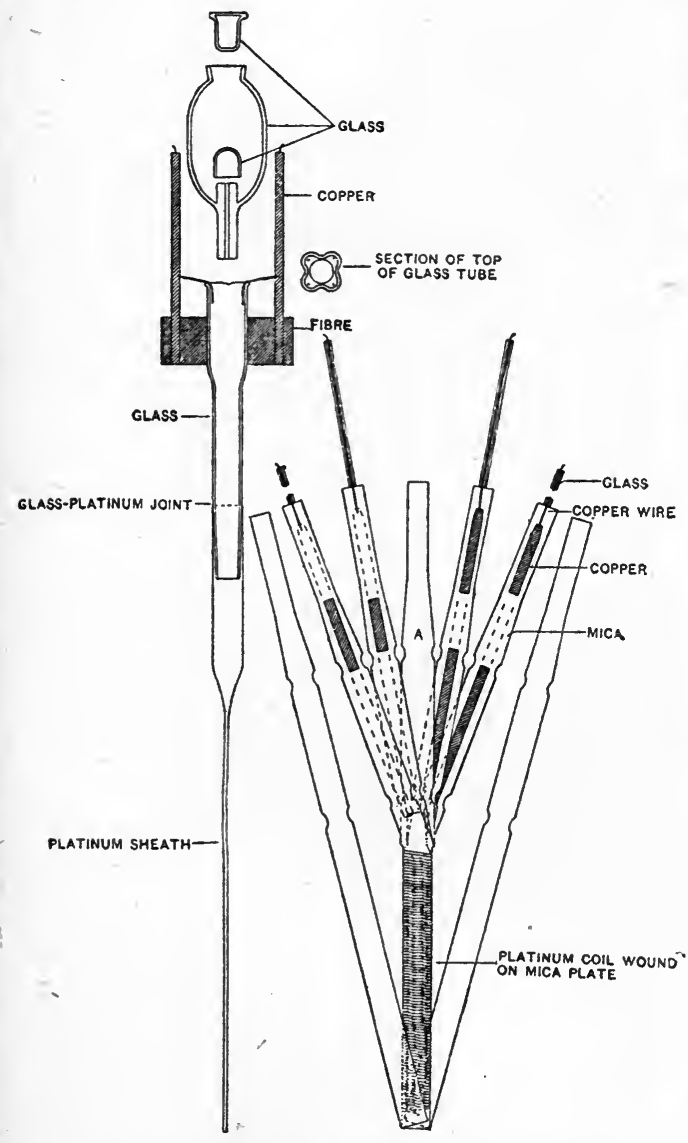

FIG. 18.-Diagrammatic sketch of parts of thermometer, separated to show construction.

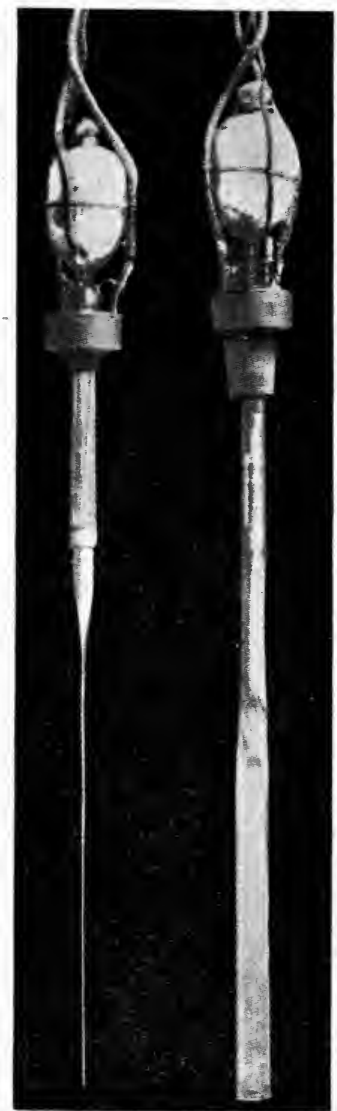

Frg. 19.-Dickinson and Mueller's type of calorimetric resistance thermometer.

winding and attaching the leads, i.e. after the coil is so far completed as not to require further handling, it is carefully washed in distilled water to remove all traces of hygroscopic salts, and is then heated to a bright red by means of an electric current to drive off all volatile matter, and to reanneal the wire.

Leads. - The leads are made of thin strips of copper $0.13 \mathrm{~mm}$. thick by 2 to $3 \mathrm{mms}$. wide. If the thermometer is of the compensating lead 
type the compensating loop is closed by a piece of the $0.1 \mathrm{~mm}$. platinum wire about 3 or $4 \mathrm{cms}$. long. All platinum joints are made by fusing with an arc, using a pure graphite electrode, while the copper platinum joints are made either by welding or with silver, using borax as a flux. 'The flat copper strips extend to just beyond the mica strips, where they are silver soldered to No. 20 copper wires, which are threaded through glass tubes. If suitable rolls are available, it is preferable to roll down the wires at the ends to take the place of the copper strips.

Sheath.-The sheaths are made of thin-drawn silver or (preferably) platinum tubes $7 \mathrm{mms}$. in diameter, 15 to $18 \mathrm{cms}$. long, and of about $0.12 \mathrm{~mm}$. wall thickness for the platinum and up to $0.2 \mathrm{~mm}$. for the silver. 'These tubes are partially flattened, as shown in Fig. 19, and after the coil is inserted are closed at the ends by fusing with an arc, and pressed down on to the coil.

Heads. - The heads are made entirely of glass and consist of four pieces, as shown in Fig. 18-the stem, drying capsule, and two small caps. The stems are usually attached to the metal cases by platinising the glass, which is just large enough to slip into the metal tube, and then soldering the glass and metal together with ordinary soft solder. As this solder melts at about $190^{\circ} \mathrm{C}$, , thermometers to be used above this temperature have the case made of platinum, which is fused directly to the glass. This method requires a rather large joint between the glass and platinum. The glass must be of special composition and the work carefully done to avoid breaking at this point.

The upper part of this tube is shaped to provide grooves for the lead wires, which are brought out between the tube and the stem of the drying capsule.

The drying capsule is sealed in with Khotinski cement, the wires passing out through this cement.

The drying capsule is about half filled with asbestos wool, the small inside cap serving to prevent loose particles from dropping into the tube below. The rest of the capsule is filled with phosphorus pentoxide. When the small upper cap is cemented on, the thermometer is kept warm to prevent the internal pressure becoming larger than one atmosphere when the thermometer is subsequently used at the higher temperatures.

Outside leads. - The coil leads are soldered to pins or small copper tubes held in a fibre collar which is cemented to the glass stem. 'To these pins or tubes the flexible leads are attached.

'These leads should be as nearly as possible alike, both as to length and total resistance.

The copper flexibles must be protected at the soldered joints to prevent sharp bending. This may be accomplished by threading the wires through the copper tubes and making the soldered joint at the lower end.

Test of insulation resistance.-The presence of moisture in the thermometer, due to a leak or to exhaustion of the drying material, may occur. The resulting phenomena are very characteristic and easily 
recognised. If the bridge, with the thermometer in circuit and galvanometer circuit closed and a key in the battery circuit, is balanced by adjusting resistance with the battery key closed, then on opening the battery circuit there will be a large deflection of the galvanometer, which gradually diminishes, and on closing it again another large deflection in the opposite direction. The latter slowly diminishes if the circuit is kept closed. This phenomenou is readily distinguished from that due to the use of an excessive measuring current; by the absence of the galvanometer deflection in the latter case when the battery circuit is opened.

'The presence of moisture also reduces the insulation resistance between the coil and sheath. This insulation resistance is easily tested and should exceed 200 megohms.

Resistance bridges adopted for thermometric work.-The requirements of platinum thermometry differ in many respects from those of ordinary resistance comparison work.

Compensation for the resistance of the leads necessitates the use of a bridge with equal ratio arms. Another requirement is that it should be capable of measuring changes in resistance to a high order of accuracy. For example, a thermometer constructed with a resistance coil of 2.56 ohms at $0^{\circ}$ will have an increase in resistance of $1 \mathrm{ohm}$ when heated to $100^{\circ} \mathrm{C}$. Hence to measure temperatures to $\frac{1}{100} 0^{\circ}$ demands resistance measurements to $\frac{1}{10000}$ th of an ohm.

In practice this presents little difficulty, since balance to the nearest 0.05 is obtained by the set of coils, and final balance obtained by means of a bridge wire or set of shunted coils.

In resistance thermometry we are only concerned with changes of resistance; the absolute value of the unit employed is of little consequence, provided the relative values of the

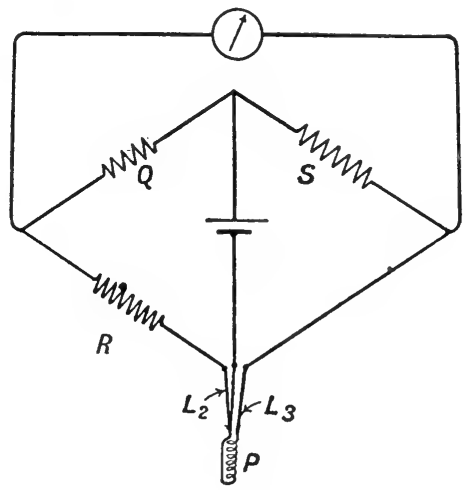

FIG. 20.-Siemens' three-lead bridge. $\mathrm{Q}$ and $\mathrm{S}$, ratio arms; $\mathrm{P}$, thermometer coil ; $\mathrm{L}_{2}$ and $\mathrm{L}_{3}$, equal leads. coils are accurately known.

Methods of calibrating the bridge coils and wire are described later.

Types of resistance bridges.--(a) Siemens' three-lead bridge.'This bridge is primarily of historical interest as representing the first attempt to eliminate lead resistance in platinum thermometry work.

Fig. 20 shows the connections.

The coils $Q$ and $S$ are the equal ratio arms. The thermometer coil $\mathrm{P}$ has three leads connected in the manner shown in diagram.

The lead $\mathrm{L}_{2}$ is adjusted in the construction of the thermometer equal to $\mathrm{L}_{3}$. When $\mathbf{R}$ is adjusted equal to $\mathbf{P}$ the bridge is balanced and the lead resistance completely eliminated. 
'The defect of this form of bridge is that a slide wire cannot be used in connection with $\mathbf{R}$ to measure minute changes of resistance.

'This difficulty can, however, be surmounted by the use of a set of shunt coils of the type described later in connection with shunted coil bridges. One setting would then determine the resistance and hence the temperature.

Siemens' procedure was to shunt one of the ratio arms and calibrate empirically.

(b) The Callendar and Griffiths bridge.--The connections on this bridge are shown in Fig. 16, p. 32. It was evolved for use with the compensating leads type of thermometer.

In the latest type of bridge manufactured by the Cambridge Scientific

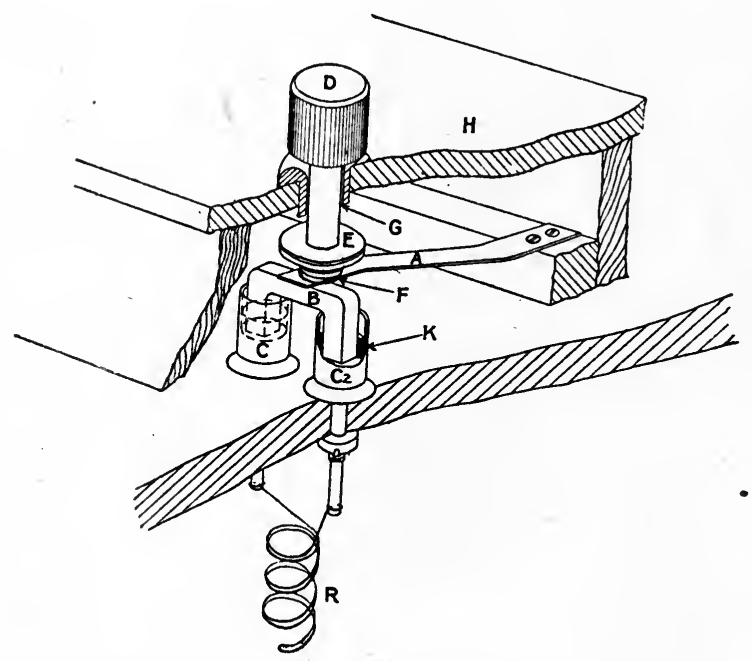

FIG. 21.-New type of bridge contact manufactured by Cambridge Scientific Instrument Company (Collins' mercury contact).

A, spring; $B, \cap$-shaped bar (copper link); $C$ and $\mathrm{C}_{2}$, mercury cups; $\mathrm{D}$, weighted plug; E, spring-plate; $\mathrm{F}$, helical spring ; G, opening ; H, bridge top ; $\mathrm{K}$, mercury ; $\mathrm{R}$, coil.

Instrument Co., mercury contacts of the form shown in Fig. 21 replace the usual plugs.

The ends of the coil are soldered to brass posts terminating in mercury cups. A $\cap$-shaped bar is carried by a light spring, which is depressed when the weighted plug $\mathbf{D}$ is inserted into the hole $\mathbf{G}$.

Fig. 22 shows the form of coil construction employed in a modern resistance bridge.

The coils are of manganin and immersed in well-stirred oil-a good grade of paraffin oil is quite satisfactory for this purpose.

Manganin has an extremely small temperature coefficient of resistance, and also a very small thermal e.m.f. agairst copper, in this respect 
affording a marked contrast to constantan or eureka, which has an e.m.f. of about 40 microvolts per degree against copper.

Manganin is, however, subject to gradual changes of resistance and consequently the coils require calibration from time to time.

Recent experiments by Rosa and by Smith have shown that the shellac varnish coating of resistance coils absorbs moisture and in the accompanying change of volume strains are set up in the wire. 'To eliminate this effect of humidity, present-day standard coils are hermetically sealed, using moisture-free paraffin. This mode of construction might well be applied to the coils of resistance bridges.

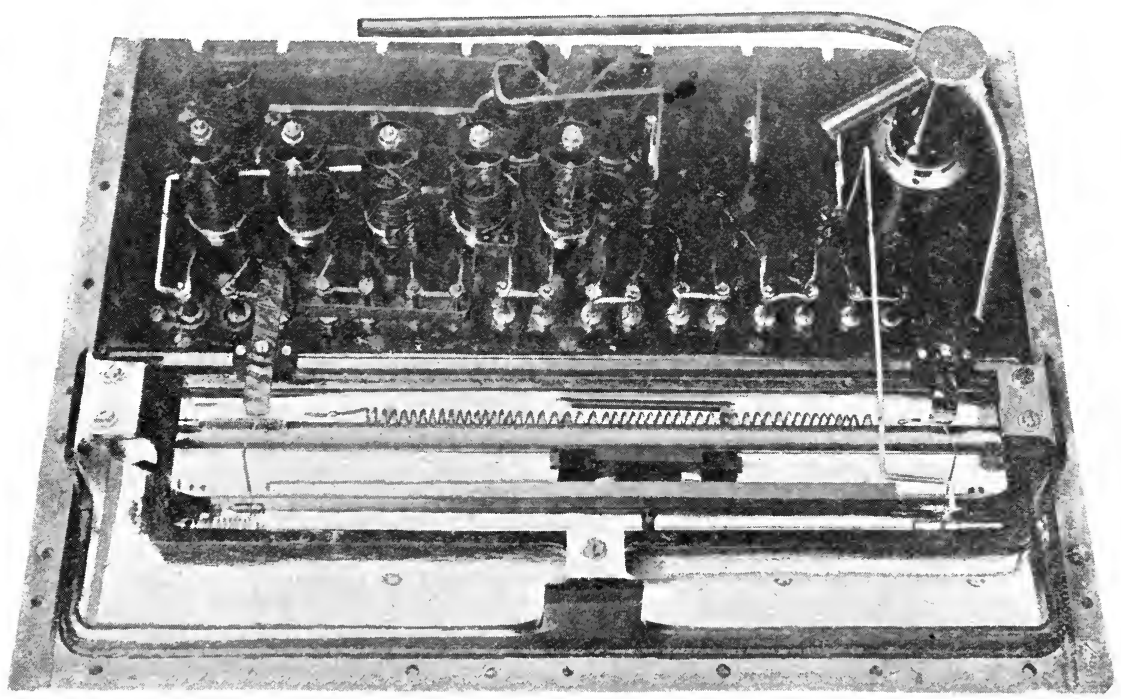

Fig. 22.-View of underside of resistance thermometer bridge (oil-immersed type), showing construction of the coils and oil circulator.

The bridge wire is of manganin, and both it and the contact maker are immersed in the oil.

(c) Potentiometer method of measuring resistance.-The wellknown potentiometer method for determining resistances, by comparison with a standard, has been applied to resistance thermometry.

The thermometer coil has four leads : two current and two potential; the current from a steady battery is passed through a standard oil immersed resistance coil and the thermometer coil in series. By measuring the fall of potential across the two coils separately, the resistances may be calculated in the usual manner.

(d) Smith's difference bridge.-In this form of bridge the connections are so arranged that, by two observations and a reversal of connections, the resistance of the leads is eliminated without recquiring absolute equality of lead resistance. 
Fig. 23 shows the disposition of the bridge connections for the first balance position. $\mathbf{P}$ is the thermometer coil with current leads $\mathbf{L}_{1}$ and $\mathrm{I}_{4}$ and potential leads $\mathrm{L}_{2}$ and $\mathrm{L}_{3}$.

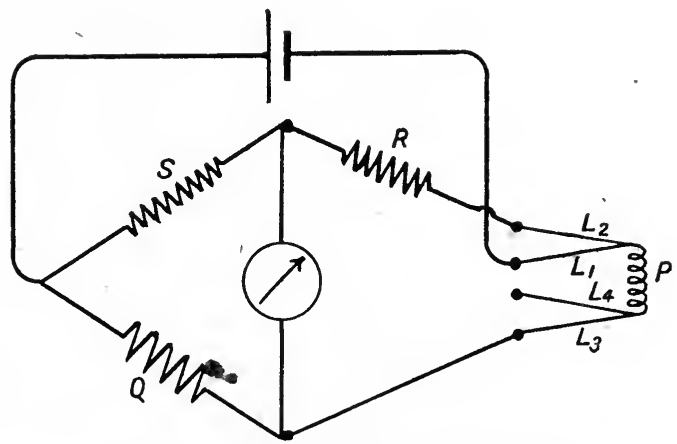

FIG. 23.-Smith's difference bridge.

$P$, thermometer coil ; $\mathrm{L}_{1}$, current lead ; $\mathrm{L}_{2}$, potential lead; $\mathrm{L}_{3}$, potential lead ; $\mathrm{L}_{4}$, current lead; $R$, adjustable arm of bridge; $S$ and $Q$, equal ratio arms; $\bullet$, mercury cup contacts.

$Q$ and $S$ are equal or nearly equal ratio arms, and $R$ is the adjustable arm of the bridge.

When balance is obtained, then

$$
\mathbf{P}+\mathbf{L}_{3}=\frac{\mathbf{Q}}{\mathbf{S}}\left(\mathbf{R}+\mathbf{L}_{2}\right)
$$

'The connections are then transposed by a mercury switch, so that

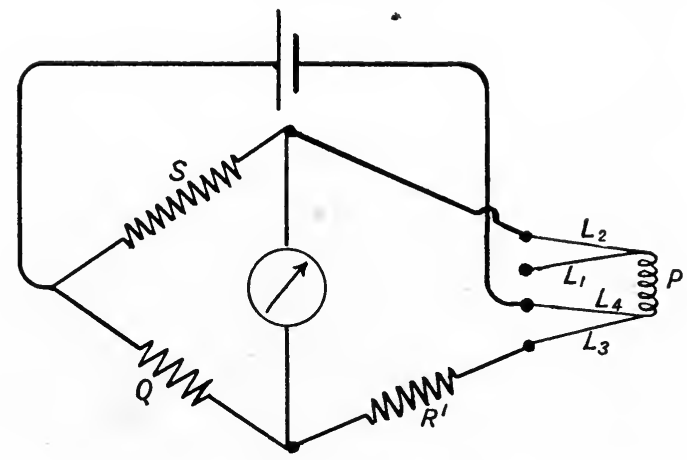

Fig. 24.

the potential lead $\mathrm{I}_{2}$ is disconnected from $R$ and joined to $\mathrm{S} ; \mathrm{L}_{3}$ to $\mathrm{R}$; the battery lead from $L_{1}$ to $L_{4}$; and $\mathbf{P}$ and $\mathbf{R}$ are interchanged.*

Fig. 24 now represents the connections.

* The object of interchanging $\mathrm{P}$ and $\mathrm{R}$ is to avoid the product of the ratio of $\mathrm{R}$ to $S$ by the sum of the two values of $R$ entering into the final equation for $P$. 
On rebalancing

$$
\mathbf{P}+\mathbf{L}_{2}=\frac{\mathbf{S}}{\mathbf{Q}}\left(\mathbf{R}^{\prime}+\mathbf{L}_{3}\right)
$$

Now $Q$ has been adjusted during the construction of the bridge to be very nearly to $S$, so that we can put

$$
\frac{\mathrm{Q}}{\mathrm{S}}=(1+a)
$$

where $a$ is a small quantity. Then

$$
\mathbf{P}=\frac{\mathbf{R}+\mathbf{R}^{\prime}}{2}-\frac{a}{2}\left\{a\left(\mathbf{R}+\mathrm{L}_{2}\right)+\left(\mathrm{L}_{2}-\mathrm{L}_{3}\right)\right\}
$$

If $\mathrm{Q}=\mathrm{S}$ within 2 parts in 10,000 , then $a=0.0002$. So that $\mathrm{P}$ is equal to $\frac{\mathbf{R}+\mathbf{R}^{\prime}}{2}$ within 2 parts in 100 millions, assuming $\mathrm{L}_{2}=\mathrm{L}_{3}$. If $L_{2}$ and $L_{3}$ each have a resistance of $0 \cdot 1 \mathrm{ohm}$, but differ by 10 per cent., then the error introduced by neglecting $a$ and taking the equation $\mathbf{P}=\frac{\mathbf{R}+\mathbf{R}^{\prime}}{2}$ as exact is equivalent to about $0.0001^{\circ} \mathrm{C}$. on a thermometer with F.I. of $1 \mathrm{ohm}$.

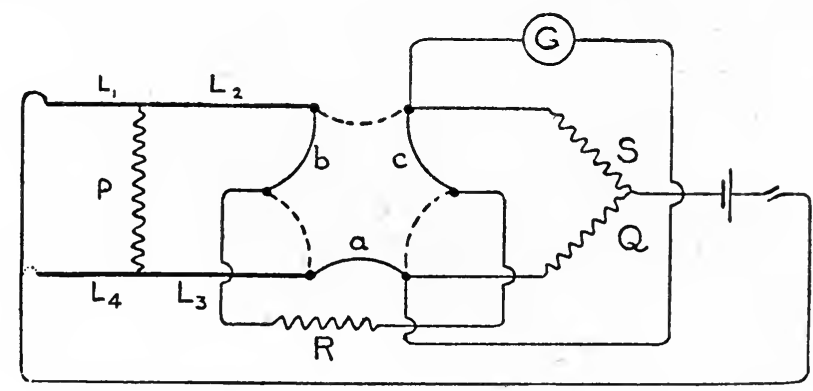

Frg. 25.-Connections to six-pole mercury contact switch.

$\mathrm{L}_{1}, \mathrm{~L}_{2}, \mathrm{~L}_{3}, \mathrm{~L}_{4}$ leads to the thermometer coil ; $\mathrm{Q}$ and $\mathrm{S}$, ratio arms ; $\mathrm{R}$, variable arm of bridge; $\mathrm{P}$, thermometer coil ; $a, b, c$, heavy copper links dipping into mercury cups.

The reversals which have been indicated above are conveniently made by means of a six-pole mercury contact-switch with connections as shown in Fig. 25. Thick copper links, $a, b$ and $c$, are attached to an ebonite disc movable on a vertical axis. The change over is effected by lifting clear of the mercury cups, rotating through $90^{\circ}$ and then lowering. 'I'he second position of the links is shown dotted in Fig. 25. It is, of course, easy to arrange for the change in position of the battery lead to be made simultaneously by contacts attached to the same disc.

This bridge method possesses one unique advantage, insomuch that it eliminates lead resistance without assuming absolute equality in their 
resistance. On the other hand, it suffers under the disadvantage of requiring two settings for each resistance reading, and that six contacts have to be broken and made; the contact resistances being assumed unchanged.

If the leads are made very nearly equal, $\mathbf{R}$ and $\mathbf{R}^{\prime}$ will only differ by an extremely small amount. This increases both the speed of working and the accuracy, since the above equation assumes reasonable identity in $\mathrm{L}_{2}$ and $\mathrm{L}_{3}$.

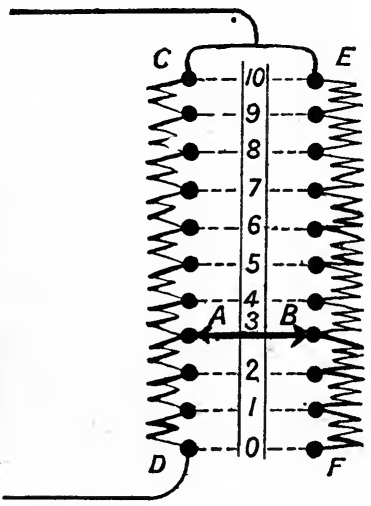

FIG. 26.-Diagram of shunted coils (Smith system).

$\mathrm{AB}$, movable cross-bar; $\mathrm{CD}$, coils of $0.1 \mathrm{ohm}$ each; $\mathrm{EF}$, shunt coils (9.9 ohms each).

Hence the bridge is primarily of value when working at steady temperatures.

It will be observed that a bridge wire cannot be employed. Small changes of resistance can, however, be obtained by means of shunted coils. The principle of this method is illustrated by Fig. 26 .

The ten coils CD each of $0.1 \mathrm{ohm}$ are in series; any number of the coils EF can be placed as a shunt across the corresponding number of coils in $\mathrm{Cl}$ ) by moving the bar AB.

Consider the bar in the position marked $O$. We have then ten $0 \cdot 1 \mathrm{ohm}$ coils shunted by ten coils of $9.9 \mathrm{ohms}$ each.

So the effective resistance is

$$
\begin{aligned}
& \frac{1}{\mathrm{X}}=\frac{1}{1}+\frac{1}{99} \\
& \text { Hence } \quad \mathrm{X}=0.990 \text {. }
\end{aligned}
$$

Suppose now the bar AB is moved to position marked 1.

We have now one coil of $0.1 \mathrm{ohm}$ in series with nine coils of $0 \cdot 1$ ohm shunted by nine coils of 9.9 ohms.

Hence, if $Y$ is the effective resistance of the shunted portion,

$$
\begin{aligned}
& \frac{1}{Y}=\frac{1}{0 \cdot 9}+\frac{1}{89 \cdot 1} \\
& Y=0.891
\end{aligned}
$$

So that the total resistance is $0 \cdot 1+0.891=0.991$. Hence moving the bar one step has increased the resistance by $0.001 \mathrm{ohm}$.

Similarly it can be shown that each step has a corresponding effect, so that the arrangement is capable of giving a total increase of $0 \cdot 01$ ohm distributed over ten steps.

It is obvious that the studs could be distributed on a circle, so the movement of $\mathrm{AB}$ would be one of rotation about its centre.

Fig. 27 illustrates the $\mathbf{R}$ arm of a bridge constructed on this principle. Coils of $0.01 \mathrm{ohm}$ and upwards (apart from the dials) have mercury contacts bridged by $n$-shaped pieces of copper (Fig. 28). resistance. 
The contact-brushes enable one or more of the lower resistance coils each to be shunted by the higher resistance ones, the shunting pro-

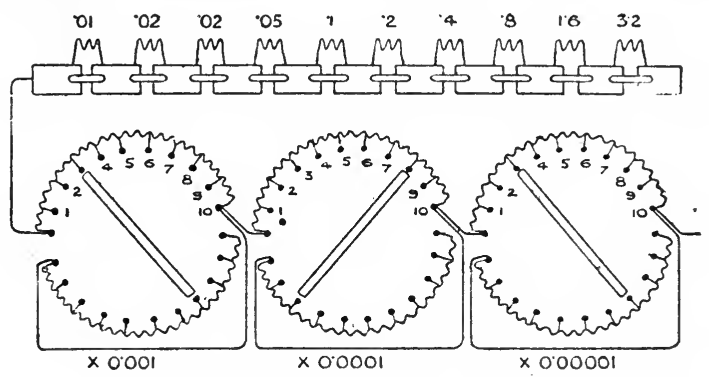

FIG. 27.-Diagram of $R$ arm of bridge.

The resistance coils in the three dials are as follows :-

For the 0.001 dial ten resistances of $0.1 \mathrm{ohm}$ each and ten of $9.9 \mathrm{ohms}$ each.

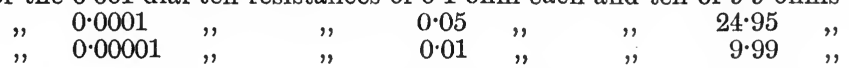

ducing a diminution of the total resistance. (As will be explained later, in constant-current bridges the $\operatorname{arm} \mathbf{R}$ is decreased in resistance with increase in resistance of the platinum thermometer : p. 48.)

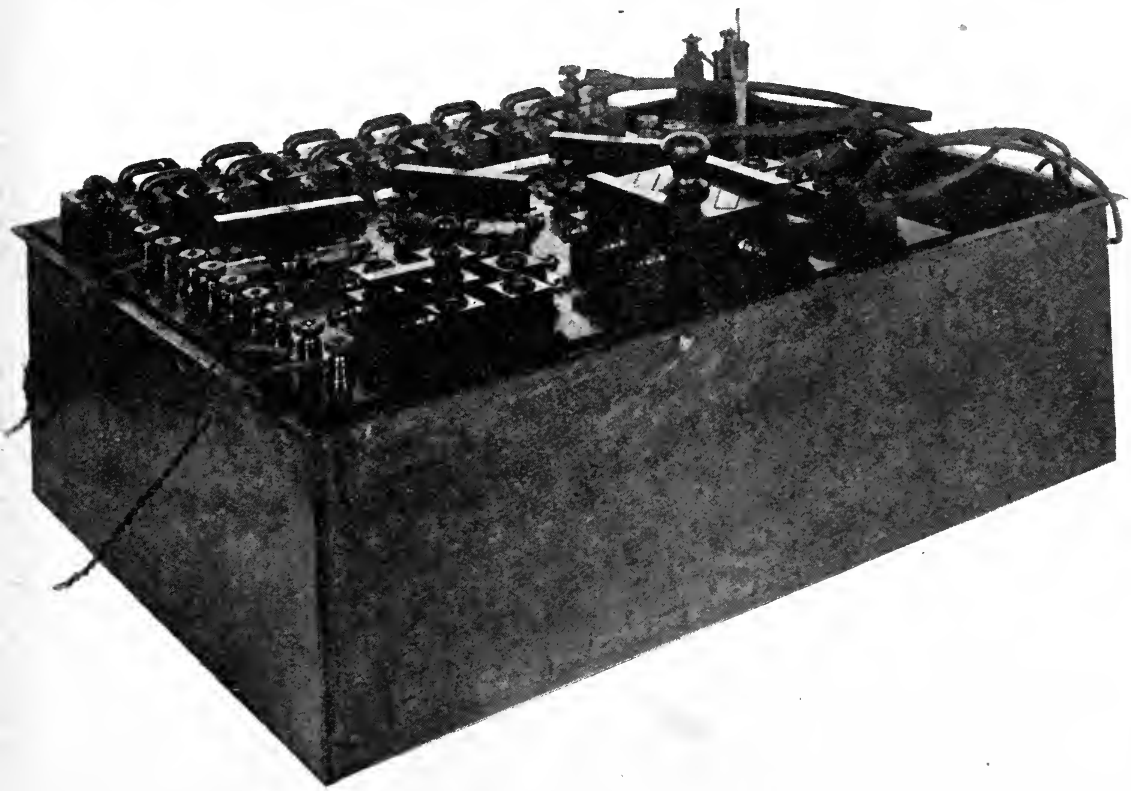

FIG. 28.-Smith's "difference" bridge (oil immersed).

This device of shunted coils does not involve any great accuracy in the adjustment of the coil values.

For instance, consider the $0.001 \mathrm{ohm}$ dial. Nominally the coils 
composing this dial are exactly $0 \cdot 1 \mathrm{ohm}$ and $9.9 \mathrm{ohms}$. If, however, the coils are badly adjusted so that, instead of a resistance coil being 9.9 ohms, it is 9.95 ohms, the change when this coil is used as a shunt resistance would be 5 millionths of an ohm less than 0.001 .

'The bridge can be calibrated in the manner described later, so that even if the coils are badly adjusted connections can be applied to the readings.

(e) Mueller's Bridge.-A different arrangement of bridge with shunt coils has been described by Mueller. In Fig. 29 the connections of the complete bridge are shown.

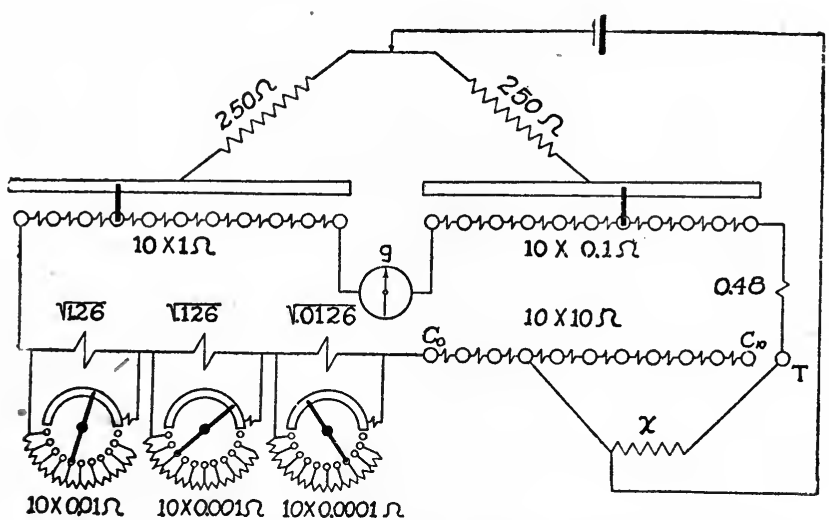

FIG. 29. Diagram of Mueller's bridge.

'The two ratio coils are $250 \mathrm{ohms}$ each, and these are connected by a short slide wire which is used in adjusting them to equality.

The ratio coils terminate in long bars which may be connected, by means of plugs, to the contact blocks of the $1 \mathrm{ohm}$ and $0 \cdot 1 \mathrm{ohm}$ decades.

In series with the shunting decades there is a set of ten 10-ohm coils, $\mathrm{C}_{0}-\mathrm{C}_{10}$. These are introduced into the circuit by plugs or mercury contacts.

Three shunted decades are employed giving $0.01,0.001$, and $0.0001 \mathrm{ohm}$ per step respectively.

In choosing the values for the shunted coils the formula for resistance of coils in parallel was put in the following form : if a resistance $r$ is shunted by a resistance $\mathbf{R}$ the effect of the shunt is to reduce $r$ by an amount $\frac{r^{2}}{\mathbf{R}+r}$. In the shunt decades (for example, the 0.01-ohm decade) $\mathbf{R}$ is given a series of values such that $\frac{r^{2}}{\mathbf{R}+r}$ successively assumes the values $0 \cdot 10,0.09,0.08 \ldots 0.00$; that is, successive values of $\mathbf{R}$ are defined by the equations $\mathbf{R}+r=\frac{r^{2}}{0 \cdot 10}$, etc., to $\mathbf{R}+r=\frac{r^{2}}{0 \cdot 00}$. 
Consequently, to secure even-valued coils, a value was sought for $r^{2}$ which should contain the factors 7 and 9 , and therefore be divisible by all numbers below 10 . The value $r^{2}=1.26$ was found to lead to suitable values for the coils of the 0.01 -ohm decade.

By making $r_{2}$ for the $0.001-o h m$ decade equal to $r / \sqrt{10}$ the successive values of $\mathbf{R}$ for this decade are made to differ by a constant amount from the values of $\mathbf{R}$ for the $0.01-\mathrm{ohm}$ decade, so that the corresponding coils for the two decades, with two exceptions, will be equal.

The values of the shunted and shunting coils for the three decades are given in Table XI.

TABLE XI.

\begin{tabular}{|c|c|c|c|}
\hline Position of & $\begin{array}{l}0 \cdot 01 \text { ohm decade. } \\
\text { Shunted coil, } \\
\sqrt{1 \cdot 26}=1 \cdot 1225\end{array}$ & $\begin{array}{l}0.001 \text { ohm decade. } \\
\text { Shunted coil, } \\
\sqrt{0 \cdot 126}=0.3550\end{array}$ & $\begin{array}{c}0.0001 \text { ohm decade. } \\
\text { Shunted coil, } \\
\sqrt{0.0126}=0.1122 .\end{array}$ \\
\hline & Individual coils. & Individual coils. & Individual coils. \\
\hline 0 & $11 \cdot 478$ & $12 \cdot 245$ & $12 \cdot 49$ \\
\hline 1 & $1 \cdot 4$ & $1 \cdot 4$ & $1 \cdot 4$ \\
\hline 2 & $1 \cdot 75$ & $1 \cdot 75$ & $1 \cdot 75$ \\
\hline 3 & $2 \cdot 25$ & $2 \cdot 25$ & $2 \cdot 25$ \\
\hline 4 & $3 \cdot 0$ & $3 \cdot 0$ & $3 \cdot 0$ \\
\hline 5 & $4 \cdot 2$ & $4 \cdot 2$ & $4 \cdot 2$ \\
\hline 6 & $6 \cdot 3$ & $6 \cdot 3$ & $6 \cdot 3$ \\
\hline 7 & $10 \cdot 5$ & $10 \cdot 5$ & $10 \cdot 5$ \\
\hline 8 & $21 \cdot 0$ & $21 \cdot 0$ & $21 \cdot 0$ \\
\hline 9 & $63 \cdot 0$ & $63 \cdot 0$ & $63 \cdot 0$ \\
\hline 10 & $\infty$ & $\infty$ & $\infty$ \\
\hline
\end{tabular}

A plan of the top of a bridge of this type is shown in Fig. 30. It differs from that shown in Fig. 29 insomuch that switches are employed instead of plugs in the 1-ohm and $0 \cdot 1-\mathrm{ohm}$ decades. The 10 -ohm decade is shown on the right-hand side, and connection to it can be made either by plug or through binding posts. Mercury contacts would be preferable to the plug contacts.

An arrangement is provided for interchanging the ratio coils so that these may be adjusted to equality by means of the slide wire.

This adjustment may be made as follows: By connecting the post marked ' $\mathrm{C}$ ' with one of the $\mathrm{C}^{\prime}$ posts - for example, $\mathrm{C}^{\prime} 40$, and connecting $t c$ to $\mathrm{C}^{\prime} 20$-the first two of the $10-\mathrm{ohm}$ coils may be balanced against the second two.

Then, on shifting the switches of the 1 -ohm and $0 \cdot 1$-ohm decades from the zero positions to $\mathbf{R}$, the ratio coils are interchanged and the bridge balance will be disturbed unless the two are equal. If the coils are not equal, adjustment may be made by means of the slide wire until no change in balance is noted on interchanging the ratio coils. A special stop with a release ordinarily prevents moving the switches to the position $\mathbf{R}$. 


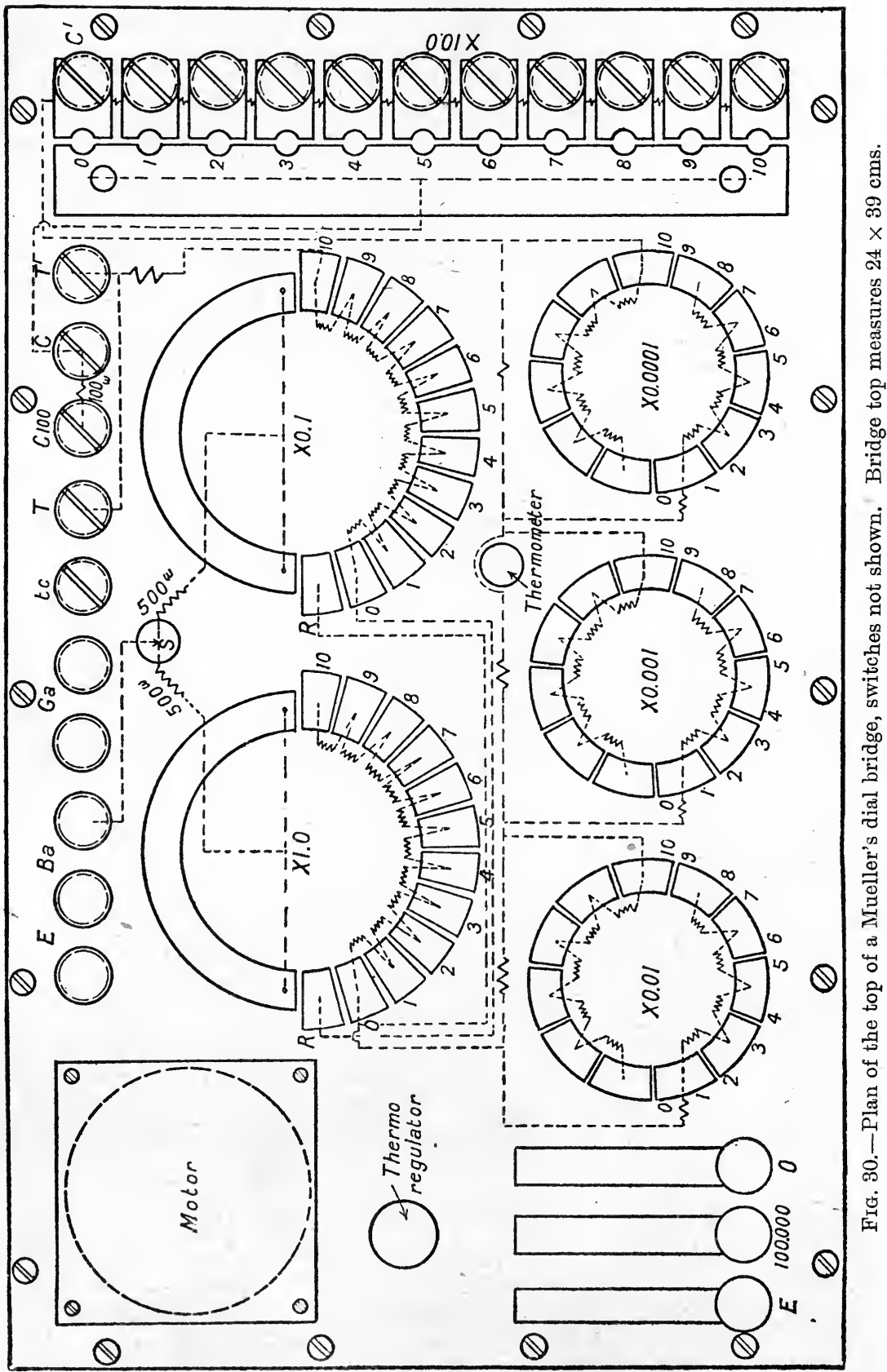


The three keys are connected in the battery circuit and so arranged that the key E closes the circuit through an external resistance connected between the key posts marked $\mathrm{E}$; the 100,000 key closes the circuit through $100,000 \mathrm{ohms}$, and the 0 key through no added resistance.

Temperature control.-While, in work of the highest precision, it is necessary to control the temperature of the bridge coils within narrow limits, a fair degree of accuracy may be obtained by applying temperature corrections to the coil values. With manganin coils of good quality measurements can be made to about 1 part in 25,000, if the coil temperatures are known within $1^{\circ}$ or $2^{\circ}$, and the indications of a mercury thermometer with its bulb near the coils should give the coil temperatures within this limit.

For great accuracy the bridge must be mounted in an oil bath and thermostatic control employed. In the bridge shown in Fig. 30 the motor for circulating the oil is mounted on the bridge coil with its axis vertical, and drives a screw propeller working in a vertical tube, which also contains a heating coil. The oil is circulated through the tube, along the bottom of the box under a false bottom, thence upward and past the coils, and through the tube again.

A liquid-in-glass thermo-regulator is mounted on the lower side of the false bottom.

A copper coil, similar to the sealed coils used for the 10-ohm and 1ohm decades, mounted in the bridge and arranged so that its resistance could be measured with the bridge, showed that in such coils the fluctuations in the temperature of the oil, as the regulator operated, were almost completely damped out.

\section{Heating effect of the current passing through the ther-} mometer coil.- In order that the thermometer bulb may be of small dimensions and the thermometric lag reduced to a minimum, the coil must be made of wire of about 6 mils in diameter, consequently the heating effect of the measuring current on the value of the resistance is quite appreciable. The bridge coils are sufficiently heavy and well cooled to make the effect on them negligible, hence the limiting value of the current is determined solely by-considerations of the thermometer coil.

At any given temperature the increase in resistance is proportional to the square of the current.

The same expenditure of watts at different temperatures does not, however, produce the same heating effect, since the rate of cooling of a surface by convection and radiation is a function of its absolute temperature.

The precise laws governing the phenomenon have not yet been investigated and it is only possible to approximate to a constant heating effect for all temperatures by keeping the current through the thermometer constant.

Callendar states : "The cooling effect of conduction and convection currents in air in the thermometer tube increases nearly in proportion to the absolute temperature. The effect of radiation also becomes important at high temperatures, and the cooling is then more rapid. If, 
therefore, the watts are kept constant, the heating effect will diminish as the temperature rises, and a small systematic error will be produced. Assuming that the rate of cooling increases as the absolute temperature $\theta$, and that the watts are kept constant, the heating effect at any temperature $\theta$ is $273 h / \theta$, where $h$ is the heating effect in degrees of temperature at $0^{\circ} \mathrm{C} . "$

This train of reasoning led Callendar to conclude that a better rule is to keep the current through the thermometer the same at all temperatures, as in that case the heating effect also is nearly constant, if the current flows sufficiently long for the steady state to be attained.

The table below shows the heating effect of the measuring current on two thermometers, using a current of 0.1 amp.-a current ten times larger than that customary in precision work.

TABLE XII.

\begin{tabular}{|c|c|c|}
\hline & \multicolumn{2}{|c|}{$\begin{array}{c}\text { Increment of temperature above } \\
\text { surroundings. }\end{array}$} \\
\hline Temp. ${ }^{\circ} \mathrm{C}$. & $\begin{array}{c}\text { Diam. wire } \cdot 15 \mathrm{~mm} . \\
\text { (Waidner \& Burgess). }\end{array}$ & $\begin{array}{c}\text { Diam. wire } \cdot 15 \mathrm{~mm} . \\
\text { (F. E. Smith). }\end{array}$ \\
\hline 0 & $1 \cdot 65^{\circ}$ & $1 \cdot 62^{\circ}$ \\
100 & $1 \cdot 69^{\circ}$ & $1 \cdot 68^{\circ}$ \\
$1 \cdot 85^{\circ}$ \\
\hline 44.5
\end{tabular}

Hence, for the usual value of current $01 \mathrm{amp}$. the rise would be $\cdot 016^{\circ}, 017^{\circ}$ at $0^{\circ}$ and $100^{\circ}$ respectively. The divergence in the values for $444.5^{\circ} \mathrm{C}$. has not been explained.

The above values are of course only strictly applicable to the particular thermometers investigated.

To eliminate the effect, the following rule has been proposed by Callendar:- "'Take away one-third the difference in reading when the battery consists of two secondary cells in series and in parallel from the reading when in parallel."

Modification of a bridge to obtain constant current through the thermometer.-To-satisfy the condition of constant current through the thermometer at all temperatures it is necessary either to vary the resistance in series with the battery according to a calculated table or arrange the bridge so that the resistance of each arm remains constant.

To effect this it is only necessary to make the value of the $\operatorname{arm} \mathbf{R}$ fixed value greater than the maximum ever attained by the thermometer coil, and then insert a variable resistance (plugs and dials) in series with the thermometer to form the other arm of the bridge. Under these conditions an increase in resistance of the thermometer coil is counterbalanced by a decrease in the variable resistance. In such a case the arm $\mathbf{R}$ may be composed of simply one coil of the required value. 
Reference to Fig. 27 will show the dials arranged to work with this system.

Determination of the bridge centre.-In thermometers of the compensated lead type it is necessary to determine the bridge centre from time to time, as this is the base point from which the resistance is measured. For this purpose the $\mathbf{P}_{1}, \mathbf{P}_{2}$ and $\mathrm{C}_{1}, \mathrm{C}_{2}$ ends of the leads should be short-circuited at the thermometer head. Any change with time in the resistance of the flexible leads can thus be detected. It is scarcely necessary to point out that the leads from the bridge to the thermometer should be approximately equal in resistance and the junctions well made. The writer has found flexibles of the material known commercially as Dynamo flexible (5 amps.) to be quite satisfactory. It is composed of about 66 strands of $0.25 \mathrm{~mm}$. diameter copper wire insulated by a double cotton covering, double indiarubber, proof taped and braided.

Elimination of thermoelectric effects.-One of the troubles of precision resistance measurements is the thermoelectric effect in the circuits, particularly under conditions where there are big temperature gradients in the thermometer head. The magnitude of the effect is readily seen by closing the galvanometer key with the battery circuit left open. The galvanometer spot under the circumstances will generally take up a new position, and the movement is a measure of the thermoelectric effects in the system.

It is the practice, therefore, to work with the galvanometer circuit always completed and observe the deflection when the battery circuit is made or reversed.

Reversal of the battery is preferable, since this procedure permits the heating effect of the current on the thermometer to become settled, and thus avoid the initial drift when the battery is first made, owing to the heating effect of the current on the resistance.

To eliminate induction effect Dr. E. H. Griffiths devised a thermoelectric key. In this key there is a series of spring tongues so arranged that the galvanometer circuit is always made. When the key is depressed, the galvanometer circuit is broken momentarily, the battery circuit completed, and then the galvanometer circuit remade. By this sequence the galvanometer circuit is open during the period the current is growing in the circuit, and consequently there is no inductive kick of the light spot. It is easy to arrange a battery reversal key on the same principle.

The various junctions and connections in the keys are a frequent source of thermal e.m.f., so it is advisable to thoroughly box in the entire key including the terminals ; some observers have even found it desirable to immerse the key in oil with only the handle projecting.

With the non-inductive windings of the resistance coils now used the induction effect is usually negligibly small, and it is sufficient to have a plain battery reversal key with an "off" position.

Calibration of box coils and bridge wire.-For platinum thermometry work the relative values only of the coils and bridge wire are of importance. The method of 
calibration is closely analogous to that employed for the standardisation of a set of weights.

Instead of a thermometer a variable rheostat is connected to the $P_{1}, P_{2}$ terminals of the bridge. This resistance must be capable of fine adjustment; a convenient type which can readily be constructed is shown in Fig.' 31 . It consists of four dials of 10 coils each, the coil values being $0 \cdot 1 \mathrm{ohm}, 1 \mathrm{ohm}, 10 \mathrm{ohms}$, and $100 \mathrm{ohms}$ respectively. A trough of mercury with a $n$-shaped piece of copper permits of tine adjustments.

The method of construction is readily understood from the diagram. Each coil terminates in mercury cups, so that a movement of the bar cuts out any number. The coils of course need not be accurately known.

As an alternative, ordinary P.O. resistance boxes may be used, one box forming a shunt on the other.

This method of successive shunts is, however, rather laborious.

(a) Calibration of the bridge wire.-To the terminals $\mathrm{C}, \mathrm{C}$ of the bridge is connected a short length of resistance wire terminating in two massive pieces of copper, which are drilled to contain mercury cups. Then by the insertion of a $n$-shaped

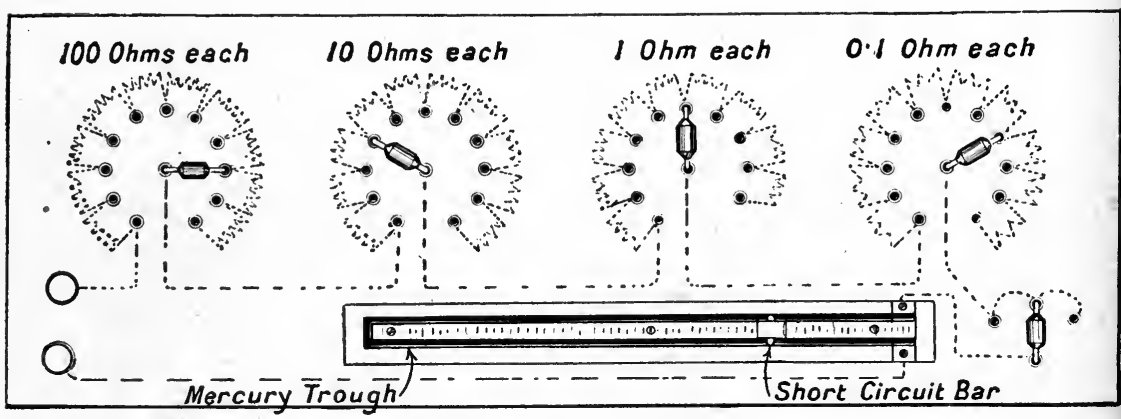

FIG. 31.-Diagram of rheostat employed in calibration of box coils and bridge wire.

piece of copper the resistance wire can be short-circuited without interfering with its connections to the bridge.

The resistance of the wire should be about 1 unit of the bridge wire.

'The variable rheostat is adjusted to bring the contact maker to one end of the bridge wire; to effect this it will generally be necessary to withdraw a plug from the box.

The bridge is balanced in the usual manner. The calibrator coil (comnected to $\mathrm{C}, \mathrm{C}$ ) is then short-circuited and balance again obtained at a distance about 1 unit away on the bridge wire. The operation should be repeated a few times.

'The rheostat is readjusted so that a new position is taken up on the bridge wire adjacent to the second balancing point and the operation repeated. By a series of such steps the entire length of the bridge wire may be covered.

If we suppose $r$ to be the resistance of the calibrator coil and $l_{1}, l_{2}$ the lengths of wire corresponding to it at-various points, then

$$
\frac{1}{l_{1}} \propto r, \text { etc. }
$$

Hence, by plotting graphically the reciprocals of $l_{1}, l_{2}$, etc., as ordinates with the mean bridge wire reading as abscissæ, a curve call be obtained representing the variation in resistance per unit length along the bridge wire.

The values can be converted into those of the "mean box unit" referred to below, by obtaining the resistance of a length of the bridge wire in terms of one of the box coils by the usual substitution method.

(b) Calibration of the box coils.-For convenience it is assumed that the coils are 
arranged on the binary system, and that the nominal values are 5, 10, 20, 40, 80 , etc. ... .

Balance is obtained at any convenient place on the bridge wire by adjustment of the variable rheostat; plug 5 is then withdrawn and the change of bridge wire reading to restore balance observed. The rheostat is readjusted to bring the balance point back to approximately the same position as when plug 5 was in ; plug 10 is then withdrawn; plug 5 inserted, and the change in bridge wire reading observed as before.

The same procedure is followed until the difference between the highest coil in the bridge and the sum of the series below is obtained in terms of a length of the bridge wire.

Let the successive differences in bridge wire readings be $x_{1}, x_{2}, \ldots x_{9}$.

Supposing coil 1280 to be the highest in the set.

Then we obtain the following series of quotations :-

Coil $1280-($ coils 640 to 5$)=x_{9}$

Coil $640-($ coils 320 to 5$)=x_{8}$

Coil $320-($ coils 160 to 5$)=x_{7}$, etc.

By subtraction-

Coil $1280-2 \times \operatorname{coil} 640=x_{9}-x_{8}$ ?

Coil $640-2 \times$ coil $320=x_{8}-x_{7}$

to

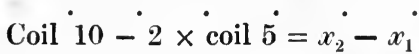

Now the values of $x_{1}, x_{2}, \ldots$. etc. in terms of coil 5 are already known from the previous operations in connection with the bridge wire calibration.

Hence the values of coils 640 to 10 in terms of coil 5 may be found.

Knowing the values of all the coils in terms of coil 5 , it is then easy to express them all in terms of the mean coil, and hence in terms of the mean box unit, a corresponding correction being made in the integrations of the bridge wire.

It is preferable, however, to express the coils in terms of the international ohm, and this of course can be done by ascertaining the resistance of a standard coil, say $10 \mathrm{ohms}$, on the bridge.

By expressing the coils in terms of an absolute standard it is possible to keep note of the variations with time in the coils.

The same procedure is followed in the calibration of a bridge fitted with a set of shunted coils instead of a bridge wire. For the shunted coil dials the changes of the shunted coils are of far less importance, and there is little difficulty in adjusting them to the required degree of accuracy.

They possess the advantage of not being subjected to wear, as is the case with a bridge wire.

\section{Standardisation of a resistance thermometer.-For tempera-} tures up to $600^{\circ}$ a platinum resistance thermometer is generally standardised at the temperature of melting ice $\left(0^{\circ} \mathrm{C}\right.$. $)$, of the vapour of water boiling under normal pressure $\left(100^{\circ} \mathrm{C}^{\mathrm{C}}\right)$, and of the vapour of sulphur boiling under normal pressure $\left(444.5^{\circ} \mathrm{C}\right.$.).

For the ice-point the thermometer should be well immersed in finely crushed ice moistened with water; a suitable form of apparatus is shown in Fig. 8, p. 21). Unless the thermometer has been carefully sealed or provided with a drying tube to prevent access of moist air, prolonged exposure to the low temperature will cause electrical leakage owing to the deposition of moisture on the mica.

The steam-point is determined in a standard form of hypsometer such as that shown in Fig. 32. It is advisable to take precautions to prevent escape of steam rising around the head of the thermometer, as the thermal effects produced are apt to be troublesome. 
Alternate readings of the barometer and bridge should be taken and correction made if necessary for the difference in level of the mercury cistern of the barometer and the hypsometer, if the difference in level be considerable.

The sulphur-point can be determined in the standard Meyer tube form of apparatus introduced by Callendar and Griffiths and shown in Fig. 33, or in the N.P.L. apparatus shown in Fig. 34.

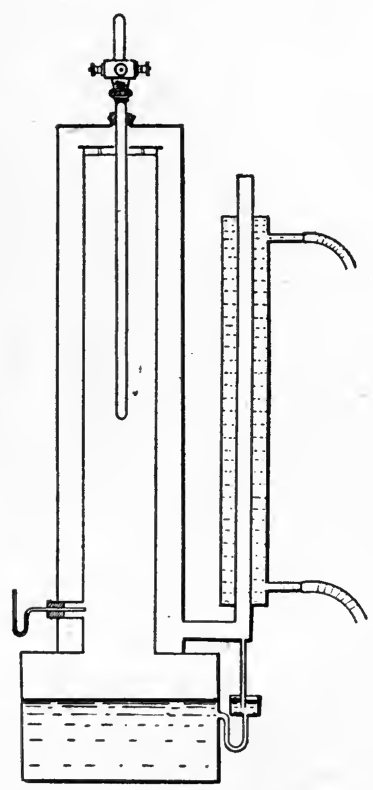

Fig. 32.-Standard hypsometer for determination of steam-point. .

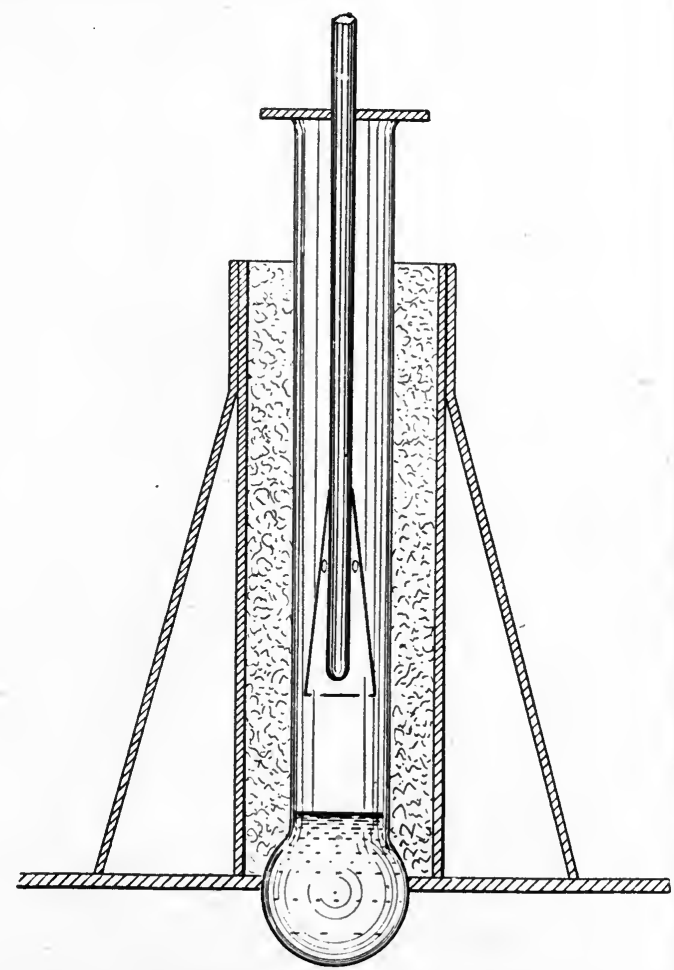

Fig. 33.- Standard Meyer tube apparatus for the determination of the sulphur-point (Callendar and Griffiths).

'The latter is a very convenient form of sulphur boiling-point apparatus and readily constructed, the vessel being made from a discarded gas cylinder and pipe steam fittings. The condenser is a quartz tube, which is less liable to crack than glass. The cheaper translucent variety of quartz is quite satisfactory, since the level of the sulphur vapour may be readily ascertained by lightly touching the tube at various points. The level of the vapour when the apparatus is working normally should be at a height of about $6^{\prime \prime}$ above the top of the apparatus.

With the Meyer tube apparatus it is necessary to fit the thermometer with an asbestos or aluminium cone as shown in Fig. 33. This cone 
serves two purposes : (1) It prevents the condensed sulphur from running down over the bulb and cooling it below the temperature of the surrounding vapour; and (2) it eliminates direct radiation from the bulb to the colder walls of large tube.

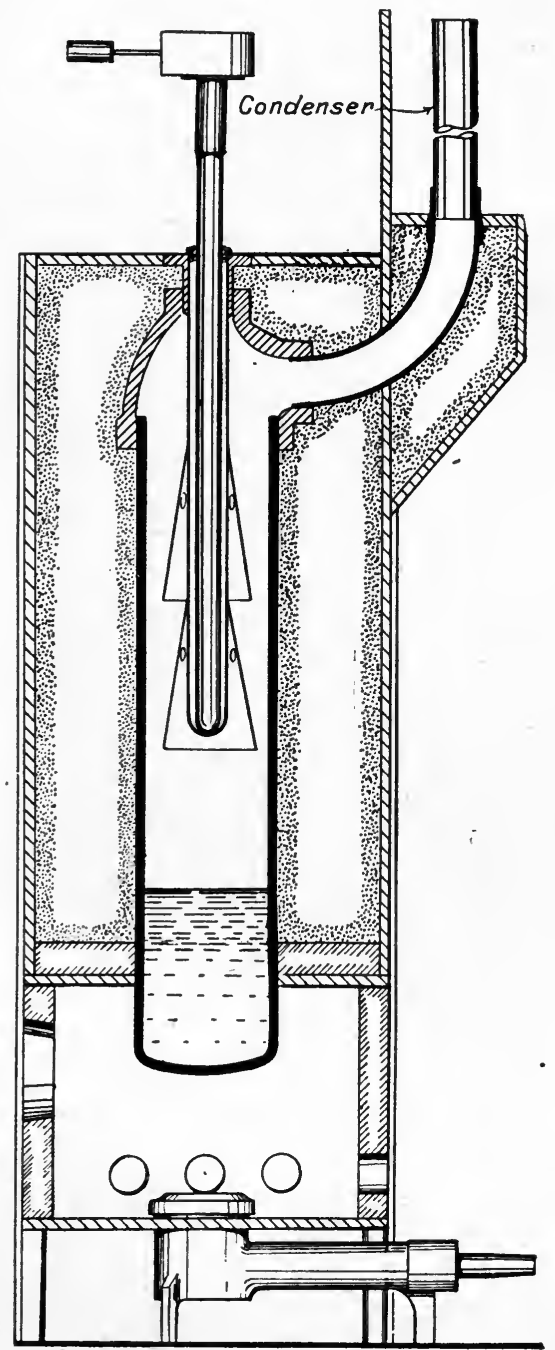

Fig. 34.-N.P.L. apparatus for determination of sulphur boiling-point.

Callendar and Griffiths in 1890 made a careful investigation of these effects ; the error due to the first cause was found to be about $0.28^{\circ}$, while that due to the second cause amounted to $0.49^{\circ}$; consequently an unprotected thermometer would read nearly a degree low in sulphur. 
It will be observed that the cones are permanently fixed in the case of the apparatus shown in Fig. 34.

The sulphur-point is an excellent "fixed point" for calibration purposes; it is possible to keep the temperature of the vapour steady to within $\frac{1}{100}^{\circ}$ for hours, account being taken of barometric changes.

Purity of the Sulphur.-Ordinary commercial stick-sulphur manufactured by the "Chance process" is satisfactory, since no difference has been observed between its boiling-point and that of highly purified sulphur.

Usually when sulphur is boiled for the first time volatile impurities distil off. A black residue (FeS) is generally found, but in the quantity in which it is usually present this appears to have no influence.

Variation with pressure of the boiling-point of sulphur.-'The influence of pressure on the boiling-point of sulphur is quite considerable in the vicinity of $760 \mathrm{mms}$. an increase of $1 \mathrm{~mm}$. in the barometric height raises the boiling-point by approximately $0.09^{\circ}$.

The relation between temperature and pressure over the range of importance in practical work has been investigated by Holborn and Henning and by Harker and Sexton (1908), and the results are in close agreement.

Over the range $720-780 \mathrm{mms}$. the relation between temperature and boiling-point may be represented by the formula-

$$
t=t_{s}+0.0904(p-760)-00000519(p-760)^{2}
$$

where $t$ is the boiling-point at pressure $p$,

760.

In Table XLVIII. the value of $t$, assuming $t_{s}=444.53^{\circ} \mathrm{C}$, , have been calculated from the above formula. In addition, the values of the quantity $\left\{\left(\frac{t}{100}\right)^{2}-\frac{t}{100}\right\}$ are given for the same values of $t$; this coefficient is required in calculating the value of $\delta$.

The freezing-point of zinc $\left(419 \cdot 4^{\circ} \mathrm{C}_{2}\right)$ is sometimes recommended as a third fixed point instead of sulphur.

As the sulphur-point is so well established and convenient to use, there does not appear to be very valid reasons, in the writer's opinion, for discarding it in favour of a freezing-point determination.

Example of method of reduction of observations taken in the standardisation of a platinum thermometer.-'The resistance observations were corrected for the errors of the coil values, the temperature, and the value of the bridge centre deduced.

The resistance at the temperature of melting ice was 257.916 units.

In steam the resistance was $357 \cdot 953$.

The barometric height during the steam-point observations was 766.26 , and the temperature of the mercury column and scale $1755^{\circ} \mathrm{C}$.

The barometric height has to be reduced to that corresponding to a column at $0^{\circ}$ in latitude $45^{\circ}$. 
Tables are available for this reduction in the case of standard types of barometers possessing a brass scale, such as the Fortin type.

The correction for temperature in this case is $-2 \cdot 19 \mathrm{mms}$, while the latitude correction is approximately +0.45 for places on the parallel through London. Hence the corrected value of the pressure is $764: 52$ at $0^{\circ}$ latitude $45^{\circ}$.

The boiling-point of water under a pressure of $764.52 \mathrm{mms}$. is $100 \cdot 1654^{\circ} \mathrm{C}$. according to Broch's recalculation of Regnault's observations.

Hence increase in resistance for a temperature change from $0^{\circ}$ to $100 \cdot 1654^{\circ} \mathrm{C} .=100 \cdot 037$ units.

To obtain the value of the F.I. the resistance at $100^{\circ} \mathrm{C}$. is required.

$$
\delta \mathrm{R} \text { for } 0 \cdot 1654=\frac{100 \cdot 037}{100 \cdot 1654} \times 0 \cdot 1654 \times 0.985=0 \cdot 163
$$

[The coefficient 0.985 is the value of $\frac{(\triangle p t)}{\triangle(t)}$ near $100^{\circ} \mathrm{C}$. for a thermometer of $\delta=1 \cdot 50$. The general formula is

$$
\left.\frac{(\triangle p t)}{\Delta(t)}=\left(1-\delta \frac{2 t-100}{10,000}\right)\right]
$$

Hence

$$
\mathbf{R}_{100}=357 \cdot 790
$$

so that

$$
\mathbf{R}_{100}-\mathbf{R}_{0} \equiv \text { F.I. }=99 \cdot 874
$$

The resistance in sulphur was $679 \cdot 165$, and the barometric height 766.23 at $17.5^{\circ}$. Correcting for temperature $(-2 \cdot 19 \mathrm{mms}$ ), and latitude $+0.45^{\circ}$, barometric height at $0^{\circ}$ and latitude $45^{\circ}=764.49 \mathrm{mms}$. For this pressure the boiling-point of sulphur at this temperature is $444.94^{\circ} \mathrm{C}$. ('Table XLVIII.).

The platinum temperature $(p t)$ corresponding to the above value of the resistance is

$$
\frac{679 \cdot 165-257 \cdot 916}{99 \cdot 874}=421 \cdot 78^{\circ} \mathrm{C} \text {. }
$$

So that $t-p t=444 \cdot 94-421 \cdot 78=23 \cdot 16$

Now from 'Table XLVIII. $\left[\left(\frac{t}{100}\right)^{2}-\frac{t}{100}\right]=15 \cdot 347$ for $t=444.94$

$$
\text { Hence } \delta=\frac{23 \cdot 16}{15 \cdot 347}=1 \cdot 51
$$

NoтE.-In reducing platinum thermometer observations to true temperatures Table XLIX. will be found convenient. It has been calculated for $\delta=1.50$; should the thermometer have a different value of $\delta$ a small correction can be applied to the readings from Table $\mathrm{L}$. In fact, these corrections can best be obtained from a small scale curve based on the data given in this table.

Some observers employ a curve connecting $t-p t$ with $p t$. Unless the curve is drawn on a very large scale it is difficult to obtain sufficient accuracy by this method.

Application of the resistance thermometer to high temperature work.-Almost the very first scientific use made of the platinum 
thermometer was for the determination of high temperature freezingpoints, as described earlier in this chapter. This application, however, is an operation which requires considerable care if results of the highest order of accuracy are desired.

The thermometer usually has a bulb of 3 to $4 \mathrm{cms}$. in length and enclosed in a heavy porcelain sheath. Consequently it is necessary to allow for a depth of immersion of from 6 to $8 \mathrm{cms}$. in the metal. Further, the rate of cooling should be slow, to diminish possible error due to lag. Heycock and Neville state that the freezing-point of gold could be read to $1^{1}{ }^{\circ}$ without difficulty. In a study of the effect.of high temperatures on the constants of platinum thermometers they found that the first few heatings to $1000^{\circ} \mathrm{C}$. increased both the $\mathrm{R}_{0}$ and the F.I. This effect they ascribed to the thickening of the mica plates after exposure to the high temperature and the consequent straining of the fine wire when the coil cools and the wire contracts on to the larger frame.

They concluded that the constants should be determined before each temperature measurement of importance, and, provided the leads had been well annealed originally, that these constants should be used in calculating the temperature, regardless of what the values of the constants might be after the experiments. A thermometer should of course be thoroughly annealed before standardisation.

Industrial types of resistance thermometers.-For industrial use the sensitive type of resistance thermometer, bridge, and galvanometer are out of the question, and several modifications have been evolved with a view to obtaining robustness combined with ample, if moderate, sensibility.

In the Whipple indicator the resistance box is replaced by a long bridge wire wound spirally on a drum. A sensitive pivoted galvanometer is fixed in the top of the case and balance obtained by rotating the drum. The instrument has a scale graduated directly in ${ }^{\circ} \mathrm{C}$., and readings may easily be taken to about $1_{3}^{\circ}$ in the range $0^{\circ}$ to $1100^{\circ} \mathrm{C}$.

In the Paul Harris indicator the principle of the ohmmeter is applied. 'The instrument consists of a moving coil indicator having two coils wound on one support and pivoted in a magnetic field. One of the coils is comnected across a shunt in the battery circuit, while the other (wound at right angles to it) consists of two windings, one of which is shunted across the platinum thermometer and the other across a standard or comparison resistance. The deflection scale can be arranged to cover a limited temperature range, so that an open scale is possible.

In the Callendar recorder the suspended coil galvanometer carries a boom, which on deflection releases the brake from a clockwork motor. The motor pulls a carriage along a slide wire until balance is obtained. A pen records the position on a rotating drum with paper surface.

In these types of instruments it is advisable to give some attention to the battery. 'To obtain sensitivity the current through the platinum coil has to be fairly considerable and is attended with the usual rise in 
temperature of the wire, due to heating effect. Unless the battery current is maintained at about the same value as when the calibration of the instrument was effected small errors in the readings will be produced.

\section{REFERENCES TO CHAPTER III.}

(Nore.-The contents of the papers are indicated, but the titles are not given below.)

Historical, construction and calibration.

Siemens, Bakerian Lecture, 1871. Proc. Roy. Soc., 19, p. 351 (1871).

, British Association Reports, p. 242 (1874).

" Trans. Soc. T'el. Engs. (1879).

, Phil. Mag., vol. xlii. (1871).

Callendar, Phil. Trans.; 178, p. 160 (1887).

, ("On construction of pt therms."), Phil. Mag., 32, p. 104 (1891).

,, ("Notes on pt thermometry"), Ibid., 47, pp. 191, 519 (1899).

Griffiths ("Freezing-points and boiling-points"), Phil. Trans., 182, A, p. 143 (1891). Values require correction on account of redetermination of sulphurpoint in 1892.

Callendar and Griffiths, "Boiling-point Sulphur," etc., Phil. Trans., 182, A, pp. 43,119 (1892).

Clarke, "Measurement of temp.," etc., Electrician, pp. 175, 241, 273, 371, 747 (1896-7).

Griffiths, "Constructiom and standardisation of Kew apparatus," Nature, 53, p. 39 (1896).

Wade, "Method of facilitating temp. measurement by pt therm.," Proc. Cam. Soc., 9, p. 526 (1898).

Chree, "Pt thermometry, sources of error," Proc. Roy. Soc., 67, p. 3 (1900).

Edwards, "' Notes on Resistance measurements in pt thermometry," describes a form of "difference" bridge, Contrib. Jefferson Phys. Lab., 2, p. 549 (1904). Proc. Am. Acad., 40, p. 549 (1905).

Haagen, "Quartz-glass resistance thermometer," Zeitschr. Angew. Chem., 20, p. 565.

Melink, "Comparison of pt therm. with hydrogen therm. and gold therm.," Com. Phys. Lab. Leiden, 93, p. 1 (1904).

Onnes and Clay, Ibid., 95, pp. 37, 49 (1906).

Onnes, Braak and Clay, Com. Phys. Lab. Leiden, 101, p. 11 (1908).

Waidner and Dickinson, "Apparatus for pt thermometry," Phys. Rev., 19, p. 51 (1904).

Northrup, "Measurement of temp. by electrical means," Proc. A.I.E. E., 25, p. 219 (1906).

Tory, "Comparison of pt therms. of different degrees of purity," Phil. May., 50 , p. $421(1900)$.

Kucera, "Modified thermoelectric key," Phys. Zeitschr., 2, p. 381 (1901)

Barnes and McIntosh, "New form of pt therm.," Phil. Mag., 6, p. 353 (1903).

Smith, "Bridge methods," Phil. Mag., p. 541 (1912).

Mueller, "Wheatstone Bridges and some accessory apparatus for resistance thermometry," Bull. Bur. Stds., 13,.p. 547 (1916). Bull. Bur. Stds., 11, p. 571 (1915).

Harper, “Resistance bridges," Bull. Bur. Stds., 11, p. 296 (1915).

Griffiths (E. H. and E.), "Thermoelectric reversal key," Phil. Trans., A, 500, 213, p. 130 (1913).

Griffiths (E. H. and E.), "Standardisation of pt therm. at low temperature," Phil. Trans., A, 518, 214, p. 325 (1914). 
High temperature measurements.

Heycock and Neville, Jl. Chem. Soc., 57, p. 376 (1890).

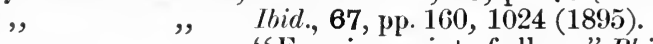

," "Freezing-point of alloys," Phil. Trans., 189, p. 25 (1897).

,, , "Use of recorder," Ibid., 202, p. 1 (1903).

Griffiths, "Measurement high temp.," Nature, 53, p. 389 (1896).

Holborn and Wien, "Measurement high temp.," Ann. d. Phys., 56, p. 360 (1895).

Stewart, "Disintegration of pt and pd. wires," Phil. Mag., 48, p. 481 (1899).

Harker and Chappuis, "Comparison with gas therm. to $500^{\circ}$ C.," Phil. Trans., 194, A, p. 37 (1900).

Harker, "High temp. standards of N.P.L.," Phil. Trans., 203, A, p. 343 (1904).

Waidner and Burgess, "Pt therm. at high temp.," Phys. Rev., 28, p. 467 (1909). Bull. Bur. Stds., 6, p. 150 (1909-10).

Industrial forms of resistance thermometers.

Callendar and Nicholson, "Steam temperatures," Proc. Inst. C.E., p. 131 (1898). B.A. Reports, p. 422 (1897).

Burstall, " Measurement cyclically varying temp.," Phil. Mag., 40, p. 282 (1895).

Callendar, "Recording pyrometer," Engineering, 67, p. 675 (1899).

Whipple, "Indicator," Lond. Phys. Soc., 18, p. 235 (1902).

Callendar and Dalby, "Gas engine temps.," Engincering, 84, p. 887 (1907). Proc. Roy. Soc., 80, p. 57 (1907).

Harris, "Deflectional resistance therm.," Electrician, 62, p. 430 (1908).

Northrup, "Cooling curves," Proc. Am. Electrochem. Soc. Mag. (1909).

Calorimetric thermometers.

Callendar, Phil. Trans., 199, A, p. 55 (1902).

Jäger and Steinwehr, Verhandl. d. Phys. Ges., 5, p. 3503 (1903).

, " Zeitschr. Phys. Chem., 53, p. 153 (1905).

", "̈ Ibid., 54, p. 428 (1906).

Dickinson and Mueller, Bull. Burr. Stds., 3, p. 641 (1907).

\section{Miscellaneous.}

" $\quad$, Phys. Rev., 26 (1908).

Holborn and Henning ("Variation of b.p. of sulphur, etc."), Ann.d. Phys., 26, p. 833 (1908).

Harker and Seaton, Ibid., B.A. Report (1908). Phil. May. (6), 17, p. 32 (1909).

Campbell, A., "On Direct-reading Resistance Thermometers, with a Note on Composite Thermocouples," Phil. Mag., p. 713 (1905) ; Proc. Phys. Soc., 19, p. 555 (1905). 


\section{CHAP'TER IV}

\section{THE . THERIMOCOUPLE}

Choice of metals for thermoelements-Potentiometers for thermoelectric work : simple circuit type ; vernier type ; deflectional type-Direct-reading temperature indicators-Insulation and mounting of thermocouples-Welding the wires-Notes on differential couples-Standardisation-Melting-points of metals and salts-Formulæ for the representation of temperature: E.m.f. relationship-Calibration of thermocouples by comparison with a standard couple.

The thermocouple.-Pouillet appears to have been the first to realise the value of the thermoelement for the measurement of high temperatures. With an iron-platinum couple and a low resistance tangent galvanometer, he employed the thermoelectric method in a crude way for the measurement of furnace temperatures. Probably the unreliability of the instrument, caused by contamination of the platinum by the reducing atmosphere within the iron gun barrel, discouraged him from pursuing the work. His method of calibration by means of a gas thermometer was very commendable.

Since that time considerable advances have been made in this method of pyrometry, notably in the direction of improving the homogeneity of the thermoelement wires; the development of high resistance moving coil indicators, and of potentiometers adapted for the measurement of the small e.m.f. produced by the thermocouple; until, at the present day, the thermoelectric method of measuring temperature has attained a degree of precision second only to the resistance thermometer, and for temperatures exceeding $1100^{\circ} \mathrm{C}$. it is the only convenient and sensitive electrical method available.

It must be emphasised, however, that the thermoelement is only a subsidiary instrument, whose scale will not stand extrapolation over extended temperature ranges, which practice has led to much confusion in high temperature work in the past.

Choice of metals for use as thermocouples.-'The choice of the pure metals or alloys for use in the construction of thermocouples is determined by the temperature to which the couple is to be heated, the e.m.f. developed, and the cost of the material.

For low temperature work up to $300^{\circ} \mathrm{C}$., the combinations copperconstantan and iron-constantan are quite satisfactory, possessing a large e.m.f. per degree of the order of 40 to 60 microvolts.

For moderately high temperatures up to about $600^{\circ} \mathrm{C}$., nickel and iron form a good combination. The general method of construction is 
to weld a stout rod of nickel to the bottom of a tube of iron or steel. The e.m.f. temperature relationship of these two metals is nearly linear between $300^{\circ}$ and $600^{\circ}$; in the vicinity of $300^{\circ} \mathrm{C}$. there is a discontinuity, due probably to molecular changes in the nickel at this temperature. Thermocouples of copper-nickel against chromium-nickel alloys are also extensively used to temperatures as high as $1200^{\circ} \mathrm{C}$. When the alloys are prepared from pure constituents the couples are homogeneous and work quite satisfactorily. It is necessary, of course, to protect them as far as possible from oxidation.

One of the advantages of such base metal couples is that the wires can be of heavy section and hence of low resistance. This permits of the use of a comparatively low resistance indicator without its indications being influenced by variation in resistance of the couple, due to different depths of immersion, oxidation, etc.

For most scientific work at high temperatures and a great many industrial installations, platinum and its alloys with rhodium and iridium are used. Such couples are non-oxidisable and withstand temperatures up to $1600^{\circ} \mathrm{C}$. Care must, however, be taken to shield them from reducing gases, carbonaceous matter, ${ }^{*}$ and metallic vapours.

The platinum $v$. platinum-iridium alloy couple is satisfactory up to about $1000^{\circ} \mathrm{C}$., but at higher temperatures iridium volatilises, and prolonged exposure to such temperatures causes contamination of the pure platinum limb of the element. Consequently the platinum $v$. platinum 10 per cent. rhodium couple is more permanent at higher temperatures, the rhodium being much less volatile than iridium under the same conditions.

The e.m.f. developed by these couples is only about one-fifth that of base metal thermocouples, consequently when deflection pivoted indicators are employed the movement has to be of delicate construction. Further, the instruments have to be of high resistance (100 to $500 \mathrm{ohms}$ ) if the readings are to be independent of variations in the depth of the couple in the hot region.

For precision work it is preferable to measure the e.m.f. by a potentiometer method by means of which observations may be taken to an accuracy of about 01 to $0.2^{\circ}$, or even better if desired.

\section{Potentiometers for the measurement of thermal e.m.f.'s. -} Since the electromotive forces to be measured are of millivolt order the potentiometer has to be specially designed for the work.

With a low resistance potentiometer and a sensitive moving coil galvanometer, it is possible to measure to 1 microvolt with certainty and with greater precautions measurements to 0.1 microvolt are possible, but rarely necessary.

Essentially, a potentiometer is a row of resistances in series through which a steady current is passed. 'This current is kept constant by occasionally adjusting it so that the fall of potential through a fixed resistance balances the e.m.f. of a standard (cadmium) cell.

* Carbon alone does not appear to contaminate platinum alloy thermoelements : it is its presence as a reducing agent with other materials which yield contaminating products on reduction, which must be avoided. 
'Then, since in a simple circuit the fall of potential is proportional to the resistance, any e.m.f. within the range of the instrument can be measured by balancing it against the drop over the appropriate known resistances.

In Fig. 35 the rheostat $\mathbf{R}$ is adjusted until the difference in potential across $\mathbf{K}$ is balanced against the e.m.f. of the standard cadmium cell $\mathrm{C}$ (1.0183 volts). The e.m.f. of the thermocouple $\mathrm{X}$ is balanced on the resistance $r$, shown here for simplicity as a uniform wire.

'The potentiometer can be made direct reading in microvolts, by so constructing that the fall in potential per ohm resistance is some definite value, for example, 1 volt per $100 \mathrm{ohms}$. Hence to measure in steps of millivolts requires subdivision of the resistances into $0 \cdot 1-\mathrm{ohm}$

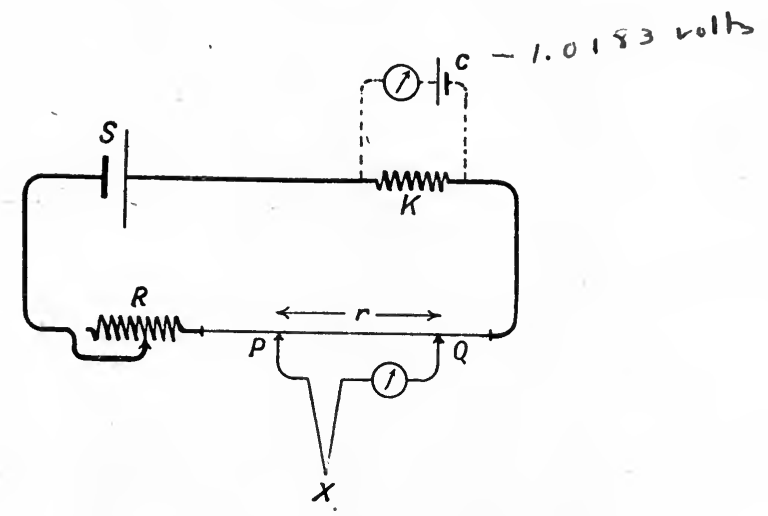

FIG. 35.-Potentiometer for measurement of thermal e.m.f.

$\mathrm{R}$, rheostat (variable) ; $\mathrm{S}$, storage cell ; $\mathrm{X}$, thermocouple; $\mathrm{C}$, standard cell ; $\mathrm{K}$, resistance across which standard cell is balanced.

coils. A bridge wire in series (of the same resistance), having a scale divided into a hundred parts, would enable readings to be taken to 10 microvolts or by estimation to 2 . In such a case the point $\mathbf{P}$ could move over the studs of the coils, while $\mathbf{Q}$ would traverse the bridge wire.

Since potential contacts only are necessary, there is no objection to the use of low resistances in the circuits.

Simple circuit potentiometer.-A practical form of the diagram above is shown in Fig. 36 .

The current through the potentiometer is adjusted to be $0.01 \mathrm{amp}$. by balancing the cadmium cell across $101.85 \mathrm{ohms}$ (circuit shown dotted in diagram).

The working range of the potentiometer consists of 100 equal coils arranged in four dials of 25 coils each.

The resistance of each coil is $0.01 \mathrm{ohm}$, hence the total fall of potential across the hundred coils is 10 millivolts, and across each coil 100 microvolts.

The bridge wire in series with the coils is of $0.01 \mathrm{ohm}$, and the scale 
is subdivided into 100 parts, consequently the value of 1 division is 1 microvolt.

By inserting a plug which short-circuits half the resistance across which the standard cell is balanced, the range of the instrument is doubled.

An alternate way of obtaining higher ranges is to employ two or three secondary cells in series and balance against 2, 3, or 4 cadmium cells.
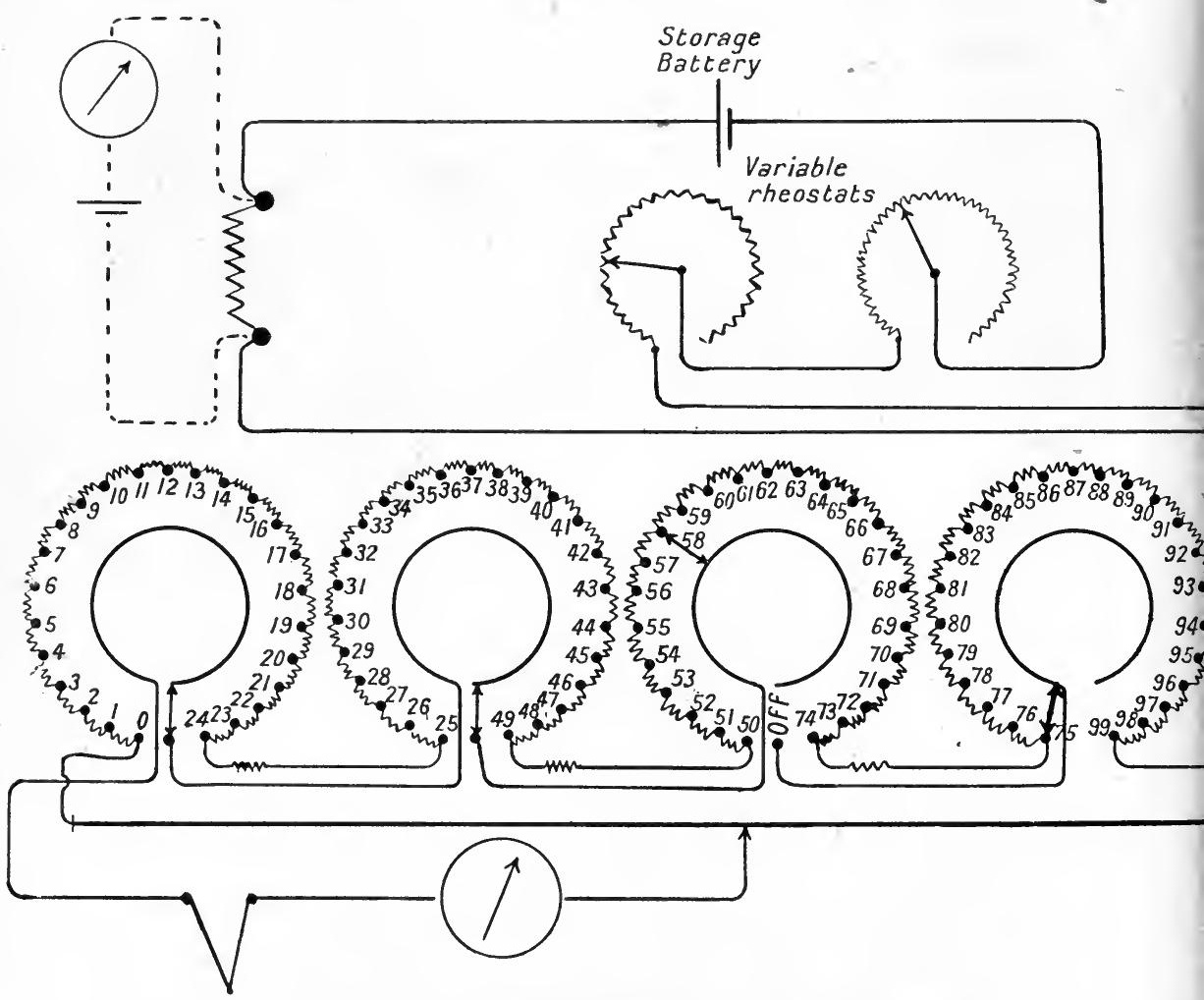

FIG. 36.-Diagram of simple circuit potientiometer.

Fig. 37 is a view of the top of the potentiometer; the switch contacts are fixed on the under surface of the ebonite top.

Vernier forms of potentiometers. - I'he above-described potentiometer, which is representative of a large class, has the disadvantage of only permitting steps of equal value. The decade principle common in P.O. resistance boxes is not possible with the simple circuit of series coils.

This difficulty was surmounted in a very ingenious manner by 'Thomson and Varley in their vernier type of potentiometer, which was designed for resistance and cell comparison work. 
fall in potential over the $\mathbf{1 0 0}$ coils in the shunt dial is the same as that over a single coil of the main dial, so that the effect of the shunt dial coils is to give 100 intermediate steps between any two points on the main dial.

It will be observed that the contact resistances at the points where the shunt dial is connected to the main dial are assumed to be negligible.

'The drawback to the application of the vernier principle to thermoelectric potentiometers is, that the coils of the latter have to be of low resistance in order to obtain sensitivity. Hence contact resistances require careful elimination when the principle is applied to low-resistance potentiometers.

Harker (1903) described a simple form of vernier potentiometer in

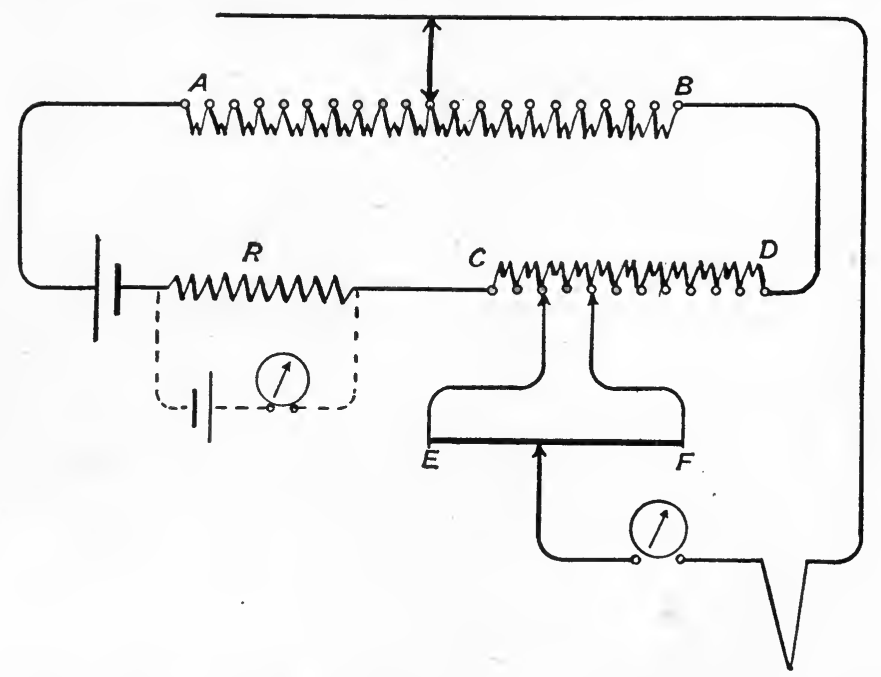

FIG. 39.-Diagram of Harker's modified form of vernier potentiometer.

A to $\mathrm{B}, 20$ coils of $0.1 \mathrm{ohm}$ cach; C to D, 11 coils of $0.01 \mathrm{ohm}$ each; EF, bridge wire of $0.02 \mathrm{ohm} ; \mathrm{R}$, coil of $101.86 \mathrm{ohms}$.

which the second dial above referred to was replaced by a plain bridge wire.

The connections are shown in Fig. 39.

The standard cell is balanced across $101.85 \mathrm{ohms}$, hence the current is 0.01 amp.

The 20 coils $\mathrm{AB}$ each have a resistance of $0 \cdot 1 \mathrm{ohm}$, so that the potential drop per coil is 1 millivolt or 1000 microvolts. Each of the 11 coils in the row $C D$ has a resistance of $0.01 \mathrm{ohm}$, consequently the potential difference per coil is 100 microvolts. 'The bridge wire EF can be placed in parallel with any two coils of CD, and is $0.02 \mathrm{ohm}$ in resistance. The scale is subdivided into 100 parts, each of which corresponds to 1 microvolt. All contacts to the coils in $A B$ and $C D$ are made by means of mercury cups. Manganin bars are laid alongside 
the cups and drilled with a corresponding series of holes, so that connection at any point may be effected by a $\cap$-shaped copper bar.

Mr. R. Paul has designed a vernier potentiometer with two ranges; on the lower range e.m.f.'s from 1 microvolt to 17 millivolts can be measured, while the second range is ten times that of the lower.

Fig. 40 shows the connections diagrammatically : in the actual instrument the coils are carried on a series of drums set alongside each other. The standard cell is balanced by varying $\mathrm{X}^{*}$ with the plug

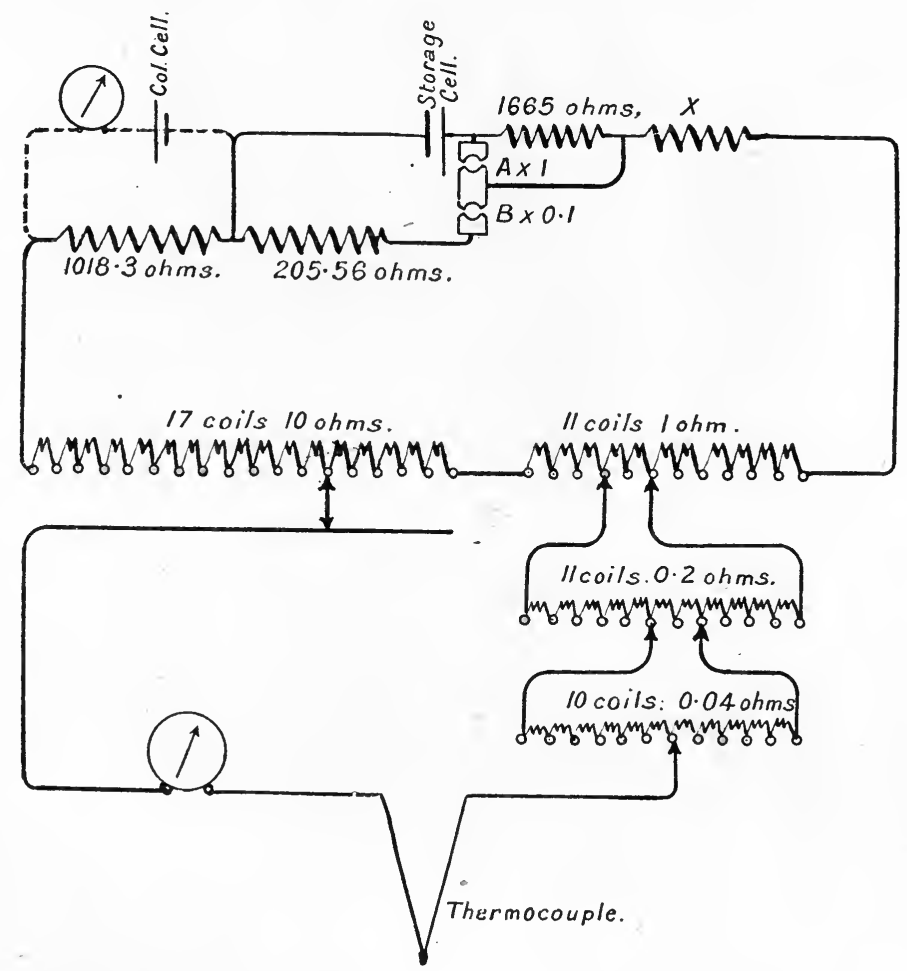

FIG. 40.-Diagram of Paul's modification of a vernier potentiometer. Plug in position $\mathrm{B}$ gives the lower range (each division on lowest dial equal to 1 microvolt).

inserted in $\mathrm{A}$, the position corresponding to the higher range. It will be seen that the values of the various resistances are so adjusted that the effect of transferring the plug from $A$ to $B$ is to reduce the e.m.f. on the working portion of the potentiometer to one-tenth the original value, while leaving the resistance of the complete circuit in series with the storage cell unchanged. The plug in the position $B$ gives the lower range.

'The current through the potentiometer coils is $0.001 \mathrm{amp}$. for the higher range, and 0.0001 amp. for the lower range.

* The adjustable resistance $\mathrm{X}$ brings the potentiometer resistance up to $1850 \mathrm{ohms}$ when the e.m.f. of the storage cell is 1.85 volts. 
The high resistance of this potentiometer necessitates the use of a galvanometer of high resistance (of the order of $1000 \mathrm{ohms}$ ) and high sensitivity. In fact, for working on the lower range the best class of noving coil galvanometer is required.

It would be beyond the scope of the present volume to deal with the constructional details of the variety of potentiometers on the market; one point, however, must be referred to, namely the elimination of parasitic thermal e.m.f.'s in the potentiometer by the employment of copper for all the terminals and connections. Brass terminals are a frequent source of trouble, since the temperature is rarely the same at both ends of one projecting through a board.

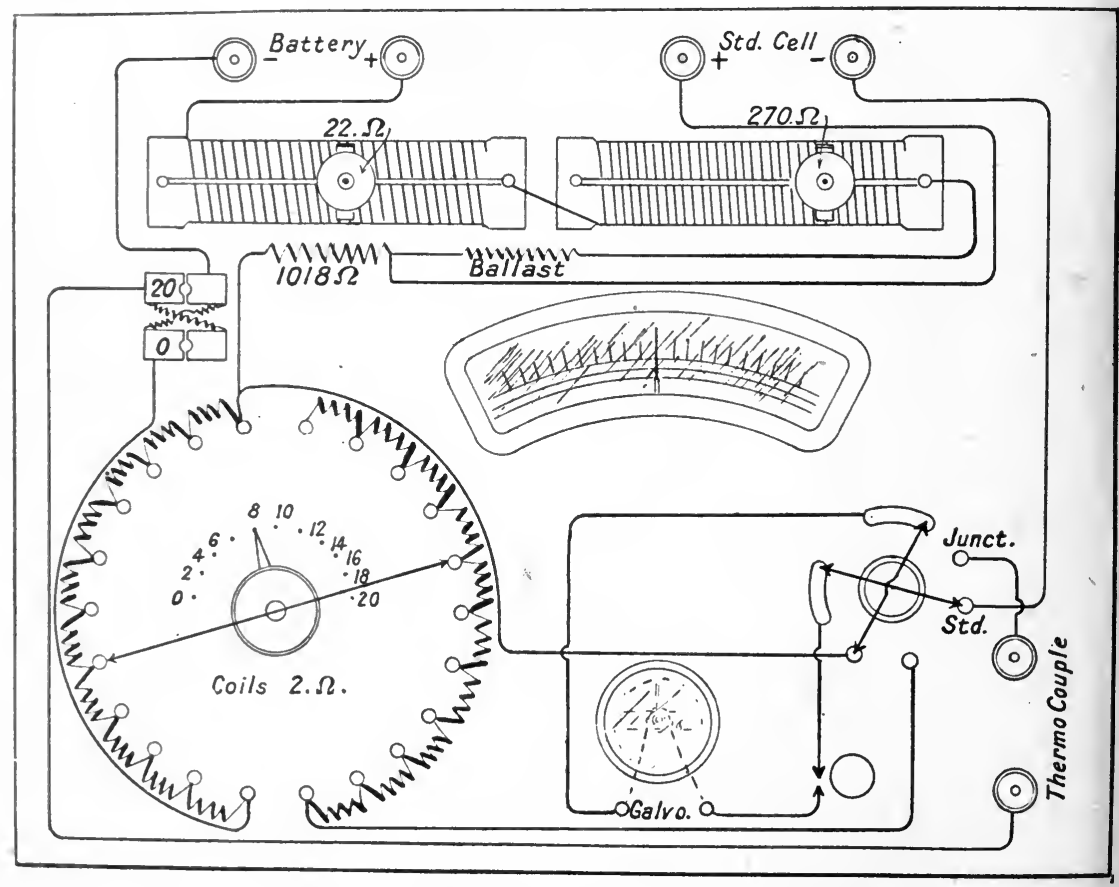

FIG. 41.-Diagram of deflection potentiometer.

(Resistance in the galvanometer circuit kept to a constant value.)

Deflection potentiometers.-A type of instrument, which occupies a position intermediate between the nul potentiometer on the one hand and the moving coil deflection instrument on the other hand, is the portable deflection potentiometer.

In one of this class of instruments the thermal e.m.f. is balanced to the nearest 2 millivolts and the deflection of the pointer observed. The galvanometer has a central zero, and 10 scale divisions correspond to 1 millivolt.

In Fig. 41 are shown the connections of an instrument designed on this basis. 
To maintain a constant sensitivity of the indicator for all potentiometer readings it is necessary to keep the total resistance in the galvanometer circuit to a constant value. This is effected by arranging that the switch on the millivolt studs also cuts out from the galvanometer circuit a resistance equivalent to that added in the potentiometer circuit.

Referring back to Fig. 35, p. 61, let-

$\mathbf{G}$ be the resistance of the galvanometer and that of a series resistance;

' $\mathrm{T}$ be the resistance of the thermoelement;

$r$ the resistance in the potentiometer circuit, across which the thermal e.m.f. is balanced.

$\mathrm{Z}+r$ is the total resistance of the main circuit of the potentiometer.

Let $\Delta e$ be the residual unbalanced e.m.f. of the thermoelement which produces the galvanometer deflection. Now the deflection of the galvanometer is proportional to the current through it, and to obtain the magnitude of this current we require the total resistance in the circuit $\mathbf{P}$ to $\mathbf{Q}$.

The resistance between the points $P$ and $Q$ is that of the resistance $r$ shunted by the main circuit of the potentiometer outside these points, viz. $Z$.

Hence the effective resistance is $\frac{r Z}{r+Z}$; so the deflection of the galvanometer is proportional to $\frac{\Delta e}{\frac{r Z}{r+Z}+\mathrm{T}+\mathrm{G}}$.

For the small e.m.f. generated by the couple $r$ is small compared with $Z$. Hence $r$ in the denominator of $\frac{r Z}{r+Z}$ may be neglected. So the deflection is proportional to $\frac{\Delta e}{r+\mathbf{T}+\mathbf{G}}$. From this it follows that to obtain deflections proportional to $\Delta e$ and independent of $r$, it is necessary to diminish the resistance in series with the galvanometer by an amount $r$, and this can be automatically effected by the brush arrangement shown in Fig. 41.

Direct-reading temperature indicators.-The majority of technical type thermocouples are equipped with moving coil indicators. The instruments are identical in construction with millivoltmeters, while the scales are generally graduated to read temperatures directly.

The calibration of such an instrument is correct so long as the total resistance of the circuit remains unaltered.

When the indicator has a resistance of from 100 to $500 \mathrm{ohms}$, small variations in the resistance of the leads or of the couple are of no consequence.

In order to obtain a robust moving coil system the indicators fitted to base metal couples sometimes have a resistance as low as $2 \mathrm{ohms}$, and 
if the couples are of heavy section wire, protected from oxidation, the outfits work satisfactorily.

Especial care must be taken with such installations not to cause any alteration of the total resistance of the circuit.

With platinum alloy thermocouples the cost of the material prohibits the use of thick wire and it is therefore necessary to employ a high resistance indicator.

Insulation of thermocouples.-For high temperature work in the laboratory the general practice is to insulate the wires of the thermocouple with thin, hard-baked fireclay tubing, of an internal diameter just sufficiently large to slip over the wires, the whole being sheathed in a closed end porcelain or fused silica tube. This method of construction gives the minimum amount of thermometric lag.

For accurate work the cold junctions should be maintained at $0^{\circ}$ by inserting the junctions with the copper leads into two tubes standing in ice.

When the cold junction is at room temperature $\left(t_{0}\right)$, the true hot junction temperature may be obtained by adding to the observed temperature $\left(t_{1}\right)$ the quantity obtained by multiplying the temperature of the cold junction $\left(t_{0}\right)$ by the ratio of the slopes of the calibration curve at the origin and at temperature $\left(t_{1}\right)$.

Or putting it into symbols-

$$
\text { Correction }=\frac{\left(\frac{d e}{d t}\right)_{0^{\circ}-30^{\circ}}}{\left(\frac{d e}{d t}\right)_{t_{1}}} \times t_{0}
$$

In industrial work the maintenance of the cold junction at $0^{\circ}$ is generally not practicable. In some cases the cold junctions are situated at the head of the pyrometer, in others they are carried to some distance beyond, by the employment of leads with the same e.m.f. temperature relationship over the range $0^{\circ}$ to $100^{\circ} \mathrm{C}$.

The necessity of correcting for the temperature of the cold junction cal be avoided by setting the pointer of the indicator at the cold junction temperature when the instrument is on open circuit.

(a) Methods of mounting thermocouples for laboratory purposes.-A convenient method of mounting a thermoelement is illustrated in Fig. 42.

The parts to be inserted in the hot region are insulated with capillaries of fireclay, while the junctions with the copper leads are inserted in glass tubes which are maintained at $0^{\circ} \mathrm{C}$. by immersion in powdered ice.

The wide-necked form of commercial vacuum flask is a useful receptacle for the ice.

The two leads on the right of Fig. 42 are of thin guttaperchacovered copper, and are connected to the potentiometer or indicator.

Where there is risk of contamination of the element it is advisable to protect it by enclosing in a glazed porcelain tube. 
For temperatures up to $500^{\circ} \mathrm{C}$. hard glass capillaries and sheaths can be employed. Similarly, fused silica is available for temperatures up to $1100^{\circ} \mathrm{C}$. for prolonged periods.

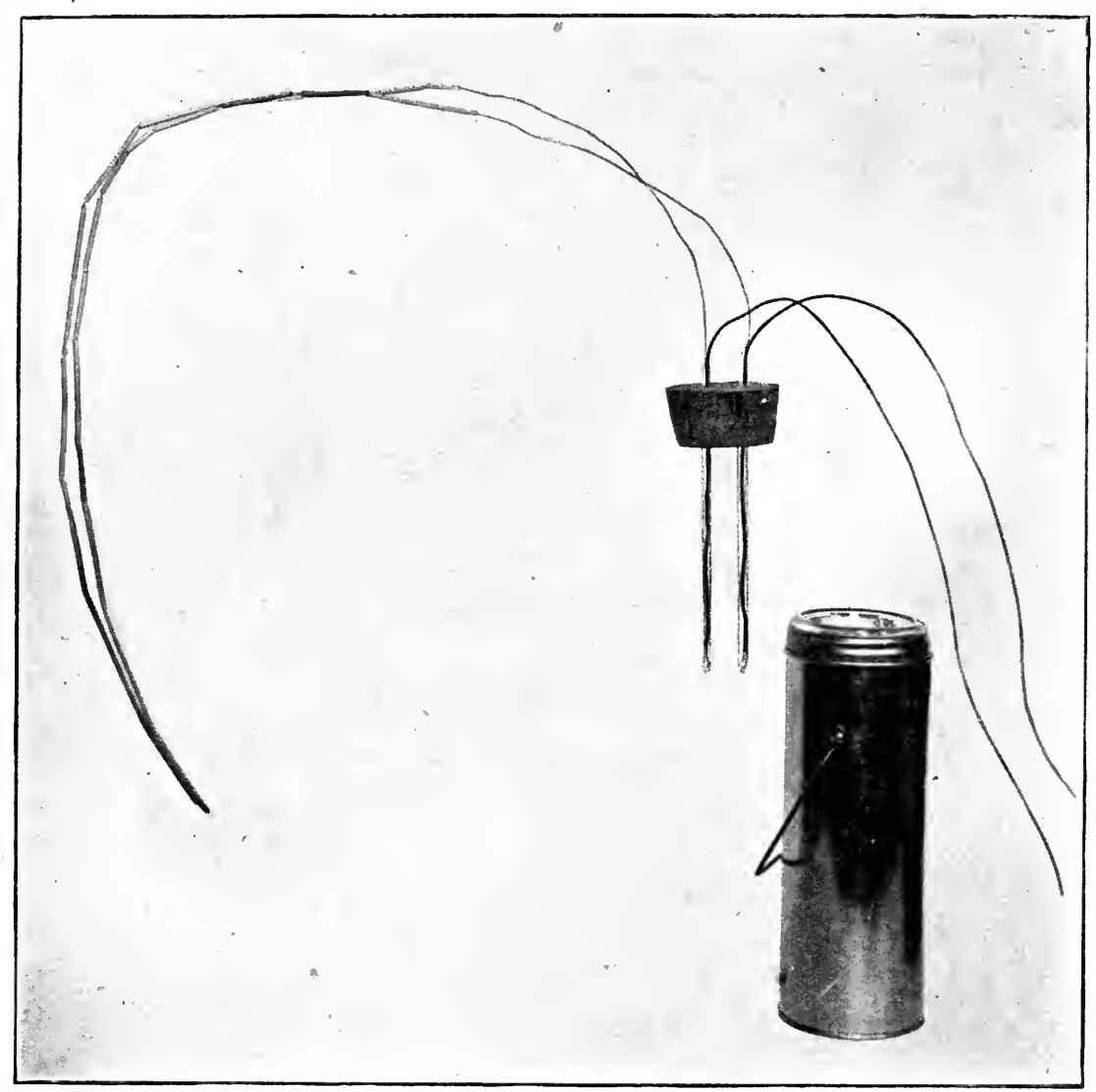

FIG. 42.-Method of mounting pt alloy thermoelement.

A compact type of covering is shown in Fig. 43. Two silica capillaries are fused into a sheath terminating in a bulb at the bottom; a section of the tubing is shown by $A$.

The wires are threaded through from the end $B$, which is then sealed up with the junction enclosed in the bulb, as shown. Since the outside diameter is only about 5 millimetres, the couple can be inserted into a small space.

When necessary the tube can be bent with the wire in situ by means of the oxy-coal gas blowpipe.*

* The thermoelement illustrated was designed for some experiments in which the distribution of temperature in a shallow bath of molten metal was required. 
For work at comparatively low temperatures cotton or silk insulation is quite satisfactory, provided it is paraffined or shellac varnished.

Twin wire of iron-eureka is obtainable with the two wires separately insulated and enclosed in a double covering of cotton or silk. In this form the wires can be laid in grooves a few millimetres deep.

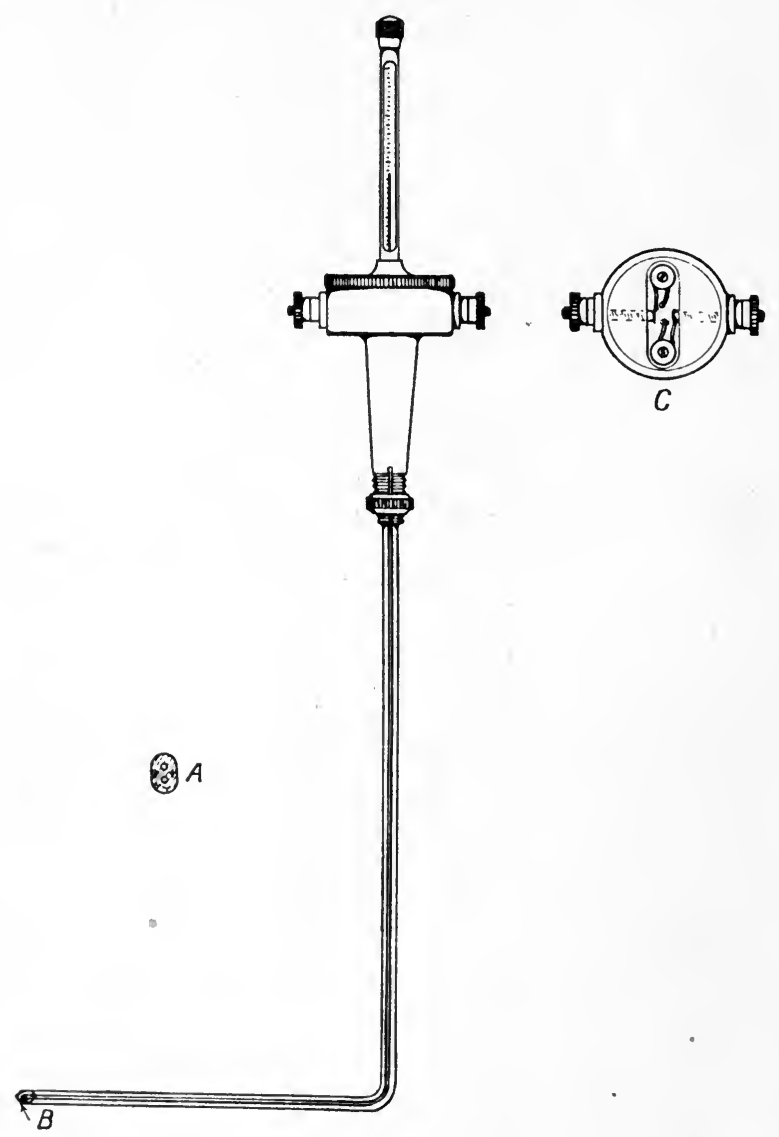

FIG. 43.-Diagram of mounting of a thermocouple for laboratory purposes. A, section of tubing (sheath) ; B, junction enclosed in quartz bulb; C, section of head.

(b) Methods of mounting employed in industrial work.-The standard practice of mounting thermocouples for taking furnace temperatures is shown in Fig. 44.

'The form shown by $\mathrm{A}$ is suitable for platinum alloy couples. Each wire is insulated by thin fireclay or silica capillaries. The couple is enclosed in a closed end tube of porcelain (glazed) or fused silica, which is protected from mechanical injury by a steel sheath.

In the same diagram at $B$ is shown one type of base metal couple 
mounting. 'The individual wires are insulated in a variety of ways : (1) by a short length of clay tubing; (2) by a winding of asbestos cord, over which is applied a solution of sodium silicate; (3) by an asbestos sleeve over one of the wires; (4) by asbestos thread painted with carborundum paint. A sheath of steel or salamander is generally employed.

'The internal sheath of porcelain or silica is not necessary as in the case of platinum alloy couples.

The difficulty with base metal couples at high temperatures is that it is practically impossible to avoid oxidation of the wires.

Welding the wires to form the hot junction end of a thermoelement.- The practice of forming the hot junction by simply twisting the wires together is not to be recommended, particularly with oxidisable metals. The only satisfactory method is autogeneous welding.

Couples composed of platinum and its alloys should be jointed by simply heating the twisted end in an oxy-coal gas blowpipe until a molten bead forms.
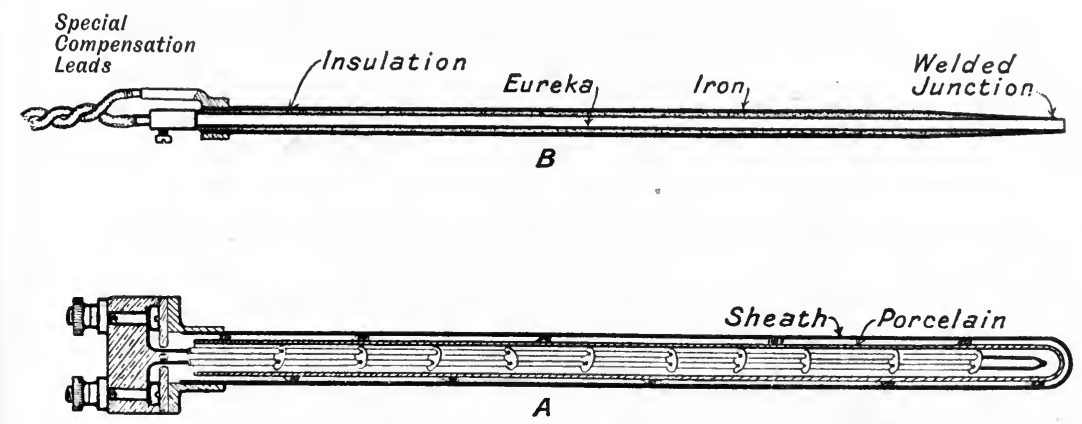

FIG. 44.-Diagram of standard methods of mounting thermocouples.

For base metal alloys such as nickel-chromium $v$. nickel-copper the following method has been found satisfactory.

A rod of carbon or graphite, about 6 inches long by 1 inch square section, is heated to incandescence by the passage of a current of a few hundred ampères. In the centre of the carbon a hole is scooped and filled with anhydrous borax. The twisted end of the couple is immersed in the pool of borax until a bead of molten metal forms around it. 'The current is then switched off' the carbon and the couple withdrawn when cold.

A second method, which is rather more difficult to carry out than the first, is to employ a low voltage arc (about 30 volts); the couple wires form one pole and a stick of carbon the other.

A flux of borax or barium chloride should be used to prevent oxidation.

Notes on the use of differential couples.-When small differences of temperature have to be measured a battery of thermoelements may be employed and connected together in series.

When the battery is composed of a large number of elements it may 
conveniently be divided into two equal groups of couples. Then, by connecting the two groups in opposition and inserting one end of each in ice, while the other is at room temperature, the e.m.f. should be zero, provided the two groups are exactly symmetrical and there are no internal short-circuits or leaks.

Generally in differential work the battery of thermoelements has to be made as compactly as possible and with the minimum of insulation consistent with safety. The copper wire, owing to its greater specific conductivity, may be of less diameter than the eureka wire without loss of sensitivity; a combination of $0.15 \mathrm{~mm}$. diam. copper wire with 0.25 $\mathrm{mm}$. diam. eureka being quite satisfactory. The junctions should be soldered with silver solder, using a little anhydrous borax as flux. This operation is facilitated by using a minute gas-jet rather than an ordinary blowpipe. Insulation of the bared parts is effected by repeatedly dipping into a solution of celluloid in acetone (freed from water); this coating is suitable for work at room or low temperatures.

The following method of insulating by means of hard rubber has been recommended by Adams: Enough precipitated sulphur, or, still better, insoluble sulphur, is stirred with rather thick rubber cement (pure gum rubber dissolved in benzene or $\mathrm{CS}_{2}$ ) to equal 20-25 per cent. of the solid rubber. The junctions are dipped in the mixture, and after drying in air are maintained at a temperature of $140^{\circ} \mathrm{C}$. for 15 hours.

Standardisation of thermocouples.-For low temperature work up to about $450^{\circ} \mathrm{C}$. the following fixed points are available for standardisation purposes:-

TABLE XIII.

\begin{tabular}{|c|c|c|}
\hline \multicolumn{2}{|c|}{ Substance. } & Boiling-point of the organic compound \\
\hline $\begin{array}{l}\text { Steam ... } \\
\text { Naphthalene } \\
\text { Tin ... } \\
\text { Benzophenone } \\
\text { Aniline .... } \\
\text { Cadmium } \\
\text { Zinc ... } \\
\text { Sulphur }\end{array}$ & $\begin{array}{ll}\ldots & \cdots \\
\ldots & \cdots \\
\cdots & \cdots \\
\ldots & \cdots \\
\ldots & \cdots \\
\ldots & \cdots \\
\ldots & \cdots \\
\ldots & \cdots\end{array}$ & $\begin{array}{l}100^{\circ} \\
217 \cdot 9_{6}+0.058(\text { p. }-760) \\
231 \cdot 9 \\
305 \cdot 9+0.063(\text { p. }-760) \\
184 \cdot 1+0.05(\text { p. }-760) \\
320 \cdot 9 \\
419 \cdot 4 \\
444.5+0.09 \text { (p. }-760)\end{array}$ \\
\hline
\end{tabular}

When great accuracy is not desired, the boiling-point of diphenylamine $\left(302^{\circ} \mathrm{C}\right.$.) may replace that of benzophenone, being a less costly substance.

For temperatures above $450^{\circ} \mathrm{C}$., the reference temperatures are freezing-points of metals or melting-points of salts.

Most of the commoner metals can be melted in small gas-fired crucible furnaces, the material of the crucible depending on the particular metal which is to be melted.

The value obtained for the melting-point should be in agreement with the freezing-point, and both should be independent of the rate of 
heating and the depth of immersion (within limits) of the thermoelement.

As a general rule, the end of the sheath protecting the thermoelement should be immersed to within about $\frac{1}{4}$ inch of the bottom of the crucible.

The chemical action of the surrounding atmosphere on the heated metal is an important factor, since the solution of the oxide or a gas in the molten metal lowers its freezing-point quite considerably.

For example, the solution of cuprous oxide to saturation ( 3.5 per cent. of $\left.\mathrm{Cu}_{2} \mathrm{O}\right)$ in copper lowers the freezing-point by $20^{\circ}$, while the absorption of oxygen by silver has a similar influence on its freezingpoint.

Metals which require a reducing atmosphere-Antimony, silver, and copper must be melted in a reducing atmosphere. This can be readily effected by covering the metal with a layer of powdered graphite, and employing a graphite or salamander crucible. Another method of preventing oxidation is to pass a stream of coal gas over the surface.

The thermocouple should be carefully protected by means of a glazed porcelain tube. In the case of antimony, Day and Sosman recommend the addition of a thin sheath of graphite over the porcelain.

When an electric furnace is employed for heating, it is possible to maintain an atmosphere of carbon monoxide inside as a reducing agent.

Metals which require a neutral atmosphere.-The metals nickel and cobalt require a neutral or reducing atmosphere free from carbon compounds.

For nickel freezing-point determinations, the-writer has found a refractory clay crucible quite satisfactory with fused borax as flux to prevent oxidation. The thermoelement should be protected by an unglazed fireclay or hard porcelain sheath.

A large-sized crucible of metal is desirable, and to diminish the rate of fall of temperature the blowpipe should not be turned completely off when the cooling curve is taken.

Covering the exterior surface of the crucible with a layer of carborundum powder, admixed with a small percentage of fireclay, greatly increases its resistance to the cutting action of the blast flame.

Nickel melted under graphite in a salamander crucible was found to give an apparent freezing-point, which was very sharply defined at a temperature about $122^{\circ} \mathrm{C}$. lower than the freezing-point of the pure metal. It is a well-known fact that nickel absorbs carbon and deposits it as graphite on cooling, so the lowering may be due to this. Or it may be the freezing-point of the nickel-carbon eutectic.

Day and Sosman, in their melting-point determinations, employed an electric furnace with an atmosphere of hydrogen which was replaced by nitrogen previous to inserting the thermoelement, since the hydrogen would be occluded by the platinum at high temperatures. The nickel 
was contained in an unglazed porcelain crucible lined with 90 per cent. $\mathrm{Al}_{2} \mathrm{O}_{3}$ and 10 per cent. $\mathrm{MgO}$.

They found that, in taking the freezing-point of nickel with oxide present, a fairly sharp halt was obtained $10^{\circ}$ below the freezing-point, which may represent the eutectic of nickel and nickel oxide. The break disappeared when the nitrogen was replaced by hydrogen for a few minutes.

For cobalt "pure magnesia" crucibles had to be employed, otherwise the metal would penetrate through the lining and attack the porcelain beneath.

Glazed marquardt or pure magnesia tubes were used to protect the thermoelement, but they found it practically impossible to prevent some contamination of the thermocouple.

The difficulties in the determination of the freezing-points of nickel and cobalt are very considerable, owing to the high temperature required.

Metals which can be melted in air.-Zinc and gold require no special atmosphere; graphite crucibles should be used and the couple protected by a hard paste porcelain tube glazed.

But for its cost, gold would be an excellent fixed point to employ for standardising purposes, on account of its non-oxidisable nature and purity. It has, however, a tendency to volatilise.

If moderate accuracy is sufficient, the wire method may be used. In this method the junction between the couple wires is effected by a short length of gold wire, and the e.m.f. observed as the furnace rises slowly in temperature. 'The break in the circuit corresponds to the meltingpoint of the bridging metal.

Palladium.-The melting-point of this metal $\left(1549^{\circ}\right.$ C.) represents the upper limit of the gas thermometer at the present time. Owing to the cost of the metal the melting-point is generally obtained by the wire method as above described. The writer has employed a vertical graphite spiral furnace with a liner tube of hard porcelain. The couple was symmetrically placed in the centre of the furnace with a small connecting piece of palladium between the junctions.

Day and Sosman employed a charge of 120 to 200 grams of the metal contained in a crucible of pure shrunk magnesia bound with magnesium chloride. The thermocouple was protected by a pure magnesia tube. The heating was effected in the internally wound furnace described in Chap. I.

The extreme temperature involved imposed a severe strain on platinum-wound furnaces. 'They found that the danger of contamination by the vapour of the palladium in such work was very considerable.

Melting- and freezing-points of salts.-The melting- and freezingpoints of salts present greater practical difficulties to accurate determination than those of the metals at medium temperatures.

The latent heat of fusion of most salts is small and as the solid salt is deposited on the pyrometer tube, it forms a poorly conducting with metals. 
It is advisable to work with large quantities of material.

For the standardisation of base metal couples in the vicinity of $800^{\circ} \mathrm{C}$., the freezing-point of common salt is very convenient.

The salt is contained in a large steel pot (lower end of a discarded gas cylinder), which is heated in a gas furnace.

'The freezing-point of pure $\mathrm{NaCl}^{*}$ is $801^{\circ} \mathrm{C}$., while the ordinary domestic material has a freezing-point from $1^{\circ}$ to $3^{\circ}$ lower. The salt is very volatile at these temperatures.

It is, of course, necessary to use the couple directly immersed, without any sheath.

The sulphates and carbonates of sodium and potassium are not entirely satisfactory as fixed points. They are rapidly acted on by the water vapour and reducing gases of the furnace Fused sulphates are slightly reduced to sulphides, and carbonates to hydrates, the magnitude of the change being dependent on the duration of the heating.

Heycock and Neville found that the freezing-point of sodium carbonate became lower the longer it was heated. The deterioration of the salt could be watched by looking into the crucible; the first two or three times the salt was fused it remained quite transparent, but afterwards it became opaque, in consequence of some chemical change.

They found that the sulphates were more stable, and no progressive change could be observed in the freezing-points.

For high-temperature salt-points platinum crucibles must be employed, with the thermocouple directly immersed in the salt, or if sheathed with glazed porcelain, this should be protected with a thinwalled platinum tube fitting it closely. This procedure was employed by them in their resistance thermometer work.

Since there is no metal freezing-point available in the region between copper $\left(1083^{\circ} \mathrm{C}\right.$.) and nickel $\left(1452^{\circ} \mathrm{C}\right.$.), attention has been directed towards the silicates to find some with melting-points in this gap. Jaeger has suggested the melting-point of lithium silicate $\left(1201^{\circ} \mathrm{C}\right.$.) as a transition-point for calibration purposes. The other two silicates, diopside $\left(1391^{\circ}\right.$ C.) and anorthite $\left(1549 \cdot 5^{\circ}\right.$ C.), have already been referred to.

'The following method was employed by White in the determination of the melting-points of silicates :-

About 3 grams of the salt was contained in a platinum crucible $10 \mathrm{mms}$. diameter and $18 \mathrm{mms}$. deep, which was suspended by a platinum sleeve from the open end of a porcelain tube (unglazed).

The supporting tube was surrounded with pure platinum foil to prevent contamination of the thermoelement by iridium vapour volatilised from the heating coil $\dagger$ of the furnace. 'The thermocouple dipped directly into the molten silicate.

It was found that the values of the melting-point were reproducible to about $1^{\circ}$. Freezing-points could not be determined, since the fused

* Pure salt guaranteed to be 99.98 per cent. purity is manufactured on a large scale for dairy purposes by C. Moore \& Co., Lymm, near Warrington, Cheshire.

$\dagger$ Commercial platinum. 
silicates undercooled considerably, sometimes to a glass, in which case of course no melting-point would be observed on reheating.

Formulæ for the representation of the temperatureE.M.F. relationship. - When a large number of temperature observations have to be taken by means of a thermoelement, it is advisable to draw up a table on some such scheme as that shown below, by means of which the observed e.m.f. may be readily converted to temperatures.

The first step towards the construction of a table is to interpolate between the fixed points by means of an empirical equation.

Experience has shown that certain classes of curves represent closely the actual form of curve characteristic of the thermoelement.

For example, Adams found that the relationship-

$$
\mathrm{E}=74 \cdot 672 t-13,892\left(1-e^{-0.00261 t}\right) \text {, }
$$

where $\mathbf{E}$ is the e.m.f. in microvolts,

$$
t \quad, \quad \text { temp. }{ }^{\circ} \mathrm{C} . \text {, }
$$

represented the temperature e.m.f. curve of a batch of copper-constantan correctly to a fraction of a microvolt over the range $0^{\circ}$ to $350^{\circ} \mathrm{C}$.

By a slight variation in the numerical coefficients the same equation could be employed for any other copper-constantan thermoelement.

In the case of $\mathrm{Pt}-\mathrm{PtRh}$ couples no single equation, with a reasonable number of constants, has been found-which will represent the curve over the whole range from $0^{\circ}$ to $1750^{\circ} \mathrm{C}$.

Hence recourse has to be made to three equations covering overlapping sections.

$$
\begin{aligned}
& \text { 1st, } 0^{\circ} \text { to } 400^{\circ} \mathrm{C} \text {. } \\
& \text { 2nd, } 300^{\circ} \text { to } 1200^{\circ} \mathrm{C} \text {. } \\
& \mathbf{E}=\mathbf{A} t+\mathbf{B}\left(1-e^{\mathrm{C} t}\right) \\
& \mathrm{E}=-\mathrm{A}^{\prime}+\mathrm{B}^{\prime} t+\mathrm{C}^{\prime} t^{2} \\
& \text { 3rd, } 1100^{\circ} \text { to } 1750^{\circ} \mathrm{C} \text {. } \\
& \mathrm{E}=-\mathrm{A}^{\prime \prime}+\mathrm{B}^{\prime \prime} t+\mathrm{C}^{\prime \prime} t^{2}
\end{aligned}
$$

It should be ascertained, in a particular case, that there are no discontinuities in the slope of the curve at the points of transition from one section to another and any slight inequalities should be evened out by adjustment of the successive differences.

'The formula proposed by Holman-

where $e=$ e.m.f. in microvolts,

$$
\log _{10} \mathrm{E}=\mathrm{A} \log _{10} t+\mathrm{B}
$$

$t=$ temp. ${ }^{\circ} \mathrm{C}$.,

$A$ and $B$ constants,

is occasionally used but does not represent the curve as accurately as the above.

From such equations a table can be calculated giving the temperature corresponding to every 100 microvolts or the e.m.f. corresponding to every $10^{\circ}$. 
Typical specimens of such tables are shown below.

TABLE XIV.

Copper-constantan. Even hundreds of E system.

\begin{tabular}{|c|c|c|}
\hline $\mathbf{E}$ E (microvolts). & $\boldsymbol{t}^{\circ} \mathrm{C}$. & 1st diff. \\
\cline { 1 - 2 } & \multicolumn{1}{c|}{0} & \\
100 & $2 \cdot 60$ & $2 \cdot 60$ \\
200 & $5 \cdot 17$ & $2 \cdot 57$ \\
300 & $7 \cdot 73$ & $2 \cdot 56$ \\
400 & $10 \cdot 28$ & $2 \cdot 55$ \\
500 & $12 \cdot 81$ & $2 \cdot 53$ \\
600 & $15 \cdot 33$ & $2 \cdot 52$ \\
etc. & & \\
\hline
\end{tabular}

Pt-PtRh. Even tens of $t$ system.

\begin{tabular}{|r|r|c|}
\hline$t$. & E. & 1st diff. \\
\cline { 2 - 3 } & & \\
0 & 0 & 55 \\
20 & 112 & 57 \\
30 & 172 & 60 \\
40 & 234 & 62 \\
50 & 297 & 63 \\
60 & 362 & 65 \\
etc. & & \\
\hline
\end{tabular}

Once a table has been calculated out it can serve as a basis of other tables for thermoelements of the same group by the aid of a "difference curve." It will be found that but little labour is involved in the construction of a second table, taking the first as basis and amending it in accordance with the requirements shown by the "difference curve."

Calibration by comparison with a standard thermoelement. - The method of standardising by freezing-point determinations above referred to should only be resorted to in the case of primary standards or as check points in case of doubt. The calibration of one couple by direct comparison with another is both simple and expeditious.

In the case of platinum alloy couples the usual procedure is as follows :-

The heavy porcelain sheath is removed and the wires insulated by capillary fireclay tubing or quartz (see Fig. 42). The junctions of the two couples are tied together by a piece of pure platinum wire and inserted at the mid-point of an electric furnace.

The couples are carried in a liner-tube supported from the cold ends of the furnace to avoid leakage from the heating circuit into that of the potentiometer. Since at temperatures exceeding $1000^{\circ} \mathrm{C}$. the electric resistivity of porcelain, quartz, etc., falls off rapidly with temperature, and quite minute electric leakages are noticeable when the apparatus 
is designed to measure e.m.f.'s of the order of one hundred-millionth that of the heating circuit (i.e. 100 volts to 1 microvolt).

The installation of a potentiometer outfit. - In the installation of a potentiometer for thermoelectric work two points require attention-

(1) 'The elimination of parasitic e.m.f.'s.

(2) The prevention of leakage into the potentiometer circuit from neighbouring lighting or furnace circuits.

Parasitic e.m.f.'s can be largely eliminated by a suitable choice of metals for the resistance-coils, binding-screws and leads.

Manganin has a comparatively small thermal e.m.f. against copper, and copper terminals are now obtainable. All keys should be protected from temperature fluctuations.

It is obvious that a leakage current must enter the circuit at one point and leave at another, after passing through the galvanometer, if it is to produce errors in the observations.

Leakage into the potentiometer circuit can be detected by observing the deflection when the thermoelement is short-circuited.

When a thermocouple is used in connection with an electric furnace, the heating circuit should be provided with a reversal switch, and the deflection of the galvanometer spot on quickly changing over noted from time to time.

It is a difficult matter to provide an effective insulation of the thermocouple from the high voltage heating circuit of a furnace at temperatures exceeding $1400^{\circ} \mathrm{C}$., since the ionised atmosphere conducts slightly.

White recommends a system of shielding, by which a good conductor is interposed at all points between the potentiometer system and the source from which leakage occurs.

For details of the method of application of the equipotential shields, reference should be made to the original papers, a list of which is given at the end of the chapter.

Good electrical insulations of the apparatus should be the first consideration when leakage troubles occur.**

Application of thermoelements to the measurement of extremely low temperatures. - The use of thermoelements in practical work at low temperatures has been studied by Onnes and Dewar. Onnes favours constantan $\vartheta$. steel on account of the large e.m.f. developed. Dewar found cupro-nickel $v$. gold to be satisfactory down to liquid hydrogen temperatures.

During the course of his work Dewar observed some curious changes after exposure of the couples to low temperature.

If the junction had been soft-soldered the e.m.f. would not be reproducible after exposure to liquid hydrogen temperatures. Hardsoldering was found to be quite satisfactory. He found it advisable to cool the couple repeatedly to the lowest temperature before calibration in order to ensure that it had settled to an equilibrium state.

* Alternating current is also advantageous for heating instead of continuous. 
For low temperature work the couples are generally calibrated by a direct comparison with a hydrogen or helium gas thermometer.

\section{REFERENCES TO CHAPTER IV.}

PAPERS ON THE THERMOELECTRIC METHOD OF MEASURING TEMPERATURES.

Thermocouples for ordinary and low temperatures.

White, "The Thermoelement as a Precision Thermometer," Phys. Rev., 31, p. 149 (1910) ; "Galvanometers," Phys. Rev., 23, p. 382 (1906) ; "A 'Test of Calorimetric Accuracy," Phys. Rev., 31, p. 687 (1910); Journ. Amer. Chem. Soc., 36, p. 2303 (1914).

Gray, "Protected Thermoelement," Bull. Bur." Stds., 10, p. 464 (1914); "Protected Thermoelement," Bull. Bur. Stds. Sc. Paper, No. 276 (1916).

Adams, "The Measurement of the Freezing Point Depressions of Dilute Solutions," Journ. Amer. Chem. Soc., 37, No. 3, p. 482 (March, 1915). Compare a similar investigation by Griffiths, in which differential platinum thermometers were employed, Proc. Roy. Soc., 83, p. 454 (1911).

Foote, "Cold Junction Correction," Met. Chem. Eng., 11, p. 329 (1913).

Offerhaus and Fischer, "Cold Junction Corrections," Electrochem. and Met. Ind., 6, p. 362 (1908).

Onnés and Crommelin, Leiden Comm., No. 27 (1896); Ibid., No. 89 (1903); lbid., No. 95a (1906).

Hall, Campbell and Serviss, "Tests of Inhomogeneity," Proc. Amer. Acad., 41, p. 559 (1906).

Kowalke, "Cobalt as an Element for Thermocouples," Trans. Amer. Electrochem. Soc., 29, p. 561 (1916).

Woodward and Harrison, "Notes on Couples of Nichrome Constantan," Met. and Chem. Eng., p. 647 (1917).

Palmer, "Constancy of Thermocouples," Phys. Rev., 21, p. 65 (1905).

Potentiometers and their installation.

White, "Potentiometer Installation," especially for Thermoelectric and High Temperature Work, Phys. Rev., 25, p. 344 j(1907); "Thermoelement Installations, especially for Calorimetry ;" "Potentiometers for 'Thermoelectric Measurements, especially in Calorimetry; Leakage Prevention by Shielding, especially in Potentiometer Systems," Journ. Am. Chem. Soc., 34, Nos. 9 and 10 (Sept. and Oct., 1914); Zeitschr. and Instr., 34 (1914) ; Ibid., 28 (1908) ; Ibid., 27 (1907) ; "The Constancy of 'Thermoelements," Phys. Rev., 23, p. 449 (1906).

Randall, Bichowsky and Rodebush, "The Practical Installation of the Double Combination Potentiometer," Am. Chem. Soc. J., 38, p. 1266 (July, 1916).

Hulett, "Standard Battery," Phys. Rev., 27, p. 33 (1908).

Wenner and Weibel, "The Testing of Potentiometers," Bull. Bur. Stds., 11, No. 1, p. 1 (Nov. 15, 1914).

Varley, British Association, 36, p. 14 (1866).

Fuessner, Zeitschr. Inst., 10, p. 668 (1903).

Holman, Phil. Mag., 42, p. 37 (1896).

Wenner, Phys. Rev., 31, p. 94 (1910).

Harker, Phil. Mag. (July, 1903); Phil. Trans., 203, p. 343 (1904).

Cärpenter and Stansfield, "Deflection Potentiometer," Phil. Mag., 46, p. 59.

Calibration of thermocouples by reference to fixed points.

Adams and Johnson, Am. J. Sci., (4) 32, p. 534 (1912).

Sosman, Am. J. Sci., (4) 30, p. 7 (1910).

Adams, J. Wash. Acad., (3) p. 469 (1913).

Day and Sosman, Am, J. Sci., (4) 33, p. 528 (1912) ; Carnegie Inst. Wash. Pub., p. 157 (1911). 
Adams, "Calibration Tables for Computing E. M. F. Table," Journ. Am, Chem. Soc., 36, No. 1 (1914).

Lindeck and Rothe, Phys. Tech. Reichsanstalt; Zeitschr. Inst., 20, p. 285, (1900).

Heycock and Neville, Trans. Chem. Soc., p. 160 (1895).

Holman, Phil. Mag., 41, p. 465 (1896).

Historical.

Pouillet, Compt. Rend., tome iii. p. 786 ; "Treatise on Physics," 4th edit., vol. ii. p. 684 (1836) ; Ibid., 9th edit., vol. i. p. 233 (1858).

Le Chatelier, C.R., 102, p. 819 (1886).

Barus, Bull. U.S. Geol. Survey, Nos. 54 and 103 (1889) (complete historical survey). 


\section{CHAP'TER V}

\section{THE "FOURTH-POWER" LAW OF RADIATION AND TOTAL RADIATION PYROMETERS}

Experimental proof of law-Work of Lummer and Pringsheim, Mendenhall and Forsythe-Féry total radiation pyrometer ; Foster's fixed focus pyrometer, etc. - Sources of error in practical forms of radiation pyrometers-Calibration under "black body" conditions.

A $\mathrm{T}$ temperatures exceeding $1300^{\circ}$ C. the practical difficulties encountered in the use of thermoelements, resistance thermometers and gas thermometers are very considerable, even under the favourable conditions prevailing in the laboratory. For industrial work the difficulties are vastly greater and other methods have to be resorted to, such as those based on the laws of radiation. With pyrometers of the radiation type it is not necessary to subject any portion of the instrument to the temperature of the furnace, and there is no upper limit to the temperature which can be measured.

The present chapter will be devoted to the consideration of the fundamental law of radiation - that connecting the total radiation and temperature-and to pyrometers based on this law.

The Stefan-Boltzmann Law.-The earliest suggestion of a simple relation connecting the radiation of a surface and its temperature was that of Stefan in 1879. He observed that the experimental results of 'Tyndall on the heat loss from a platinum wire at $1200^{\circ} \mathrm{C}$. and at $525^{\circ} \mathrm{C}$. were in the ratio of 11.7 to 1 , while the ratio of the fourth powers of these two temperatures (in absolute measure) was 11.6 to 1 .

From this he concluded that the total radiation is proportional to the fourth power of the absolute temperature.

Subsequent investigation, however, showed that this generalisation was too wide, the law being valid only for "full radiators," and that metallic surfaces of high reflecting power obeyed a different law. Platinum, for example, radiates at a rate more nearly proportional to the fifth power of the absolute temperature.

'Tyndall's temperature scale was probably incorrect, and the loss by convection was not separated from the radiation loss.

In 1884 Boltzmann gave a theoretical proof of the fourth-power law based on thermodynamic principles and Maxwell's electromagnetic theory of light. He pointed out that the law was only valid for an "ideal black body," i.e. one which absorbs all the radiation falling upon it. 
'The radiation emitted by such a body would possess a character independent of the properties of any particular substance and would be identical with the radiation within a uniformly heated enclosure. 'This conception of a perfect black surface and its practical realisation, by means of an enclosure at a uniform temperature, is due to Kirchhoff.

$\mathrm{He}$ demonstrated conclusively that the radiation issuing from a small hole in a uniformly heated enclosure would be "full radiation" for that temperature, such as would be emitted by an ideal black body.

The simplicity of the law and the fact that most industrial furnaces, etc., are fair approximations to uniform temperature enclosures have been factors of immense service in the development of high-temperature pyrometry.

The formal statement of the Stefan-Boltzmann law is

$$
\mathrm{S}=\sigma\left(\theta^{4}-\theta_{0}^{4}\right)
$$

where $\mathrm{S}$ is the energy per sq. cm. per sec.;

$\sigma$ a numerical constant the experimental value of which is $1.279 \times 10^{-12} \mathrm{gm}$. cals. per sec. per $\mathrm{cm}^{.2}$.;

$\theta$ the absolute temperature of the surface ;

$\theta_{0}$ radiation.

It will be observed that as a method of defining absolute temperature the law is independent of the specific properties of any particular substance; the ideal black body in this respect playing the same rôle as that of a perfect gas in the definition of the gas scale.

A comparison at one temperature above zero with the gas scale would suffice to determine $\sigma$ and hence connect the two scales.

Since, however, Boltzmann's demonstration involves an imaginary thermodynamic cycle with radiation as working fluid, it is necessary to confirm the theoretical deduction by experimental observations over an extended temperature range. Shortly after its formulation the law was submitted to test by various investigators; the most comprehensive series of experiments were carried out by Lummer and Pringsheim, who investigated the radiation from a "black body" enclosure over the temperature range $100^{\circ}$ to $1300^{\circ} \mathrm{C}$.

Lummer and Pringsheim's Experiments.-For the measurement of the radiation the authors employed a modified form of Langley bolometer-an instrument depending on the change of electrical resistance of platinum with temperature. Details of the instrument are given later.

The general disposition of the apparatus is shown in Fig. 45.

A was a hollow vessel containing boiling water. This source of radiation was used as a standard of reference for calibrating the bolometer from time to time, since only by this means could the variations produced by changes in the battery current and galvanometer sensibility be eliminated.

'The radiation could be cut off from the bolometer by means of a water-cooled shutter. 
The "black body" C was employed for the range of temperature from $200^{\circ}$ to $600^{\circ} \mathrm{C}$. It consisted of a hollow sphere of copper blackened inside with platinum black and contained in a bath of wellstirred molten salt. 'This salt bath could be maintained at any desired temperature by regulating the flame. The temperature was measured by means of a high-range mercury thermometer and a thermoelement.

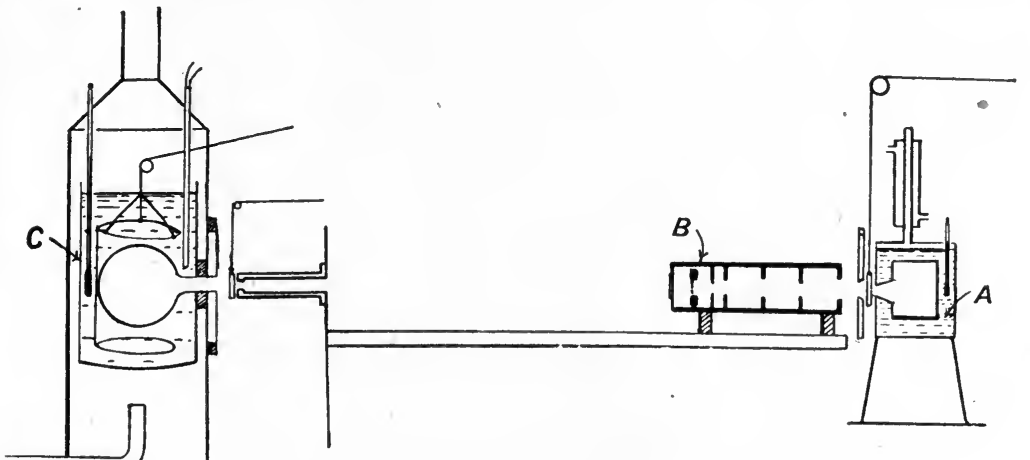

FIG. 45.-Diagram of apparatus for the range $200^{\circ}$ to $600^{\circ} \mathrm{C}$.

A, vessel with boiling water; $\mathrm{B}$, bolometer; $\mathrm{C}$, molten salt bath around the hollow sphere (black body enclosure).

The procedure in carrying out the observations was as follows :-

The bath was heated up to the desired temperature and maintained steady; then the water-cooled shutter was raised to allow radiation to fall on the receiving face of the bolometer. When the galvanometer deflection had attained its maximum value the shutter was lowered and galvanometer zero redetermined; if it differed slightly from the previous value the mean was taken.

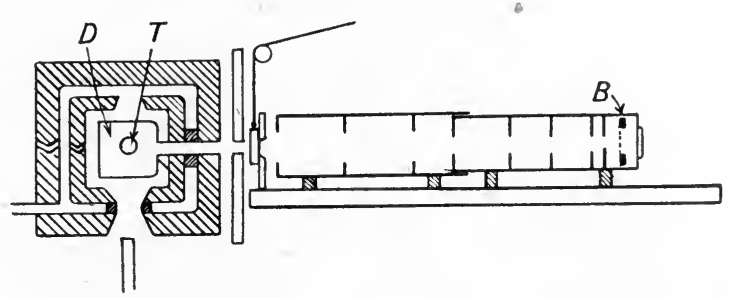

FIG. 46.-Diagram showing construction of " black body," for the range $600^{\circ}$ to $1300^{\circ} \mathrm{C}$. D, iron cylinder, " black body" enclosure; T, porcelain tube carrying thermoelement ; $\mathrm{B}$, bolometer.

For higher temperatures, from $600^{\circ}$ to $1300^{\circ} \mathrm{C}$., the construction of the "black body" is shown in Fig. 46. D was an iron cylinder (coated inside with platinum black) enclosed in a double-walled gas muffle. The temperature of the interior of the iron cylinder was obtained by a 
thermoelement enclosed in a porcelain tube $\mathrm{T}$ passing through the furnace.

The Bolometer.-Essentially this is a Wheatstone's bridge, the four arms of which consist of grids of thin platinum foil similar in all respects. The method of connecting up the grids is shown in Fig. 4\%.

Grids 1 and 3 are in the opposite

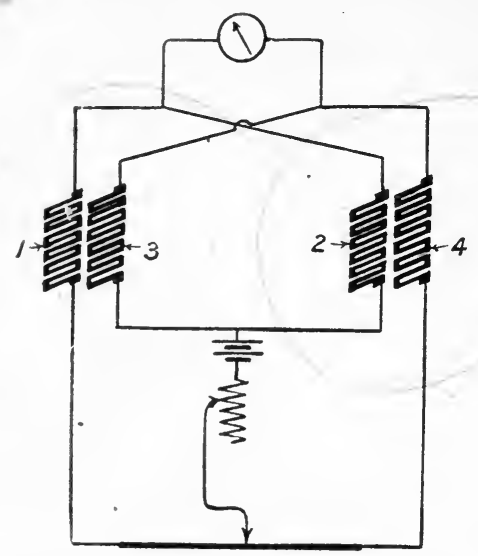

FIG. 47.-Diagram of the connection of the resistance grids in a bolometer. arms of the bridge, and the strips of 3 are set to receive the radiation passing through the gaps of 1 . The other two grids, 2 and 4, are similarly disposed, but shielded from radiation by a box.

To prevent wandering of the galvanometer zero, the disposition must be as symmetrical as possible and the whole instrument enclosed in a welllagged box provided with diaphragms to cut down the radiation, falling on the absorbing surface, to a parallel beam of about $16 \mathrm{mms}$. in diameter.

The grids are of foil from one to two thousandths of a millimetre thick and with a resistance of about 60 ohms each.

The method of constructing such exceedingly thin conductors is worthy of notice. A sheet of platinum is welded to a thick sheet of silver and both are rolled down.

The grid is then punched out and attached to a hollow slate frame. When thus supported the silver is dissolved by nitric acid from the straight limbs, the elbows on the slate being protected by varnish.

The appearance of the face of one of the grids after coating with platinum black is shown in Fig. 48, while Fig. 49 is a view of the back surface.

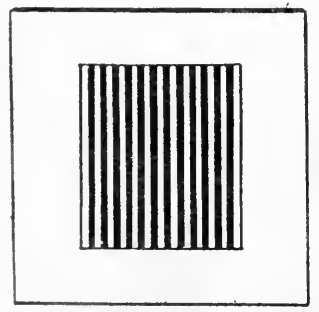

FIG. 48.-Front view of a grid, after being coated with platinum black.

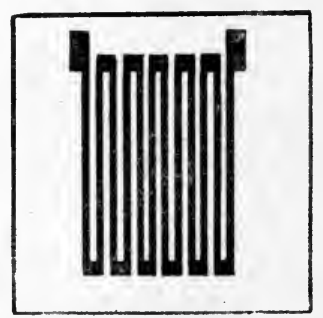

Fig. 49.-View of the back surface of grid, after coating with platinum black.

'Theoretically the quantity of radiation received per unit time, by unit area, at a distance $r$ from a point source, varies inversely as $r^{2}$. Lummer and Pringsheim ascertained that their experimental arrangements 
complied with this theoretical condition, by taking observations at. varying distances between the "black body" and bolometer. It was found that the galvanometer deflections varied inversely as the square of the distance. Since the quantity of radiation received varied as the difference of the fourth powers of the absolute temperatures of the radiator and receiver, it was necessary to vary the sensitivity of the bolometer in order to keep the galvanometer deflections within measur-' able limits. Two means of effecting this were employed : (1) variation of the sensitivity of the Wheatstone bridge by changing the battery current; (2) alteration of the distance between the "black body" and the bolometer.

The observations were all reduced to a common unit (arbitrary), based on the radiation from the "black body" at $100^{\circ} \mathrm{C}$. at a standard distance of $633 \mathrm{mms}$.

If $d$ is the deviation of the needle for "black body" at absolute temperature $\theta$, and $k$ a constant, the mean value of which for their instrument is $123 \cdot 8$,

$$
\text { Then } d=k\left(\theta^{4}-290^{4}\right)
$$

where $290^{\circ}$ is the absolute temperature of the water-cooled shutter (i.e. $\left.17^{\circ} \mathrm{C}.\right)$.

In Table XV. the experimental observations are compared with values calculated from the fourth-power law. 'The calculated temperatures are obtained by taking the mean value of $k$.

TABLE XV.

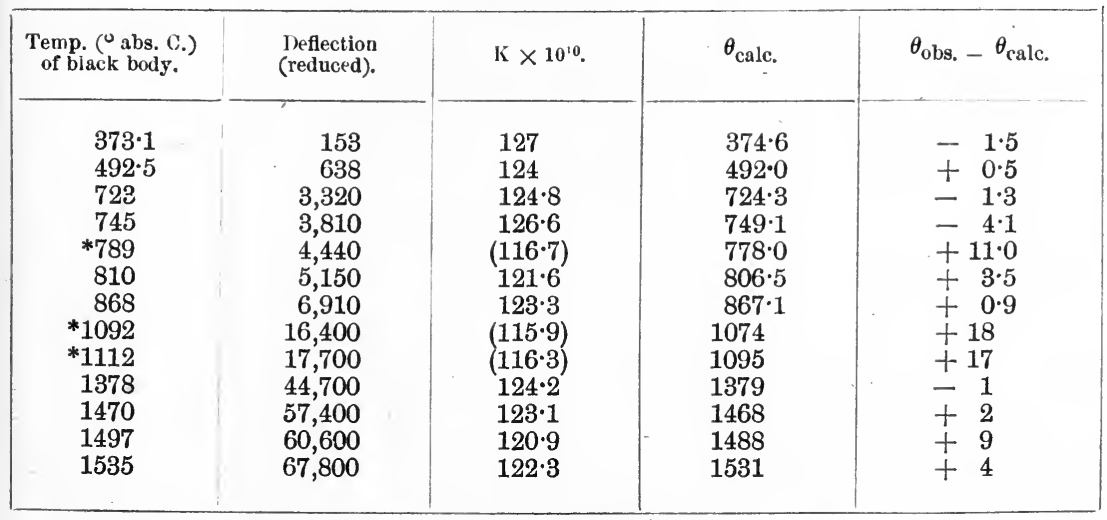

* These experiments were carried out with the gas furnace at temperatures overlapping those obtained with the salt bath. The large discrepancies are due to lack of uniformity of temperatures with a small flame. It will be seen that the observation at $789^{\circ} \mathrm{C}$. is eliminated by observations 4,6 , and 7 with the nitrate bath.

Between $100^{\circ} \mathrm{C}$. and $1000^{\circ} \mathrm{C}$. the deviation of the calculated from the observed temperatures are small, of the order of $3^{\circ}$, and exhibit no systematic variation. Between $1000 \mathrm{C}$. and $1360^{\circ} \mathrm{C}$. the discrepancies are greater, and the observed values are systematically larger than the 
calculated. It should be remembered, however, that their temperature scale is based on the gas thermometer work of Holborn and Day, and this extended to $1150^{\circ} \mathrm{C}$. only. Beyond this point the values are based on extrapolation of the e.m.f.-temperature curves of thermocouples, a procedure which has since been shown to lead to erroneous results. Up to $1100^{\circ} \mathrm{C}$. it is probable that the temperature scale of Day and Holborn is reliable to about $3^{\circ}$. Consequently Lummer and Pringsheim's experiments establish the validity of the fourth-power law to $1150^{\circ} \mathrm{C}$. to the same order of accuracy as the gas scale was known at that time.

Fourth-power law between $1063^{\circ} \mathrm{C}$. and $1549^{\circ} \mathrm{C}$. - In an investigation, whose primary object was the comparison of the "optical scale," based on Wien's distribution law, and the "total radiation" scale, based on the fourth-power law, Mendenhall and Forsythe checked the Stefan-Boltzmann law at the two temperatures $1063^{\circ} \mathrm{C}$. and $1549^{\circ} \mathrm{C}$. 'These temperatures are the melting-points of gold and palladium respectively as determined by Day and Sosman.

'The comparison was effected in an indirect method. The meltingpoints of gold and palladium were observed in terms of the scale of a certain optical pyrometer under "black body" conditions. The temperature of a carbon tube furnace could then be maintained at these two temperatures by observations with the optical pyrometer, which merely served as a transfer instrument. The apparatus for verifying the fourthpower law is shown in Fig. 50 .

The "black body" is the graphite tube T, $30 \mathrm{cms}$. long, 14 mms. inside diam., and $3 \mathrm{mms}$. wall thickness. A graphite diaphragm $\mathbf{G}$ is placed $1 \mathrm{~cm}$. out of centre, the left-hand segment being used as "black body." The coaxial tubes $\mathbf{H}$ and $\mathrm{K}$ are merely to reduce the heat loss by radiation, etc.

The apparatus was water-cooled as shown; the total radiation thermopile $\mathrm{P}$ being protected from stray radiation by water-cooled diaphragms, while a movable water-cooled shutter $\mathbf{Q}$ contained the limiting aperture. The geometry of the apparatus was so arranged that radiation from the graphite diaphragm $\mathbf{G}$ alone entered the thermopile. A motor M, movable by means of a rod V, carried a sector $\mathrm{S}$ of definite aperture on its shaft. By a movement of the rod the motor could be swung up and the rotating sector placed in front of the thermopile so that the radiation from the furnace was reduced in a known ratio, depending on the clear aperture of the sector.

The thermopile consisted of a single. Bi-Sb and $\mathrm{Sb} \cdot \mathrm{Cd}$ alloys couple, the "hot" junction being soldered to a very light receiving disc of silver foil $3 \mathrm{mms}$. in diameter, a similar disc being attached to each cold junction, where the alloys joined copper leads. The silver disc "hot" junction was blackened with acetylene smoke and mounted at the centre of a hemispherical concave mirror, so as to make the absorp. tion as perfect as possible. 'The thermocouple was directly connected with a low-resistance galvanometer, a resistance box being connected in series to control the sensibility. 


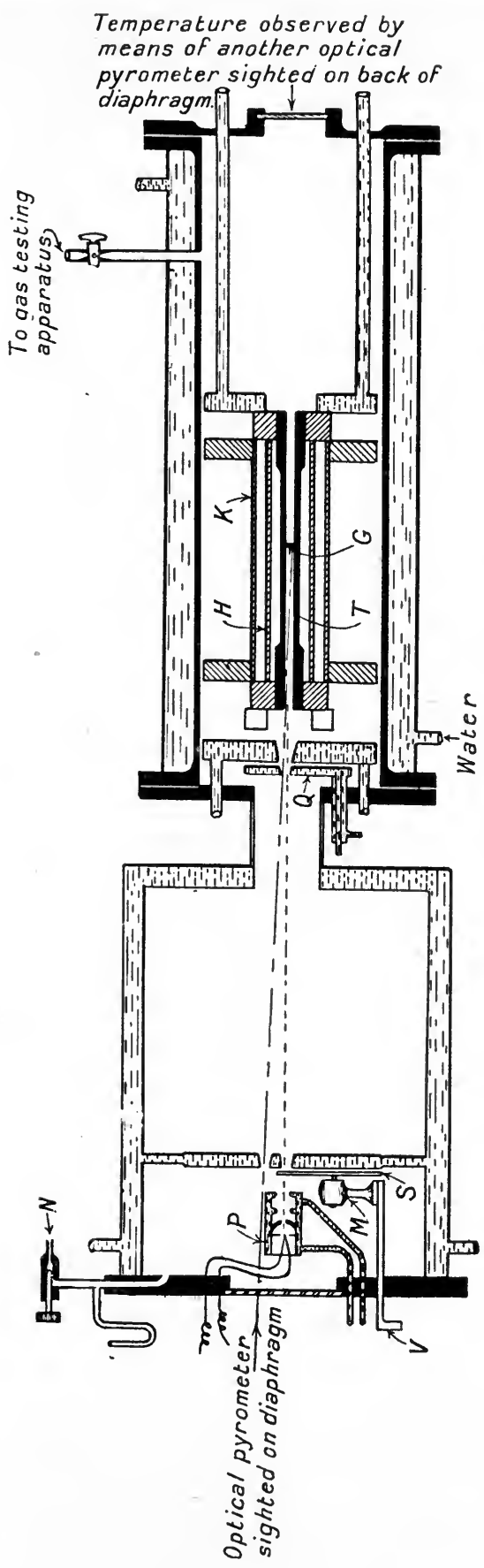

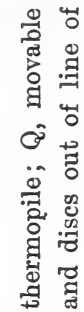

密蒡蒂

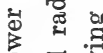

总 尊

용

蒫

๑

$\pm 0$

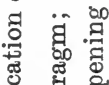

承 \%

ऽ

\& 0

年

究急

$\&$ - 0

웅 ซో.

落设票

02 ... प्र

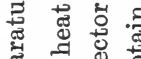

范

일

4

붕유

क्ष

.

1.

ำ

ช

保

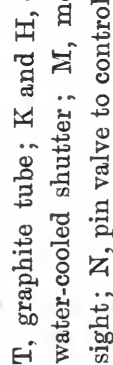


Special attention was given to the elimination of any possible error due to absorption of radiation by the gases inside the furnace. With a hot object, such as graphite, it is impossible to obtain a perfect vacuum, and fluctuations of pressure would have had a serious influence on the sensibility of the thermopile.

During the observations a steady pressure (from 5 to $15 \mathrm{mms}$. of mercury) was maintained in the apparatus by controlling a valve governing the nitrogen supply ; the pressure could be maintained constant within $0.2 \mathrm{~mm}$. by careful regulation; a Fluess and Gaede pump steadily exhausting at the other end.

To ascertain whether the residual gas exerted appreciable absorption on the radiation, samples were drawn off from time to time to a side tube and the deflections of an auxiliary thermopile read with and without the gas, employing a Nernst filament as radiator; the authors claim that they could detect such effect if it amounted to $\frac{1}{10}$ per cent

Theory of the sectored disc.-The object of a sectored disc is to cut down the radiation by a definite fraction so that the same galvanometer deflection is obtained for two different temperatures of the radiator or" "black body."

Suppose the deflection $x$ is obtained when radiation from an object at absolute temperature $T_{1}$ is received through a clear aperture sector, and the same deflection obtained for temperature $\mathrm{T}_{2}$ with a rotating sector having transmission ratio $\mathbf{S}$ (where $\mathbf{S}<1$ ).

$$
\begin{aligned}
\text { Then } x & =\mathrm{KAT}_{1}{ }^{4} \text { for the first condition } \\
\text { and } x & =\mathrm{KSAT}_{2}{ }^{4} \quad \text { second }, \\
\text { Hence } \mathrm{T}_{1}{ }^{4} & =\mathrm{ST}_{2}{ }^{4} \quad \text { or } \quad \mathrm{T}_{2}=\frac{\mathrm{T}_{1}}{\sqrt[4]{\mathrm{S}}}
\end{aligned}
$$

In practice it was found impossible to bring the two deflections to absolutely the same value, consequently it was assumed that the deflections were proportional to the total energy in the two cases.

The aperture in the sector was cut in the ratio [1336/1822 $]^{4}$, where 1336 is the melting-point of gold and 1822 the melting-point of palladium, in absolute temperatures.

Consequently, the ratio of the galvanometer deflections at these two temperatures, if the fourth-power law was obeyed, should be unity.

From twelve comparisons the observed mean value was 1.001. The maximum value of the ratio found was 1.007 and the minimum 0.998 . A few typical observations are shown in Table XVI.

This indicates an agreement woll within the possible limits of experimental error of \pm 0.5 per cent. at each of the two temperatures.

All the experimental evidence available supports the conclusion that the Stefan-Boltzmann law is valid over the entire temperature range covered by the gas thermometer. It may therefore be employed with confidence, in view of its plausible theoretical foundation, as the basis of methods for the evaluation of high temperatures. 
TABLE XVI.

\begin{tabular}{|c|c|c|}
\hline Deflection at $1063^{\circ} \mathrm{C}$. & $\begin{array}{c}\text { Deflection at } 1549^{\circ} \mathrm{C} ., \\
\text { with sectored } \\
\text { aperture. }\end{array}$ & $\begin{array}{c}\text { Ratio column 2 to } \\
\text { column 1. }\end{array}$ \\
\hline & $29 \cdot 33$ & $1 \cdot 002$ \\
$29 \cdot 28$ & $29 \cdot 17$ & $1 \cdot 003$ \\
$29 \cdot 08$ & $29 \cdot 33$ & $1 \cdot 000$ \\
$29 \cdot 33$ & $28 \cdot 27$ & $0 \cdot 999$ \\
$28 \cdot 29$ & $28 \cdot 25$ & $0 \cdot 999$ \\
$28 \cdot 27$ & & Mean 1.001 \\
\hline
\end{tabular}

Total Radiation Pyrometers.-Pyrometers based on the fourthpower law for the measurement of high temperatures are merely thermopiles so arranged that the instruments are (1) direct reading, (2) robust, (3) quick in action, (4) and have arrangements to render the readings independent of the distance between pyrometer and hot body, within certain limits.

Féry's Telescope Pyrometer.-Féry appears to have been the first to evolve a practical form of pyrometer based on the StefanBoltzmann law, and capable of measuring temperatures between $500^{\circ} \mathrm{C}$. and $1500^{\circ} \mathrm{C}$.

In the early types the instrument consisted of a telescope having a minute thermocouple connected to a sensitive portable galvanometer. The hot junction and the source of radiation were brought to the conjugate foci of the lens by focussing in the usual manner.

'The difficulty with this type was the lens, which had to be transparent for both the visible and the infra-red.

Fluorite was found satisfactory for temperatures above $900^{\circ} \mathrm{C}$., since it possesses a nearly constant coefficient of absorption throughout the spectrum. The indications of the instrument, however, did not follow the fourth-power law owing to the fact that fluorite has an absorption in the infra red at about $6 \mu$.

For industrial work fluorite was too costly, so glass was employed and the instrument calibrated empirically over the working range.

Féry's mirror pyrometer.-These difficulties were avoided by the use of a concave mirror to collect the radiation.

Fig. 51 represents a modern type of instrument. The mirror $\mathbf{M}$ is capable of being racked backwards and forwards to focus the radiation on the thermocouple receiver at S. The cold junctions of the couple are shielded from radiation by the tongue $\mathrm{T}$ and a box surrounding both the couple and the inclined mirrors $\mathrm{X}$.

To enable the observer to focus accurately the radiation on to the hot junction, in the same plane as this, two small mirrors are inclined at an angle and fixed. Then, unless the image of a straight line viewed through $\mathbf{E}$ is exactly in the same plane as the two inclined mirrors, it 
will appear broken at the plane of intersection of these mirrors. Fig. 52 illustrates the paths of the rays producing the distorted images. The observer moves the concave mirror until the relative displacement of the

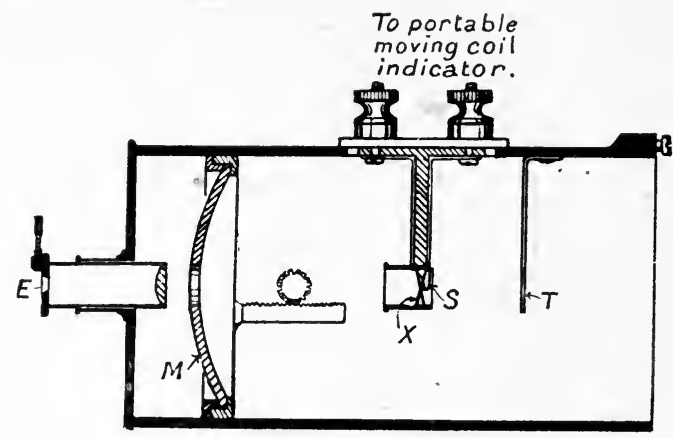

FIG. 51.-Diagram of Féry's mirror pyrometer.

M, mirror (nickel-plated); S, hot junction of thermocouple; T, projecting metal tongue to shield thermocouple from direct radiation; $\mathrm{X}$, inclined mirrors.

two halves of the image disappears; an operation within the capacity of an intelligent workman.

In the earlier forms of this instrument the mirror was of glass silvered on the back. Since glass is a very good reflector of the infra-

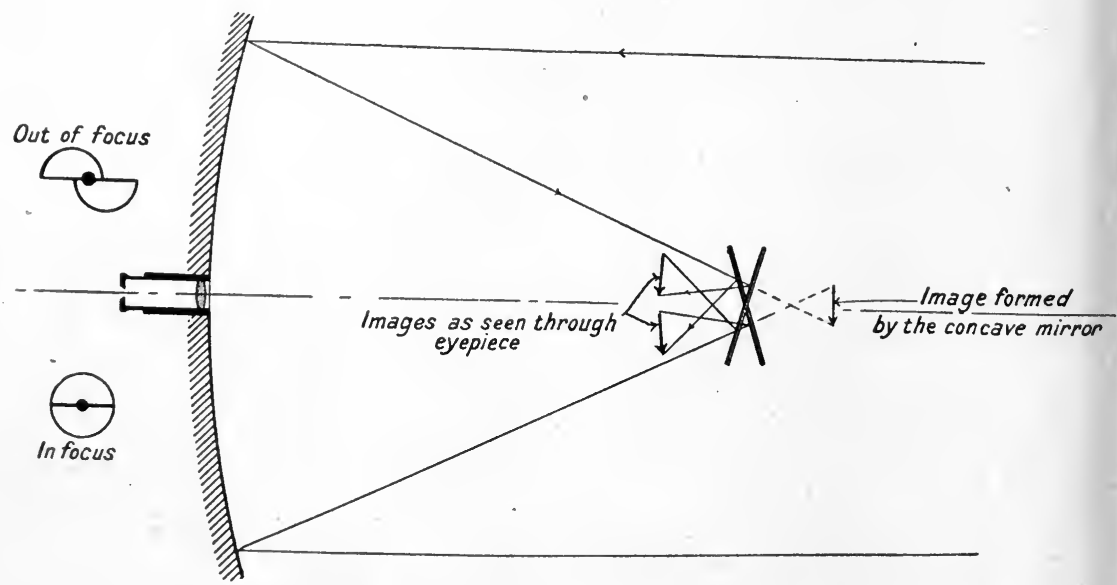

FiG. 52.-Diagram to illustrate the paths of the rays producing the distorted image.

red, the heat rays were reflected in part from the front air-glass surface and in part from the back glass-silver surface. 'The two groups of rays were brought to the same focal point by making the radii of curvature of the two surfaces slightly different. If, however, the thickness of the 
glass is small, 1 to $2 \mathrm{mms}$, the same radius of curvature can be used for the two surfaces without appreciable error.

Later instruments have a glass mirror with a gold deposit on the front surface, others gold or nickel on copper.

Independence of distance.-So long as the image of the hot object formed by the concave mirror is sufficiently large to overlap the sensitive thermo-element, then it is the intensity of the heat image and not the total heat reflected that is measured by the instrument. Now, it can be easily shown that this intensity is independent of the distance from the hot object. If, for example, the distance between the instrument and the hot object is doubled, then the total amount of heat received by the concave mirror is reduced to one-fourth, but the area which the image covers is simultaneously reduced to one-fourth, so that the actual heat intensity of the image remains constant.

To limit the cone of radiation falling on the disc attached to the hot junction, a small diaphragm is fixed on the front of the box containing the couple and mirrors. In other forms the box is dispensed with and the inclined mirrors used as diaphragm, the disc being placed a millimetre or so below the plane of the mirrors, which in all types are cut away opposite the disc.

Relation between size of object and the distance for the Féry type of pyrometer.-It is a simple matter to calculate the minimum size of object required by the geometry of the Féry optical system.

The relation between the sizes of the object and image formed by a concare mirror is $\mathrm{O}=\mathrm{I}\left(\frac{u}{f}-1\right)$, where $\mathrm{O}$ is the diameter of the object, I that of the image, $u$ the distance from the object to the mirror, $f$ the focal length.

For the ordinary types of Féry's the aperture in the diaphragm in front of the receiving disc is about $1.5 \mathrm{mms}$. diam., $f$ the focal length about $7 \cdot 6 \mathrm{cms}$.

The table below, due to Burgess and Foote, gives the size of source for various distances assuming the above data.

TABLE XVII.

\begin{tabular}{|c|c|}
\hline$u$ (cms.). & Diameter source (cms.). \\
\hline 70 & $1 \cdot 2$ \\
80 & $1 \cdot 4$ \\
100 & $1 \cdot 8$ \\
150 & $3 \cdot 1$ \\
200 & $4 \cdot 2$ \\
300 & $6 \cdot 3$ \\
500 & $10 \cdot 7$ \\
\hline
\end{tabular}

Extension of the Temperature range by the use of Diaphragms. - Instruments are often provided with a second scale extending over a 
higher range of temperature. 'This is effected by the addition of a diaphragm over the front of a pyrometer, which cuts down the radiation by a definite fraction. While theoretically the " law " of the instrument should be unaffected by the addition of the diaphragm, it is generally found that the index is not exactly the same with and without the diaphragm. The change is probably due to secondary radiation from the diaphragm, which necessarily becomes heated by exposure to direct radiation from the hot object, and also to the change in the distribution of the air currents within the case, caused by the presence of the diaphragm.

The extrapolation of the scale of temperature is effecter by assuming the validity of the "law" of the instrument as determined by experiments over the range of temperature measurable with thermoelements.

The Foster fixed-focus pyrometer.-The construction of this pyrometer will be understood from Fig. 53.

'The receiving disc on the couple and the front diaphragm $\mathrm{D}$ of the

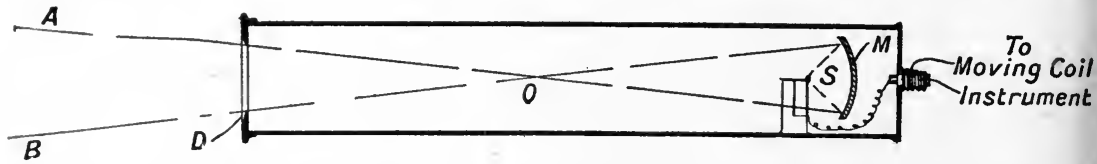

FIG. 53.-Diagram illustrating construction of the Foster fixed-focus pyrometer. $\mathrm{A}$ and $\mathrm{B}$, limiting value of cone of radiation; $\mathrm{D}$, front diaphragm; $\mathrm{M}$, concave mirror ; $\mathrm{S}$, receiving disc on end of thermocouple.

pyrometer are located at the conjugate foci of the mirror $M$. 'Then so long as the cone is filled by the radiation from the hot object the readings are independent of the distance.

The rather large area required to sight upon is occasionally a disadvantage.

Various precautions are taken to prevent secondary effects, such as stray radiation from the sides of the tube, etc., from influencing the readings. 'This is generally effected by additional diaphragms in the tube, and also by cutting a coarse screw-thread on the internal surface.

'The Thwing pyrometer is somewhat similar to the Foster, but has a cone instead of a concave mirror. 'The receiving disc of the couple is situated at the apex.

Whipple has introduced a modification of the Féry pyrometer. In this type a closed tube of salamander or fireclay is inserted into the furnace or molten metal, and the radiation from the hot end focussed on a minute thermocouple; the instrument being of the fixed focus type.

For taking temperatures of molten metals, the radiation from which departs considerably from full radiation, and for furnaces with a smoky atmosphere, the pyrometer has proved to be of considerable service.

\footnotetext{
* Value of the index in $\mathrm{E}=a \mathrm{~T}^{b}$.
} 
The drawback of this type for very high temperature work is the impossibility of obtaining an impermeable tube, and should oil vapour or fumes pass into the interior it would seriously vitiate the results.

Sources of error in practical forms of radiation pyrometers.Since the ideal radiation pyrometer would give galvanometer deflections proportional to the intensity of the radiation emitted by the hot object, and hence the difference in the fourth powers of the absolute temperatures, a calibration at one temperature would be sufficient to supply all the data necessary for the computation of the temperature scale. When $\mathrm{T}$ is large compared with $\mathrm{T}_{0}$, the deflections should be proportional to ' $\mathrm{T}^{4}$ (' $\mathrm{T}_{0}{ }^{4}$ being negligible).

It is generally found, however, that the index is not 4, but varies between the limits $3 \cdot 8$ to $4 \cdot 2$ for various instruments.

In any particular case the value of the index may be obtained by plotting the logarithms of the deflections and temperatures. The experimental points will in general be found to lie on a straight line.

Many factors contribute to produce variations in the value of the index from 4.

1. The electromotive force generated by the thermocouple is not strictly proportional to the temperature difference between the hot and cold junctions. When the rise in temperature of the receiving disc above the surroundings is of the order of $80^{\circ}$ this factor has an appreciable influence.

2. The thermocouple and inclined mirrors are enclosed in a small cell. Stray reflections from the walls falling on the receiving disc produce disturbances.

3. The rate of heat loss from the junction is not strictly proportional to its temperature excess.

4. Conduction of heat along the couple wires produces a slight temperature rise in the cold junction.

5 . In addition there are the various errors to which the millivoltmeter readings are liable.

Occasionally one finds that an instrument will follow the fourthpower law with considerable exactitude. 'This is to be ascribed to the fact that the small residual effects accidentally neutralise each other's influence, rather than to theoretical perfection of design.

'The other characteristics of practical types of radiation pyrometers which require study in the case of each individual instrument are-

1. 'That its indications are independent of the distance from source to pyrometer and independent of the size of the source when this is above the minimum size required by the geometry of the instrument.

2. That the final reading is quickly attained. While theoretically an infinite time is required to reach the equilibrium state (i.e. when the receiving disc emits as much heat as it receives), most practical types reach the steady state in a minute or so. The time interval required depends, of course, on the individual pyrometer.

Occasionally a maximum reading will be quickly reached and then 
it begins to decrease, the final value only being reached after 15 to 20 minutes. This anomalous behaviour is generally due to conduction along the wires of the couple and to secondary radiation from the sides of the cell and the diaphragms.

Such an instrument must be calibrated under the same conditions as it is to be used in practice.

\section{CALIBRATION OF RADIATION PYROMETERS.}

Instruments are generally calibrated by comparison with a standard instrument over the range $500^{\circ}$ to $1400^{\circ} \mathrm{C}$. A uniformly heated muffle forms a convenient source of radiation closely approximating to a "black body" radiator.

'The standard instrument requires more elaborate study. For this purpose a large platinum foil wound electric furnace is convenient; this should be provided with suitably disposed diaphragms, and the pyrometer focussed on a plug of refractory material fixed in the centre of the furnace. Across the face of this plug one or more platinumplatinum-rhodium couples should be stretched, so that the mean temperature of the surface is obtained with accuracy.

To obtain a cone of radiation of sufficient size to fill the field of the pyrometer it is necessary to employ a furnace with an aperture of two or three inches in diameter.

At high temperatures a considerable amount of cooling takes place by convection from the open mouth of a horizontal furnace.

Some improvement is effected by inclining the mouth downwards at an angle of $20^{\circ}$ to $30^{\circ}$, but for steadiness of temperature and for economy a vertical arrangement of the furnace, open downwards, is the most satisfactory.

'This method of mounting has been adopted at the National Physical Laboratory, and a general view of the arrangement is shown in Fig. 54. 'Three furnaces A, B, and C, are mounted on an iron platform.

The furnaces consist of brick shells covered externally with .cement and closed by a square fireclay slab. They are approximately cubes of $2 \mathrm{ft}$. side.

For temperatures up to $1100^{\circ} \mathrm{C}$. the furnaces are wound with nickel-chromium alloy tape $1 \mathrm{~cm}$. wide by $1 \mathrm{~mm}$. thick.

For higher temperatures up to $1400^{\circ} \mathrm{C}$. it is necessary to employ platinum foil, since the life of a nickel-chromium alloy winding is only a few hours at a temperature of $1300^{\circ}$.

The internal diameter of the furnace tubes is almost 4 inches, and diaphragms are fitted to approximate to "black body" conditions.

The pyrometers are carried on a wheel which can be turned on a vertical axis. 'Thus each pyrometer in turn can be brought opposite the mouth of any furnace.

The arrangement is illustrated in Fig. 55.

The thermoelements employed for obtaining the temperature of the 
"FOLR'TH-POWER" LAW OF RADIATION PYROME'TERS 95

radiating discs have their cold junctions extended, by compensating leads passing through the tube D to the ice box E.

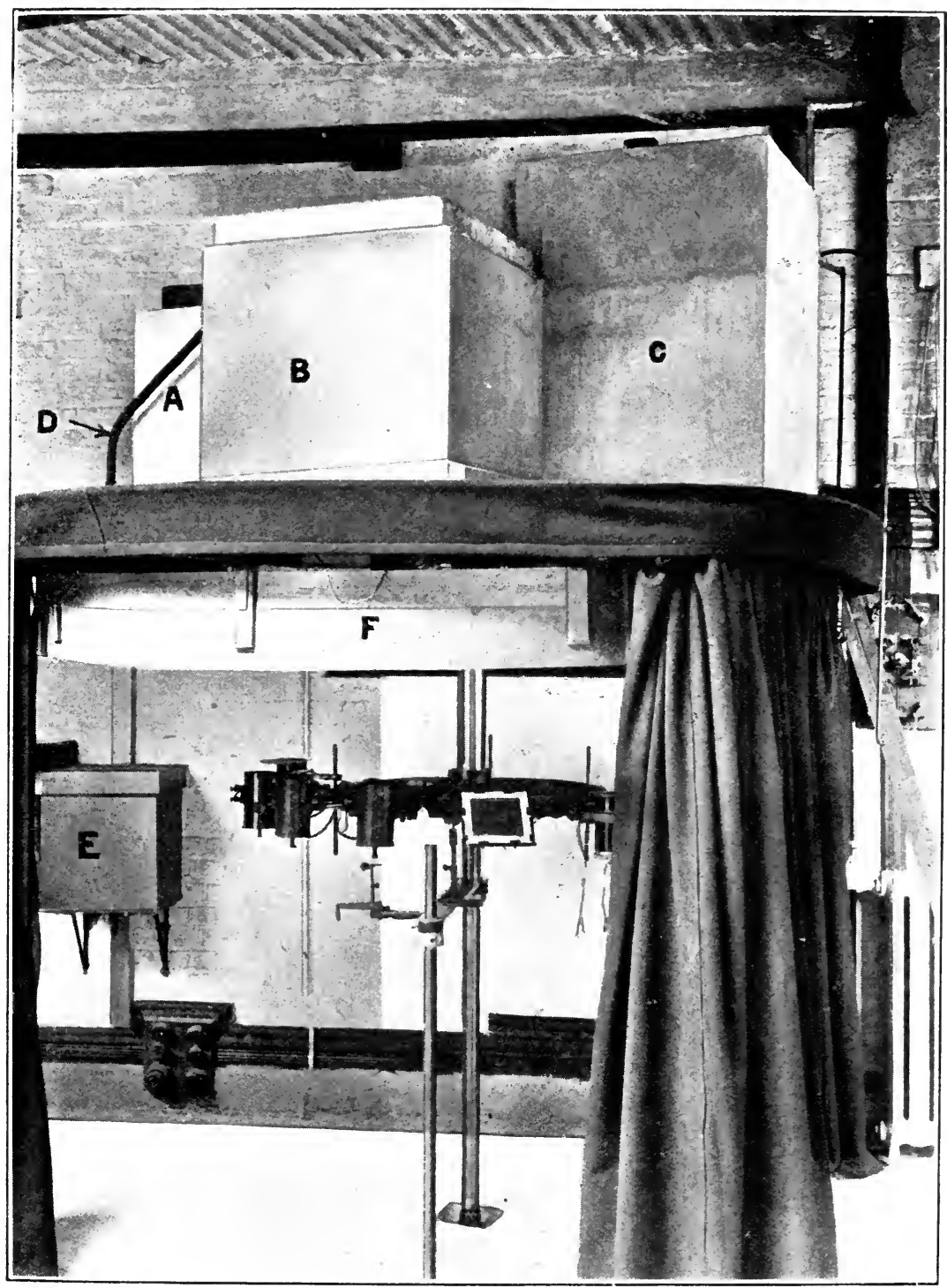

FIG. 54.-General view of arrangements for the standardisation of total radiation pyrometers.

By a switch arrangement the couples giving the furnace temperature may be connected either to the galvanometer or to a potentiometer. 
The beam of light from the galvanometer mirror is focussed on the circular scale $\mathrm{F}$, which is directly graduated in temperatures.

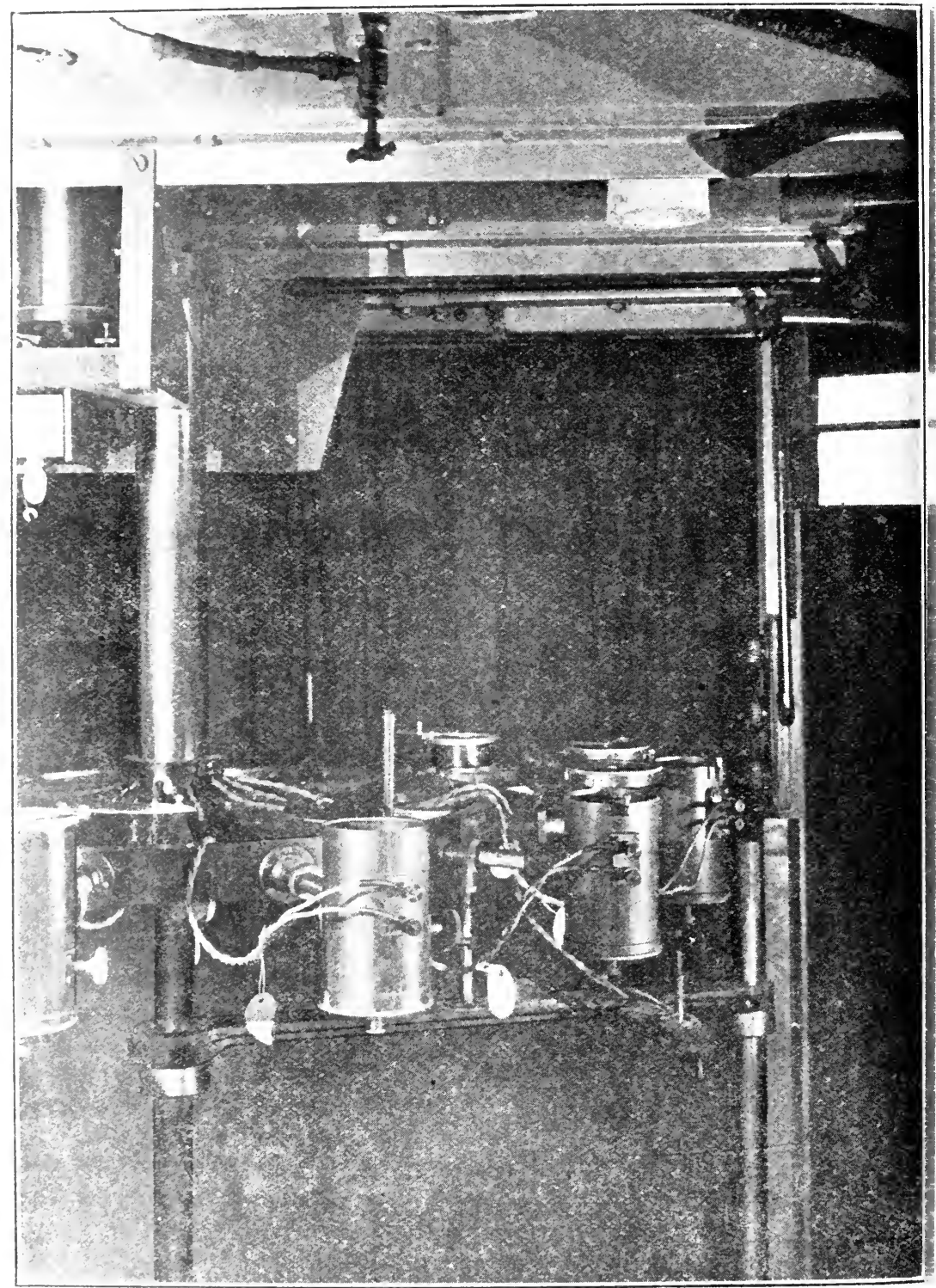

FiG. 55.-Method of mounting the pyrometers. Galvanometer in top left-hand corner ; direct-reading temperature scale on right. 


\section{"FOURTH-POWER" LAW OF RADIA'TION PYROMETERS 97}

\section{REFERENCES TO CHAPTER V.}

Lummer and Pringsheim, Ann. der Physik., Bd. 63, p. 395 (1897).

Mendenhall and Forsythe, Phys. Rev. 4 (1) (July, 1914).

Gillette, Journ. Phys. Chem., 15 (1911).

Féry and Drecq, Journ. de Phys., 1 (5), p. 551 (1911).

Millochau, C.R., 159, p. 171 (1914).

Burgess and Foote, "Characteristics of Radiation Pyrometers," Bull. Bur. Stds., 12, p. 91 (1915).

Coblentz, "Coefficient .Total Radiation," Bull. Bur. Stds., 9, p. 283 (1913); 12, p. 533 (1916) ; Proc. Nat. Acad. Science, 3, p. 504 (1917). 


\section{CHAPTER VI}

\section{TOTAL RADIATION FROM OXIDE AND METALLIC SURFACES}

Emissivity of nickel oxide, iron oxide, molten copper, and copper oxide-Corrections to convert apparent temperatures to true temperatures.

Total radiation from metallic surfaces. - While muffles, furnaces, and heating chambers generally employed in the industries closely approximate to "full radiators," the surfaces of metallic objects depart considerably from the ideal contemplated by the Stefan-Boltzmann law. Consequently, a radiation pyrometer calibrated on a "full radiator," if employed to take the temperatures of such surfaces, will give readings which are too low.

When the surface is oxidised, the difference between the apparent and real temperature will be a function of the condition of the surface, and it is difficult to apply a correction with any degree of certainty.

The radiation from some of the commoner metals has been investigated with the conclusions summarised below.

Definition of the emissivity of a surface.-At the present time the term "emissivity" is used to denote the ratio of the heat emitted by unit area of the surface to that emitted by an equal area of a "full radiator" at the same temperature, and not in the older sense of the term, when it denotes the heat emitted divided by the temperature excess of the surface above the surroundings.

Hence, if $\mathrm{W}$ is the total radiation emitted by unit area of the surface at absolute temperature $\mathbf{T}$ to surroundings at temperature $\mathbf{T}_{1}$, and $\sigma$ is the "black body" constant, then

$$
\mathrm{W}=\mathrm{E} \sigma\left(\mathrm{T}^{4}-\mathrm{T}_{1}^{4}\right)
$$

where $\mathbf{E}$ is defined as the emissivity constant for the surface at ' $\mathrm{T}$.

The emissivity of oxidised metallic surfaces.-I. Nickel Oxide, NiO. - When nickel is heated to a high temperature in air, there is formed on its surface a tough, smooth layer of NiO.

The emissivity of this oxide surface has been studied over an extended temperature range.

(a) Randolph and Overholser investigated the subject up to a temperature of about $500^{\circ} \mathrm{C}$. The work of these observers was primarily directed towards the determination of the heat loss from surfaces, and to separate the effects of convection and radiation, the total loss and the 
radiation loss were independently determined, so that the convection loss could be obtained by difference.

- The radiation was measured by a robust absorption pyrometer. The comparison black body was a cast-iron pipe, closed at one end and heated by three independent resistance coils. A number of thermoelements were distributed to obtain the average temperature, and at $500^{\circ} \mathrm{C}$. the variations were of the order of $3^{\circ} \mathrm{C}$.

The nickel disc was $19.3 \mathrm{cms}$. in diameter; it was electrically heated, the temperature being obtained by a thermocouple soldered to the back, allowance being made for the gradient through the disc.

As might be anticipated, the emissivity was dependent on the state of oxidation of the surface, and this again on the time during which it had been maintained at a given temperature. For example, starting with a polished disc maintained steady at $500^{\circ} \mathrm{C}$. the emissivity increased rapidly at first, and did not attain a steady stage until about 90 hours had elapsed.

If observations were made at a lower temperature, after the surface had been maintained at a higher temperature for some time, the emissivity constant would depend on the maximum temperature only.

'i he results obtained for a surface previously heated to a temperature exceeding $600^{\circ} \mathrm{C}$. are shown graphically in Fig. 56, in conjunction with those obtained at higher temperatures by Burgess and Foote.

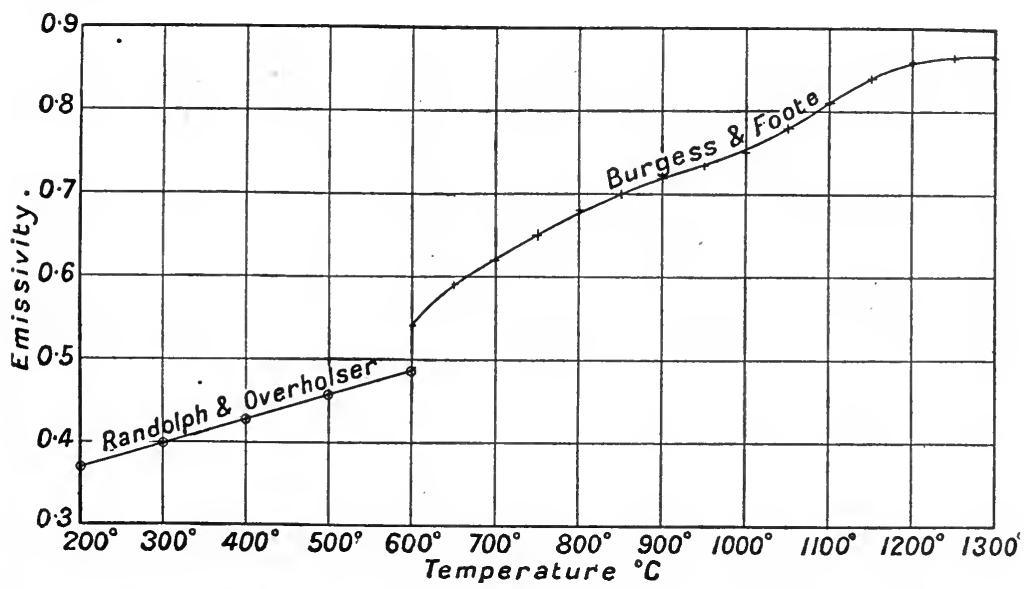

FIG. 56.-Variation with temperature of the emissivity of nickel oxide.

(b) Burgess and Foote employed an ordinary Féry radiation pyrometer for the measurement of the radiation, calibrated to give true temperatures under black body conditions.

Observations were made of the apparent temperatures, the corresponding true temperatures being obtained by methods described below.

Theory of the method.-If $\mathrm{E}$ denotes the total emissivity of an 
approximately non-selective, radiating surface at absolute temperature $\mathrm{I}_{1}$ and $\mathrm{S}$ the apparent temperature observed with the radiation pyrometer, then

Hence

so that

$$
\begin{aligned}
\mathbf{Q} & =\sigma\left(\mathrm{S}^{4}-\mathrm{T}_{0}^{4}\right) \\
\mathbf{Q} & =\mathrm{E} \sigma\left(\mathrm{T}_{1}^{4}-\mathrm{T}_{0}^{4}\right) \\
\sigma\left(\mathrm{S}^{4}-\mathrm{T}_{0}^{4}\right) & =\mathrm{E} \sigma\left(\mathrm{T}_{1}-\mathrm{T}_{0}^{4}\right) \\
\mathbf{E} & =\frac{\mathbf{S}^{4}-\mathrm{T}_{0}^{4}}{\mathrm{~T}_{1}{ }^{4}-\mathrm{T}_{0}^{4}}
\end{aligned}
$$

Above $600^{\circ} \mathrm{C}$. the term $\mathrm{T}_{0}{ }^{4}$ may be neglected, as a simple calculation will show :-

If, for example, $\mathrm{E}$ is about 0.5 , the error in its value by neglecting $\mathrm{T}_{0}$ would be only 0.007 at $600^{\circ} \mathrm{C}$. and 0.0002 at $1300^{\circ} \mathrm{C}$.

Hence the emissivity may be calculated by the simple expression

$$
\mathrm{E}=\left(\frac{\mathrm{S}}{\mathrm{T}}\right)^{4}
$$

Since in practical types of radiation pyrometers the index is rarely exactly 4, the above expression requires slight modification in such cases.

Taking the characteristic exponent of the empirical relationship between e.m.f. and temperature as $b$ so that

$$
e=a \mathrm{~T}^{b}
$$

then, if $e^{\prime}$ is the e.m.f. generated when sighted on a radiating surface of apparent temperature $\mathrm{S}^{\circ}$ (absolute) and true temperature $\mathrm{T}$,

$$
\mathrm{E}=\left(\frac{e^{\prime}}{e}\right)^{\frac{4}{b}}
$$

To obtain the true temperatures corresponding to the apparent temperatures two methods were available which gave results in close accord.

(1) The application of the idea embodied in the Joly meldometer, in which the melting-points of microscopic specimens of various substances were observed, such as $\mathrm{NaCl}\left(800^{\circ} \mathrm{C}\right.$. $) ; \mathrm{Na}_{2} \mathrm{SO}_{4}\left(884^{\circ} \mathrm{C}\right.$.); $\mathrm{Au}\left(1063^{\circ} \mathrm{C}\right.$.).

Experiments were made to ascertain that the temperature of the strip did not differ appreciably from that of the specimens.

(2) By the use of an optical pyrometer calibrated to read true temperatures when sighted on such a surface. This pyrometer is based on the principle of matching the intensity of the light from an electric lamp filament with the light from the hot object.*

The pyrometer was calibrated initially for "full radiator" conditions, and then the departure of the nickel oxide surface was obtained by sighting on the surface of a nickel tube, electrically heated, and into a small diaphragmed enclosure in the centre of the tube. By properly 
locating the diaphragms in the interior of the tube "black body" conditions could be realised quite satisfactorily.

Theoretically the experiment might be simplified by using the total radiation pyrometer directly to sight on the outside of the oxidised tube and on the interior: the first observation giving the apparent temperature while the second would give the true temperature. But, owing to the large aperture that would be necessary in comparison with that required for an optical pyrometer, this method of obtaining the true temperature would present practical difficulties.

It should be remarked, however, that the principle employed (of measuring the radiation by concentrating it on the thermocouple by means of a metallic mirror) is only valid so long as coefficient of reflection of the surface does not vary with the wave-length.

This appears to be the case for gold over the spectrum range from 1 to $14 \mu$.

The variation of emissivity with temperature of $\mathrm{NiO}$ is shown graphically in Fig. 56, while the data are given in Table XVIII.

TABLE XVIII.

\begin{tabular}{|c|c|c|c|c|c|c|c|c|c|}
\hline $\begin{array}{l}\text { Temp. }{ }^{\circ} \mathrm{C} . \\
\text { Emissivity }\end{array}$ & $\begin{array}{l}600 \\
0.54\end{array}$ & $\begin{array}{r}650 \\
0.59\end{array}$ & $\begin{array}{l}700 \\
0 \cdot 62\end{array}$ & $\begin{array}{l}750 \\
0.65\end{array}$ & $\begin{array}{l}800 \\
0 \cdot 68\end{array}$ & $\begin{array}{c}850 \\
0 \cdot 70\end{array}$ & $\begin{array}{r}900 \\
0.72\end{array}$ & $\begin{array}{r}950 \\
0 \cdot 73\end{array}$ & $\begin{array}{r}1000 \\
0.75\end{array}$ \\
\hline $\begin{array}{l}\text { Temp. }{ }^{\circ} \mathrm{C} \text {. } \\
\text { Emissivity }\end{array}$ & $\begin{array}{r}1050 \\
0.78\end{array}$ & $\begin{array}{r}1100 \\
0.81\end{array}$ & $\begin{array}{r}1150 \\
0.84\end{array}$ & $\begin{array}{r}1200 \\
0.86\end{array}$ & $\begin{array}{l}1250 \\
0 \cdot 86_{5}\end{array}$ & $\begin{array}{l}1300 \\
0 \cdot 86\end{array}$ & & & \\
\hline
\end{tabular}

The data for lower temperatures obtained by Randolph and Overholser were-

\begin{tabular}{|c|c|c|c|}
\hline Temperature & $200^{\circ} \mathrm{C}$. & $400^{\circ} \mathrm{C}$. & $600^{\circ} \mathrm{C}$. \\
\hline Emissivity & 0.37 & $0 \cdot 42_{3}$ & $0 \cdot 47_{5}$ \\
\hline
\end{tabular}

TABLE XIX.

Corrections which must be added to the apparent readings of radiation pyrometers to give true temperatures when sighted on an oxidised nickel surface.

\begin{tabular}{|c|c|c|c|c|c|}
\hline Apparent temp. ${ }^{\circ} \mathrm{C}$. & 500 & 600 & 700 & 800 & 900 \\
\hline Correction & $120^{\circ}$ & $110^{\circ}$ & $100^{\circ}$ & $95^{\circ}$ & $85^{\circ}$ \\
\hline Apparent temp. ${ }^{\circ} \mathrm{C}$. & 1000 & 1100 & 1200 & & 1250 \\
\hline Correction & $75^{\circ}$ & $65^{\circ}$ & $55^{\circ}$ & & $50^{\circ}$ \\
\hline
\end{tabular}


II. Iron Oxide.-The emissivity of iron oxide is of considerable importance technically, since it permits of correction to the readings of radiation pyrometers when taking the temperatures of billets, rails, etc.

Burgess and Foote made observations on the same lines as those described above in the case of nickel ; in this case, however, electrically heated iron tubes of various sizes were employed as radiators.

The results are given in Table $\mathrm{XX}$.

TABLE XX.

\begin{tabular}{|l|c|c|c|c|c|c|c|c|}
\hline True temp. ${ }^{\circ} \mathrm{C}$. & 500 & 600 & 700 & 800 & $900_{1}$ & $1000_{1}$ & $1100_{1}$ & 1200 \\
\hline Emissivity . & 0.85 & 0.85 & 0.86 & 0.87 & 087 & 0.88 & 0.88 & 0.89 \\
\hline $\begin{array}{c}\text { Correction to } \\
\text { apparent temp. }\end{array}$ & $30^{\circ}$ & $30^{\circ}$ & $35^{\circ}$ & $35^{\circ}$ & $40^{\circ}$ & $40^{\circ}$ & $45^{\circ}$ & \\
\hline
\end{tabular}

It is possible to calibrate a total radiation pyrometer to give approximately true temperatures when sighted on an oxide surface by inserting a resistance coil in series with the indicator when standardising on the customary "black body" furnace. The value of the resistance can be calculated from the constants of the instrument.

Temperature gradient through the oxide layer.-Iron oxide is a comparatively poor heat conductor, consequently it might be expected that the true surface temperature would be appreciably below that of the body of the metal.

Experiments with a thermocouple inside the tube to give the true temperature showed that the gradient through the oxide was considerable and apparently independent of the size of the tube. It would appear that the thickness of the oxide layer is automatically rendered of the same order of magnitude for different times of heating by the flaking off which occurs.

Data obtained by Burgess and Foote concerning this gradient are in good agreement with those obtained by Burgess, Crowe, Rawdon, and Waltenberg on rail sections, the couple being inserted in a small hole drilled parallel to the length of the rail and as near the oxide as possible.

Temp. inside layer , outside,"

\begin{tabular}{l|l}
$610^{\circ} \mathrm{C}$. & $715^{\circ} \mathrm{C}$. \\
$600^{\circ} \mathrm{C}$. & $700^{\circ} \mathrm{C}$.
\end{tabular}

$$
\begin{aligned}
& 820^{\circ} \mathrm{C} \text {. } \\
& 800^{\circ} \mathrm{C} \text {. }
\end{aligned}
$$

$930^{\circ} \mathrm{C}$. $900^{\circ} \mathrm{C}$. $1080^{\circ} \mathrm{C}$. $1000^{\circ} \mathrm{C}$.

These results show that any method of obtaining the temperature of rails, ingots, etc., by observations of the surface temperature, is liable to serious error unless account is taken of the gradient through the oxide film.

Emissivity of molten metals. - The total radiation pyrometer is of very limited use with molten metal surfaces. Such surfaces can 
never be freed from haze or fog, and the radiation from the walls of the furnace or crucible reflected at the molten surface is apt to produce serious errors.

Burgess has made some observations on the difference between the apparent and real temperatures in the case of metallic copper and cuprous oxide surfaces, using a Féry pyrometer.

The following relationships were found to be approximately true. In these equations $t$ is the true temperature and $\mathrm{F}$ the apparent.

Molten copper, clear surface-

$$
t=3.55 \mathrm{~F}-1018
$$

Surface covered by cuprous oxide-

$$
t=1 \cdot 41 \mathrm{~F}-169
$$

The difference between the apparent temperatures-when the pyrometer was first sighted on the clear copper surface and then on the oxide surface, both being at the same temperature-amounted to as much as $300^{\circ} \mathrm{C}$.

The apparent freezing-point of copper (clear surface) was found to be $600^{\circ} \mathrm{C}$. compared with the true value of $1083^{\circ} \mathrm{C}$.

The emissivities of the two surfaces at various temperatures are given in Table XXI.

\begin{tabular}{|c|c|c|c|}
\hline Temperat ure ${ }^{\circ} \mathrm{C}$. & $\underset{\text { (molten copper). }}{\text { Emiseity }}$ & Temperature ${ }^{\circ} \mathrm{C}$. & $\begin{array}{l}\text { Emiseivity } \\
\text { (caprous oxhle). }\end{array}$ \\
\hline $\begin{array}{l}1075 \\
1125 \\
1175 \\
1225 \\
1275\end{array}$ & $\begin{array}{l}0.16 \\
0.15 \\
0.15 \\
0.14 \\
0.13\end{array}$ & $\begin{array}{r}800 \\
900 \\
1000 \\
1100\end{array}$ & $\begin{array}{l}0.66 \\
0-60 \\
0-56 \\
0.54\end{array}$ \\
\hline
\end{tabular}

TABLE XXI.

Thwing has made some observations on the emissivities of both molten iron and molten copper relative to that of iron in the solid state (presumably oxidised). No details are given concerning the experiments. $\mathrm{He}$ states that molten cast iron at $1300^{\circ} \mathrm{C}$. to $1400^{\circ} \mathrm{C}$. has an emissivity of 0.29 that of the solid metal. Mild steel (molten) at $1600^{\circ} \mathrm{C}$. has a relative coefficient of $0 \cdot 28$, which coefficient appears to hold up to $1800^{\circ} \mathrm{C}$. Molten copper has an emissivity of 0.14 that of solid iron.

Some of the experiments appear to have been made on the streams of molten metals issuing from the furnaces.

Absorption in the medium through which the radiation passes. - The radiation has generally to pass through a gaseous medium before reaching the pyrometer. At present the information available 
concerning the effect of any absorption by the medium on pyrometric observations is very scanty.

The subject is complicated by the fact that most gases and vapours have fairly sharply defined absorption bands, and that the distribution of energy among the wave-lengths of the continuous spectrum emitted by a "black body" varies with the temperature. Should one of the absorption bands coincide with the maximum energy wave-length of the spectrum its influence would be very marked, whereas at another temperature that particular wave-length might contain but a very small fraction of the total energy in the spectrum, consequently the loss by absorption would be insignificant.

- Tyndall, about 1859, made a thorough investigation of the diathermancy of gases and vapours. The apparatus employed consisted of a brass tube closed at the ends by plates of rock salt. Facing one end of the tube was a source of radiation, such as a cube containing boiling water or a glowing spiral of platinum. At the other end was placed a thermopile. - When the interior of the tube was exhausted the deflection of the galvanometer connected with the thermopile was reduced to zero by bringing up a compensating cube to the other face of the thermopile. The gas under test was then introduced into the tube ;

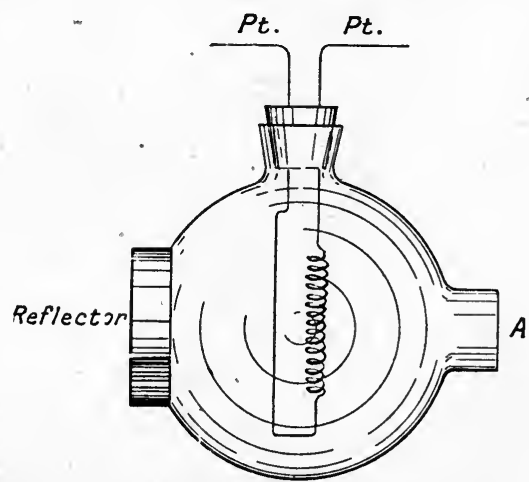

Fig. 57.- Mounting of platinum spiral.

if it exerted any absorption effect the galvanometer needle would be deflected. The fraction of radiation absorbed could be obtained by observing the full deflection produced when a screen was interposed between the thermopile and the tube. The compensating cube then produced the same effect as the radiation which previously traversed the exhausted tube.

Tyndall found that air, oxygen, hydrogen, and nitrogen, if carefully purified, exerted no sensible absorption, while water vapour and carbon dioxide had a marked absorption. Vapours of organic compounds also had a considerable absorbing effect.

Table XXII. summarises the results obtained for a few of the substances investigated by him. The source of radiation was a platinum 
spiral enclosed in a glass globe $3^{\prime \prime}$ in diameter with an opening at A : shown in Fig. 5\%. 'The metallic reflector was used to augment the flux of radiation without sensibly altering its quality.

In some lamps the spiral was in vacuo, a plate of rock salt being employed for the window.

\section{TABLE XXII.}

Percentage absorption of various gases.

Source of radiation: a platinum spiral at various temperatures.

\begin{tabular}{|l|r|r|r|r|}
\hline \multirow{2}{*}{ Gas. } & \multicolumn{3}{|c|}{ Appearance of spiral. } \\
\cline { 2 - 5 } & Barely visille. & Bright red. & White hot. & Near fusion. \\
\hline & & & & \\
\hline & & $4 \cdot 5$ & $2 \cdot 9$ & $2 \cdot 5$ \\
Carbon disulphide & $9 \cdot 1$ & $6 \cdot 3$ & $5 \cdot 6$ & $23 \cdot 7$ \\
Chloroform & $43 \cdot 4$ & $31 \cdot 4$ & $25 \cdot 9$ & $21 \cdot 3$. \\
Fulphuric ether & $45 \cdot 2$ & $31 \cdot 9$ & $25 \cdot 1$ & \\
\hline
\end{tabular}

\section{REFERENCES TO CHAPTER VI.}

Randolph and Overholser, Phys. Rev., 2, p. 144 (1913).

Burgess and Foote, Bull. Bur. Stds., 2, No. 1 (1914).

Whipple, "Coefficient of Reflection of Gold," Engineering, 90, p. 142 (1910).

Burgess, Crowe, Rawdon, and Waltenberg, Bull. Bur. Stds., Tech. Paper No. 38.

Burgess (molten copper), Bull. Bur. Stds., 6 (1909-10).

Thwing, 'Phys. Rev., 26, p. 190 (1908).

Tyndall, "Heat a Mode of Motion," 12th impr. (1904).

Coblentz, Proc. Nat. Acad. Sci., 3, p. 504 (1917). 


\section{CHAPTER VII}

\section{THE DISTRIBUTION OF ENERGY IN THE SPECTRUM OF A "FULL RADIATOR" AND THE PRINCIPLES OF OPTICAL PYROIMETRY}

Experimental work on the distribution of energy in the spectrum-Radiation laws :

Wien's, Planck's, and Rayleigh's-Variation with temperature of "total brightness"-Commercial forms of optical pyrometers : disappearing filament type and the polarising type-Theory and calibration of the instrumentsAbsorption devices-Determination of the " effective wave-length" transmitted by red glass-Extension of the scale of optical pyrometers above $1500^{\circ} \mathrm{C}$. Relative merits of the two types-Measurement of temperature in terms of total intrinsic brilliancy.

The distribution of energy in the spectrum of a "full radiator." --The theoretical work of Boltzmann established the fourthpower law of radiation, which received ample experimental verification by Lummer and Pringsheim.

The next advance in the development of the theory was made by Wien in 1896, who deduced a number of relationships between the radiation in the spectrum of a "full radiator" and the temperature.

The first deduction is known as Wien's displacement law :

$$
\lambda_{m}=b \mathrm{~T}^{-1} \quad \text { or } \quad \mathrm{E}_{m}=k \mathrm{~T}^{5}
$$

where $\lambda_{m}$ is the wave-length of maximum energy and $\mathbf{E}_{m}$ is the maximum energy ordinate.

For the distribution of the energy among the various wave-lengths in the spectrum Wien deduced the expression

$$
\mathrm{E}_{\lambda} d \lambda=c \lambda^{-5} f(\lambda \mathrm{T})
$$

in which $f(\lambda \mathrm{T})$ could not be determined by purely thermodynamical reasoning.

By making certain arbitrary assumptions concerning the radiation emitted by vibrating gaseous molecules, he succeeded in resolving the function of $\lambda \mathrm{T}$, and obtained the relationship

$$
\mathrm{E}_{\lambda} d \lambda=c_{1} \lambda^{-5} e^{-\frac{c_{2}}{\lambda \mathrm{T}}}
$$

for the distribution of energy among the various wave-lengths in the spectrum. 
Experimental work, which will be referred to later, showed that the above expression only represented the facts for a limited range of $\lambda$ and T. Since that time various attempts, based on plausible assumptions, have been made to discover the correct expression, but without success.

The one formula which does represent the experimental data closely under all conditions is that of Planck's-

$$
\mathrm{E}_{\lambda} d \lambda=c_{1} \lambda^{-5} \frac{1}{e^{\frac{c_{2}}{\lambda T}}-1}
$$

This expression, however, is based on assumptions which are inconsistent with the fundamental laws of electrodynamics.

The subject has aroused considerable interest during recent years and reference must be made to the literature of the subject for fuller information.*

It will be observed that for small values of $\lambda$ and 'T Planck's equation approximates to that of Wien's, and the concordance is sufficiently close for wave-lengths in the visible spectrum to permit of the use of the simple form of Wien's for the range of temperature covered in practical optical pyrometry.

Experimental study of the distribution of energy in the spectrum of a "full radiator " at various temperatures.-In 1899 Lummer and Pringsheim published a further contribution to the subject. Their experiments on this occasion were directed to the determination of the distribution of energy in the spectrum of a "full radiator." At first they employed the various types of uniformly heated enclosures, which they had constructed for their experiments to test the Stefan-Boltzmann law. Later they introduced many practical improvements in the apparatus, and, by basing their method of measuring temperature on the fourth-power law, they were able to continue their experiments to very high temperatures. This procedure also led to a great simplification in the form of their "full radiator," which could then be reduced to an electrically heated carbon tube.

Description of the experimental arrangements.-The carbon tube furnace construction is shown in Fig. 58.

The tube was of uniform wall thickness (1.2 millimetres), $34 \mathrm{cms}$. long, and $1 \mathrm{~cm}$. internal diameter. The ends were inserted into heavy carbon blocks, copper-plated and fixed into metallic clamps.

A stream of nitrogen was passed into the cap at the mouth of the furnace to diminish oxidation.

The plug $\mathbf{P}$ (in the centre of the tube) and the left half of the furnace was equivalent to a "black body" in respect of radiation.

The spectrum was produced by a fluor spar prism, and corrections applied to convert the prismatic to normal energy curves by means of the known dispersion curve of fluor spar.

* See list at end of chapter. 
The distribution of energy was measured by means of a linear bolometer, which was enclosed in an air-tight case to diminish the absorption effects of carbon dioxide and water vapour. wide.

The bolometer consisted of a single strip of platinum foil $0.6 \mathrm{~mm}$.

The distribution of energy corresponding to wave-length is shown graphically in Fig. 59.

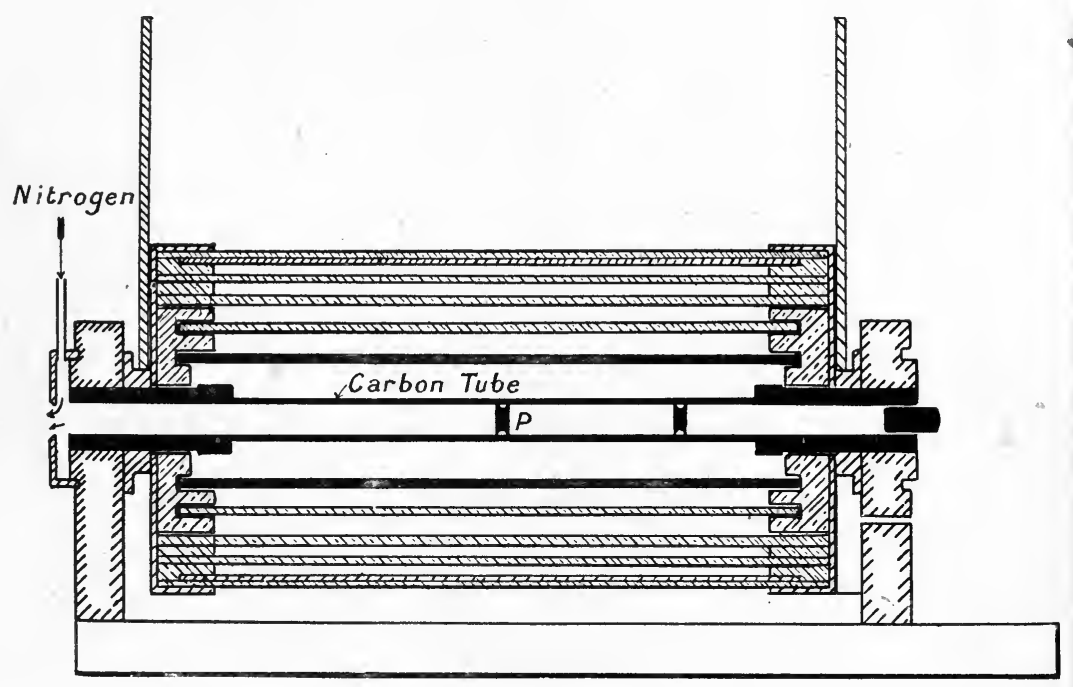

FIG. 58.-Diagram illustrating the construction of the carbon tube furnace.

The shaded areas on the curves represent the absorption effects of the intervening medium.*

From these curves the values of $\lambda_{m}$ and the energy corresponding to $\mathrm{E}_{m}$ could be directly obtained.

The experimental results were in agreement with the two laws-

$$
\begin{aligned}
& \lambda_{m} \mathrm{~T}^{-1}=\text { constant }=\mathrm{A} \text {, say } \\
& \mathrm{E}_{m} \mathrm{~T}^{-5}=\quad, \quad=\mathbf{B}
\end{aligned}
$$

The distribution formula-

$$
\mathrm{E}_{\lambda} d \lambda=c_{1} \lambda-5 e^{-\frac{c_{2}}{\lambda T}}
$$

was found to. be only approximately true, as shown graphically by the dotted lines. Table XXIII. summarises the numerical data.

* Carbon dioxide has an absorption band at $4 \cdot 27 \mu$, while water vapour has a number of bands in the neighbourhood of $6 \mu$, giving a maximum about $5 \cdot 95 \mu$. 
DISTRIBUTION OF ENERGY IN THE SPECTRUM 109

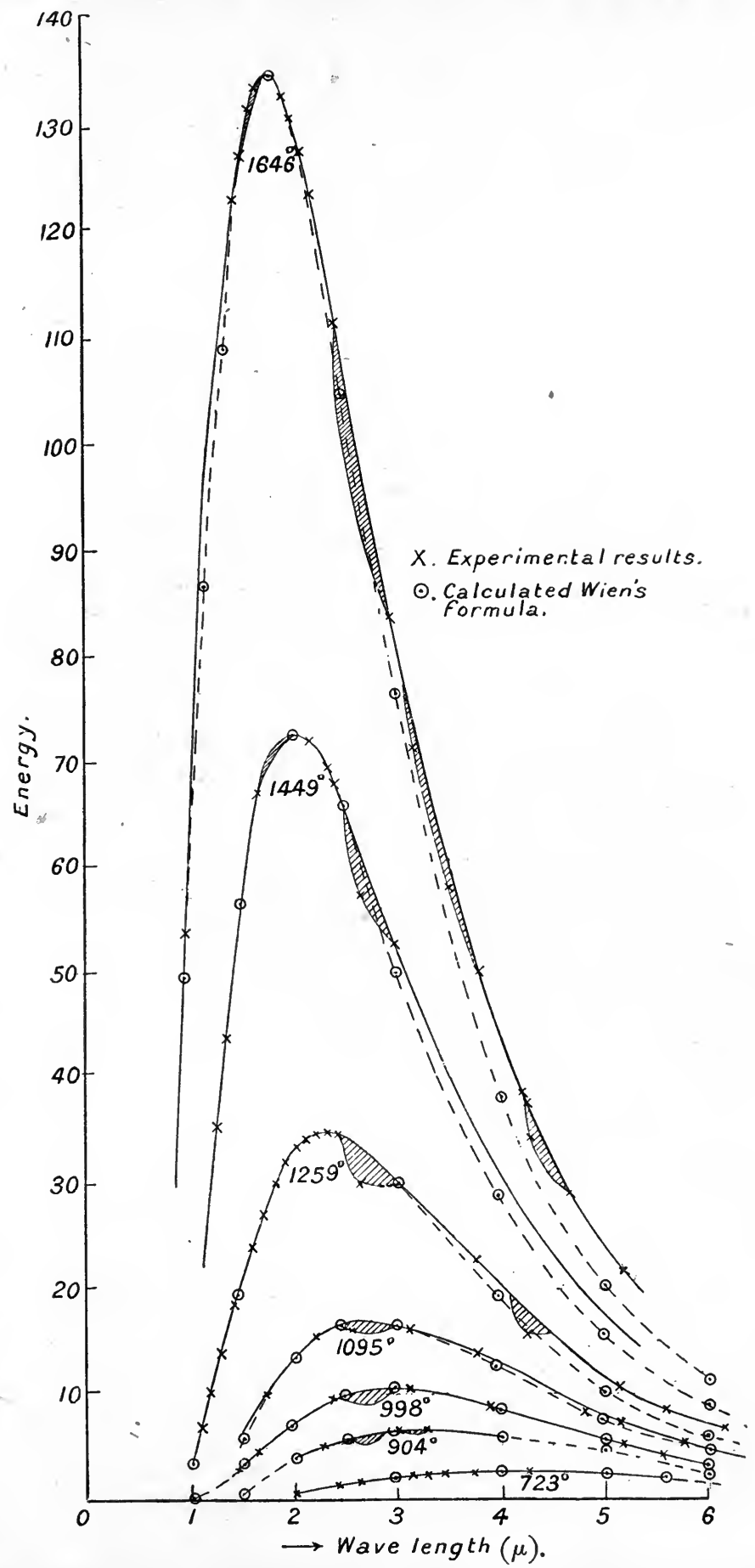

FIG. 59.-Diagram showing the distribution of energy corresponding to wave-length. 
TABLE XXIII.

\begin{tabular}{|c|c|c|c|c|c|c|}
\hline $\begin{array}{l}\text { Temp. abs. } \\
\text { oC. }\end{array}$ & $\lambda_{m}$. & $\mathrm{E}_{m}$ & From $\lambda_{m^{T^{-1}}}=A$. & From $\mathbf{E}_{m} \mathbf{T}^{-5}=\mathrm{B}$ & $\begin{array}{l}=\sqrt[5]{\frac{\mathrm{E}_{m}}{\mathrm{~B}_{\text {mean }}}} \\
{ }^{\circ} \mathrm{C} .\end{array}$ & $\begin{array}{l}\text { Diff. } T_{\text {obs }} \\
-T_{\text {calc. }}\end{array}$ \\
\hline $\begin{array}{l}621 \cdot 2 \\
723 \\
908 \cdot 5 \\
998 \cdot 5 \\
1094 \cdot 5 \\
1259 \cdot 0 \\
1460 \cdot 4 \\
1646\end{array}$ & $\begin{array}{l}4 \cdot 53 \\
4 \cdot 08 \\
3 \cdot 28 \\
2 \cdot 96 \\
2 \cdot 71 \\
2 \cdot 35 \\
2 \cdot 04 \\
1 \cdot 78\end{array}$ & $\begin{array}{c}2 \cdot 026 \\
4 \cdot 28 \\
13 \cdot 66 \\
21 \cdot 50 \\
34 \cdot 0 \\
68 \cdot 8 \\
145 \cdot 0 \\
270 \cdot 6\end{array}$ & $\begin{array}{l}2814 \\
2950 \\
2980 \\
2956 \\
2966 \\
2959 \\
2979 \\
2928\end{array}$ & $\begin{array}{l}2190 \times 10^{-7} \\
2166 \\
2208 \\
2166 \\
2164 \\
2176 \\
2184 \\
2246\end{array}$ & $\begin{array}{r}621 \cdot 3 \\
721 \cdot 5 \\
910 \cdot 1 \\
996 \cdot 5 \\
1092 \cdot 3 \\
1257 \cdot 5 \\
1460 \cdot 0 \\
1653 \cdot 5\end{array}$ & $\begin{array}{l}+0.1 \\
-1.5 \\
+1.6 \\
-2.0 \\
-2.2 \\
-1.5 \\
-0.4 \\
+7.5\end{array}$ \\
\hline & & Mean & 2940 & $2188 \times 10^{-7}$ & & \\
\hline
\end{tabular}

The above data refer to the early series, in which the temperatures were obtained by means of a thermocouple. Since the couple had been calibrated to $1000^{\circ} \mathrm{C}$. only, temperatures above this point are dependent on extrapolation of the thermoelectric scale. The variations in the values of $A$ are within the limits of error possible in the determination of $\lambda_{m}$, and it will be observed that the values of $B$ depend on the 5 th power of the temperature.

The departure from Wien's law is systematic; this can be seen by comparing the various values of the constants $c_{1}$ and $c_{2}$, corresponding to increasing wave-lengths:-

\begin{tabular}{|c|r|r|r|r|r|}
\hline$\lambda$ & $1 \cdot 21 \mu$ & $1 \cdot 96 \mu$ & $2 \cdot 20 \mu$ & $3 \cdot 63 \mu$ & $4 \cdot 56 \mu$. \\
\cline { 2 - 3 } $\begin{array}{c}c_{1} \times 10^{-11} \\
c_{2} \text { (Micron-degrees) }\end{array}$ & $\begin{array}{rlr}1,067 \\
13,510\end{array}$ & $\begin{array}{r}1,219 \\
13,810\end{array}$ & $\begin{array}{r}1,449 \\
14,240\end{array}$ & $\begin{array}{r}1,771 \\
14,800\end{array}$ & $\begin{array}{r}2,261 \\
13,510\end{array}$ \\
\hline
\end{tabular}

In the series at higher temperatures with the carbon tube furnace, it was possible to measure the energy of still greater wave-lengths, and the results show that Wien's law is not applicable to values of $\lambda^{\prime} \mathrm{T}$ exceeding 3000. The departure from the formula is shown by the following values of $\lambda$ and $c_{2}$ :--

\begin{tabular}{|l|c|c|c|}
\hline$\lambda$ & $8 \cdot 3 \mu$ & $12 \cdot 3 \mu$ & $17 \cdot 9 \mu$ \\
$c_{2}$ & 18,500 & 24,800 & 31,700 \\
\hline
\end{tabular}

Planck's formula.-Planck's formula reduces to that of Wien's for small values of $\lambda \mathrm{T}$, consequently experimental proof of the validity of Wien's law is equally applicable to Planck's formula. 


\section{DIS'TRIBU'TION OF ENERGY IN THE SPECTRUM 111}

It now remains to consider the evidence for Planck's formula when $\lambda \mathrm{T}$ is so large that Wien's law is not capable of representing the results.

Rubens and Kurlbaum studied the radiation of wave-length $51 \cdot 2 \mu$ in the "black body" spectrum of a radiator at various temperatures.

This particular wave-length was chosen for practical reasons. If radiation of all wave-lengths is successively reflected from rock-salt surfaces, that corresponding to the wave-length 51:2 $\mu$ alone receives metallic reflection; the rest is either absorbed or refracted.

Advantage was taken of this property to isolate monochromatic radiation of long wave-length from the continuous "black body" spectrum.

In Table XXIV. the experimental results are compared with those obtained by calculation from the various formulæ.

It will be observed that Planck's formula represents the experimental results with a fair degree of accuracy, although subsequent investigations have shown that the divergences are greater than the possible error of experiment.

\section{TABLE XXIV.}

$$
\lambda=51 \cdot 2 \mu \text {. }
$$

\begin{tabular}{|c|c|c|c|c|}
\hline Temp. abs. ${ }^{\circ} \mathrm{C}$. & $\mathrm{E}_{\lambda} d_{\lambda}$ (observed). & Calc. Wien's. & Calc. Rayleigh's. & Calc. Planck's. \\
\cline { 2 - 5 } & & $-121 \cdot 5$ & -20 & $-23 \cdot 8$ \\
85 & $-20 \cdot 6 *$ & $-107 \cdot 5$ & -19 & $-21 \cdot 9$ \\
193 & $-11 \cdot 8$ & $-48 \cdot 0$ & $-11 \cdot 5$ & -12.0 \\
293 & 0 & 0 & 0 & 0 \\
523 & $+31 \cdot 0$ & $+63 \cdot 5$ & $+28 \cdot 5$ & $+30 \cdot 4$ \\
773 & $+64 \cdot 5$ & +96 & +62.5 & $+63 \cdot 8$ \\
1023 & $+98 \cdot 1$ & +118 & +97 & $+97 \cdot 2$ \\
1273 & $+132 \cdot 0$ & +132 & +132 & +132 \\
1523 & $+164 \cdot 5$ & +141 & +167 & +166 \\
1773 & $+196 \cdot 8$ & $+147 \cdot 5$ & +202 & +200 \\
$\infty$ & & +194 & $\infty$ & $\infty$ \\
\hline
\end{tabular}

Experiments with the wave-lengths $\lambda=24 \cdot 0 \mu$ and $\lambda=31 \cdot 6 \mu$ were also in accord with Planck's formula.

Rayleigh's formula-

$$
\mathrm{E} d \lambda=\frac{c_{1}}{\lambda^{4}} \frac{\mathrm{T}}{e^{\frac{c_{2}}{\lambda^{\top}}}}
$$

is based on plausible assumptions, consistent with the law of electrodynamics, and fits the experimental results for large values of $\lambda \mathrm{T}$, failing for values of $\lambda^{\prime} \mathrm{T}$ less than 3000 .

For large values of $\lambda \mathrm{T}$ Planck's formula reduces to that of Rayleigh's.

Variation with temperature of the "total brightness." To verify the relationship

$$
\mathbf{E}_{m}=\mathbf{K}^{\prime} \mathbf{T}^{5}
$$

* The negative values are due to the fact that, when the radiator was below room temperature $\left(20^{\circ} \mathrm{C}.\right)$, it received more energy from the thermopile than it emitted. 
Lummer and Pringsheim employed a Lummer-Brodhun spectro-photometer, and worked with different parts of the luminous spectrum from red to violet. Owing to the rapid increase in the intensity of the lumimous radiation with temperature, it was necessary to employ a number of absorption plates; at the highest temperature the intensity was reduced to $\frac{1}{8000}$ part to bring it within measurable limits.

\begin{tabular}{|c|c|c|c|c|}
\hline $\begin{array}{c}\text { Temp. by 4th-power } \\
\text { distances) }\end{array}$ & $\begin{array}{l}\text { v (various } \\
\ldots \quad \quad \ldots\end{array}$ & $\begin{array}{l}{ }^{\circ} \mathrm{C} . \\
2345\end{array}$ & $\begin{array}{c}{ }^{\circ} \mathrm{C} . \\
2348\end{array}$ & $\begin{array}{l}{ }^{\circ} \mathrm{C} . \\
2339\end{array}$ \\
\hline Temp. by $\mathrm{E}_{m}=\mathrm{KT}^{5}$ & $\ldots \quad \ldots$ & 2325 & 2327 & 一 \\
\hline
\end{tabular}

They were able to obtain an accuracy of about $\pm 20^{\circ} \mathrm{C}$. with the total radiation pyrometer, and the calculated temperatures were in agreement within these limits of accuracy.

The relationship $\lambda_{m} \mathrm{~T}=$ constant was also checked and the value 2930 obtained for the constant of a "full radiator." When the radiation from polished platinum was studied the constant was found to be 2620.* Hence it is possible to estimate roughly the temperature of any object whose radiation is intermediate in character between that from a perfectly black body and polished platinum by determining $\lambda_{m}$ by means of a bolometer and a dispersion apparatus.

'This has been done for a number of radiators by Lummer and Pringsheim. The maximum value of ' $\mathrm{T}$ is obtained from $\frac{2930}{\lambda_{m}}$ and the minimum from $\frac{2620}{\lambda_{m}}$.

TABLE XXV.

\begin{tabular}{|c|c|c|c|}
\hline Hot object. & $\lambda_{m}$ & $\mathrm{~T}_{\max .}{ }^{\circ} \mathrm{C}$ & $\mathrm{T}_{\min .}{ }^{\circ} \mathrm{C}$. \\
\hline $\begin{array}{l}\text { Arc light } \\
\text { Nernst lamp } \\
\text { Welsbach mantle } \\
\text { Incandescent lamp } \\
\text { Candle } \\
\text { Argand burner }\end{array}$ & $\begin{array}{l}0 \cdot 7 \mu \\
1 \cdot 2 \\
1 \cdot 2 \\
1 \cdot 4 \\
1 \cdot 5 \\
1 \cdot 55\end{array}$ & $\begin{array}{l}4200 \text { abs. } \\
2450 \\
2450 \\
2100 \\
1960 \\
1900\end{array}$ & $\begin{array}{l}3750 \mathrm{abs} . \\
2200 \\
2200 \\
1875 \\
1750 \\
1700\end{array}$ \\
\hline
\end{tabular}

Comparison of Wein's law and Stefan Boltzmann's law to $2800^{\circ}$ C. - The work of Lummer and Pringsheim and their contemporaries was carried out before the researches of Holborn and Valentiner,

* There is no theoretical basis for the application of the law to the radiation from platinum, and subsequent investigations have shown that $\lambda_{m} \mathrm{~T}$ is not a constant for polished metallic surfaces, but increases with temperature. The constant value obtained by Lummer and Pringsheim is due possibly to the small range of temperature employed, or to lack of polish on the radiating surface. 
of Jacquerod and Perot, and of Day and Sosman, had established the high temperature scale in terms of the gas thermometer, consequently it is difficult to form any precise estimates of the limits of accuracy to which the radiation laws may be regarded as proven at high temperatures. Recently Mendenhall and Forsythe have made a comparison up to $2800^{\circ} \mathrm{C}$. between two pyrometers, one based on "fourth-power" law and the other on Wien's law. The pyrometers were calibrated by observations of the melting-points of gold and palladium, the values for which, on the scale of the nitrogen gas thermometer, had been determined by Day and Sosman.

The optical pyrometer.-This was of the disappearing filament type described on p. 114. The principle of the instrument is that of a telescope.- An image of the hot object is superposed on the filament of a small electric lamp. Matching is effected by making the apparent brightness of the image identical with that of the filament by varying the current through the latter.

Since Wien's law is applicable to monochromatic radiation and not the entire visible spectrum, it is necessary to isolate as narrow a spectral range as possible. Generally this is effected by the use of a piece of good red glass; in the present case, however, they employed a spectroscopic eyepiece. The latter has the theoretical advantage of giving a narrower band and consequently a nearer approach to the ideal conditions contemplated by Wien's law. The width of the band transmitted was determined and found to be $200 \mathrm{~A} . \mathrm{U}$. $(0 \cdot 02 \mu)$ with a centre at $\lambda=0.658 \mu$.

The calibration of the instrument, i.e. the relationship between intensity of radiation and the current necessary to match it, was effected by the use of a system of rotating discs of measured aperture.

This method of reducing the intensity has already been referred to in connection with total radiation pyrometers, and the same principle is involved here.

Taking the logarithmic form of W'ien's law,

$$
\log \mathrm{E}_{\lambda}=\mathrm{K}_{1}-\frac{c_{2}}{\lambda} \cdot \frac{1}{\mathrm{~T}}
$$

If balance was obtained with clear aperture on a "black body" at temperature $T_{1}$, and an apparent temperature $T_{2}$ was obtained through a sector of transmission ratio $\mathrm{S}$, then

$$
\log \frac{1}{\mathrm{~S}}=\frac{c_{2} \log e}{\lambda}\left(\frac{1}{\mathrm{~T}_{1}}-\frac{1}{\mathrm{~T}_{2}}\right)
$$

so that, by a series of observations on a furnace maintained at a constant known temperature, it was possible, by employing a series of discs with various values of $S$, to calibrate the pyrometer over a range of temperature. The apertures of the discs were measured by means of a dividing engine. Two steady temperatures were used as checks on the calibration. 
The minimum aperture enıployed was about " $\frac{1}{180}$." This proved difficult to make accurately, and on measurement was found to be $2^{\circ} \mathbf{1}^{\prime} 50^{\prime \prime}$ instead of $2^{\circ}$. 'This error, however, would only produce a divergence of $5^{\circ} \mathrm{C}$. in the computed scale if the nominal value of $2^{\circ}$ angle had been taken.

The apparatus employed in the intercomparison is shown in Fig. 50, and the results are summarized below :-

TABLE XXVI.

\begin{tabular}{|c|c|c|c|}
\hline No. of comparisons. & Temp. ${ }^{\circ} \mathrm{C}$. & $\mathbf{T}_{\text {optical }} \mathbf{T}_{\text {total radiation. }}$ & Range of observations. \\
\cline { 2 - 4 } 9 & 1750 & & $2^{\circ}$ \\
7 & 2200 & Less than $\pm 0.5^{\circ}$ & 4 \\
3 & 2500 & About " $+2^{\circ}$ & 4 \\
4 & 2800 &,$"-4^{\circ}$ & 7 \\
\hline
\end{tabular}

The difference is systematic but not greater than the possible error of experiment. By an alteration in the assumed value of either $c_{2}$ or $\lambda$ the systematic difference could be eliminated. For example, if, instead of $0.658 \mu$, the value $0.657 \mu$ is taken, the differences disappear.

The total radiation pyrometer. - It will be observed from a study of Fig. 50, page 87, that the "total radiation" pyrometer was enclosed in the evacuated chamber containing the furnace, while the optical pyrometer observations were taken through a glass window. A small correction * was necessary for the absorption of this window in the visible radiation.

\section{OPTICAL PYROIMETRY}

While theoretically the "total radiation" type of pyrometer has the advantage of being based on principles whose validity have received ample confirmation, the optical type of pyrometer possesses considerable practical advantages in so much that it does not demand an object of large dimensions to sight upon. Also the influence of imperfect "black body" conditions are not so serious as in the case of the total radiation types.

Commercial forms of optical pyrometers.-The two common forms of optical pyrometers are the "disappearing filament" type and the "polarizing" type.

The disappearing filament type. - The original form of this type was invented by Morse; later Holborn and Kurlbaum introduced several refinements.

One practical form of the instrument, is shown diagrammatically in Fig. 60. 'The instrument is a telescope, in which the image of the hot object is focussed in a plane containing the filament of an electric lamp.

* The method of obtaining this correction is described on p. 123 . 
A red filter glass is fitted over the eyepiece, so that approximately monochromatic illumination is employed.

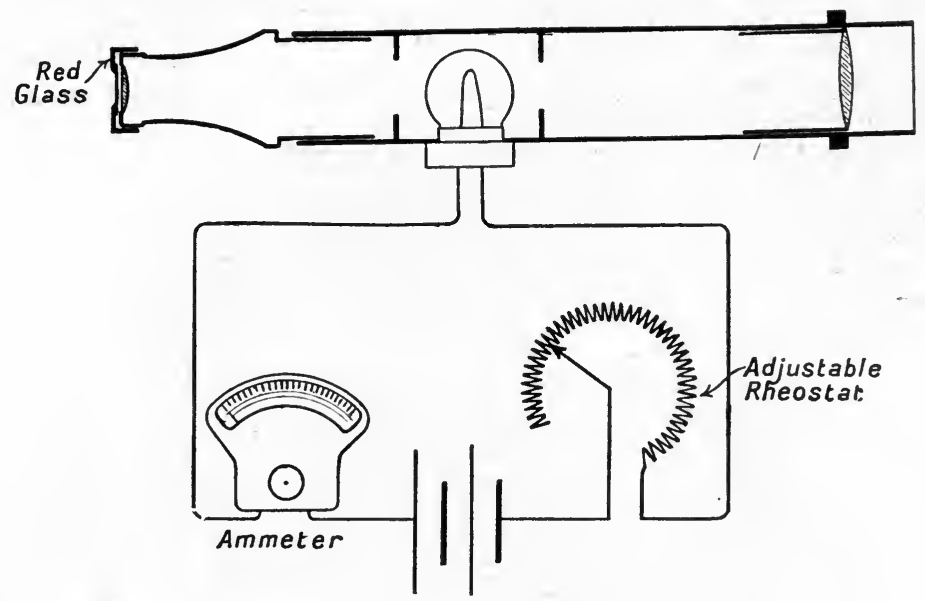

Fra. 60. Diagram of connections of the disappearing filament type of pyrometer.

Approximate theory.-Féry and Cheveneau investigated the relation between the energy dissipated in a carbon filament lamp and the temperature. When the watts expended in the lamps varied from 16.8 to 71.4 the temperature of the filament changed from about $1200^{\circ} \mathrm{C}$. to $1900^{\circ} \mathrm{C}$.

They found that energy expended varied approximately as the 4th power of the absolute temperature.

From this it would appear that at these temperatures for the lamps studied the energy is almost entirely dissipated in radiation. This conclusion is possibly not applicable to lamps now employed for optical pyrometer work. For it has been found that the hair-pin filaments $(0.17 \mathrm{~mm}$. diameter and $5 \mathrm{mms}$. long) of such lamps lose a considerable fraction of their energy by conduction along the leads. This accounts for the fact frequently observed that the lamp requires an appreciable interval to settle down to the steady state.

However, assuming with Féry and Chevenau that the energy dissipated varies as the 4th power of the absolute temperature, the next step is to obtain the relation between the intensity of a particular roavelength and the watts at various temperatures.

By Wien's law

\begin{tabular}{|c|c|}
\hline Since & $\begin{aligned} \mathrm{E}_{\lambda} d \lambda & =\mathrm{A} e^{-\frac{\mathrm{B}}{\mathrm{T}}} \\
\mathrm{T} & \propto \sqrt[4]{\mathrm{W}}\end{aligned}$ \\
\hline 'Ihen & $\mathrm{E}_{\lambda} d \lambda=\mathrm{A} e^{-\frac{B}{4 \sqrt{\mathrm{W}}}}$ \\
\hline
\end{tabular}




\section{METHODS OF MEASURING TEMPERATURE}

This relationship* was found to hold within 2 to 3 per cent. over the temperature range investigated.

So far as the writer is aware this formula has not been used to any extent in the calibration of pyrometers of this type.

Calibration of the instrument empirically.-The calibration of optical pyrometers can be readily effected by reference to a standardized thermocouple in an electric furnace arranged to give approximately full radiation by a series of diaphragms suitably disposed.

Fig. 61 shows a furnace arranged for optical pyrometer calibration up to $1370^{\circ} \mathrm{C}$.

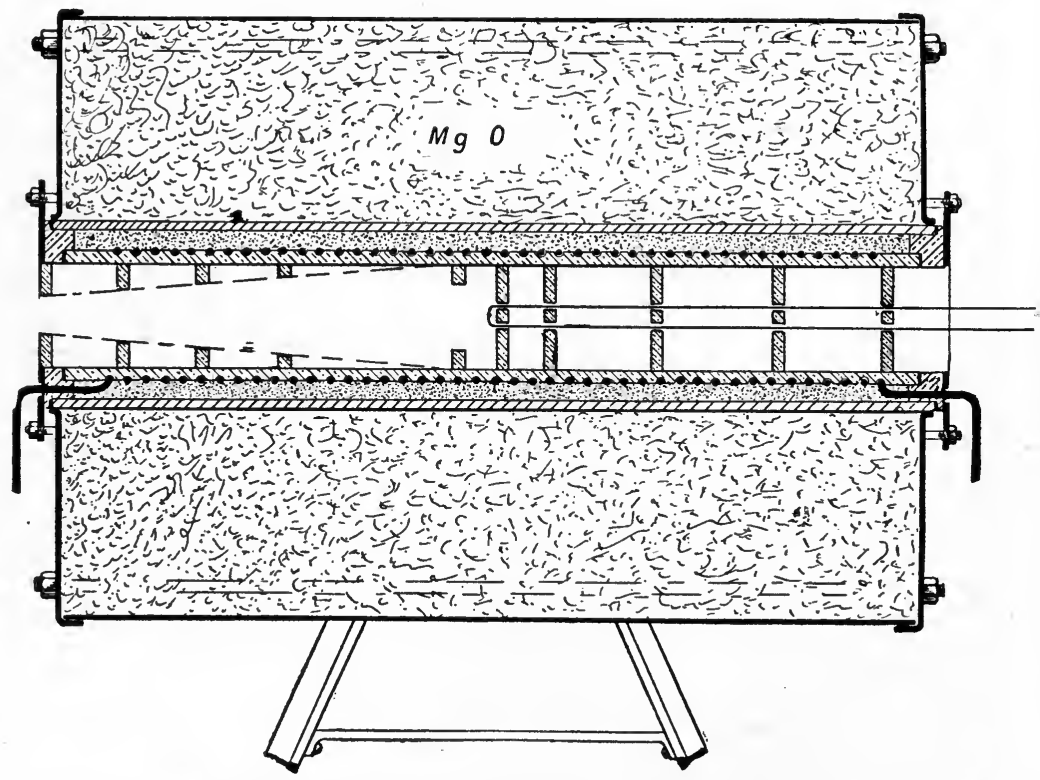

FIG. 61.-Diagram illustrating the construction of a furnace for optical pyrometer calibration.

The pyrometer is sighted upon the central diaphragm, which has the junction of a thermojunction on its surface to give the temperature of the enclosure.

The calibration of the disappearing filament type cannot be carried beyond $1400^{\circ} \mathrm{C}$. without the use of an absorbing glass, since the permanency of the resistance of the filament is liable to be affected by running for long periods to the top temperatures.

For representing the relationship between current and temperature a parabolic formula

$$
c=a+b t+c t^{2}
$$

is sufficiently accurate.

* The index for a platinum filament was $4 \cdot 6$. 
Absorption devices.-The absorbing device generally used with this type of instrument consists of two black glass mirrors inclined at at angle of $45^{\circ}$. In this arrangement the beam of light from the hot body is reflected twice at an angle of $45^{\circ}$ incidence and thereby weakened to about $\frac{1}{2} 00$ of its original intensity, thus allowing continuous observations to be made up to about $2700^{\circ} \mathrm{C}$. without risk of overrunning the pyrometer lamp.

Another form of absorption device is a piece of neutral-tinted glass interposed in the path of the beam.

The use of a rotating sectored disc has already been referred to in connection with the work of Mendenhall and Forsythe.* This method of reducing the intensity is not quite as convenient as the others.

Spectroscopic eyepiece.-Practically all of the disappearing filament type of optical pyrometers are provided with a red glass in the eyepiece to produce approximately monochromatic radiation. Even the best varieties of red glass give a spectrum band rather than a single wave-length and this frequently gives rise to troublesome differences of tint at high temperatures. A typical transmission curve for a good sample of red glass is shown in Fig. 62. It will be observed that the band extends from 0.6 to $0.7 \mu$ with a maximum at about $0.67 \mu$.

A narrower band would have advantages, both theoretical and practical, for work at high temperatures, and this object has been achieved by Mendenhall by the use of a spectroscopic eyepiece. He employs a small auxiliary eyepiece and a totally reflecting prism which slides in a side tube just behind the lamp. The images of the comparison filament and of the hot surface are thrown in sharp focus across the middle of the spectroscope slit

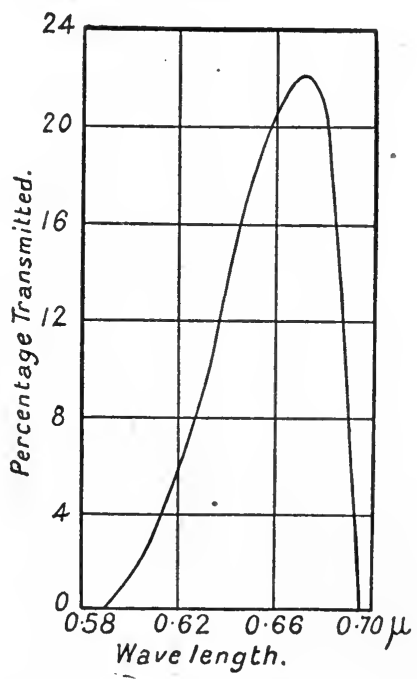

FIG. 62.-Type of transmission curve for a sample of red glass. by means of an intermediate achromatic lens, the primary image of the hot surface having previously been brought into the plane of the comparison filament by focussing in the usual way.

* When using a rotating sector in conjunction with a "disappearing filament" type of pyrometer, for the determination of the temperature of lamp filaments, they found that if the sector was mounted near the lens with the opening of the sector parallel to the axis of the filament when passing the centre of the lens, the definition was bad. On the other hand, if the opening was perpendicular to the filament the definition was quite good.

The best position for the sector is near the lamp, since then the definition is practically independent of the position of the opening of the sector relative to the filament when crossing the field. This trouble was not encountered when taking the temperature of large objects. 
The eyepiece and ocular slit of variable width are movable with a micrometer screw, giving about 500 divisions for the visible, and it is easy to work with an ocular slit covering not more than 25 A.U. $(=0.0025 \mu)$. The field then shows a central band due to the filament bordered by light from the hot object.

A comparative series of tests on the same object under the same conditions, employing in the one case a spectroscopic eyepiece, and in the other a piece of red Jena glass having a maximum ordinate at $\lambda=0.652 \mu$, is given below. The distribution of light in the transmission spectrum of the red glass was determined by spectrophotometric observations.

TABLE XXVII.

\begin{tabular}{|c|c|}
\hline $\begin{array}{c}\text { Temp. }{ }^{\circ} \mathrm{C} . \\
\text { Red glass. }\end{array}$ & $\begin{array}{c}\text { Temp. }{ }^{\circ} \mathrm{C} . \\
\text { Spectroscopic eyepiece. }\end{array}$ \\
\hline 1063 & 1062 \\
1858 & 1861 \\
1990 & 1990 \\
2000 & 1995 \\
2370 & 2380 \\
\hline
\end{tabular}

The polarizing type of optical pyrometer.-König in 1894 described a new type of spectrophotometer. In this instrument the two beams of light were resolved into two spectra and comparison effected between beams of identical colour throughout the spectrum. In 1901 Wanner applied the essential principles of this instrument to the design of an optical pyrometer. In this case the radiation from the hot object is the one beam while the light of constant intensity from an electric lamp supplies the comparison beam.*

'The essential features of the instrument will be understood from Fig. 63.

The radiation from the hot object is received through the circular hole $\mathbf{S}$ while the electric lamp illuminates the matt surface of the rightangled prism $P$, which in turn directs the light on to the circular hole $\mathrm{L}$ symmetrically disposed with $\mathrm{S}$ about the optical axis of the system.

'The lens $O$ renders the two beams parallel. $R$ is a Rochon prism, which splits each beam up into components polarized at right angles.

The function of the biprism lens $B$ is to produce deviation in the beams of such amount that an image from each of the two sources is brought into juxtaposition. On consideration it will be seen that the biprism splits each image up into two, thus bringing the total up to eight.

* The current through the lamp is maintained at a predetermined value by means of a rheostat and ammeter. From time to time the intensity of the beam given by the electric lamp is matched against that from an amyl acetate lamp by adjustment of the current. This renders the scale of the pyrometer independent of the permanency of the electric lamp. 
DISTRIBU'TION OF ENERGY IN 'THE SPECTRUM 119

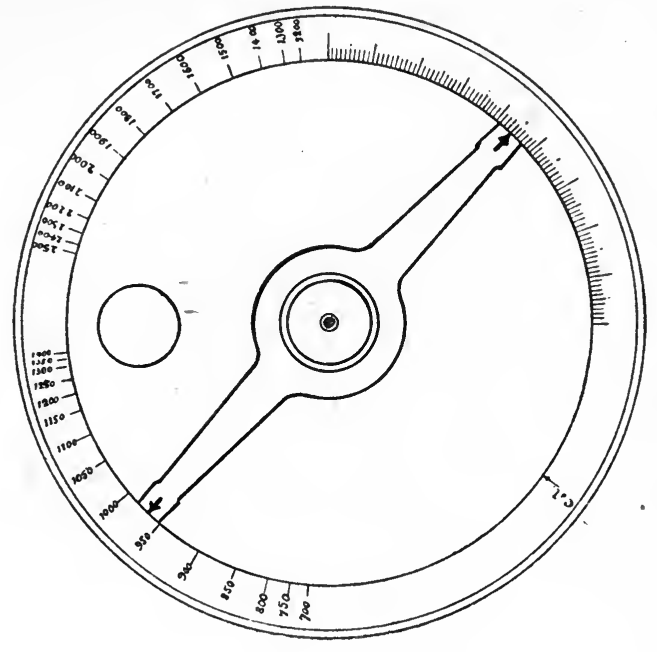

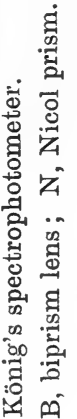

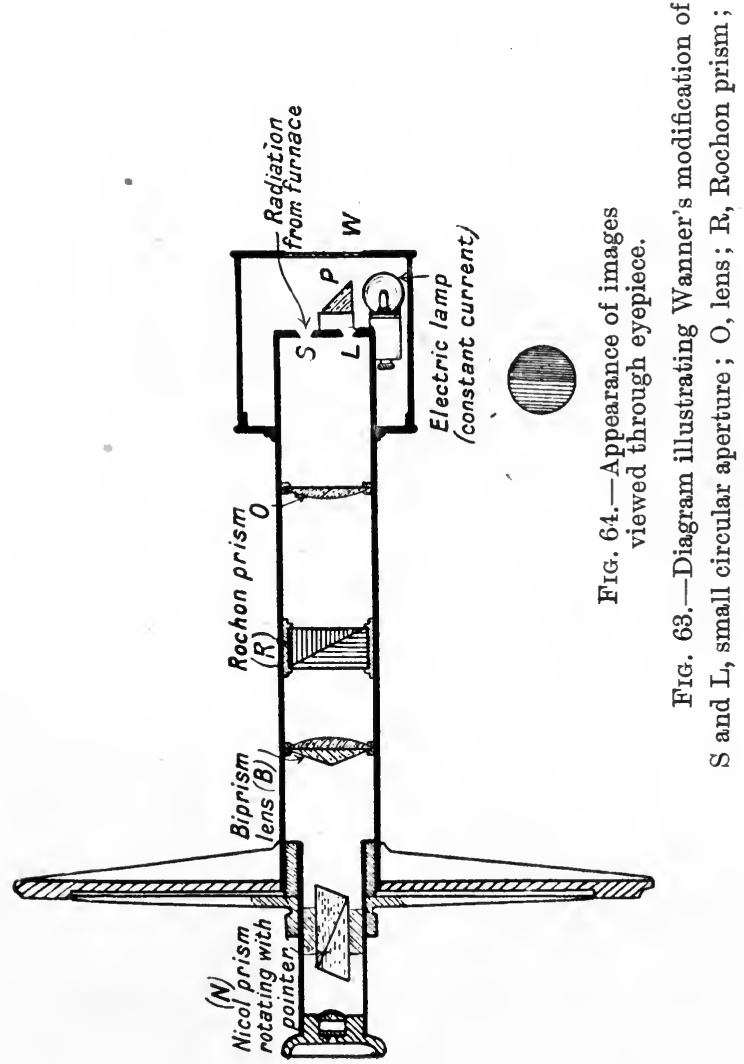


These images are semicircular patches uniformly illuminated. The two in juxtaposition are polarised at right angles (Fig. 65) and are viewed through the eyepiece, the other images being screened out.

- The Nicol prism $\mathbf{N}$ can be rotated around the optical axis, its position being indicated by a pointer attached.

To understand the precise functions of the various optical parts it is advisable to consider the effect of each individually.

In Fig. 65 the contribution of each component is shown. The circular holes $\mathrm{S}$ and $\mathrm{L}$ are at the focus of $\mathrm{O}$, so the images produced will be uniformly illuminated circular discs, i.e. of the face of the lens, which the biprism splits up into semicircles.

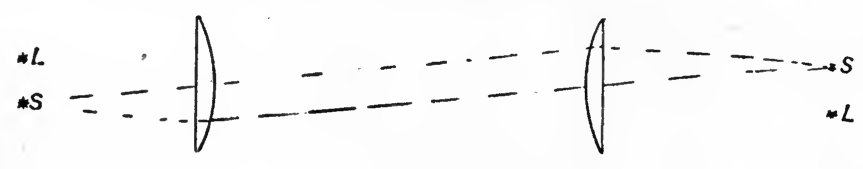
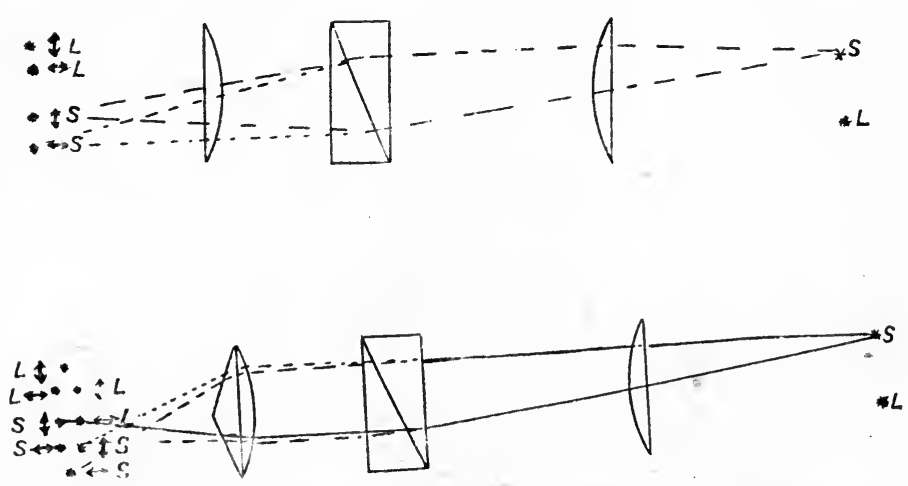

FIG. 65.-Diagram showing functions of various optical parts of the spectrophotometer. The arrows $\longleftrightarrow$ and $\uparrow$ indicate plane of polarisation. Eight images are formed in all, of which six are stopped out.

The arrows indicate the plane of polarisation of the light.

A screen is arranged to cut off all the images except the two worked with.

To understand the function of the Nicol prism suppose for the moment that the two beams are of equal intensity, then, with the plane of polarisation of the Nicol prism making an angle of $45^{\circ}$ with the direction of polarisation of either beam, a uniformly illuminated circle would be observed having a diametrical line across where the two fields come into contact. 


\section{DISTRIBUTION OF ENERGY IN THE SPECIRUM 121}

Rotation of the Nicol prism in either direction will cut down the intensity of one of the beams and increase that of the other.

Hence, if the beams are initially of unequal intensity, matching of the intensities, as viewed through the eyepiece, is possible for a certain position of the prism between the extinction positions $0^{\circ}$ and $90^{\circ}$.

Theory of the polarising type of pyrometer.-It is proved in textbooks of Light, that if $I_{1}$ and $I_{2}$ are the intensities of two plane polarised beams of radiation matching at angles $\phi_{1}$ and $\phi_{2}$, a beam of constant intensity, such as that from an electric lamp, when viewed through a Nicol prism, then :-

$$
\frac{\mathrm{I}_{1}}{\mathrm{I}_{2}}=\frac{\tan ^{2} \phi_{1}}{\tan ^{2} \phi_{2}}
$$

In optical pyrometry, by the insertion of a direct-vision prism or a piece of suitable red glass in the path of the two beams it is possible to work with narrow spectral bands and consequently apply Wien's law.

According to this law the intensity of light of wave-length $\lambda$ emitted by a "full radiator", is given by the expression-

$$
\mathrm{I}=\frac{c_{1}}{\lambda^{5}} e^{-\frac{c_{2}}{\lambda \mathrm{T}}}
$$

Suppose $I_{1}$ is the intensity of wave-length $\lambda$ at temperature $T_{1}$.

$\mathrm{I}_{2}, ", \quad, \quad \mathbf{T}_{2}$.

By Wien's law

$$
\frac{\mathbf{I}_{1}}{\mathbf{I}_{2}}=e^{\frac{e_{2}}{\lambda}\left(\frac{1}{T_{2}}-\frac{1}{T_{1}}\right)}
$$

Hence

$$
\frac{\mathrm{I}_{1}}{\mathrm{I}_{2}}=\frac{\tan ^{2} \phi_{1}}{\tan ^{2} \phi_{2}}=e^{\frac{c_{2}}{\lambda}\left(\frac{1}{\mathrm{~T}_{2}}-\frac{1}{\mathrm{~T}_{1}}\right)}
$$

Taking logarithms to the base $e$,

$$
2\left(\log \tan \phi_{1}-\log \tan \phi_{2}\right)=\frac{c_{2}}{\lambda}\left(\frac{1}{\frac{\mathrm{T}_{2}}{\mathrm{~T}_{1}}}\right)
$$

so that the relation between $\phi$ and $\mathrm{T}$ is of the form

$$
\log \tan \phi=a+\frac{b}{\mathrm{~T}}
$$

Hence, if a series of values of $\phi$ and $\mathrm{T}$ are obtained when (log tan $\phi)$ is plotted against $\frac{1}{\mathrm{~T}}$, the points should fall on a straight line.

Wave-length of the radiation transmitted by the red glass.Theoretically, a single determination of the angle $\phi$ corresponding to a known temperature ' $I$ ', together with a knowledge of $c_{2}$ and $\lambda$, should suffice to give a complete calibration of the instrument. In practice, however, it is very difficult to determine $\lambda$ by spectroscopic 
observations when a red glass is employed, owing to the band not possessing a sharply defined maximum.

Hence it is necessary to carefully consider the function of the red glass in deciding on the value of $\lambda$ to employ. On consideration it will be seen that the "effective" wave-length for a given red glass is such, that for any definite temperature interval the ratio of the radiation intensities for this wave-length shall equal the ratio of the integral luminosities through the glass: since the quantities which are actually compared in pyrometry are the integral luminosities as observed through the screen. 'Therefore, in computation, a wave-length should be used for which the ratio is the same.

A wave-length as defined above would lead to the same result for a given temperature interval as would be obtained if the screen were absolutely monochromatic.

Owing to the breadth of the transmission band obtained with the usual variety of red glass the "effective" wave-length is subject to change with changes in the spectral distribution of the incident radiation, which of course occur when the temperature of the radiating source is altered.

Determination of the "effective." wave-length for various temperature ranges.-The following method for the determination of the "effective" wave-length for the interval between two definite temperatures of a full radiator has been described by $\mathrm{Hyde}$, Cady, and Forsythe. Other methods, depending on a knowledge of the sensibility curve of the eye, have been described by the same authors, by Pirani, and by Foote, who gives a mathematical treatment of the question.

Direct determination.-The ratios of the intensities of emission of the source for a number of wave-lengths are measured, and these ratios compared with the ratio of the integral luminosities of the radiation from the source, when observed through the red glass under test.

These measurements can be made in two ways-

In one set of measurements the ratios of the intensities of radiation are measured with a spectrophotometer, and the ratio of the integral luminosities with a Lummer-Brodhun photometer having the red glass over the eyepiece. In the other set the ratio of the intensities are measured with a spectral photometer (Henning type), and the ratio of the integral luminosities with an optical pyrometer, either disappearing filament or polarising type, with the red glass over the eyepiece.

Indirect determination. - The results obtained by calculation from the transmission curve of the red glass (from which the integral luminosities are calculated on the basis of Wien's law) and the sensibility curve for the eye are in close agreement with those obtained by direct experiment.

The order of magnitude of the change in "effective" wave-length with temperature is shown by the data in Table XXVIII.

This procedure for obtaining the values of $\lambda$ is laborious, and is resorted to only in the case of standard instruments for use at temperatures exceeding $1500^{\circ} \mathrm{C}$. At lower temperatures the calibration is 
TABLE XXVIII.

\begin{tabular}{|c|c|}
\hline Temp. interval, ${ }^{\circ} \mathrm{C}$. & Effective wave-length. \\
\hline $1336-1822^{\circ}$ abs. & $0 \cdot 664_{6}$ \\
$1822-2400$ & $0 \cdot 662_{9}$ \\
$2400-3100$ & $0 \cdot 661_{7}$ \\
\hline
\end{tabular}

generally effected in the same manner as that described in the case of the disappearing filament type of pyrometer.

Extension of the scale above $1400^{\circ}$ C.-The range available with this type of pyrometer without an absorption device is from $700^{\circ}$ to about $1400^{\circ} \mathrm{C}$. It is possible to go a little below $700^{\circ} \mathrm{C}$., but the intensity of the light transmitted is so feeble as to preclude accurate observations below this point. The scale closes in rapidly as angle $90^{\circ}$ is approached, consequently $1400^{\circ} \mathrm{C}$. is the general working limit for this range.

By employing absorption glasses of appropriate density it is customary to have a second scale from $900^{\circ}$ to $2000^{\circ} \mathrm{C}$. ; a third (two absorption glasses) from $1200^{\circ}$ to $2500^{\circ} \mathrm{C}$. ; and a fourth (three glasses) from $1400^{\circ}$ to $4000^{\circ} \mathrm{C}$. The last mentioned covers the extreme temperature possible terrestrially, namely, that of the electric arc.

The intensity of the radiation emitted by a hot object increases very rapidly with the temperature; for example, the intensity of red light from a "full radiator" at the temperature of the melting-point of iridium $\left(2290^{\circ} \mathrm{C}\right.$.) is roughly 2000 times greater than that at the temperature of the melting-point of gold $\left(1063^{\circ} \mathrm{C}\right.$.).

Calculation of the constant of an absorption glass.-It is assumed that the absorption glass cuts down the intensity of the light in the spectral band dealt with in the ratio of $k$ to 1 .

If $\mathrm{T}_{1}$ is the observed temperature without absorption glass, and $\mathrm{T}_{2}$ the apparent temperature of the same object with absorption glass-
By Wien's law

$$
\mathrm{E}=\frac{c_{1}}{\lambda^{5}} e^{-\frac{c_{2}}{\lambda T_{1}}}
$$$$
\mathrm{KE}=\frac{c_{1}}{\lambda^{5}} e^{-\frac{c_{2}}{\lambda T_{2}}}
$$
Hence

$$
\log _{e} \mathrm{~K} \doteq \frac{c_{2}}{\lambda}\left(\frac{1}{\mathrm{~T}_{1}}-\frac{1}{\mathrm{~T}_{2}}\right)^{*}
$$

where $c_{2}$ is a numerical constant about 14,500 micron degrees ; and $\lambda$ for the usual red glasses 0.6 to $0.7 \mu$.

Hence $\left(\frac{1}{T_{2}}-\frac{1}{T_{1}}\right)$ is a constant quantity.

* This expression:-is also applicable for calculating the small absorption effect of a glass window closing a furnace. 
Rotating sectors have been advocated by some observers for cutting down the intensity, since it is then possible to obtain the coefficient of transmission by actual measurement of the sector.

Mendenhall employed sectors $13.5 \mathrm{cms}$. in diameter with the disappearing filament type of instrument. With discs of this diameter it was found possible to cut radial openings as small as $3^{\circ}$, giving a factor of $\frac{1}{120}$.

The absence of any error due to diffraction was proved by comparing the effect of ten equal and separate openings with that due to a single opening of the same total area.

The range of temperature available with various-sized sectors is illustrated by the following example :-

A pyrometer calibrated with full aperture had a scale covering the range up to $1549^{\circ} \mathrm{C}$. (melting-point of palladium); with a $\frac{1}{60}$ sector the range was from $1755^{\circ}$ to $2482^{\circ} \mathrm{C}$. ; and with a $\frac{1}{180}$ sector the scale was extended to include the melting-point of tungsten $\left(3300^{\circ} \mathrm{C}\right.$. approx.).

For the very small apertures it is advisable to use a large disc; Mendenhall employed one of $27 \mathrm{cms}$. diameter with an opening of $1.7 \mathrm{mms}$. at its narrowest part.

For most work the use of a neutral-tinted glass is to be preferred on account of its simplicity.

There is, however, one disadvantage common to both methods to be noted. The effective wave-length in either system shifts towards the green with increasing temperature. The best "neutral" absorption glasses are far from being neutral. The transmission coefficient of the glasses obtainable is low in the blue, green and yellow, and increases very rapidly in the red, with a maximum transmission in the early infra-red.

Nutting states that he has succeeded in producing strictly neutral absorption screens from dye materials.

If such materials prove permanent and do not bleach, they should be of great utility.

Standardisation by observation of transition points.-It is possible to calibrate optical pyrometers by direct observations of freezing- or melting-points, without the use of a thermocouple as intermediary.

In the case of materials which require a reducing atmosphere and do not react at high temperatures with graphite, Kanolt employed the following method:-

The substance was contained in a graphite crucible with re-entrant tube carried from the lid, as shown in Fig. 66.

The crucible was heated in a graphite spiral furnace and the pyrometer sighted on the bottom of the tube; this ensured that approximately black body conditions were obtained.

On plotting the heating or cooling curves a well-defined halt was observed at the transition point.

The following metals and salts were employed:-Antimony, $630^{\circ} \mathrm{C}$.; copper-silver eutectic, $779^{\circ}$ C.; silver, $960.5^{\circ}$ C. ; copper, $1083^{\circ} \mathrm{C}$.; 
diopside (melting), $1391^{\circ} \mathrm{C}$. Prolonged heating of diopside in contact with graphite had no apparent effect on the value obtained for the melting-point.

Attempts have been made by Hoffmann and Meissner to employ a similar method in the case of the palladium freezingpoint.

A hard porcelain crucible and tube were used with an oxidizing or neutral atmosphere around the metal. It was found that the molten palladium attacked the porcelain with the formation of a brownish substance.

An additional difficulty was the "spitting" of the fused metal, accompanied by considerable temperature fluctuations; this could not be prevented even by the passage of a stream of pure nitrogen into the metal.

For the direct calibration of a pyrometer in terms of the melting-point of palladium the simplest procedure is to make the palladium wire a part of an electrical circuit and heat it up in a furnace under

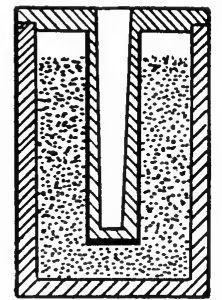

FIG. 66.-Graphite crucible with reentrant tube supported from the lid. "black body" conditions.

'The melting-point can be detected by the break of the circuit, and the temperature at this instant should be noted.

The melting-point of platinum can also be employed as a fixed point in the same way.

Calibration of optical pyrometers by comparison with a standard instrument.-When an optical pyrometer has been standardised by reference to high temperature melting-points and its scale calculated, it is a simple matter to calibrate other instruments by comparison.

A carbon tube furnace suitable for temperatures up to about $2500^{\circ} \mathrm{C}$. is illustrated in Fig. 67, while Fig. 68 shows, on a large scale, the carbon tube complete with its water-cooled electrodes.

The body of the furnace is of cast aluminium with water-cooled covers.

The carbon tube is protected from oxidation by filling the shell with finely divided lamp-black.

The ends are closed by thin glass windows and a stream of nitrogen is passed through the tube to clear away any smoke produced.

A loosely fitting plug of carbon is fixed about midway in the tube, and the pyrometers sighted upon it in turn when the furnace is at a steady temperature.

Alternating current of the order of 100 amps., from a low-tension transformer, is required to operate the furnace.

Relative merits of the disappearing filament and polarising types of optical pyrometers.-The filament type is essentially a telescope, and consequently it is easy to select out the object whose temperature is desired; the polarising type does not permit of a sharply defined image ; in fact, the field should be a uniformly illuminated semicircular patch. A blurred image of the hot object is, however, 
distinguishable by moving the eye about a little. With the polarising type it is necessary, when taking the temperature of a metallic

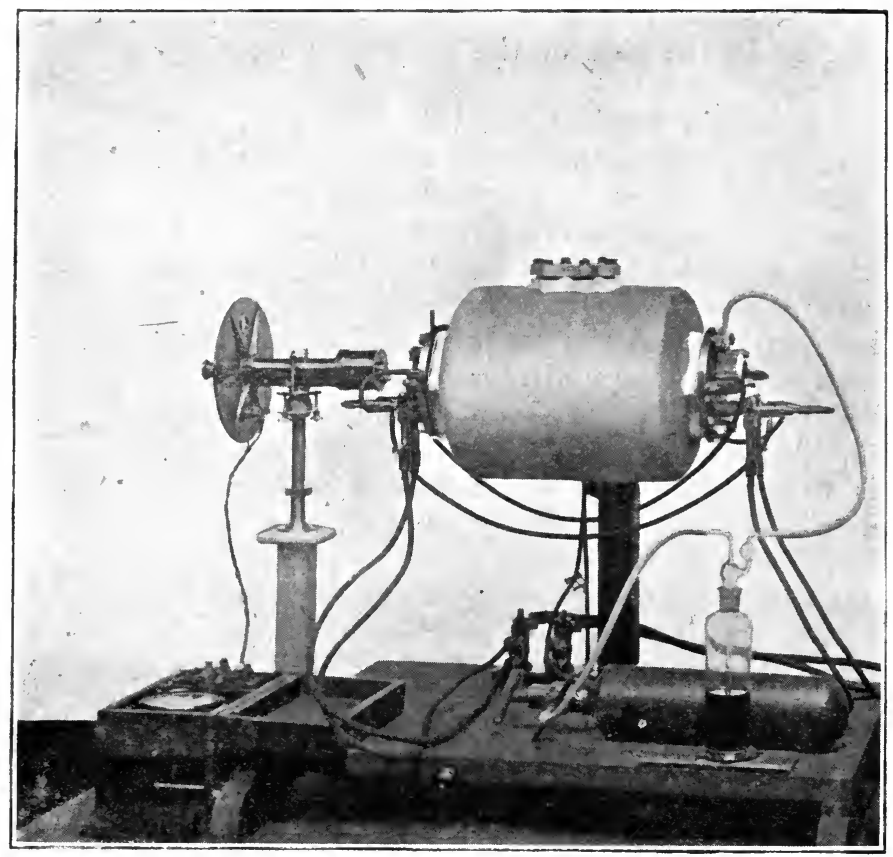

FIG. 67.-General view of Eden's carbon tube furnace for the comparison of optical pyrometers.

The pyrometer is sighted on a disc of carbon in the middle of the furnace.

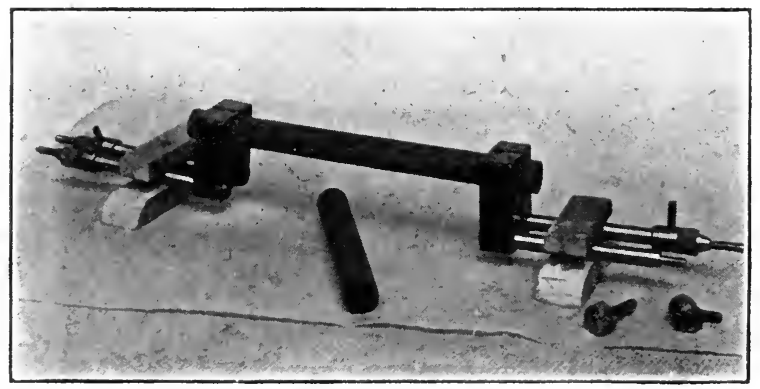

FIG. 68.-Carbon tube and water-cooled electrodes of furnace shown in Fig. 67. The leads carrying the current to the furnace are clamped to the brass tubes.

surface, to sight normally since the light given out at oblique incidence is largely polarised. 
The polarising type has the following advantages:-

1. Extrapolation of the scale on the basis of Wien's or any other. radiation law is readily effected, as the instrument is essentially a photometer.

2. The temperature scale is independent of the permanency of the electric lamp, ${ }^{*}$ which is set from time to time against an amyl acetate lamp.

3. The scale closes in at high temperatures and is reasonably open over the middle portion $\left(800^{\circ}\right.$ to $1200^{\circ} \mathrm{C}$.).

Temperature measurement in terms of total intrinsic brilliancy.-An empirical method of estimating temperatures which is occasionally used in connection with light sources, such as incandescent lamp filaments, is one developed by Rasch.

He proposed the relationship

$$
\log H=-\frac{A}{T}+B
$$

for connecting the temperature $\mathrm{T}$ (abs.) of a black "body" and its total intrinsic brilliancy $\mathrm{H}$.

It will be observed that this equation is merely Wien's law, in which monochromatic light is replaced by the total radiation visible to the normal eye.

'This, of course, is a somewhat questionable assumption, but some support is given to it by the fact that Crova has shown, that for all ordinary light sources giving a continuous spectrum, there is one wavelength for which the monochromatic intensity is proportional to the total intensity. This wave-length is about $0.58 \mu$.

In order to test Rasch's equation it is necessary to measure the intrinsic brilliancy of a "black body," i.e. the candlepower per sq. $\mathrm{mm}$. It is a difficult matter to do this with sufficient accuracy on the usual type of uniform temperature enclosure form of "black body," and the following indirect method was adopted by Nernst.

Nernst lamp filaments were measured, and the relation between the watts expended and the candlepower obtained was observed in the usual manner by photometering.

A filament was then set up in front of a "black body" furnace, and at a series of steady temperatures the filament was brought to a temperature when it disappeared against the background, i.e. emitted the same intensity of light.

From the watts expended in the filament the intrinsic brilliancy of the filament, and hence that of the furnace, was obtained.

The actual temperatures of the furnace were obtained by means of a Wanner pyrometer standardised by the melting-point of gold $\left(1064^{\circ} \mathrm{C}\right.$.), and assuming $c_{2}$ in Wien's equation to be 14,600 .

* It may be remarked that a one per cent. variation in the current through the lamp produces a nine per cent.-variation in the light emitted, consequently the current requires accurate adjustment. 
Rasch's equation was verified within $10^{\circ}$ over the temperature range from $1400^{\circ}$ to $2300^{\circ} \mathrm{C}$, and from the experiments the constants of the equation were obtained:

$$
\mathrm{T}=\frac{11,230}{5 \cdot 367-\log _{10} \mathrm{~K}}
$$

where $\mathrm{K}$ is the intrinsic brilliancy in Hefner candles per sq. $\mathrm{mm}$.

This equation requires a correction factor if employed for taking the temperature of surfaces which are not full radiators.

For example, tungsten has an emissivity of about 0.51 (of a "black body") for light of $\lambda=0.56 \mu$.

Hence, if $\mathrm{H}$ is the intrinsic brilliancy of a tungsten filament, and $\mathbf{K}$ that of a "black body" at the same true temperature, then $\mathrm{H}=0.51 \mathrm{~K}$.

\section{REFERENCES TO CHAPTER VII.}

\section{Laws of radiation and their experimental basis.}

Wien, Ann. der Physik., Bd. 58, p. 662 (1896).

Lümmer and Pringsheim, Ann. der Phys., Bd. 6, p. 192 (1901); Verb. Deutsh. Phys., 1, p. 3 (1903); E'lectrician (Aug. 7, 1903).

Rubens and Kurlbaum, Ann. der Phys., 4, p. 649 (1901).

Planck, Ann. der Phys., 1, pp. 69, 719 (1900); "The Theory of Heat Radiation," Trans. Masius.

Paschen, Astro-phys. Journ., 10, p. 40 (1899); 11, p. 288 (1900).

J. H. Jeans, "Report on Radiation and the Quantum-Theory," published by the Physical Society of London (1914).

Foote and Fairchild, "Luminosity of a Black Body and Temperature," Bur. Stds. Sci., Paper No. 270 (1916).

Mendenhall and Forsythe, Phys. Rev., 4, No. I (July, 1914) : Rapp.d. Congrès Int. Paris, 2 (1900).

British Association Reports, 1913.

J. J. Thomson, "On the Structure of the Atom," Phil. Mag., 26, p. 7:2.

Millikan, "Atomic Theories of Radiation," Science, 37, p. 119 (1913).

Wien, "Neuere Probleme der Theoretischen Physik," Columbia Lectures, 1913.

Buckingham, "On Wien's Displacement Law," Bull. Bur. Stds., 8, p. 543 ; "Calculation of $c_{2}$ in Planck's Equation," Bull. Bur. Stds., 7, p. 393.

\section{Pyrometers.}

(1) Disappearing filament type.

Holborn and Kurlbaum,'Ann. d. Phys., 10, p. 225 (1902).

Waidner and Burgess, Bur. Stds. Sci., Paper No. 11 (1904).

Henning, "Spectral Pyrometer," Zeits. f. Inst., 30, p. 61 (1910).

Mendenhall, "Spectroscopic Eyepiece and Rotating Sector," Phys. Rev., 33, p. 74 (1911).

Féry and Cheveneau, Journ. de Physique, p. 397 (1910).

Forsythe, "A Morse Optical Pyrometer adapted to a Wide Range of Laboratory Uses," Astrophys. Journ., 43, p. 295 (1916) ; "Position of Rotating Sector," etc., Astrophys. Journ., 42, p. 303 (1915); "Eyepiece and Diaphragms for use in determining Lamp Filament Temperatures," Phys. Rev., 4, p. 163 (1914); "High Temperature Measurements with the Optical Pyrometer," Gen. Elec. Rev., p. 749 (1917). 


\section{DIS'TRIBU'TION OF ENERGY IN THE SPEC'IRUM 129}

(2) Polurising type.

Wanner, Phys. Zeits., 1, p. 226 (1900); 3, p. 112 (1902).

König, Wied. Ann., 53, p. 785 (1894).

Nernst and Wartenberg, Deutsch. Phys. Ges., 8, pp. 48, 146 (1906).

Hildebrand, Zeits. f. Electrochemie, 14, p. 349 (1908).

\section{Miscellaneous.}

Hyde, Cady, and Forsythe, "Effective Wave-length of Transmission of Red Glass," Astrophys. Journ., 42, p. 294 (1915).

Foote, "Centre of Gravity" and "Effective Wave-length of Transmission of Pyrometer Color Screens, and the Extrapolation of the High Temperature Scale," Bur. Stds. Sci., Paper No. 260 (1916).

Kanolt, "Standardisation by Transition Points," Bur. Stds. Tech., Paper No. 10.

Heinecke, " Platinum Melting-point," Zeits. f. Angew. Ch., 21, p. 687 (1908).

Waidner and Burgess, Bur. Stds. Sci., Paper No. 55 (1907).

Rayleigh, "Correction for Finite Width of Spectral Band in Distribution of Energy Determination," Phil. Mag., 42, p. 441 (1871).

Hoffmann and Meissner, "Melting-point of Palladium," P.T.R. Report (1912). Rasch, Ann. d. Phys., 14, p. 193 (1904)

Crova, C.R., 93, p. 512.

"Standard Amyl Acetate Lamp," Zeits. f. Inst. (1893). 


\section{CHAPTER VIII}

\section{DISTRIBUTION OF ENERGY IN THE HEAT EMISSION SPECTRUM OF THE METALS}

Emissivity of iron, iron oxide, copper, copper oxide, nickel, gold, and silverCorrections to "apparent" temperatures taken with optical pyrometers.

Distribution of energy in the heat emission spectrum of the metals. - While Planck's formula is capable of representing with considerable accuracy the distribution of energy among the wave-lengths of the spectrum of a "full radiator," the corresponding problem for a metal has not yet been solved.*

A considerable amount of experimental data has been accumulated, which is of practical value, insomuch as that it permits of the calculation of the corrections to temperature observations on such surfaces when taken with an optical pyrometer calibrated under "black body" conditions.

Unfortunately, however, such corrections can only be regarded as approximations, since it has been shown that the slightest oxide film seriously affects the emissivity of a metallic surface.

The work done on this subject may be roughly grouped under two headings: the one in which experiments have been made with spectral bands of appreciable width, such as those obtained in practical forms of optical pyrometers, and over extended ranges of temperature; the other in which experiments have been made with almost monochromatic illumination for various wave-lengths in the spectrum, the investigation being usually confined to a few steady temperatures.

Emissivity for red light $(\lambda=0.66 \mu$ approx. $)$.-Bidwell investigated the emissivity of a number of metals, employing an optical pyrometer of the disappearing filament type. He compared the apparent temperature of the surface with its real temperature.

* Attempts have been made to apply a modification of Wien's form of equation to represent the distribution of energy in the heat spectra of the metals, such as-

$$
\mathrm{E}_{\lambda}=c_{1}{ }^{\prime} \lambda-\alpha e^{-\frac{c_{2}{ }^{\prime}}{\lambda \mathrm{T}}}
$$

For platinum Paschen obtained the value 6.4 for $\alpha$; Lummer and Pringsheim 6.0; while McCauley, in a detailed investigation, was unable to find any constant value of $\alpha$, to satisfy the equation or a modified form of Planck's. 
The emissivity was then obtained as follows :-

Let $\mathbf{I}_{a}$ be the intensity of the radiation of wave-length $\lambda$ from the surface whose apparent temperature is $\mathbf{T}_{a}$ and real temperature $\mathrm{T}$,

and I the intensity from a "full radiator" at temperature ' $\mathrm{T}$.

Then

$$
\begin{aligned}
\mathbf{I} & =c_{1} \lambda^{-5} e^{-\frac{c_{2}}{\lambda \mathrm{T}}} \\
\mathbf{I}_{a} & =c_{1} \lambda^{-5} e^{-\frac{c_{2}}{\lambda \mathrm{T}_{a}}} \text { by Wien's law }
\end{aligned}
$$

If $\mathrm{E}$ is the emissivity,

$$
\mathbf{E}=\frac{\mathbf{I}_{a}}{\mathbf{I}}=e^{\frac{c_{2}}{\lambda}\left(\frac{\mathrm{l}}{\mathrm{T}}-\frac{1}{T \cdot a}\right)}
$$

Now $c_{2}=14,500$ micron degrees, while for the particular red glass employed in the pyrometer the maximum ordinate of the transmission band was taken as $0 \cdot 66 \mu$.

Hence $\quad \log _{10} \mathrm{E}=9535\left(\frac{\mathrm{T}_{a}-\mathrm{T}}{\mathrm{T}^{\top} \mathrm{T}_{a}}\right)$

The assumption that $\lambda=0.66 \mu$ is only approximately true; it can be shown, however, that the error due to the finite width of the band is unimportant, and the conditions approximate to those which would obtain in practice when optical pyrometers are employed for taking temperatures.

Method of experiment.-The pyrometer was calibrated under "black body" conditions up to $1600^{\circ} \mathrm{C}$., and beyond this point by comparison with one of "polarising" type.

'The apparatus adopted for the observations were determined by the properties of the metal under consideration.

For most of the metals the heating arrangement consisted of a carbon rod shortcircuiting the secondary of a transformer. 'The metal was contained in a small cavity and projected above the upper surface of the carbon rod, thus avoiding the possible error due to light, reaching the surface from the hot surroundings, being reflected into the pyrometer.

Temperatures up to $2200^{\circ} \mathrm{C}$. were obtainable. Direct observations with the pyrometer gave the "apparent" temperature of the metal surface, while the real temperature was obtained by various methods. One such method was to fuse a Pt-Pt-Rh couple into the surface; another, to observe the radiation from the bottom of a hole $1 \mathrm{~mm}$. in diameter and $2 \mathrm{mms}$. deep drilled in the surface of the metal. A cavity of these dimensions was found to approximate to a " full radiator," since temperatures obtained by a thermocouple (at $1000^{\circ} \mathrm{C}$.) agreed with those obtained by the optical pyrometer, assuming that the cavity was a "full radiator." 'The agreement was the order of $10^{\circ}$.

The "cavity method" was applied in the case of $\mathrm{Au}, \mathrm{Ag}, \mathrm{Cu}$ and $\mathrm{Ni}$ in the solid state.

For the molten metals an attempt was made to obtain true 
temperatures by the use of a thermoelement of graphite and carbon. These, however, were not very satisfactory on account of the want of homogeneity in the materials.

Some observations with molten silver were taken with a Pt-Pt-Rh couple sheathed in a thin quartz tube and pressed on the surface.

Emissivity of iron. (a) In the molten state.-The iron was .contained in a small graphite crucible $5 \mathrm{cms}$. deep, heated in a granular resistor furnace. In the centre of the crucible a small carbon rod was fixed with the end flush with the surface of the iron. The true temperature was obtained by observations on a cavity $5 \mathrm{mms}$. deep and 2 mms. wide, drilled into the rod.

Check experiments were made with a couple pressed on the surface, but this method could not be employed at the higher temperatures, owing to the softening of the quartz sheath.

(b) In the solid state. - The cavity for "black body" temperatures and a clean uncontaminated surface in the case of solid iron were very simply obtained by pressing a small carbon rod into the metal when it was solidifying and in the pasty state. The frozen surface layer was thus pressed down and the still liquid mass below caused to flow up over it from around the edges, and, while so doing, to solidify. The operation was carried out under burning hydrogen.

A brilliant reflecting surface was thus obtained and the observations on such a surface gave a curve continuous with the curve for the molten state. On the other hand, a surface obtained by high burnishing would not retain its lustre nor give a curve continuous with that for the molten metal.

Effect of the surface films.-The great experimental difficulty in work of this character was to obtain an absolutely pure metal surface. Polishing was useless; the only satisfactory method was to melt the metal, allow the slag or oxide to float to the edge, thus leaving the centre clean on solidification; or the same result could be obtained by the procedure described in the case of iron. During the observations oxidation was prevented by the use of an atmosphere of nitrogen or hydrogen.

When a surface was prepared in this manner, there was no sudden change of emissivity on solidification or melting, and it was impossible to tell optically whether the metal was liquid or solid at temperatures in the region of the melting-point. An artificially prepared surface always showed a sudden drop in emissivity on melting, and when a molten metal solidified in air a rise in emissivity occurred, as shown by a sudden brightening or flashing up.

The results of Bidwell's experiments are shown in Fig. 69.

It will be observed that silver has a very low emissivity for the wave-length considered, amounting to but 5 per cent. at $1400^{\circ} \mathrm{C}$. Molten nickel rapidly takes up carbon from the crucible, and beyond $1800^{\circ} \mathrm{C}$. becomes a semi-solid pasty mass. On cooling, the carbon, which is either in solution or combined as carbide, crystallises out as graphite, the mass becoming fluid again. 
Bidwell states that the freezing-point is apparently unaffected * by this phenomenon, but that the emissivity of the molten nickel is probably modified by this absorbed carbon, the sharp rise shown on the curve being due to an actual change in composition, which might not occur if the metal were melted in some other kind of container than carbon.

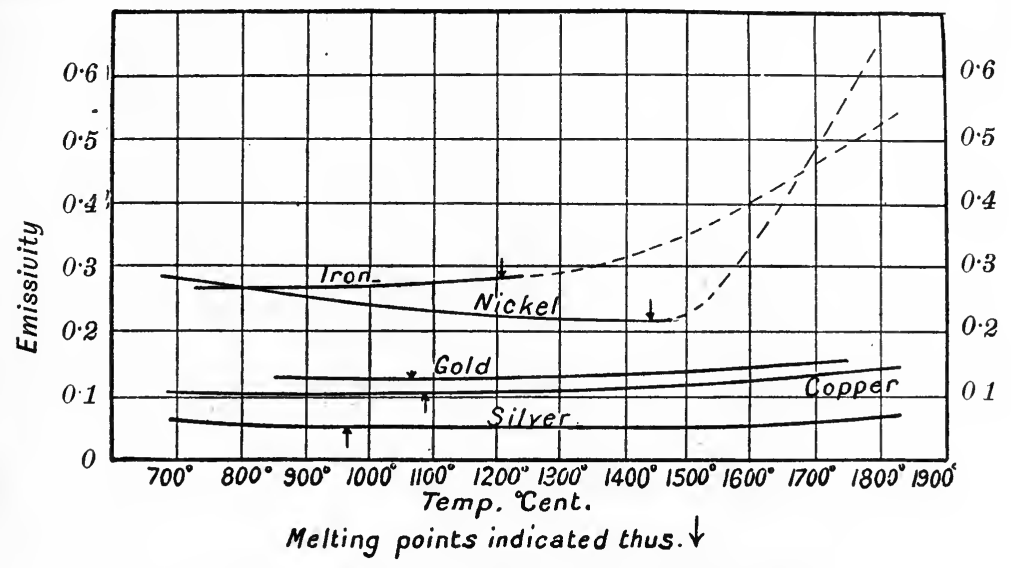

FrG. 69.-Variation of emissivity with temperature.

The same effect was observed in the case of iron, and for this reason the lines are shown dotted in Fig. 69.

In the case of $\mathrm{Ag}, \mathrm{Cu}$ and $\mathrm{Au}$ the emissivities are practically constant from $600^{\circ}$ to $1800^{\circ} \mathrm{C}$.

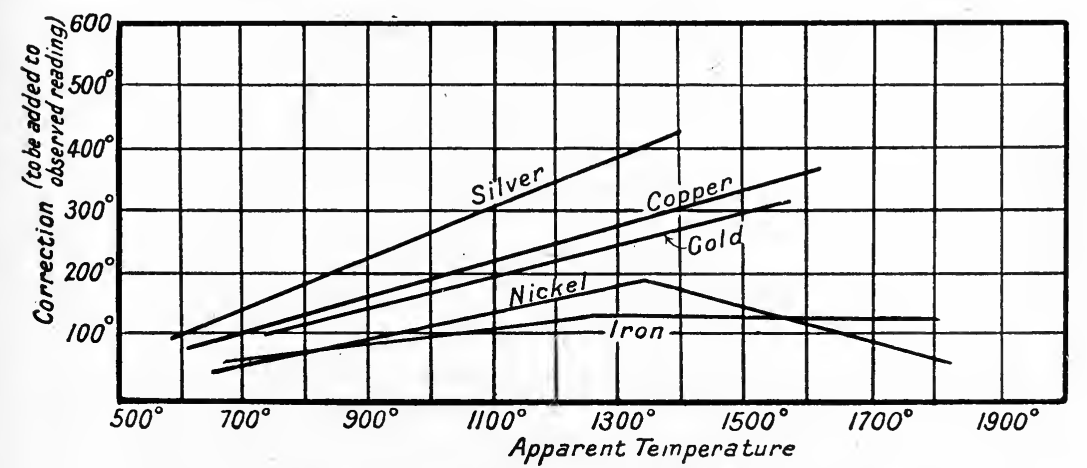

FiG. 70.-Diagram showing corrections to pyrometer observations.

The corrections to a pyrometer, employing a similar red glass, are shown in Fig. 70. It is of course assumed that the apparent "black

* Direct experiment has shown that the apparent freezing-point of nickel in a salamander crucible is about $122^{\circ}$ lower than the value obtained in a clay crucible, oxidation being prevented by fused borax. 
body" temperatures are those observed with a surface free from contamination.

Emissivity of iron oxide. - When iron is heated in air to a temperature of about $800^{\circ} \mathrm{C}$. its surface becomes covered with a brittle coating of oxide, apparently consisting of $\mathrm{FeO}$ and $\mathrm{Fe}_{2} \mathrm{O}_{3}$ in various proportions. In appearance the surface is silky and pitted with minute depressions, which produce the same effect as a collection of minute "black bodies," and consequently the surface has a high emissivity. Burgess and Foote have measured the emissivity of this oxide surface.

A small sample of the oxide was heated up on a platinum strip and its apparent temperature observed with a disappearing filament type of optical pyrometer, having a red glass with transmission band at $\lambda=0.65 \mu$.

The true temperature was obtained by placing on the platinum strip minute specimens of $\mathrm{NaCl}, \mathrm{Na}_{2} \mathrm{SO}_{4}$, and $\mathrm{Au}$.

The table below gives the emissivity of the oxide surface at various temperatures.

TABLE XXIX.

\begin{tabular}{|l|c|c|c|c|}
\hline Melting-point of & $\begin{array}{c}\text { True temperature, } \\
{ }^{\circ} \mathrm{C} .\end{array}$ & $\begin{array}{c}\text { Apparent } \\
\text { temperature, } \\
{ }^{\circ} \mathrm{C} .\end{array}$ & $\begin{array}{c}\text { Average devia- } \\
\text { tion from mean. }\end{array}$ & Emissivity. \\
\cline { 2 - 4 } & $801 \pm 1$ & 801 & $\pm 1 \cdot 5$ & $1 \cdot 00$ \\
$\mathrm{NaCl}$ & $884 \pm 1$ & 882 & \pm 3 & 0.97 \\
$\mathrm{Na}_{2} \mathrm{SO}_{4}$ & $1063 \pm 2$ & 1058 & \pm 2 & 0.94 \\
$\mathrm{Au}$ & & & \\
\hline
\end{tabular}

The emissivity was calculated by the equation-

$$
\frac{1}{\mathrm{~T}}-\frac{1}{\mathrm{~S}_{\lambda}}=\frac{\lambda}{.4343 c_{2}} \log \mathrm{E}_{\lambda}
$$

where ' $\mathrm{T}$ ' is the true temperature,

$\mathrm{S}_{\lambda}$ is the observed temperature,

$\lambda$ is the wave-length of light considered measured in $\mu$ units,

$c_{2}$ is Wien's constant $(14,450)$.

'The emissivity appears to decrease slightly with increasing temperature, which is the case also with nickel and other oxides.

The authors ignore the observation at $801^{\circ} \mathrm{C}$., and by extrapolation -assuming a straight line-obtain the following corrections to reduce apparent to true temperatures :-

\begin{tabular}{|l|c|c|c|c|c|c|c|}
\hline Observed temperature, ${ }^{\circ} \mathrm{C}$. & 600 & 700 & 800 & 900 & 1000 & 1100 & 1200 \\
\hline Correction, $\mathrm{C}^{\circ}$. & 0 & 0 & +1 & +2 & +4 & +6 & $+10^{\circ}$ \\
\hline
\end{tabular}


Emissivity of copper and cuprous oxide.-Burgess investigated the emissivity of a clear copper surface and one of the oxides, employing the disappearing filament type of pyrometer with red $(\lambda=0.65 \mu)$ and green $(\lambda=0.55 \mu)$ glasses.

The copper was contained in shallow crucibles of magnesia and graphite, about $8 \mathrm{cms}$. inside diameter. These were heated in a gas furnace, and by regulating the gas and air supply, it was possible to obtain either the clear metal surface or the oxide surface. The crucible was set in the furnace so that the flames could not play on the surface, and also in such a position as to avoid direct radiation from the walls of the crucible into the pyrometer.

In the case of the rough oxide surface diffuse reflection from the surface might vitiate the observations. But when sighting on the mirror-like surface of the molten metal only specular reflection was possible, and there could be no error due to this cause, unless the image of some hot object was actually visible in the telescope.

Temperatures were measured by means of a thermoelement bent into the form of a crook.

From the observations the following equations were deduced, in which $t$ is the true temperature and $s$ the apparent.

Clear molten copper surface.

Red light

Green light

$$
(\lambda=0.65 \mu)
$$

$$
\begin{aligned}
t & =1.515 s-359 \\
(\lambda & =0.55 \mu) \\
t & =1.515 s-477
\end{aligned}
$$

Hence at the melting-point the apparent temperature, with the red glass, is too low by $130^{\circ}$.

The green glass gives a temperature $78^{\circ}$ higher than the red glass throughout the range.

Burgess states that in deducting the equations a slight allowance was made for the fact that the optical readings would tend to be too high on account of the slightest traces of impurity on the copper surface.

The maximum difference between the observed and computed values of the temperature over the range $1073^{\circ}$ to $1200^{\circ} \mathrm{C}$. was about $13^{\circ}$.

Cuprous oxide surface.-The formation of an oxide film caused an apparent increase of $100^{\circ}$ in the temperature of the molten copper when observed with the red glass, and $35^{\circ}$ in the case of the green glass.

The smaller increase with the green glass is due to the fact that molten copper radiates strongly in the green. This greenish appearance persists in the case of incandescent solid copper as may be observed by adjusting the gas feed to remove surface oxidation.

The relation between the apparent and true temperatures, in the case of the oxide, is not quite linear. This can be seen by a consideration 
of the data in Table $\mathrm{XXX}$, which refer to the red light of wavelength $\lambda=0 \cdot 65 \mu$.

TABLE XXX.

\begin{tabular}{|c|c|c|c|}
\hline \multicolumn{2}{|c|}{ Molten copper. } & \multicolumn{2}{|c|}{ Cuprous oxide. } \\
\cline { 1 - 2 } $\begin{array}{c}\text { Pyrometer } \\
\text { reading, }{ }^{\circ} \mathrm{C} .\end{array}$ & $\begin{array}{c}\text { True tempera- } \\
\text { ture, }{ }^{\circ} \mathrm{C} .\end{array}$ & $\begin{array}{r}\text { Pyrometer } \\
\text { reading, }{ }^{\circ} \mathrm{C} .\end{array}$ & $\begin{array}{c}\text { True tempera- } \\
\text { ture, }{ }^{\circ} \mathrm{C} .\end{array}$ \\
\cline { 1 - 2 } 950 & 1082 & 900 & 903 \\
975 & 1118 & 950 & 958 \\
1000 & 1156 & 1000 & 1020 \\
1025 & 1193 & 1050 & 1087 \\
1050 & 1231 & 1100 & 1159 \\
& & 1150 & 1233 \\
\hline
\end{tabular}

TABLE XXXI.

Emissivities.

\begin{tabular}{|c|c|c|c|c|c|}
\hline \multicolumn{3}{|c|}{ Molten copper. } & \multicolumn{3}{c|}{ Cuprous oxide. } \\
\hline $\begin{array}{c}\text { Temperature, } \\
{ }^{\circ} \mathrm{C} .\end{array}$ & $\lambda=0.65 \mu$. & $\lambda=0.55 \mu$. & $\begin{array}{c}\text { Temperature, } \\
{ }^{\circ} \mathrm{C} .\end{array}$ & $\lambda=0.65 \mu$. & $\lambda=0.55 \mu$. \\
\hline & & & & & \\
\hline 1075 & 0.17 & 0.47 & 1000 & 0.80 & - \\
1125 & $0 \cdot 15$ & 0.38 & 1100 & 0.60 & 0.68 \\
1175 & 0.14 & 0.32 & 1200 & $(0.49)$ & $(0.49)$ \\
1225 & 0.13 & 0.28 & & & \\
\hline
\end{tabular}

Emissivity of solid and liquid gold.-Gold is one of the metals which does not oxidise appreciably when heated.

Both copper and gold emit greenish or bluish light at high temperatures. Stubbs and Prideaux made a study of the emissivity of gold. The radiation of the various wave-lengths was measured by means of a König spectrophotometer and direct comparison made with the radiation from a "black body" at the same temperature.

The metal was contained in a silica capsule of $4.5 \mathrm{cms}$. diameter and $6 \mathrm{mms}$. deep. The "black body" was placed in exactly the same position for the second experiment. It consisted of a cylindrical graphite block, $11 \mathrm{cms}$. long, $5 \mathrm{cms}$. in diameter, in the centre of which a hole $12 \mathrm{mms}$. in diameter by $9 \mathrm{cms}$. deep was bored.

True temperatures were obtained by means of thermocouples.

In the case of the gold the two couples dipped into the metal, one on either side of the field of view. Owing to the shallowness of the depth of immersion an error of the order of $6^{\circ}$ at $1000^{\circ} \mathrm{C}$. was introduced in the observed readings. A correction was applied, this being determined by observing the apparent freezing-point. 'Two couples 
were also embedded in the graphite. The black body conditions were sufficiently perfect to make it impossible to distinguish the white thermocouple when it projected into the central hole.

Impurities or inequalities in the gold surface.-Any slight surface film present was found to produce an increase in the red radiation in which the gold spectrum was weak.

The impurities were got rid of in the case of the molten surface by the application of borax.

The solid gold surface proved to be more difficult to obtain free from oxide.

It was found that a surface turned flat, treated with four grades of fine emery powder and then with jeweller's rouge, gave an apparently perfect mirror. On heating, however, a conspicuous red film was produced. This film could be removed by repeatedly treating the surface with borax at a temperature near the melting-point. Although a clear, solid gold surface was obtained when the liquid solidified, it was generally uneven owing to contraction, crystallisation, etc., and consequently reflected heat from the furnace walls into the spectrophotometer.

Occasionally by very slow cooling an area could be obtained which was free from unevenness.

The following values were obtained for the emissivity of molten gold at the temperature of its freezing-point :-

\section{TABLE XXXII.}

Emissivity of gold in the molten state.

\begin{tabular}{|c|c|c|c|c|c|}
\hline Wave-length & 0.7014 & 0.6712 & 0.6409 & 0.6149 & 0.5895 \\
\cline { 1 - 2 } Emissivity & 0.184 & 0.203 & 0.232 & 0.263 & 0.304 \\
\hline Wave-length & 0.5649 & 0.5418 & 0.5186 & 0.4961 & 0.4750 \\
\hline Emissivity & 0.347 & 0.390 & 0.434 & 0.473 & 0.503 \\
\hline
\end{tabular}

For solid gold at various temperatures the values in Table XXXIII were obtained. 'The data are shown graphically in Fig. 71.

Stubbs and Prideaux observed that in passing from the solid to the molten state a sharp discontinuity occurred in the emissivity wavelength relationship, the relative emissivity increasing in the red and decreasing in the violet. Roughly the emissivity for red light of the solid gold is only about three-fifths that of molten gold.

For the limited range of temperature investigated $\left(110^{\circ} \mathrm{C}\right.$. in the case of the molten state) no change of the relative emissivity of either molten or solid gold with temperature was observed. 
TABLE XXXIII.

Emissivity of gold in the solid state.

\begin{tabular}{|c|c|c|c|c|c|}
\hline \multirow{2}{*}{ Wave-length. } & \multicolumn{4}{|c|}{ Temperature, ${ }^{\circ} \mathrm{C}$. } & \multirow{2}{*}{$\begin{array}{c}\text { Mean } \\
\text { emissivity. } \\
\text {. }\end{array}$} \\
\hline & $949^{\circ}$. & $1040^{\circ}$. & $1061^{\circ}$ & $1046^{\circ} . *$ & \\
\hline $\begin{array}{l}0 \cdot 7014 \\
0.6712 \\
0 \cdot 6409 \\
0 \cdot 6149 \\
0.5895 \\
0.5649 \\
0.5418 \\
0.5186 \\
0 \cdot 4961\end{array}$ & $\begin{array}{l}{[0.164]} \\
{[0.146]} \\
{[0.169]} \\
{[0.198]} \\
0.241 \\
0.315 \\
0.379 \\
0.520 \\
0.595\end{array}$ & $\begin{array}{c}{[0 \cdot 134]} \\
0 \cdot 114 \\
0 \cdot 144 \\
0 \cdot 172 \\
0 \cdot 229 \\
0.291 \\
0 \cdot 371 \\
0 \cdot 465 \\
0.492\end{array}$ & $\begin{array}{c}0 \cdot 103 \\
0 \cdot 114 \\
0 \cdot 143 \\
0 \cdot 171 \\
0 \cdot 221 \\
0 \cdot 289 \\
0 \cdot 366 \\
-\end{array}$ & $\begin{array}{l}0.103 \\
0.116 \\
\overline{-} \\
0 \cdot \overline{178} \\
\overline{-} \\
0.361 \\
\overline{-} \\
0.516 \\
0.541\end{array}$ & $\begin{array}{l}0 \cdot 103 \\
0 \cdot 114 \\
0 \cdot 143 \\
0 \cdot 175 \\
0 \cdot 229 \\
0 \cdot 301 \\
0 \cdot 371 \\
0 \cdot 494 \\
0 \cdot 531\end{array}$ \\
\hline
\end{tabular}

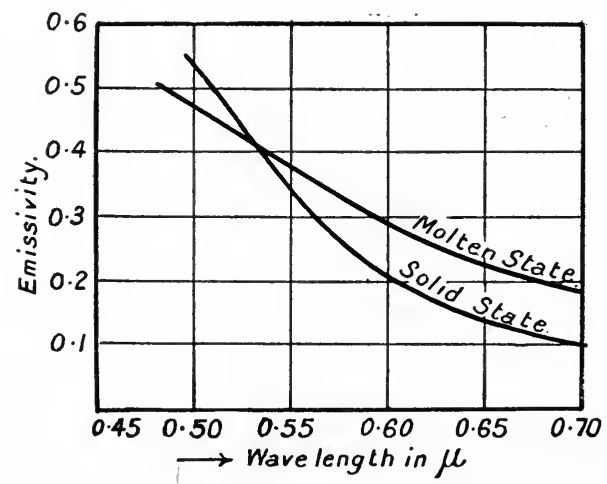

FIG. 71.-Diagram to illustrate emissivity of gold.

From the above values of the emissivities the "black body" or true temperatures corresponding to various values of the apparent temperatures can readily be calculated from the relationship :-

$$
\frac{1}{\mathrm{~T}}-\frac{1}{\mathrm{~S}_{\lambda}}=\frac{\lambda}{c_{2}} \log _{e} \frac{\mathrm{E}_{\lambda}^{\prime}}{\mathrm{E}_{\lambda}}
$$

where $\frac{\mathbf{E}_{\lambda}{ }^{\prime}}{\mathbf{E}_{\lambda}}$ is the emissivity for wave-length $\lambda$.

The data below give the apparent temperatures by Wien's equation for various wave-lengths corresponding to a true temperature of $1063 \cdot 2^{\circ} \mathrm{C}$.

* Data given in this column refer to a surface naturally crystallised from the molten state. Values enclosed in brackets [ ] were obtained with a surface having a slight film over it. 
TABLE XXXIV.

True temperature, $1063 \cdot 2^{\circ} \mathrm{C}$.

\begin{tabular}{|c|c|c|}
\hline \multirow{2}{*}{$\begin{array}{c}\text { Wave-length } \\
\text { in } \mu .\end{array}$} & \multicolumn{2}{|c|}{ Apparent temperature, ${ }^{\circ} \mathrm{C}}$. \\
\cline { 2 - 3 } & Solid state. & Molten state. \\
\hline & & \\
\hline 0.7014 & 891.5 & 931 \\
0.6409 & 925.5 & 956.5 \\
0.5895 & 964 & 982 \\
0.5418 & 1000 & 1003 \\
0.4961 & 1025.5 & 1019 \\
\hline
\end{tabular}

Solid and molten copper and silver.--An investigation on the same lines as the above described in the case of gold was carried out by Stubbs for the metals silver and copper.

Copper.-The metal was contained in a silica pot and heated in a closed furnace with a hydrogen atmosphere, the observations being taken through a glass window (microscope cover glass).

The block of copper (4.2 cms. diameter) was turned up to a flat surface, rubbed smooth with emery paper, and polished with metal polish. The use of rouge was avoided as it was found to tarnish on heating. No trace of filming was observed, and the surface showed no deterioration until a temperature of about $10^{\circ}$ from the melting-point had been attained, when recrystallisation rapidly set in, and this produced stray reflection of light from the furnace walled into the photometer, owing to the roughening of the surface.

A perfect mirror of molten copper, free from film, was obtained without difficulty.

The emissivities for the solid and molten copper for various wavelengths are shown in Fig. 72. The values are for a temperature of $1010^{\circ} \mathrm{C}$. for solid copper and $1130^{\circ} \mathrm{C}$. for molten copper. As in the case of gold, there is a discontinuity at the melting-point, but of smaller magnitude. above.

The values differ markedly from those obtained by Burgess described

This may be due to the fact that the experimental conditions in Burgess' work were less favourable, and that the red glass of his pyrometer transmitted a comparatively wide spectral band $(100 \mu \mu)$, while the width of the band in the photometer employed by Stubbs and Prideaux was $8 \mu \mu$.

Silver.-It was unnecessary to take the extreme precautions for the exclusion of oxygen in the case of silver as for copper. A satisfactory reducing atmosphere was produced by placing a small quantity of powdered graphite in the furnace below the crucible containing the silver. The solid metal surface lost its polish on heating, so that no measurements could be made of its true emissivity. 
The emissivity of the molten surface for various wave-lengths is shown in Fig. 72.

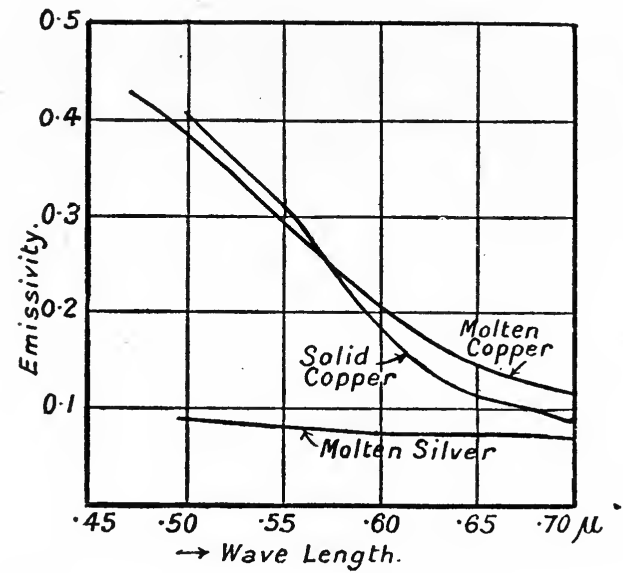

FIG. 72.-Diagram showing emissivities of solid and molten copper.

There appeared to be a slight increase in the relative emissivity with temperature, but owing to the small magnitude of the coefficient the authors are in some doubt as to its real nature.

In 'Table XXXV the apparent temperatures corresponding to the various wave-lengths at the melting-points of the metals are given.

TABLE XXXV.

\begin{tabular}{|c|c|c|c|}
\hline \multirow{2}{*}{$\begin{array}{c}\text { Wave-length } \\
\text { in } \mu \mu .\end{array}$} & \multicolumn{2}{|c|}{ Copper, m.p. 1083 ${ }^{\circ} \mathrm{C}}$. & $\begin{array}{c}\text { Silver, m.p. 961 } \\
\text { (Liquid) } \\
\text { Apparent } \\
\text { temperature. }\end{array}$ \\
\cline { 2 - 4 } & $\begin{array}{c}\text { Apparent temperature. } \\
\text { (Solid). }\end{array}$ & (Liquid). & \\
\hline 700 & 896 & 917 & 792 \\
650 & 924 & 942 & 804 \\
600 & 966 & 973 & 816 \\
550 & 1007 & 1003 & 831 \\
500 & 1028 & 1026 & 845 \\
\hline
\end{tabular}

Emissivity of polished platinum.- The permanency of a polished platinum surface greatly simplifies the study of the emissivity of the metal at high temperatures.

Holborn and Kurlbaum, and Waidner and Burgess have independently investigated the difference between the apparent and true temperatures for approximately monochromatic radiation of a platinum surface. The former employed a small box of platinum, with a thermo- 
couple in the interior, to give the true temperature, the apparent temperature being obtained by means of an optical pyrometer.

'The latter worked with a Joly meldometer (Fig. 73).

The apparent temperature of the strip was determined with a "disappearing filament" type of optical pyrometer. This was calibrated under "black body" conditions by comparison with a thermocouple up to $1150^{\circ} \mathrm{C}$., which temperature, at the time (1904), marked the upper limit of reliable gas thermometry work.

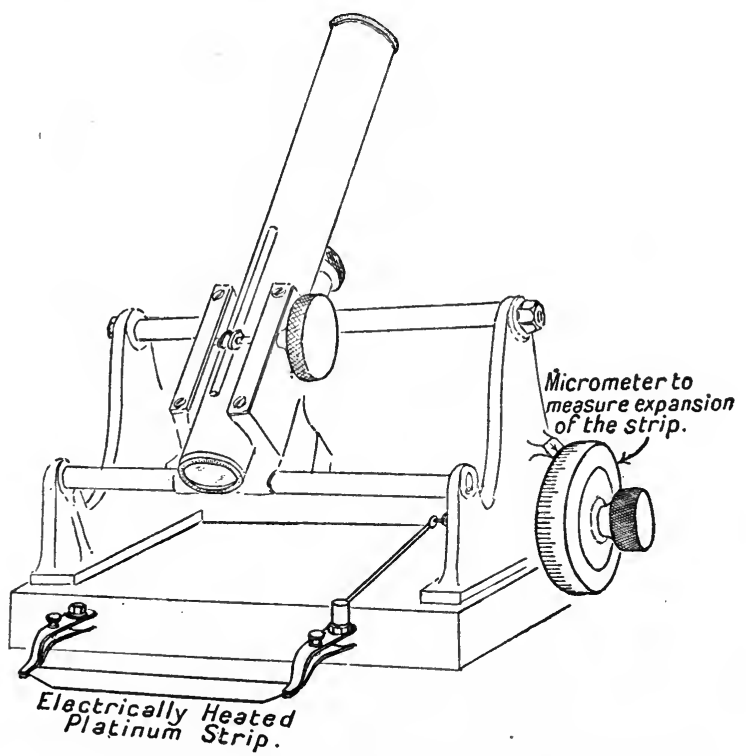

FIG. 73.-Illustration of Joly's meldometer.

The thermo-electric formula was extrapolated to about $1350^{\circ} \mathrm{C}$, and beyond this point the calibration of the optical pyrometer was extended by means of Wien's law.

True temperatures were obtained by calibrating the strip by meltingpoints of pure metals and salts.

The electric contact micrometer permitted of accurate determinations of lengths corresponding to the melting-temperatures of minute specimens heated on the strip.

In the observations of the "apparent temperature" the current through the strip was regulated to keep the length of the strip constant at a measured value.

The following "fixed points" were assumed for the calibration of the strip :- 
TABLE XXXVI.

\begin{tabular}{|l|c|c|}
\hline Melting-point. & $\begin{array}{c}\text { Value accepted } \\
\text { by W. and B. } \\
\text { o. C. }\end{array}$ & $\begin{array}{c}\text { Value on the } \\
\text { Day and Sosman } \\
\text { scale. } \\
{ }^{\circ} \text { C. }\end{array}$ \\
\hline Palladium & 1500 & 1549 \\
Gold & 1064 & 1063 \\
Sodium chloride & 782 & 801 \\
Potassium bromide & 723 & 730 \\
\hline
\end{tabular}

The apparent temperature corresponding to the melting point of platinum was obtained by increasing the temperature of the strip until it fused.

For this melting-point Waidner and Burgess assumed the value $1780^{\circ} \mathrm{C}$., which, according to Day and Sosman, is $25^{\circ}$ too high.

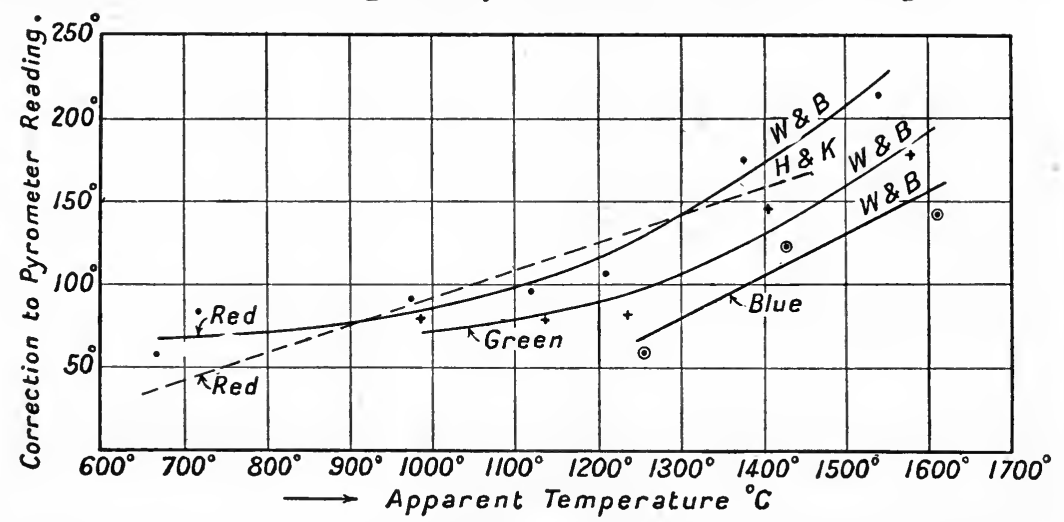

Fig. 74.-W. and B., Waidner and Burgess ; H. and K., Holborn and Kurlbaum.

In 'Table XXXVII and Fig. 74 the data have been recalculated on the basis of the standard scale of temperature referred to in Chap. I.

The curves given in Fig. 74 differ considerably from the original of Waidner and Burgess, in which the lines terminate at the temperature of the melting-point of palladium.

TABLE XXXVII.

Red light $\lambda=0.651 \mu$.

\begin{tabular}{|c|c|c|}
\hline $\begin{array}{c}\text { Apparent } \\
\text { temperature, }{ }^{\circ} \mathrm{C} .\end{array}$ & $\begin{array}{c}\text { True } \\
\text { temperature, }{ }^{\circ} \mathrm{C} .\end{array}$ & $\begin{array}{c}\text { Difference, } \\
{ }^{\circ} \mathbf{C} .\end{array}$ \\
\cline { 1 - 2 } 1541 & $1755^{*}$ & 214 \\
1374 & $1549 \dagger$ & 175 \\
1209 & 1315 & 106 \\
1119 & 1215 & 96 \\
973 & 1064 & 91 \\
717 & 801 & 84 \\
666 & 723 & 57 \\
\hline
\end{tabular}

* Melting-point of platinum.

$\uparrow$ Melting-point of palladium. 
Green light $\lambda=0.550 \mu$.

\begin{tabular}{|c|c|c|}
\hline $\begin{array}{c}\text { Apparent } \\
\text { temperature, }{ }^{\circ} \mathrm{C} .\end{array}$ & $\begin{array}{c}\text { True } \\
\text { temperature, }{ }^{\circ} \mathrm{C} .\end{array}$ & $\begin{array}{c}\text { Difference, } \\
{ }^{\circ} \mathrm{C} .\end{array}$ \\
\cline { 3 - 3 } 1577 & $1755^{*}$ & 178 \\
1403 & $1549 \dagger$ & 146 \\
1233 & 1315 & 82 \\
1136 & 1215 & 79 \\
985 & 1064 & 79 \\
\hline
\end{tabular}

Blue light $\lambda=0.474 \mu$.

\begin{tabular}{|c|c|c|}
\hline $\begin{array}{c}\text { Apparent } \\
\text { temperature, }{ }^{\circ} \mathrm{C} .\end{array}$ & $\begin{array}{c}\text { True } \\
\text { temperature, }{ }^{\circ} \mathrm{C} .\end{array}$ & $\begin{array}{c}\text { 1)ifference, } \\
{ }^{\circ} \mathrm{C} .\end{array}$ \\
\hline 1612 & $1755^{*}$ & 143 \\
1426 & $1549 \dagger$ & 123 \\
1256 & 1315 & 59 \\
\hline
\end{tabular}

The values for red light obtained by Holborn and Kurlbaum are shown by the dotted line in Fig. 74 .

Distribution of energy in the spectra of platinum, palladium and tantalum.-McCauley has investigated the distribution of energy in the heat spectra of $p t, p d$ and $t a$ over a wide range of temperature.

The experiments were made on electrically heated strips $3.5 \mathrm{cms}$. long, $0.05 \mathrm{~mm}$. thick, by $7 \mathrm{mms}$. wide, folded into wedge-shaped filaments with $12^{\circ}$ angular opening.

The "true temperature" was deduced from observations of the radiation from the interior of the wedge, using a disappearing filament type of optical pyrometer.

The distribution of energy was obtained with the usual spectrobolometric arrangement.

With tantalum great precautions had to be taken to obtain the highest vacuum in the enclosure containing the filament. 'The slightest trace of residual gas would cause the resistance to increase rapidly and the metal would become brittle, losing its metallic appearance.

If the vacuum was satisfactory the metal after heating remained bright and ductile except for a slight flaking off at the highest temperatures.

The spectral energy curves for $p t, p d$ and $t a$ were perfectly continuous and showed no bands of selective emission. They resembled generally those of a "black body," but no modifications of Wien's or Planck's formulæ were found capable of resembling the curves over the range. 'Taking the general form of Planck's equation-

$$
\mathbf{E} d \lambda=c_{1} \lambda^{-a} \frac{1}{e^{\frac{c_{2}}{\lambda T}}-1}
$$

* Melting-point of platinum.

$\dagger$ Melting-point of palladium. 
and determining a mean value of $a$ from the data of a given isothermal curve, McCauley found that the computed emission for $p d$ was in general from 4 to 7 times smaller than the observed value at $6 \mu$. The agreement was better for shorter wave-lengths and correspondingly worse for longer ones.

For all three metals the emission diminishes more rapidly than that of a "black body" at the same temperature in the infra red.

The wave-length of maximum emission shifts much more slowly towards the shorter wave-lengths for increasing temperature than for a "black body" especially at the higher temperatures. The product $\lambda_{m} \mathrm{~T}$ increases with temperature, and the constant value for $p t$ found by Lummer and Pringsheim is probably in error. Their value of $\lambda_{m} \mathrm{~T}=2620$ is correct only in the neighbourhood of $2000^{\circ} \mathrm{abs}$.

\section{REFERENCES TO CHAPTER VIII.}

Bidwell, Phys. Rev., 3, p. 439 (1914).

Burgess and Foote, Bull. Bur. Stds., p. 83 (1915).

Burgess, ibid., 6, p. 111 (1909-10).

Stubbs and Prideaux, Proc. Roy. Soc., 87, p. 451 (1912).

Stubbs, Proc. Roy. Soc., 88, p. 195 (1913).

McCauley, "Distribution of energy in the spectra of $p t, p d$ and ta," Astrophys. Journ., 37, p. 164 (1913).

Mendenhall and Forsythe, "The relation between 'black body' and true temperatures of tungsten, tantalum, molybdenum and carbon and the temperature variation of their reflecting power," Astrophys. Journ., 37, p. 380 (1913).

Snow, "On the infra red spectra of the alkalies," Phys. Rev., 1, p. 28, etc. (1893).

Burgess, "Temperature measurements in Bessemer and open-hearth practice," Bur. Stds. Sci., Paper No. 299, Journ. Frank. Inst., May, 1917.

Paschen, Wied. Ann., 58, p. 455 (1896) ; 60, p. 662 (1897).

Lummer and Pringsheim, Ber. d. Deutsch. Phys. Ges., 1, p. 215 (1899).

Lummer and Kurlbaum, ibid., 17, p. 106 (1898).

Coblentz, Bull. Bur. Stds., 5, p. 339 (1909) ; Phys. Rev., 29, p. 553 (1909).

Mendenhall, "Temp. of filaments and thin strips," Astrophys. Journ., 33, p. 91 (1911); Phys. Rev., 33, p. 74 (1911).

\section{Emissivity of polished platinum.}

Holborn and Kurlbaum, Ann. d. Phys., 10, p. 225 (1903).

Waidner and Burgess, Bull. Bur. Stds., 1, p. 243 (1904-5).

Joly, "Meldometer," Proc. Roy. Irish Acad., 2, p. 38 (1891).

Coblentz, "Selective radiation from Nernst glower material," Bull. Bur. Stds., 9, p. 102 (1913). 


\section{CHAP'TER IX}

\section{HIGH TEMPERATURE MELTING-POINTS AND BOILING-POINTS}

Melting-points of refractory oxides-Metals of the platinum group-.'Tungsten and tantalum-The temperature of the positive crater of the electric arc and its dependence on external conditions- "Boiling-points" of the metals and the variation with pressure.

For temperature measurements beyond $1600^{\circ} \mathrm{C}$. it is necessary to employ some type of pyrometer based on the laws of radiation. Hence it is necessary either to make the experimental arrangements such that "black body" conditions are obtained, or determine the emissivity of the material by experiment, so as to correct "apparent temperatures" to "true temperatures."

A practical difficulty frequently encountered is the prevention of chemical reaction between the material and the container, since in the case of very high temperatures the range of substances capable of being used in the manufacture of crucibles, etc., is a limited one.

'The researches described below illustrate the procedure which has been followed in certain cases and may serve as a guidance in analogous determinations.

Melting-points of refractory oxides. - Kanolt has redetermined the melting-points of lime, magnesia, alumina, and chromium oxide.

An Arsem graphite spiral furnace was employed for heating and temperatures measured with a disappearing filament type of optical pyrometer.

The Arsem furnace is designed for working in vacuo; in this case, however, it was found that the vaporisation of some of the oxides at high temperatures made observations impossible under reduced pressure conditions. Consequently the furnace had to be rearranged so as to permit of working with atmospheric pressure inside.

To diminish heat loss from the resistor the Arsem furnace is provided with a shield consisting of a cylindrical-shaped box of graphite filled with powdered magnesia or graphite. The shield surrounds the heater without being in actual contact with it.

Kanolt modified the standard form by substituting a smaller heater and adding a second shield-placed within the first-filled with powdered graphite.

The refractory oxide was contained in a crucible with re-entrant 
tube (see Fig. 66), or was formed into a long narrow crucible which could be carried from the top of the furnace.

Except in the case of lime, the material itself was not directly under observation, consequently to determine the melting-point a heating up

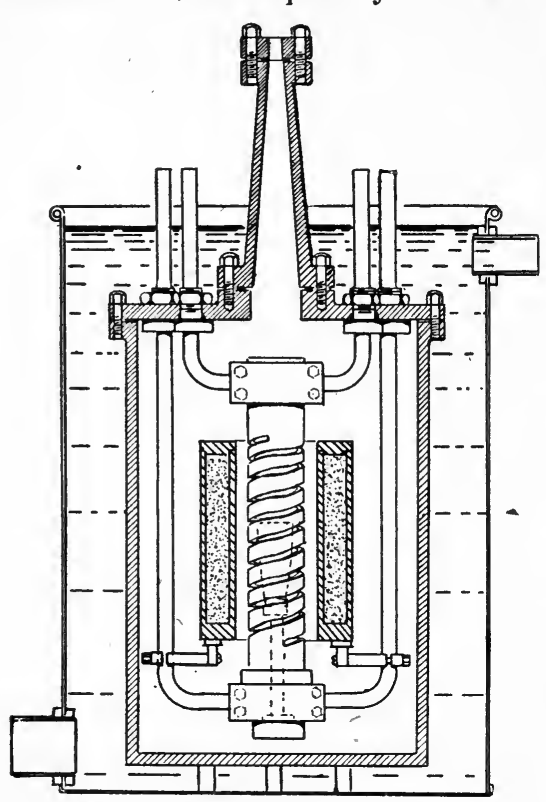

FIG. 75.-Arsem furnace. curve was taken and the halt at the melting observed, the rate of heating being of the order of $100^{\circ} \mathrm{C}$. per minute.

The accuracy of the method was checked by observations with samples taken to temperatures just below and just above the temperature at which the halt occurred and noting the change in appearance when cold.

Most oxides react with carbon at high temperature to form carbides, the only exception being the oxide of magnesium ( $\mathrm{MgO})$, which, however, is slowly decomposed by carbon with the formation of carbon monoxide and magnesium vapour. In consequence of this the volatilisation after fusion is very rapid.

Some difficulty was encountered in the early experiments, owing to the formation of smoke which interfered with the temperature observations; this was overcome by the usual method of passing a stream of gas into the interior of the furnace.

Lime $(\mathrm{CaO})$. - 'Two methods were employed in the examination of this oxide. In the first the material was in the form of a long closed tube supported from the upper end, and observations were made by sighting into the interior on the bottom surface. To clear away fog a gentle stream of hydrogen was passed into the tube.

It was observed that the parts melted were perfectly white, while the upper portions, which had been submitted to a lower temperature, were grey. The explanation suggested by Kanolt is, that the grey material is calcium carbide, produced by the reaction of the lime and the carbon "spluttered" on to the tube. At higher temperatures any carbide formed would react with the lime, forming carbon monoxide and calcium vapour, consequently the grey appearance would be confined to the lower temperature zone.

In the second method crucibles of tungsten were employed.

By moulding powdered tungsten and then heating rapidly to high temperatures, it is possible to manufacture hard, porous, metallic crucibles. The lime, when melted, was absorbed by the porous material ; this, however, did not interfere with the observations. 
The value $2570^{\circ} \mathrm{C}$. was found for the melting-point.

Magnesia $(\mathrm{MgO})$. - This oxide was melted in a graphite crucible with re-entrant tube.

After fusion the magnesia was a colourless, fairly transparent, solid of compact crystalline structure.

The value $2800^{\circ} \mathrm{C}$. was obtained for the melting-point, with an average deviation of $13^{\circ}$ from the mean.

Alumina $\left(\mathrm{Al}_{2} \mathrm{O}_{3}\right)$. - Alumina reacts with carbon to form a carbide, but since the reaction takes place very slowly the melting-point could be determined with graphite containers. After melting the material was white, but on prolonged exposure to high temperatures it became grey.

The same values were obtained with both graphite and tungsten crucibles, the melting-point being $2050^{\circ} \mathrm{C}$.

Alumina is not so volatile as most oxides at high temperatures, and experiments could be made in a vacuum of two millimetres of mercury.

Chromium Oxide $\left(\mathrm{Cr}_{2} \mathrm{O}_{3}\right)$. - With this oxide both tungsten and graphite crucibles were tried.

In the case of the tungsten crucibles the melted oxide soaked into the porous tungsten to a considerable extent, while with the graphite crucibles in vacuo, vigorous reduction of the oxide occurred on melting.

'The value obtained by both methods was $1990^{\circ} \mathrm{C}$.

TABLE XXXVIII.

Melting-points of refractory oxides (Kanolt).

\begin{tabular}{|l|c|}
\hline \multicolumn{1}{|c|}{ Substance. } & $\begin{array}{c}\text { Melting-point, } \\
\text { oc. }\end{array}$ \\
\hline Lime & 2570 \\
Magnesia & 2800 \\
Alumina & 2050 \\
Chromium oxide & 1990 \\
\hline
\end{tabular}

Melting-points of the elements of the iron group-nickel, cobalt, iron, manganese and chromium-also of vanadium and titanium.-Burgess has devised a valuable instrument, which he terms a micropyrometer, for the determination of the melting-points of minute specimens of materials.

The apparatus is somewhat similar to a Joly meldometer, with a microscope pyrometer.

Fig. 76 illustrates the essential features of the instrument.

Within the Huyghens eyepiece of an ordinary microscope a small incandescent lamp is mounted. In series with the lamp there is an ammeter and rheostat operated in precisely the same manner as in the case of a disappearing filament type of optical pyrometer. 'The eyepiece of the microscope is fitted with a piece of good red filter glass. 
For temperatures exceeding $1400^{\circ} \mathrm{C}$. an absorption glass is placed between the microscope objective and the furnace window.

The tip of the filament of the lamp is set to the same brightness as the platinum strip viewed from above at the instant of melting of

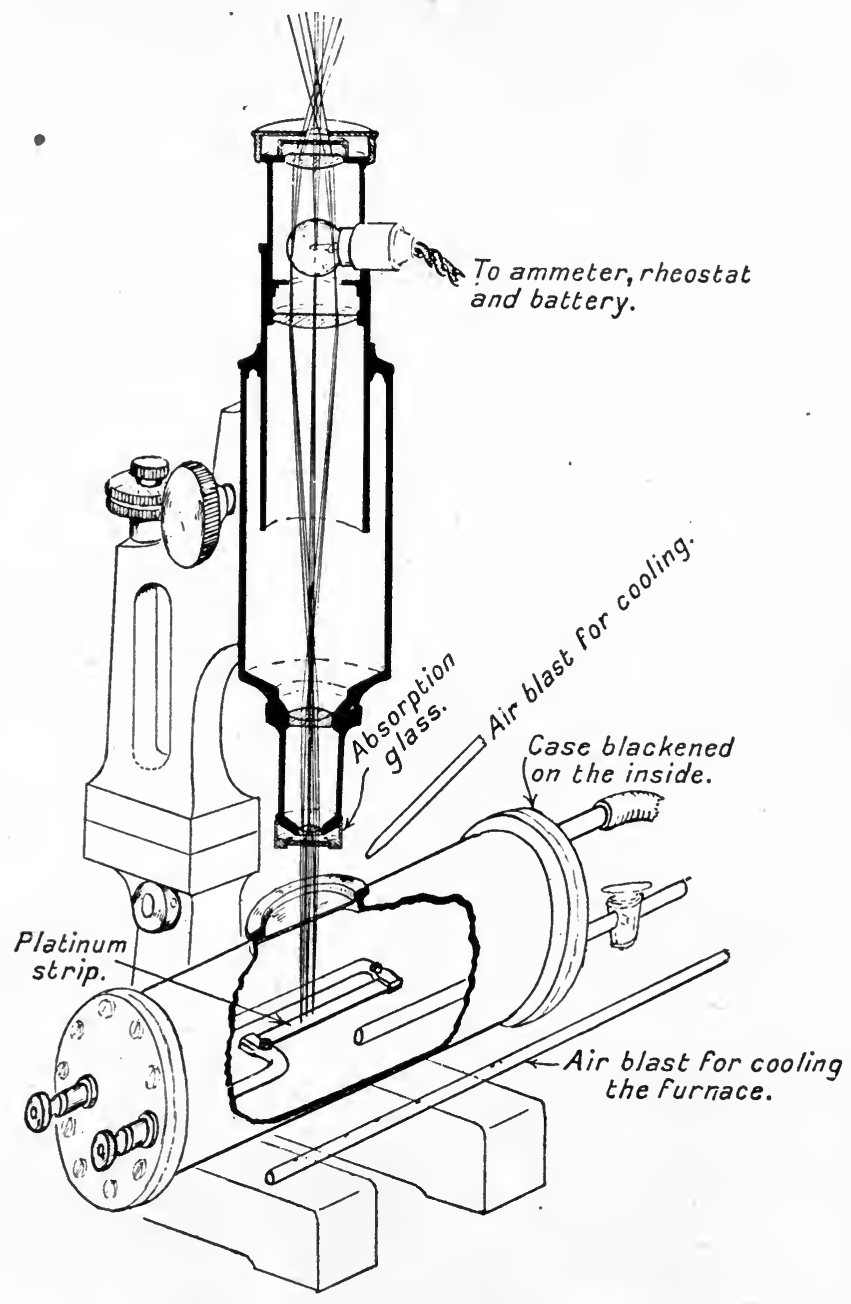

FIG. 76.-Burgess' micropyrometer.

the metallic or other specimen on which the microscope is focussed. The eye of the observer sees the specimen, the platinum strip, and the lamp filament all in focus at once.

Calibration of the pyrometer.*-The most convenient method

* Melting-point determinations made by Burgess and Waltenberg. 
of calibration is to observe the lamp currents at the known meltingpoints of two or more pure substances, such as gold, nickel and palladium, and from the equation expressing the relation between temperature and current (in lamp), the temperature of melting of any specimen may be computed. For moderate temperature intervals the equation $\log c=a+b \log$ T may be used,

where $c$ is the current,

' $\mathrm{T}$ ' is the absolute temperature,

$b$ a constant very nearly unity.

The melting-points of nickel and palladium were taken for calibration purposes.

'The accuracy of the equation was checked by extrapolating to the melting-point of platinum, which could be directly observed by matching the lamp and strip at the instant the latter burnt out. The value $1755^{\circ} \mathrm{C} . \pm 5$ was obtained from six observations.

An atmosphere of pure hydrogen was maintained in the enclosure, to prevent oxidation of the metal under test.

For those metals for which the melting is sharp, such as nickel, cobalt and iron, a precision of $1^{\circ}$ to $2^{\circ}$ was possible with only a few thousandths of a milligram of material.

Iron (purity 99.98 per cent. Fe).-Pure electrolytic iron from three sources was tested. There appeared to be no systematic difference either among the several samples or for different sized pieces, and the mean value $1533^{\circ} \mathrm{C} . \pm 1$ was obtained for the melting-point.

The melting and freezing-points of iron, in vacuo and in hydrogen, were also taken in the Arsem furnace (Fig. 75). Four observations in vacuo gave $1531^{\circ}, 1531^{\circ}, 1529^{\circ}, 1527^{\circ} \mathrm{C}$., and two in hydrogen gave $1523^{\circ}, 1527^{\circ} \mathrm{C}$.

Cobalt (purity 99.95 per cent. Co).-Samples from three sources were tested. Mean value $1477^{\circ} \mathrm{C} . \pm 2$.

Day and Sosman employed the same method for cobalt as that described for nickel.* They found the value $1490^{\circ} \mathrm{C}$. in a nitrogen atmosphere.

Burgess and Waltenburg suggest that Day and Sosman's higher value might be caused by some oxidation of the powdered cobalt.

Chromium (98 per cent. ? Cr).-Two different samples gave values varying from $1536^{\circ} \mathrm{C}$. to $1513^{\circ} \mathrm{C}$.

Manganese $(97.5$ ? $\mathrm{Mn})$.-Melts were taken both on platinum and on nickel strips using gold $\left(1063^{\circ} \mathrm{C}\right.$.) and palladium as calibration points.

Those on nickel were generally $10^{\circ}$ to $20^{\circ}$ lower than on platinum, due, apparently, to evaporation of the nickel.

The mean value $1254^{\circ} \mathrm{C}$. was obtained for the impure samples of manganese available.

Vanadium (about $9 \% \cdot 5$ per cent. Va).--None of the samples investigated melted sharply, the substance being quite viscous and showing evidences of incipient melting many degrees below the temperature at which the melting was complete. In some samples evidence of melting 
was apparent as low as $1500^{\circ} \mathrm{C}$, and melting was complete at about $1720^{\circ} \mathrm{C}$.

The authors estimate the melting-point of pure vanadium to lie about $1720^{\circ} \mathrm{C}$.

Titanium.-The melting-points were taken on an iridium strip. Some samples of colloid titanium melted at $1450^{\circ}$ to $1500^{\circ} \mathrm{C}$.; other samples showed no signs of melting when tested on a platinum strip.

Two samples from different sources gave the values $1787^{\circ} \mathrm{C}$. and $1800^{\circ} \mathrm{C}$., the melting-points being fairly sharp.

TABLE XXXIX.

Melting-points of elements of atomic weight 48 to 59 (Burgess and Waltenberg).

\begin{tabular}{|c|c|c|c|}
\hline Metal. & $\underset{\text { Melting-point, }}{\text { Mel }}$ & Purity. & $\begin{array}{c}\text { Probable melting- } \\
\text { point of pure } \\
\text { element. }{ }^{\circ} \mathrm{C} .\end{array}$ \\
\hline Nickel & $\left\{\begin{array}{l}1452^{*} \\
1449+\end{array}\right\}$ & $99 \cdot 83_{5}$ & $1452 \pm 3$ \\
\hline Cobalt & $\left\{\begin{array}{l}1477 \pm 2 \\
1478 \pm 1 \ddagger\end{array}\right\}$ & $99 \cdot 95_{1}$ & $1478 \pm 5$ \\
\hline Iron & $\left\{\begin{array}{l}1533 \pm 1 \\
15288\end{array}\right\}$ & $99 \cdot 98 \pm 0.01$ & $1580 \pm 5$ \\
\hline Manganese & 1255 & $97-98$ & $1260 \pm 20$ \\
\hline Chromium & 1520 & $98 \div 99$ & 1520 to $>\mathrm{Fe}$ ? \\
\hline Vanadium & 1720 & $97-98$ & $1720 \pm 30$ \\
\hline Titanium & $1794 \pm 12$ & $99 \cdot 9+$ & $1795 \pm 15$ \\
\hline
\end{tabular}

Melting-points of the metals of the platinum group.(a) Platinum.- The determination of the melting-point of this metal has been the object of numerous investigations. 'The favourite procedure has been to determine the relationship between the e.m.f. and the temperature of a thermoelement of which platinum was one component, and then obtain the value of the melting-point by extrapolation of this formula.

It is, for example, a comparatively simple matter to determine the e.m.f. at the instant when the circuit breaks for a couple of platinum $v$. platinum 10 per cent. rhodium.

The uncertainty arises in the extrapolation of the formula over large intervals of temperature, and the values for the melting-point obtained by various observers differ by as much as $14.5^{\circ} \mathrm{C}$.

When the gas thermometer scale was carried to $1550^{\circ} \mathrm{C}$. by Day and Sosman and the e.m.f. temperature relationship of couples was determined with considerable accuracy in terms of it, the extrapolation over the $200^{\circ} \mathrm{C}$. to the platinum melting-point could be made with greater confidence than had previously been the case.

* Assumed value on platinum strip ; also observed value on iridium strip.

$\uparrow$ Crucible melts in electric furnace.

$\ddagger$ Crucible melts in electric furnace; also on iridium strip.

$\S$ Five samples agreeing to within $3^{\circ}$. 
'The method employed by Day and Sosman was to heat up the thermoelement slowly until the platinum arm melted. The couple was enclosed within a glazed Marquardt porcelain tube inserted into a carbon tube furnace. A stream of carbon monoxide around the outside of the porcelain tube protected the furnace from oxidation, while a current of dry air through the inside prevented contamination of the wires by reducing gases.

Both wires were enclosed in capillaries, leaving about $2 \mathrm{mms}$. exposed near the junction. It was this projecting portion that melted, the point being marked by a halt of about one minute in the gradual rise in temperature of the thermoelement (measured by the e.m.f. generated). This halt preceded the formation of a globule and the interruption of the circuit.

The mean value $1752^{\circ} \mathrm{C}$. was obtained for the melting-point.

Another method for the determination of the melting-point of platinum is to measure the temperature interval between the meltingpoints of palladium and platinum by means of optical pyrometers calibrated on the basis of Wien's law.

Several observers have employed this method with various forms of experimental arrangements.

The values obtained for the interval are in close agreement. Nernst and Wartenberg gave the value $204^{\circ} \mathrm{C}$.; Holborn and Valentiner, $207^{\circ} \mathrm{C}$.; Waidner and Burgess, $207^{\circ} \mathrm{C}$. Hence the probable mean is $206^{\circ} \mathrm{C}$. Accepting Day and Sosman's value for the palladium point $1549^{\circ} \mathrm{C}$, , we obtain the value $1755^{\circ} \mathrm{C}$. for platinum, with a probable error of $\pm 5^{\circ} \mathrm{C}$.

It will be observed that this figure is in close agreement with the one obtained by extrapolation of the e.m.f. temperature relationship by Day and Sosman.

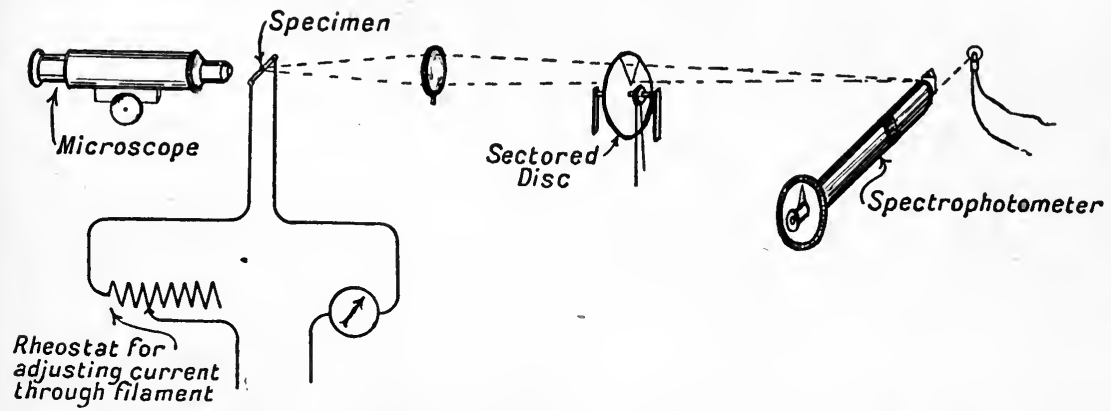

Fig. 77.-Diagram of apparatus employed by Mendenhall and Ingersoll in their use of the Nernst glower for melting-point determinations.

(b) Rhodium and Iridium.-The other metals of the group have not received the careful study given to platinum. Some experiments have been made by Mendenhall and Ingersoll, in which a Nernst glower was ingeniously used as the source of high temperature heat supply.

The apparatus employed is shown diagrammatically in Fig. 77. The 
metal to be investigated was in the form of a minute globule and placed on the glower, whose temperature could be varied by controlling the current through it.

The globule was observed by means of a microscope, and by careful manipulation of the current through the glower it was possible to maintain one part melted and the other part solid in the case of the metals gold and platinum.

The apparent temperature of the glower was obtained by focussing an image across the slit of a Martens-König spectrophotometer, the image being more than sufficient to fill the aperture.

The radiation from a Nernst glower departs considerably from that corresponding to a "full radiator," consequently Wien's law is not applicable. The authors based the extrapolation of the temperature scale on an empirical equation of the same form as Wien's, namely-

$$
\mathrm{E}_{(\lambda T)}=c_{1} \lambda-\alpha e^{-\frac{c_{2}}{\lambda T}}
$$

where $\mathbf{E}_{(\lambda T)}$ is the energy of wave-length $\lambda$ at temperature $T$.

Taking logarithms,

$$
\log \mathrm{E}_{(\lambda \mathrm{T})}=\log c_{1}-a \log \lambda-\frac{c_{2}}{\lambda \mathrm{T}} \log e
$$

Now $c_{1}$ has been found by experiment for the radiating surfaces hitherto studied to lie between 500,000 and 2,000,000. Hence, for wave-lengths near unity $(1 \mu)$, the term $a \log \lambda$ in the above equation is small compared with $\log c_{1}$, so that any variation with temperature in the value of $a$ (which in the case of a "full radiator" is numerically equal to 5) will not exert much influence.

Hence a relationship of the form

$$
\log \mathrm{E}_{\lambda \mathrm{T}}=\kappa_{1}+\frac{\kappa_{2}}{\mathrm{~T}}
$$

may be taken as a basis for extrapolation as in the case of a "full radiator."

Standardisation of the spectrophotometer.-From the above it will be observed that two calibration points are sufficient for obtaining the constants of the equation. For this purpose the melting: points of gold and platinum were selected, the standardisation being effected by melting globules of these metals on the glower in exactly the same way as that followed in the case of the samples for test. The value $1065^{\circ}$ was taken for the melting-point of gold, but in the case of platinum at that time the two values $1745^{\circ}$ and $1789^{\circ}$ had been put forward without decisive proof in favour of either.

As previously shown the value $1755^{\circ}$ is the probable one, and the data given by Mendenhall and Ingersoll have been interpolated to refer to this value in Table XL.

As a check point on the line between the melting-points of gold and platinum the melting-point of palladium was determined and found to be $1555^{\circ} \mathrm{C}$., which is in tolerable agreement with the accepted value $1549^{\circ} \mathrm{C}$. 
A further indirect check on the work was obtained by the use of two different wave-lengths, and it was found that the melting-points agreed to within $10^{\circ}$.

Generally the wave-length $0 \cdot 606 \mu$ was adopted for the observations.

An experimental detail which required careful attention was the thermal contact between the globule and the filament. It was observed that the first melts were not so reliable as subsequent ones when the globules had effected good contact. Errors amounting to $100^{\circ}$ to $200^{\circ}$ were possible from this cause. The effect was studied by taking globules of varying size until ultimately the melting-point was found to be independent of the diameter. The limiting value of the diameter was of the order of $0.05 \mathrm{~mm}$. In cases where it was not possible to maintain the globule partly molten and partly solid the melting-point and not the solidifying-point was accepted owing to the considerable super-cooling which occurred.

The method, of course, is only applicable to metals which draw into clear metallic beads and which give consistent readings for successive melts : oxidisable metals cannot be studied under the same conditions.

The most serious criticism of the work is that no attempt was made to ascertain the purity of the metals used.

TABLE XL.

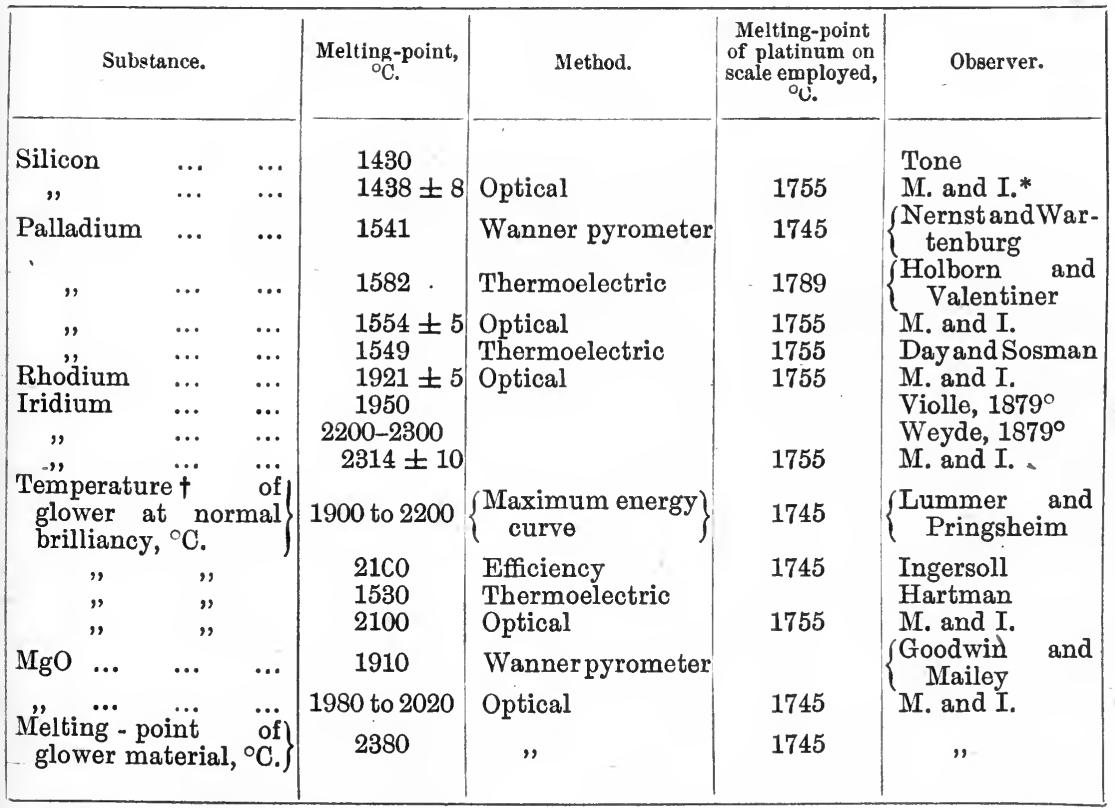

* Mendenhall and Ingersoll.

$\dagger$ On the temperature of normal brilliancy of the glower.-The temperature of a $0.8 \mathrm{amp}$. 110 volt glower $1.04 \mathrm{mms}$. diam. was found to be $2100^{\circ} \mathrm{C}$., while that of one $1.30 \mathrm{mms}$. diam. was about $200^{\circ}$ lower.

Lummer and Pringsheim's value was obtained from measurement of the wave-length 
The iridium, it is stated, might possibly contain traces of ruthenium.

Their value for $\mathrm{MgO}$ differs considerably from that given by Kanolt $\left(2800^{\circ}\right)$.

The melting-points of tungsten and tantalum.-'The extensive use of these metals in incandescent lamp filament manufacture, furnace windings, etc., has naturally resulted in attention being directed to their melting-points.

Many of the published values are based on extrapolations which have no theoretical foundation, and consequently such values have to be regarded as being more or less in the nature of estimates.

Pirani determined the relationship between true temperature, apparent temperature and electrical energy supply in the case of tungsten and tantalum wires heated up to $1700^{\circ} \mathrm{C}$.

The true temperature was obtained by means of a thermocouple inserted between twisted filaments, while the apparent "black body" temperature was determined by sighting a Wanner optical pyrometer on the same filaments.

From the observations he found that the energy varied as the $m$ th power of the absolute temperature,

$$
\text { i.e. } \mathrm{W}=e i=\mathrm{AT}^{m}
$$

where $e$ is the applied voltage,

$i$ is the current,

$\mathrm{T}$ the absolute temperature,

so that $\log e i=\mathbf{A}^{\prime}+m \log \mathrm{T}$.

'This linear relationship between $\log \mathrm{E}$ and $\log$ ' $\mathrm{T}$ was found to hold over a range of $500^{\circ} \mathrm{C}$.

of maximum energy and applying Wien's law, making the assumption that the radiating properties of the glower material were intermediate between those of platinum and a "full radiator."

Ingersoll assumed it to be a "full radiator."

Hartman used thermocouples of wires of various sizes and extrapolated. Mendenhall and Ingersoll showed that Hartman's value was too low, by placing small bits of platinum wire on the glower and noting that it melted at temperutures far below normal brilliancy, hence the temperature of normal brilliancy must be higher than $1755^{\circ}$.

It was observed that it was not possible to melt platinum in the form of fine wire or strip hung over the glower. Hence the probable explanation of Hartman's result is that area of the glower in contact with the platinum wire was maintained at a lower temperature by the conduction of heat along the wire.

This method of employing progressively thinner wires and extrapolating the results to obtain the temperature of flames, etc., is one liable to serious errors. For example, the value $1675^{\circ} \mathrm{C}$. has been given as the temperature of a candle flame, yet it is possible to melt very fine strip platinum in almost any part of the flame. This, however, cannot be regarded as decisive proof that the temperature of the flame exceeds the melting-point of platinum, since the reducing gases present may deteriorate the platinum and affect its melting-point.

Change of radiating power of the metals at the melting-point.-Mendenhall and Ingersoll state that gold shows a marked increase of radiating powér on melting, while palladium, platinum, rhodium and iridium exhibit a similar effect, but to a smaller extent.

Silicon shows a very marked decrease of radiating power on melting.

With rhodium a change occurs at about $1100^{\circ} \mathrm{C}$., which exhibits a decided increase of radiating power as the temperature falls; a slight rise in temperature is sufficient to reverse the effect. 
To obtain the melting-point it was necessary to extrapolate over $1300^{\circ} \mathrm{C}$. The values obtained were

$$
\begin{aligned}
& 3250^{\circ} \mathrm{C} \text {. for tungsten and } \\
& 3000^{\circ} \mathrm{C} \text {. for tantalum. }
\end{aligned}
$$

It is doubtful whether a thermocouple as disposed in these experiments would give the true temperatures. Further, $m$ decreases slightly with the temperature.

To allow for these errors Pirani applied a correction of the order of $200^{\circ} \mathrm{C}$. to the above results.

Wartenberg used tungsten as the anode, and with the discharge from a Wehnelt cathode raised it by bombardment to the melting-point. He measured both the apparent temperature and the reflecting power of the surface.

If $\mathbf{A}$ is the absorbing and $\mathbf{R}$ the reflecting power, then

$$
\mathbf{A}=1-\mathbf{R}
$$

So that if $\mathbf{S}$ is the apparent temperature and $\mathrm{T}$ the true temperature, then by Wien's law-

$$
\frac{1}{\mathrm{~S}}-\frac{1}{\mathrm{~T}}=\frac{c_{2}}{\lambda} \log \frac{\mathrm{A}}{\log e}
$$

where $\lambda$ is the wave-length of the radiation transmitted by the optical pyrometer, and $c_{2}$ the constant in Wien's equation.

The method was tested by him in the case of several metals up to a temperature of $2400^{\circ} \mathrm{C}$.

'The value obtained for the melting-point of tungsten was $2930^{\circ} \mathrm{C}$.

Ruff attempted a direct determination of the melting-point of tungsten, employing a carbon tube furnace mounted in vacuo.

The tube had a longitudinal slit to permit of observations on the metal in the interior under approximate "black body" conditions.

The tungsten was in the form of a cone, and the value $2650^{\circ} \mathrm{C}$. was obtained for its melting-point.

A determination by a similar method by Forsythe gave the value $2974^{\circ} \mathrm{C}$. for the melting-point.

There is but little doubt that these figures are in error owing to the fact that tungsten is attacked by carbon at high temperatures.

Tantalum could not be studied in the carbon tube furnace owing to its reaction with the incandescent carbon, and the specimens tried had the appearance of cinder when taken out of the furnace.

Langmuir's experiments with the tungsten arc.-Langmuir redetermined the melting-point of tungsten by a novel method.

An arc was formed between tungsten electrodes, and the emission of radiation from the areas of molten tungsten observed by means of a disappearing filament type of optical pyrometer.

From observations of the multiple reflections in the arc it was 
possible to calculate the emissivity, and hence the correction to convert apparent to true temperature.

The arc was formed between two tungsten cylinders of the form shown in Fig. 78.

In Langmuir's apparatus the diameter of the large part was $2 \mathrm{mms}$,

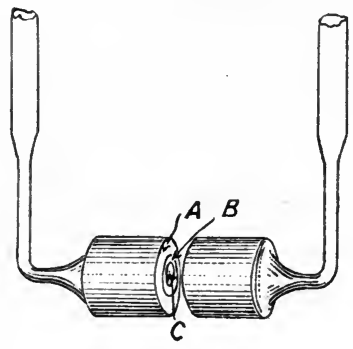

FIG. 78. length $2.5 \mathrm{mms}$., while the small part was $0.3 \mathrm{~mm}$. diameter and the faces $1 \mathrm{~mm}$. apart.

The electrodes were enclosed in an atmosphere of nitrogen, and the arc maintained with alternating current. With a sufficiently high current density the ends of both electrodes melted and formed mirror-like convex surfaces, in which multiple reflections of the electrodes could be seen.

The surfaces could be maintained above the melting-point, without perceptible change, for periods of half an hour and more, during which time the intrinsic brilliancy of the molten tungsten and of the successive reflected images were repeatedly measured.

By adjusting the current the extent to which the ends melted could be controlled; at first only a small wandering spot of molten tungsten was seen, but with larger currents the end of each electrode became uniformly melted and assumed a slightly convex form in which the opposite electrode formed a beautifully reflected image (marked B in Fig. 78) of elliptical shape.

Inside of this image could be seen a series of concentric ellipses which constituted the successive multiple reflections between the two electrodes, such as C. Altogether four such images could be distinguished, and two were sufficiently large to permit of accurate determinations of their intrinsic brilliancy.

The molten tungsten was readily distinguishable in the pyrometer from the solid. In the first place, the solid tungsten always appeared brighter than the molten tungsten in contact with it, and furthermore, the crystalline structure of the solid could easily be seen, especially if it had been previously melted.

On the contrary Worthing states that the brightnesses of molten and solid tungsten at the melting-point are nearly identical, and he was unable to repeat Langmuir's observations. 'The latter states that the surface of molten tungsten is perfectly uniform and entirely devoid of visible structure.* Worthing observed large temperature gradients across the molten tungsten which rendered satisfactory determinations of the emissive power impossible.

The arc itself is practically non-luminous, as can be observed in the case of the commercial form of tungsten arc lamp $\dagger$ invented by

* Luckey ascribes the difference observed by Langmuir to the diffuse reflection of light from the other electrode when the solid surface was roughened by rapid cooling from the molten state.

$\dagger$ These lamps are run at a current density below that necessary to raise the temperature of the electrodes to the melting-point. 
Gimingham and Mullard and manufactured by the Edison and Swan Company.

The method of obtaining the reflecting power of the molten tungsten was as follows.

'Taking the intrinsic brilliancy of the molten surface at (A) as unity, then the brilliancy of the first image (B) is $1+r$, where $r$ is the reflectivity, since at $(\mathbf{B})$ we have the first image superposed on the original surface.

Similarly the brilliancy of the second image (C) should be $1+r+r^{2}$. The values obtained are shown in Table XLI.

TABLE XLI.

\begin{tabular}{|c|c|c|}
\hline Surface. & Relative brilliancy. & $\begin{array}{c}\text { Calculated } \\
(\text { for } \lambda=0.667 \mu \text { ) } \\
\text { taking the value } \\
0.575 \text { for } r .\end{array}$ \\
\hline $\begin{array}{l}\mathrm{A} \\
\mathrm{B} \\
\mathrm{C}\end{array}$ & $\begin{array}{ll}1.00 & 1 \\
1.59 & 1+r \\
1.89 & 1+r+r^{2}\end{array}$ & $\begin{array}{l}1 \cdot 000 \\
1 \cdot 575 \\
1 \cdot 905\end{array}$ \\
\hline
\end{tabular}

Hence $r=0.575$ appears to be the most probable value to fit the observations, so that the emissivity of molten tungsten is 0.425 .

When determining the brilliancy of the portion A of the surface it was necessary to observe on the edge of the molten pool to avoid errors due to superheating of the liquid, and also to take the observations in a direction as nearly normal to the surface as possible.

The apparent "black body" temperature as deduced from observations on the portion (A) of the surface was $2850^{\circ} \mathrm{C}$. Applying a correction on account of the emissivity being only 0.425 , the value $3290^{\circ} \mathrm{C}$. was obtained for the true melting-point temperature.

Langmuir states that this value may be a trifle too high owing to a possible slight inaccuracy in the value taken for the equivalent wavelength * of the red glass employed.

The most probable value given is $3270^{\circ} \mathrm{C} . \pm 30^{\circ}$.

For red light of wave-length $\lambda=0.667 \mu$ the emissivity of a tungsten surface in the solid state is 0.46 and 0.425 in the molten state.

Worthing's determination of the tungsten melting-point.- $\mathrm{He}$ employed a hollow, cylindrical tungsten filament perforated with small holes. This was mounted in a large lamp bulb.

Determinations of the brightness were made by sighting on a hole and on the adjacent surface. The ratio of the latter brightness to the former when corrected for (1) the difference in temperature between the interior and the surface; (2) for the departure from "full radiation" of that from the interior due to the presence of the hole: (3) for the lack of symmetry in the temperature distribution over the filament, gives the emissive power for the metal at that temperature.

* An error of one per cent. in the value of $\lambda$ would cause a discrepancy of $32^{\circ}$ at the temperature of the melting-point of tungsten. 
A linear relation was obtained between the emissive power and the true temperature over the range $900^{\circ}$ to $2900^{\circ} \mathrm{C}$.; the values at these two temperatures being 0.467 and 0.406 respectively for $\lambda=0.666 \mu$. The corresponding corrections to convert apparent to true temperatures are $33^{\circ}$ and $375^{\circ} \mathrm{C}$.

Assuming that the linear relationship between emissive power and temperature for solid tungsten continues to hold up to the meltingpoint this occurs at $3360^{\circ} \mathrm{C}$.

The apparent temperature (for red radiation) of the melting-point is $2870^{\circ} \mathrm{C}$., and the emissivity 0.390 . The values are stated to be of a preliminary nature only.

TABLE XLII.

Melting-point of tungsten.

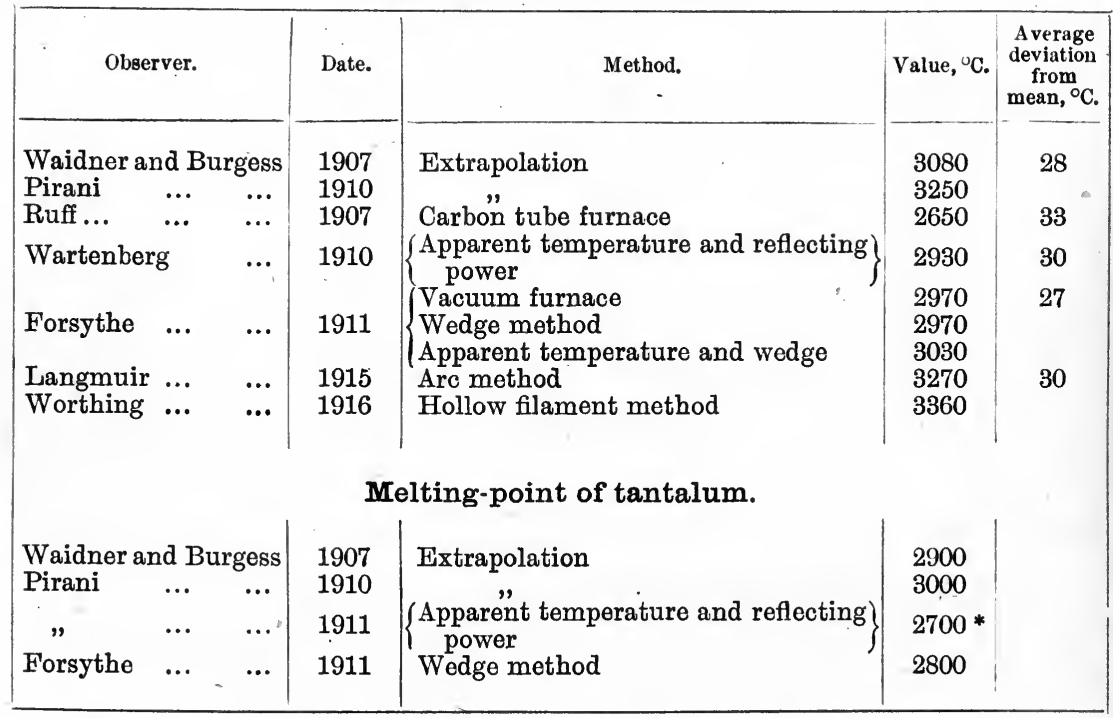

The temperature of the electric arc.--The temperature of the positive crater of the electric arc represents the highest terrestrial

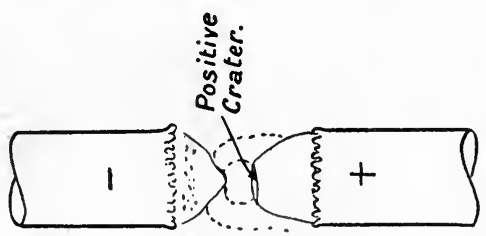

FIG. 79.

temperature, and the estimation of its value has been a frequent subject for investigation.

* Corrected to palladium $1549^{\circ}$ instead of $1575^{\circ} \mathrm{C}$., and $c_{2}=14,500$ instead of 14,200 . 
The theory of the mechanism of the arc which has received the greatest support up to the present is that the arc is produced by carbon vapour volatilised from the electrodes, which are supposed to be in a state of incipient fusion, the surface being covered by a layer of viscous carbon from which the vapour boils.

Variations in temperature of the arc with change in the external conditions.- I. Influence of current density.-As far back as 1878 it was observed by Rossetti that the brightness of the arc did not depend on the value of the current. Since the brightness is a function of the temperature it would follow from this observation that the temperature would be independent of the current.

Violle varied the current from 10 to 400 ampères, and found that the brightness of the positive crater was independent of the power expended in the arc. In these experiments a larger sized electrode was used for the higher energies, and consequently the experiments of Violle do not necessarily prove that for a given size of electrode the temperature is constant.

Wilson and Gray, Wanner, and Waidner and Burgess made further investigations of the same point.

Wilson and Gray and Wanner conclude from their observations that doubling the current through the arc had no influence on the temperature. It should be remarked, however, that their measurements were not particularly concordant, and errors of the order of $100^{\circ} \mathrm{C}$. were possible.

Waidner and Burgess found that the temperature was a function of the current when the potential difference was constant and the arc was burning normally.

The change is comparatively small, since doubling the current caused an increase of $70^{\circ}$ only, from $3420^{\circ}$ to $3490^{\circ} \mathrm{C}$.

The observations were made with a disappearing filament type of optical pyrometer, which had the advantage of only requiring a small area to sight on, and consequently the wandering of the brightest spot of the crater could easily be followed.

Reich using a pyrometer of the polarising type found the value $3430^{\circ} \mathrm{C}$. for the temperature of the positive crater, and $2870^{\circ} \mathrm{C}$. for the cathode, the temperature of both poles being independent of current when this was varied from 3 to 12 amps. He believed that the change observed by Waidner and Burgess might have been due to the increased brilliancy of the gases in the arc with larger currents.

Lummer, in 1913, described experiments in which the current was varied from 10 to 68 ampères, and the length from $1 \mathrm{~mm}$. to $18 \mathrm{mms}$. without apparent effect on the temperature.

The explanation of these effects is not difficult, since increase in current merely involves a larger area covered by the arc, while the small increase of temperature observed by Waidner and Burgess may be caused by superheating of the viscous layer-the vapour still maintaining the temperature of the normal boiling-point-or to the fact that with the smaller current the area heated is reduced, and consequently 
there is a greater tendency to cool the crater by thermal conduction to the colder parts of the carbon.

II. Influence of pressure.-If the theory advanced is correct, that the arc temperature corresponds to the boiling-point or the sublimation temperature of carbon, we should expect the temperature to depend upon the pressure of the atmosphere surrounding the arc. Thus the temperature would be raised when the pressure is raised, and lowered if the pressure is lowered, assuming of course that carbon obeys the laws found to hold for other substances.

Lummer's experiments show that this is the case. At 0.1 atmosphere pressure the temperature is $3670^{\circ} \mathrm{C}$, at 1 atmosphere $3930^{\circ} \mathrm{C}$., and at 22 atmospheres $5730^{\circ} \mathrm{C}$.

III. Influence of impurities.-Wanner observed that cored * carbon gave an arc temperature about $170^{\circ} \mathrm{C}$. lower than that of retort carbon.

Waidner and Burgess found that homogeneous carbons prepared for optical projection purposes gave temperatures of the order of $40^{\circ}$ below those obtained with very pure graphite. The difference would probably be still greater for the commercial carbons which contain salts.

Determinations of the temperature of the positive crater under normal conditions.-Determinations of the temperature of the arc afford a severe test of the validity of the various laws of radiation, owing to the wide ranges of temperature which have to be covered by extrapolation.

It is generally assumed that carbon radiates as a "full radiator," and this assumption is probably not wide of the mark ; in any case the temperature obtained would represent the lower limit if carbon radiates as a "grey body." $\dagger$

(a) Estimations based on Wien's law.-Wanner in 1900 calibrated an optical pyrometer of his design (Chap. VII.) under "full radiator" conditions up to $1100^{\circ} \mathrm{C}$, and verified the linearity of the relationship between $\log \tan \phi$ and $\frac{1}{\mathrm{~T}}$.

He then determined the temperature of the hottest portion of the positive crater, using red $(\lambda=0.6563 \mu)$ and green $(\lambda=0.5461 \mu)$ radiation. below :-

The results obtained with two different grades of carbon are shown

\begin{tabular}{|l|c|c|}
\hline & Cored carbons, ${ }^{\circ} \mathrm{C}$. & Retort carbons, ${ }^{\circ} \mathrm{C}$. \\
\hline Red light $\ldots$ & 3450 & 3600 \\
Green light ... & 3430 & 3620 \\
\hline
\end{tabular}

* The material generally employed for coring is very finely ground carbon, of approximately the same composition as the carbon rod itself, mixed to a paste with a solution of potassium silicate. The composition and the percentage of the silicate used influence considerably the length of the arc.

$\dagger$ One with a constant coefficient of emissivity over the entire spectrum range. 
Féry employed a Le Chatelier form of optical pyrometer and obtained the value $3870^{\circ} \mathrm{C}$. with red light and $3900^{\circ} \mathrm{C}$. with green light. These values appear to be abnormally high; this may be due to the fact that the red glass screen transmitted a wide band and at high temperatures the short wave-lengths would have a disturbing effect on the extrapolation of the low temperature calibration curve.

Waidner and Burgess determined the arc temperature with three different types of optical pyrometers with the results given below.

\begin{tabular}{|cc|c|}
\hline Pyrometer. & \multicolumn{2}{|c|}{ Temperature, ${ }^{\circ} \mathrm{C}}$. \\
\hline & & \\
\hline Holborn-Kurlbaum * & 3420 \\
Le Chatelier & $\ldots$ & 3450 \\
Wanner $\dagger \ldots$ & $\ldots$ & 3410 \\
\hline
\end{tabular}

The determinations above described, with instruments whose calibrations are based on Wien's law, are probably the ones upon which reliance should be placed.

(b) Estimations based on the fourth-power law of radiation.Féry employed one of his early types of total radiation pyrometers in the determination of the temperature of the positive crater.

In this method the image of the crater was focussed by means of the fluorite objective of the telescope on to an iron constantan thermojunction.

The instrument was calibrated up to $1500^{\circ} \mathrm{C}$. on a "full radiator" and its indications shown to comply with the fourth-power law.

The value $3490^{\circ} \mathrm{C}$. was obtained for the temperature of the positive crater.

(c) Estimations based on the Displacement Law $\lambda_{m} \mathbf{T}=$ constant. -This law which connects the wave-length of maximum energy with the temperature has a sound theoretical foundation, but is difficult of practical application, owing to the fact that the energy curve does not possess a well-defined maximum.

Lummer and Pringsheim in 1901 utilised this law to estimate the limiting temperatures of a number of light sources. The value of the constant for a "full radiator" was found to be 2940 .

Hence as a maximum estimate of the temperature of the positive crater we have

$$
\mathrm{T}_{\max .}=\frac{2940}{0 \cdot 7}=4200^{\circ} \mathrm{C} . \mathrm{abs} .
$$

It is probable that carbon approaches but is not quite a "full radiator"; the other extreme is represented by platinum, for which the constant is 2630 .

Hence

$$
\mathrm{T}_{\min .}=\frac{2630}{0 \cdot 7}=3750^{\circ} \mathrm{C} . \text { abs. }
$$

* Disappearing filament type. 
Later determinations of the ordinate of maximum energy by Abney and Festing and by Very have given the value $0 \cdot 73 \mu$ for $\lambda_{m}$.

Hence the limits become

$$
\begin{aligned}
& \mathrm{T}_{\max .}=4025^{\circ} \mathrm{C} \text {. abs. } \equiv 3750^{\circ} \mathrm{C} . \\
& \mathrm{T}_{\min .}=3600^{\circ} \mathrm{C} \text {. abs. } \equiv 3330^{\circ} \mathrm{C} \text {. }
\end{aligned}
$$

(d) Estimations based on various empirical methods of extrapolating the temperature scale.-Le Chatelier (1892) determined the relationship between the intensity of red light and temperature over the range $700^{\circ}$ to $1800^{\circ} \mathrm{C}$., using his optical pyrometer for the purpose.

He deduced the relationship

$$
\mathrm{I}=10^{6 \cdot r} \mathrm{~T}^{-\frac{3210}{\mathrm{~T}}}
$$

Extrapolating this equation to obtain the arc temperature he found the value $4130^{\circ} \mathrm{C}$; ; a result which is probably too high.

Violle (1893 and 1895) described an ingenious method based on the extrapolation of the specific heat-temperature line for carbon.

In this method a small button of carbon from the end of the positive crater was dropped into a calorimeter and its total heat observed.

Assuming the validity of the linear variation of specific heat with temperature, which had been experimentally verified up to a temperature of $1000^{\circ} \mathrm{C}$., he deduced the value $3600^{\circ} \mathrm{C}$. for the temperature of the arc.

Wilson and Gray employed a differential method in which the radiation from the positive crater was balanced against that from a platinum surface at a known temperature.

The radiation was received on the thermojunction of a radiomicrometer.

The relation between the radiation from polished platinum and platinum covered with copper oxide was ascertained, and it was then assumed that carbon obeyed the same law as that found for copper oxide.

From the ratio of the projected areas emitting radiation the temperature of the radiator could be calculated.

For the arc temperature the value $3330^{\circ} \mathrm{C}$. was obtained.

It might be remarked that their scale of temperature was in error, according to present standards, by about $20^{\circ}$ at the melting-point of gold.

Petavel, in his study of the luminous emission from the incandescent platinum, obtained the following relationship between temperature and intrinsic brillancy :-

$$
(t-400)=889 \cdot 6 \sqrt[6 \cdot 9]{b}
$$

where $t$ is temperature in ${ }^{\circ} \mathrm{C} ., b$ the intrinsic brilliancy per sq. $\mathrm{cm}$.

In the case of the positive crater he found for $b$ the value 11,000 candles per $\mathrm{cm}^{2}$. Hence $t=3830^{\circ} \mathrm{C}$., assuming that carbon obeyed the same law as platinum. This of course is hardly a plausible assumption, and the value of $t$ is too high. 
Summarizing the results we have the following series of values for the temperature of the crater:-

TABLE XLIII.

\begin{tabular}{|c|c|c|c|c|c|}
\hline \multicolumn{3}{|c|}{ Observer. } & Date. & Temperature, ${ }^{\circ} \mathrm{C}$. & Method. \\
\hline Le Chate & elier & $\ldots$ & 1892 & 4100 & Intensity red light \\
\hline Violle & $\ldots \quad \ldots$ & $\ldots$ & 1893 & 3600 & Specific heat carbon \\
\hline Wilson a & nd Grey & $\ldots$ & 1895 & 3330 & Total radiation \\
\hline Petavel & $\ldots \quad \ldots$ & $\ldots$ & 1898 & 3830 & Luminosity \\
\hline Wanner & $\ldots \quad \ldots$ & $\ldots$ & 1900 & $3430-3630$ & Wien's law. Different carbons \\
\hline Lummer & and Pringsh & eim & 1901 & $3480-3930$ & $\lambda_{m} \mathrm{~T}=\mathrm{C}$ \\
\hline Very & $\ldots \quad \ldots$ & $\ldots$ & 1899 & $3330-3730$ & $\lambda_{m} \mathrm{~T}=\mathrm{C}$ \\
\hline Féry & $\ldots \quad \ldots$ & $\ldots$ & 1902 & 3490 & fourth-power law \\
\hline Waidner & and Burgess & $\begin{array}{l}\ldots \\
\ldots\end{array}$ & 1904 & $\begin{array}{c}3880 \\
3400-3450\end{array}$ & $\begin{array}{l}\text { Wien's law } \\
\text { Wien's law }\end{array}$ \\
\hline Reich & ... $\quad \ldots$ & $\cdots$ & 1906 & 3430 & Wien's law \\
\hline
\end{tabular}

Boiling-points of the metals. - With a few exceptions metals boil at an extremely high temperature, and in most cases vigorous sublimation occurs at temperatures below the boiling-point which renders observations of the transition points very indefinite.

Experiments on the boiling-points of metals have been described by Féry, Wartenberg, and Greenwood.

Greenwood employed a carbon tube furnace with the metal contained in a crucible suspended from the top of the furnace. Temperature observations were taken with a polarising type of optical pyrometer sighted on the side of the crucible, while visual observations of the surface of the metal were made through a window closing the top of the furnace.

It was observed that the surface of the metal during the heating at first remained perfectly still, but on approaching the boiling-point a slight agitation was seen, which rapidly became vigorous. In most cases the difference between the temperatures indicated when a gentle agitation was first apparent, and when the ebullition was so vigorous that globules of metal were projected to a height of over $10 \mathrm{cms}$, , did not exceed $100^{\circ} \mathrm{C}$.

By accepting as the "boiling-point" that temperature at which ebullition first became decided, quite concordant results were obtained in different experiments.

Hence the " boiling-point" determined by these experiments may be defined as the temperature at which vaporisation becomes sufficiently vigorous to cause a decided projection of drops from the surface.

This definition is, however, somewhat arbitrary, since the temperature of ebullition when hydrogen was passed through the furnace was from $50^{\circ} \mathrm{C}$. to $100^{\circ} \mathrm{C}$. lower than when the nitrogen was used. It would seem that the dislodging of the heavy vapour above the surface of the metal, by the diffusion of hydrogen through the crucible, is apt to mask the true effect. 
'The non-carburisable metals were contained graphite crucibles, while the metals which combine with carbon were contained in a carbon crucible "brasqued" with fused magnesid. Electrically shrunk magnesia was powdered and kneaded with a solution of magnesium chloride. By the use of a wooden former a uniform lining $2 \mathrm{mms}$. thick was obtained. The crucible was dried at $200^{\circ} \mathrm{C}$., and then heated gradually in a carbon tube furnace to $\mathrm{dry}$ off the $\mathrm{HCl}$ which was copiously evolved during the heating.

The temperature was allowed to fall somewhat, and the charge of metal introduced.

Using this method the linings remained perfectly intact and coherent after heating to $1800^{\circ} \mathrm{C}$., and could be used up to $2500^{\circ} \mathrm{C}$.

At temperatures above $1700^{\circ} \mathrm{C}$. some trouble was caused by the interaction of the magnesia and the carbon, with the formation of a dark grey sublimate. 'This, however, was not sufficiently energetic to materially interfere with the observations of the metal surface except at the high temperatures required in the case of iron.

In the case of aluminium the ebullition occurred quite suddenly owing to the formation of an oxide film and its disruption.

With manganese and chromium no tenacious film was obtained, but failures were caused by the corrosive action of the metal on the magnesia lining.

TABLE XLIV.

I. Non-carburisable metals.

\begin{tabular}{|c|c|c|}
\hline Metal. & Boiling-point, ${ }^{\circ} \mathrm{C}$. & Authority. \\
\hline $\begin{array}{l}\text { Copper } \\
\text { Tin" } \\
\text { Silver } \\
\text { Lead } \\
\text { Bismuth } \\
\text { Antimony } \\
\text { Magnesium } \\
\text {," }\end{array}$ & $\begin{array}{r}2100 \\
\text { above } 2200 \\
2310 \\
\text { above } 2200 \\
2275 \\
2070 \\
1955 \\
1580 \\
1525 \\
1550 \\
1420 \\
1500-1700 \\
1440 \\
1100 \\
1120\end{array}$ & $\begin{array}{l}\text { Féry } \\
\text { Wartenberg } \\
\text { Greenwood } \\
\text { Wartenberg } \\
\text { Greenwood } \\
\text { Wartenberg } \\
\text { Greenwood } \\
\text { Wartenberg } \\
\text { Greenwood } \\
\text { Barns } \\
\text { Greenwood } \\
\text { Biltz and Meyer } \\
\text { Greenwood } \\
\qquad, " \quad "\end{array}$ \\
\hline
\end{tabular}

II. Carburisable metals.

\begin{tabular}{l|c|c} 
Aluminium & 1800 & Greenwood \\
Manganese & 1900 &, \\
Chromium & 2200 & $"$ \\
Iron & 2450 & $"$
\end{tabular}

* It is interesting to note that tin remains in the molten stage over a temperature range exceeding $2000^{\circ} \mathrm{C}$.

$\dagger$ Thermocouple determination. Temperature remained steady while the metal distilled into the upper portion of the crucible. 
Boiling-points at different pressures.-By enclosing the furnace in a steel bomb observations could be made under several atmospheres pressure.

At first considerable difficulty was caused by the convection effects in the column through which the surface was observed; this trouble was reduced by prolonging the furnace tube by a chimney up to the window.

The sharpness of the observations was not so satisfactory as at atmospheric pressure owing to the clouds of sublimed vapour obscuring the metal surface.

It was possible, however, to decide the temperature at which globules began to be thrown up.

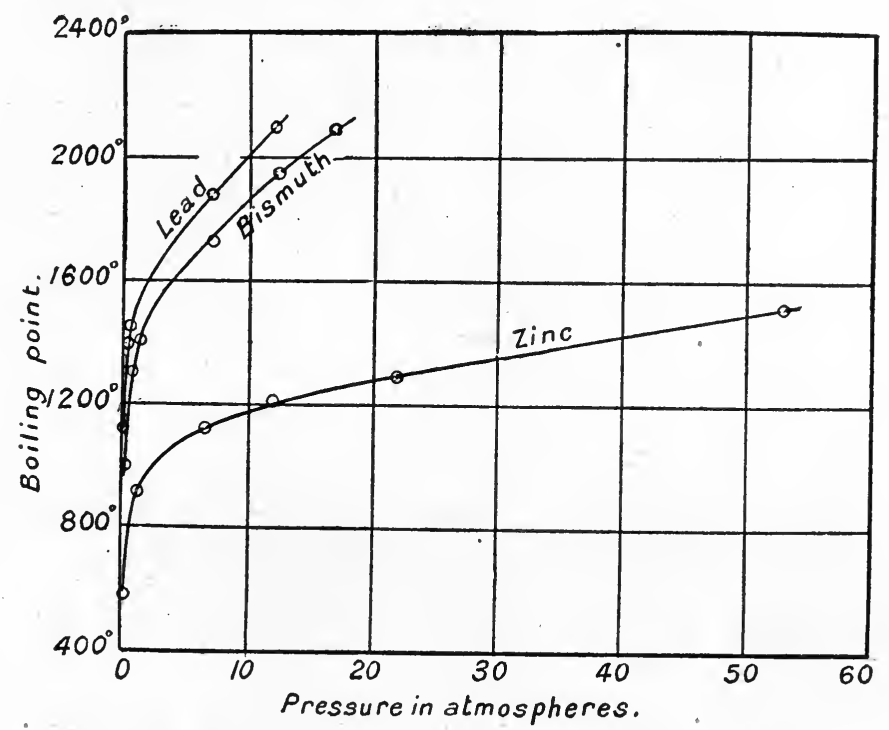

FIG. 80.-Boiling-points of the metals at different pressures.

Zinc exhibited a somewhat abnormal behaviour, the character of the distillation, particularly at the higher pressures, having more the appearance of a very rapid volatilisation than an actual ebullition.

The results are shown graphically in Fig. 80.

Furnace for high temperature melting-points in air.For the determination of the melting-points of certain substances, for example the platinum group, it is essential to employ an oxidising, or at least a neutral atmosphere.

There is a considerable advantage in using a furnace in preference to a strip for heating purposes, particularly if it is practicable to arrange diaphragms so that approximate "black body" conditions are obtained in the interior.

The furnace described below was designed by Dr. Harker in 1905 
for the determination of the melting-point of platinum by the thermoelectric method. It should, however, be possible to so modify it that melting-point determinations could be carried out under " black body" conditions, and an optical pyrometer employed for the temperature observations.

It is a well-known fact that most oxides, when heated to redness, conduct electricity fairly well, and this phenomenon has found practical application in the Nernst lamp.

The resistor element of the furnace illustrated in Fig. 81 is a tube of "rare earths" of a composition which has a high specific electrical conductivity.

The preliminary heating of the material to the temperature $\left(1000^{\circ} \mathrm{C}\right.$.) at which it has a reasonably low resistance, is effected by a nickel wound tube which encloses the resistor element but is separated from it by a layer of powdered zirconia.

The resistor tube $\mathrm{A}$ is about $10 \mathrm{mms}$. internal diameter by $70 \mathrm{mms}$. long. It is made of a mixture of zirconia $\left(\mathrm{ZrO}_{2}\right)$ and 10 per cent. yttria and erbia mixture bound with about 5 per cent. of gum tragacanth. The mixture is moulded and baked at a high temperature. This causes a shrinkage of about 40 per cent. in the volume; consequently the admixture of a considerable proportion of hard burnt material is advisable to reduce the shrinkage.*

The current is led in by platinum flexibles autogenously welded to thick leads of platinum or nickel. The tube is sunk below the level of the surrounding furnace to permit of the upper electrode being heated to the temperature necessary for obtaining good electrical conductivity in the material. The tube $B$ is of hard porcelain of 30 to $40 \mathrm{mms}$. inside diameter and wound with nickel wire.

To start up the furnace, about 200 watts are supplied to the nickel spiral-for half an hour or so-until the interior is red hot. The zirconia tube, with a resistance in series, is then switched on to a 200 to 500 volt circuit.

To maintain the tube at about $2000^{\circ} \mathrm{C}$. a current of the order of 2 amps. is required, with a fall of potential of 60 to 80 volts between the electrodes. Temperatures much in excess of $2000^{\circ} \mathrm{C}$. cannot be obtained, since the material softens about this temperature.

All solid electrolytic conductors have a negative temperature coefficient of resistance, hence a very large ballast resistance is necessary in series with the tube, and normally, a voltage drop of 20 to 25 per cent. occurs in this resistance.

A furnace of the dimensions given above requires-for maintaining a steady temperature of about $1700^{\circ} \mathrm{C}$.- about 150 watts expended in the nickel winding and 140 watts in the tube itself.

The resistance of the tube when at room temperature is of the order of 1000 megohms, but from $400^{\circ} \mathrm{C}$. upwards decreases with great rapidity.

* In the manufacture of refractory bricks it is the standard practice to add a certain amount of "grog," or hard burnt material, to reduce shrinkage. 
The practical difficulty with this type of furnace is the electrodes, the temperature of which must not rise beyond the melting-point of platinum, and with the large sizes this point is a particularly troublesome one. In such cases it is advisable to construct the resistor in the form of a reel, the electrode wires being wound around the wider parts at the ends, and thus kept relatively cool by conduction losses.

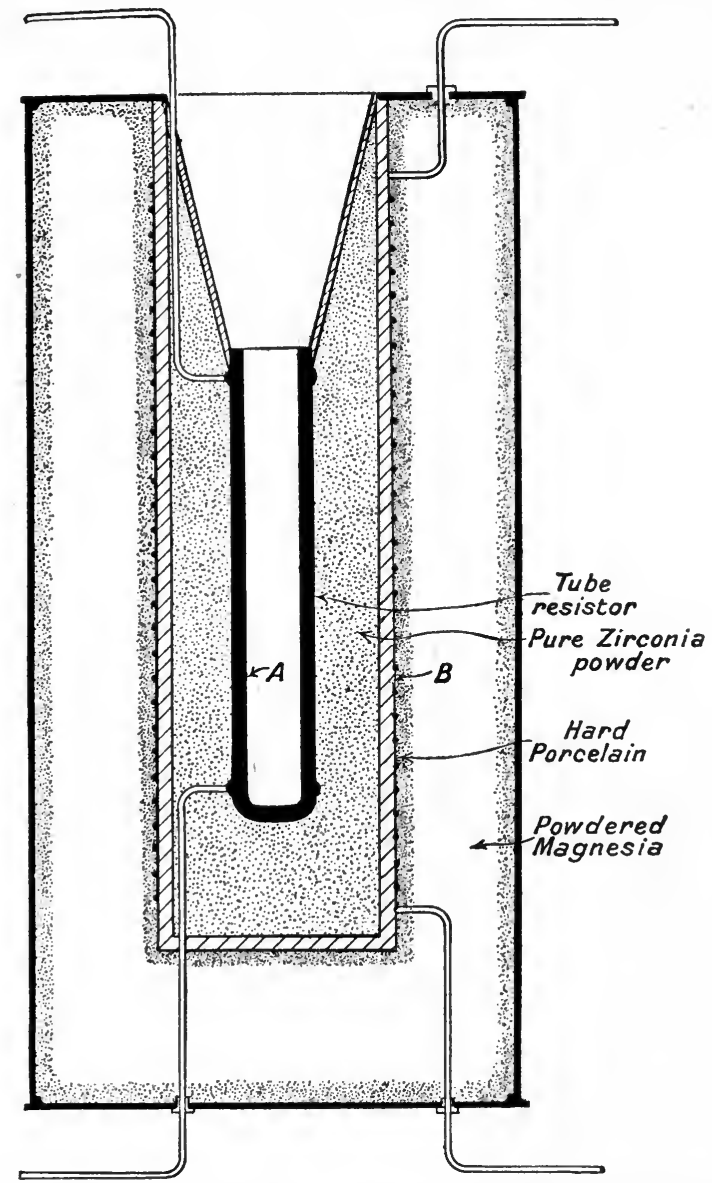

FIG. 81.-Illustration of a furnace for high temperature melting-points in air.

It should be remarked that furnaces of this type cannot be operated at low temperatures, since the current tends to flow along a hot streak and not distribute itself uniformly over the cross-section of the tube. This effect is observed when the furnace has been operated at higher temperatures and then the energy supply is gradually cut down. It is, of course, due to the instability caused by the negative temperature coefficient of resistance. 


\section{REFERENCES' TO CHAPTER IX.}

\section{Melting-points of refractory oxides.}

Kanolt, Bull. Bur. Stds., 10, p. 295 (1914); Tech. Paper, No. 10 (1912).

Ruff, Seiferheld and Suda, "Fusion and Volatilization of Refractory Oxides in the Electric Vacuum Furnace," Zeitschr. f. Anorg. Chem., 82, p. 373 (1913).

Watts and Mendenhall, "Softening of Carbon at High Temperatures," Phys. Rev., 33, p. 65 (1911).

Mendenhall and Ingersoll, Phys. Rev., 25, p. 1 (1907).

Hartman, Phys. Rev., 22, p. $3 \tilde{5} 1$ (1906).

Nicols, Phys. Rev., 10, p. 234 (1900).

Melting-points of metals of the iron group.

Burgess, Journ. Washington Acad., 3, p. 7 (1913); Bull. Bur. Stds., 3, p. 345 (1907); ibid., 9, p. 475 (1913).

Burgess and Waltenberg, Bull. Bur. Stds., 10, p. 3 (1914); Journ. Amer. Chem. Soc., 28, p. 921 (1906).

Kanolt, Tech. Paper, No. 10, Bur. Stds. (1912).

Carpenter, Iron and Steel Inst., Sept. 1908.

Ruff and Martin, Zeitschr.f. Angew. Chem., 25, p. 49 (1912).

Melting-point of platinum and metals of the same group.

Nernst and Wartenberg, Ber. d. Deutsch. phys. Ges., 4, pp. 48 and 146 (1906).

Holborn and Valentiner, Ann. d. Phys. (4), 22, 1 (1907).

Waidner and Burgess, Bull. Bur. Stds., 3, p. 163 (1907).

Day and Sosman, Carnegie, Inst. Publication, No. 157, p. 113 (1911).

Melting-points of tungsten and tantalum.

Pirani, Verh. der deuts. phys. Gesells., 12, 301 (1910).

Wartenberg, Berichte, 12, 105 (1910).

Ruff, Berichte der deutsch. chem. Gesells., 43, 1564 (1910).

Langmuir, Phys. Rev., 6, p. 153 (1915).

Worthing, Journ. Frankl. Inst., 181, p. 417 (1916).

Gimingham and Mullard, "A new high efficiency incandescent lamp," Journ. Instit. Elect. Eng., 54, p. 15 (1915).

Luckey, "The tungsten arc under pressure," Phys. Rev., 9, p. 129 (1917).

\section{Temperature of the arc.}

Violle, Journ. de Phys. (3), 2, p. 545 (1893).

Lummer, "Liquefaction of carbon and the production of sun temperature," (in German) "Sammlung Viehweg," Engineering, Sept. 3, p. 244 (1915).

Wanner, Ann. d. Phys., 2, p. 141 (1900).

Féry, Comptes rend., 134, pp. 977, 1201 (1902).

Lummer and Pringsheim, Verh. d. Deutsch. Phys. Ges., 1, p. 235 (1899); ibid., 3 , p. 36 (1901).

Abney and Festing, Proc. Roy. Soc., 35, p. 334 (1883).

Very, Astro. Phys. Journ., 10, p. 208 (1899).

Le Chatelier, Comptes rend., 114, p. 737 (1892); Journ. de Phys. (3), 1, p. 185 (1892).

Violle, Comptes rend., 95, p. 1273 ; Journ. de Phys. (3), 2, p. 545 (1893); Comptes rend., 120, p. 868 (1895).

Wilson and Gray, Proc. Roy. Soc., 58, p. 24 (1895) ; Phil. Trans., A., 185. p. 361 (1894).

Petavel, Phil. Trans., A., 191, p. 515 (1898).

Waidner and Burgess, Bull. Bur. Stds., 1, p. 109 (1904-05).

Reich, Phys. Zs., 7, p. 73:(1906). 
Boiling-points of metals.

Greenwood, Trans. Faraday Society, 7, p. 145 (1911) ; Proc. Roy. Soc., A., 82, p. $396(1909) ; 83$, p. $483(1910)$.

Johnson, "The vapour pressure and volatility of several high-boiling metalsA review," Journ. Ind. and Eng. Chem., 9, p. 873 (1917).

\section{Furnaces.}

Harker, "Solid electrolyte tube furnace," Proc. Roy. Soc., 76, p. 235 (1905).

Wartenberg, "Tungsten furnace," Zeitschr. f. Elek. Chem., 15, p. 876 (1909).

Heraeus, "Iridium furnace," Zeitschr. f. Angew. Chem., 18, p. 49 (1905). 



\section{A P PENDIX}

\section{TABLES}

TABLE XLV.

Boiling-point of water at different pressures.

\begin{tabular}{|c|c|c|c|c|c|}
\hline Pressure. & Temp. ${ }^{\circ} \mathrm{C}$. & Diff. pr. 1:mm. & Pressure. & Temp. ${ }^{\circ} \mathrm{C}$. & Diff. pr. $1 \mathrm{~mm}$. \\
\hline $\begin{array}{l}730 \\
731 \\
732 \\
733 \\
734 \\
735 \\
736 \\
737 \\
738 \\
739 \\
740 \\
741 \\
742 \\
743 \\
744 \\
745 \\
746 \\
747 \\
748 \\
749 \\
750\end{array}$ & $\begin{array}{r}98 \cdot 8802 \\
\cdot 9182 \\
\cdot 9561 \\
\cdot 9939 \\
99 \cdot 0318 \\
\cdot 0695 \\
\cdot 1073 \\
\cdot 1449 \\
\cdot 1826 \\
\cdot 2202 \\
\cdot 2577 \\
\cdot 2953 \\
\cdot 3327 \\
\cdot 3702 \\
\cdot 4075 \\
\cdot 4449 \\
\cdot 4822 \\
\cdot 5194 \\
.5567 \\
\cdot 5938 \\
\cdot 6310\end{array}$ & 0.0378 & $\begin{array}{l}750 \\
751 \\
752 \\
753 \\
754 \\
755 \\
756 \\
757 \\
758 \\
759 \\
760 \\
761 \\
762 \\
763 \\
764 \\
765 \\
766 \\
767 \\
768 \\
769 \\
770\end{array}$ & $\begin{array}{r}99 \cdot 6310 \\
\cdot 6681 \\
\cdot 7051 \\
\cdot 7421 \\
\cdot 7791 \\
\cdot 8160 \\
\cdot 8529 \\
\cdot 8897 \\
\cdot 9265 \\
\cdot 9633 \\
100 \cdot 0000 \\
\cdot 0367 \\
\cdot 0733 \\
\cdot 1099 \\
\cdot 1465 \\
\cdot 1830 \\
\cdot 2194 \\
\cdot 2559 \\
\cdot 2923 \\
\cdot 3286 \\
\cdot 3649\end{array}$ & 0.0369 \\
\hline
\end{tabular}

\section{TABLE XLVI.}

Boiling-point of sulphur at different pressures. Also the corresponding values of the function $\left\{\left(\frac{t}{100}\right)^{2}-\left(\frac{t}{100}\right)\right\}$.

\begin{tabular}{|c|c|c|c|c|c|}
\hline Pressure. & Temp. ${ }^{\circ} \mathrm{C}$. & $\left\{\left(\frac{t}{100}\right)^{2}-\left(\frac{t}{100}\right)\right\}$ & Pressure. & Temp. ${ }^{\circ} \mathrm{C}$. & $\left\{\left(\frac{t}{100}\right)^{2}-\left(\frac{t}{100}\right)\right\}$ \\
\hline $\begin{array}{l}730 \\
731 \\
732 \\
733 \\
734 \\
735 \\
736 \\
737\end{array}$ & $\begin{array}{r}441 \cdot 77 \\
\cdot 86 \\
\cdot 96 \\
442 \cdot 05 \\
\cdot 14 \\
\cdot 24 \\
\cdot 33 \\
\cdot 42\end{array}$ & $\begin{array}{r}15 \cdot 098 \\
\cdot 105 \\
\cdot 113 \\
\cdot 120 \\
\cdot 127 \\
\cdot 135 \\
\cdot 142 \\
\cdot 149\end{array}$ & $\begin{array}{l}737 \\
738 \\
739 \\
740 \\
741 \\
742 \\
743 \\
744\end{array}$ & $\begin{array}{r}442 \cdot 42 \\
\cdot 52 \\
\cdot 61 \\
\cdot 70 \\
\cdot 79 \\
.89 \\
\cdot 98 \\
443 \cdot 07\end{array}$ & $\begin{array}{r}15 \cdot 149 \\
\cdot 157 \\
\cdot 164 \\
\cdot 171 \\
\cdot 178 \\
\cdot 186 \\
\cdot 193 \\
\cdot 201\end{array}$ \\
\hline
\end{tabular}


TABLE XLVI.-continued.

\begin{tabular}{|c|c|c|c|c|c|}
\hline Pressure. & Temp. ${ }^{\circ} \mathrm{C}$. & $\left\{\left(\frac{t}{100}\right)^{2}-\left(\frac{t}{100}\right)\right\}$ & Pressure. & Temp. ${ }^{\circ} \mathrm{C}$. & $\left\{\left(\frac{t}{100}\right)^{2}-\left(\frac{t}{100}\right)\right\}$ \\
\hline $\begin{array}{l}744 \\
745 \\
746 \\
747 \\
748 \\
749 \\
750 \\
751 \\
752 \\
753 \\
754 \\
755 \\
756 \\
757\end{array}$ & $\begin{array}{r}443 \cdot 07 \\
\cdot 16 \\
\cdot 25 \\
.35 \\
.44 \\
.53 \\
.62 \\
.71 \\
.80 \\
.89 \\
.98 \\
444 \cdot 08 \\
\cdot 17 \\
\cdot 26\end{array}$ & $\begin{array}{r}15 \cdot 201 \\
\cdot 208 \\
\cdot 215 \\
\cdot 222 \\
\cdot 229 \\
\cdot 237 \\
\cdot 244 \\
.251 \\
.258 \\
\cdot 265 \\
\cdot 272 \\
.280 \\
.287 \\
\cdot 294\end{array}$ & $\begin{array}{l}757 \\
758 \\
759 \\
760 \\
761 \\
762 \\
763 \\
764 \\
765 \\
766 \\
767 \\
768 \\
769 \\
770\end{array}$ & $\begin{array}{r}444 \cdot 26 \\
\cdot 35 \\
\cdot 44 \\
\cdot 53 \\
\cdot 62 \\
\cdot 71 \\
\cdot 80 \\
\cdot 89 \\
\cdot 98 \\
445 \cdot 07 \\
\cdot 16 \\
\cdot 25 \\
\cdot 34 \\
\cdot 43\end{array}$ & $\begin{array}{r}15 \cdot 294 \\
\cdot 301 \\
\cdot 308 \\
\cdot 315 \\
\cdot 322 \\
.329 \\
.336 \\
.343 \\
.351 \\
.358 \\
.365 \\
.372 \\
.379 \\
\cdot 386\end{array}$ \\
\hline
\end{tabular}

Calculated from the formula

$$
t=444.53+0.904(p-760)-0.0000519(p=760)^{2} .
$$

TABLe XLVII.

\begin{tabular}{|c|c|c|c|c|c|}
\hline$p t{ }^{\circ} \mathrm{C}$. & $t^{\circ} \mathrm{C}$ & Difference for $1^{\circ} \mathrm{pt}$. & $p t^{\circ} \mathrm{C}$. & $t^{\circ} \mathrm{C}$ & Difference for $1^{\circ} \mathrm{pt}$. \\
\hline-40 & $-39 \cdot 18$ & 0.975 & 270 & $277 \cdot 38$ & 1.075 \\
\hline-30 & -29.43 & 0.978 & 280 & $288 \cdot 13$ & 1.079 \\
\hline-20 & -19.65 & 0.981 & 290 & $298 \cdot 92$ & 1.083 \\
\hline-10 & -9.84 & 0.984 & 300 & $309 \cdot 75$ & $1 \cdot 086$ \\
\hline 0 & 0.00 & 0.987 & 310 & $320 \cdot 61$ & 1.090 \\
\hline 10 & $9 \cdot 87$ & 0.990 & 320 & $331 \cdot 51$ & $1 \cdot 095$ \\
\hline 20 & $19 \cdot 76$ & 0.992 & 330 & $342 \cdot 45$ & $1 \cdot 098$ \\
\hline 30 & $29 \cdot 69$ & 0.995 & 340 & $353 \cdot 44$ & $1 \cdot 102$ \\
\hline 40 & $39 \cdot 64$ & 0.998 & 350 & $364 \cdot 46$ & $1 \cdot 106$ \\
\hline 50 & $49 \cdot 63$ & $1 \cdot 001$ & 360 & $375 \cdot 52$ & $1 \cdot 110$ \\
\hline 60 & $59 \cdot 64$ & $1 \cdot 004$ & 370 & $386 \cdot 62$ & $1 \cdot 114$ \\
\hline 70 & $69 \cdot 68$ & 1.007 & 380 & $397 \cdot 76$ & $1 \cdot 118$ \\
\hline 80 & $79 \cdot 76$ & $1 \cdot 011$ & 390 & $408 \cdot 95$ & $1 \cdot 123$ \\
\hline 90 & $89 \cdot 86$ & $1 \cdot 014$ & 400 & $420 \cdot 18$ & $1 \cdot 127$ \\
\hline 100 & $100 \cdot 00$ & 1.017 & 410 & $431 \cdot 45$ & $1 \cdot 132$ \\
\hline 110 & $110 \cdot 17$ & $1 \cdot 020$ & 420 & $442 \cdot 76$ & $1 \cdot 136$ \\
\hline 120 & $120 \cdot 37$ & 1.023 & 430 & $454 \cdot 13$ & $1 \cdot 140$ \\
\hline 130 & $130 \cdot 60$ & $1 \cdot 026$ & 440 & $465 \cdot 53$ & $1 \cdot 144$ \\
\hline 140 & 140.86 & 1.030 & 450 & $476 \cdot 97$ & $1 \cdot 149$ \\
\hline 150 & $151 \cdot 16$ & $1: 033$ & 460 & $488 \cdot 46$ & $1 \cdot 154$ \\
\hline 160 & $161 \cdot 49$ & $1 \cdot 036$ & 470 & $500 \cdot 00$ & $1 \cdot 158$ \\
\hline 170 & $171 \cdot 85$ & 1.040 & 480 & $511 \cdot 58$ & $1 \cdot 163$ \\
\hline 180 . & $182 \cdot 25$ & $1 \cdot 043$ & 490 & $523 \cdot 21$ & $1 \cdot 168$ \\
\hline 190 & $192 \cdot 68$ & $1 \cdot 046$ & 500 & $534 \cdot 89$ & $1 \cdot 173$ \\
\hline 200 & $203 \cdot 14$ & 1.050 & 510 & $546 \cdot 62$ & $1 \cdot 178$ \\
\hline 210 & $213 \cdot 64$ & 1.054 & .520 & $558 \cdot 40$ & $1 \cdot 182$ \\
\hline 220 & $224 \cdot 18$ & $1 \cdot 057$ & 530 & $570 \cdot 22$ & $1 \cdot 188$ \\
\hline 230 & $234 \cdot 75$ & 1.060 & 540 & $582 \cdot 10$ & $1 \cdot 193$ \\
\hline 240 & $245 \cdot 35$ & 1.064 & 550 & $594 \cdot 03$ & $1 \cdot 198$ \\
\hline 250 & 255.99 & 1.068 & 560 & $606 \cdot 00$ & $1 \cdot 203$ \\
\hline 260 & 266.67 & 1.071 & 570 & $618 \cdot 03$ & 1.208 \\
\hline
\end{tabular}


TABLE XLVII.-continued.

\begin{tabular}{|c|c|c|c|c|c|}
\hline$p t^{\circ} \mathrm{C}$ & $t^{\circ} \mathrm{C}$ & Difference for $1^{\circ} p t$. & $p t^{\circ} \mathrm{C}$ & $t^{\circ} \mathrm{C}$ & Difference for $1^{\circ} p t$ \\
\hline 580 & $630 \cdot 11$ & $1 \cdot 213$ & 800 & $910 \cdot 76$ & $1 \cdot 352$ \\
\hline 590 & $642 \cdot 24$ & $\mathrm{~J} \cdot 219$ & 810 & $924 \cdot 28$ & $1 \cdot 359$ \\
\hline 600 & $654 \cdot 43$ & $1 \cdot 224$ & 820 & $937 \cdot 87$ & $1 \cdot 367$ \\
\hline 610 & $666 \cdot 67$ & $1 \cdot 230$ & 830 & $951 \cdot 54$ & $1 \cdot 374$ \\
\hline 620 & $678 \cdot 97$ & $1 \cdot 235$ & 840 & $965 \cdot 28$ & $1 \cdot 383$ \\
\hline 630 & $691 \cdot 32$ & $1 \cdot 241$ & 850 & $979 \cdot 11$ & $1 \cdot 390$ \\
\hline 640 & $703 \cdot 73$ & $1 \cdot 247$ & 860 & $993 \cdot 01$ & $1 \cdot 399$ \\
\hline 650 & $716 \cdot 20$ & $1 \cdot 253$ & 870 & $1007 \cdot 00$ & $1 \cdot 407$ \\
\hline 660 & $728 \cdot 73$ & $1 \cdot 259$ & 880 & $1021 \cdot 07$ & $1 \cdot 416$ \\
\hline 670 & $741 \cdot 32$ & $1 \cdot 264$ & 890 & $1035 \cdot 23$ & 1.424 \\
\hline 680 & $753 \cdot 96$ & $1 \cdot 271$ & 900 & $1049 \cdot 47$ & $1 \cdot 433$ \\
\hline 690 & $766 \cdot 67$ & $1 \cdot 277$ & 910 & $1063 \cdot 80$ & $1 \cdot 441$ \\
\hline 700 & $779 \cdot 44$ & $1 \cdot 283$ & 920 & $1078 \cdot 21$ & $1 \cdot 450$ \\
\hline 710 & $792 \cdot 27$ & $1 \cdot 290$ & 930 & $1092 \cdot 71$ & $1 \cdot 460$ \\
\hline 720 & $805 \cdot 17$ & $1 \cdot 296$ & 940 & $1107 \cdot 31$ & $1 \cdot 469$ \\
\hline 730 & $818 \cdot 13$ & $1 \cdot 303$ & 950 & $1122 \cdot 00$ & $1 \cdot 479$ \\
\hline 740 & $831 \cdot 16$ & $1 \cdot 310$ & 960 & $1136 \cdot 79$ & $1 \cdot 490$ \\
\hline 750 & $844 \cdot 26$ & $1 \cdot 316$ & 970 & $1151 \cdot 69$ & $1 \cdot 499$ \\
\hline 760 & $857 \cdot 42$ & $1 \cdot 323$ & 980 & $1166 \cdot 68$ & 1.508 \\
\hline 770 & $870 \cdot 65$ & $1 \cdot 330$ & 990 & $1181 \cdot 76$ & 1.519 \\
\hline 780 & $883 \cdot 95$ & $1 \cdot 337$ & 1000 & $1196 \cdot 95$ & 1.529 \\
\hline 790 & $897 \cdot 32$ & $1 \cdot 344$ & 1010 & $1212 \cdot 24$ & $1 \cdot 541$ \\
\hline
\end{tabular}

TABLE XLVIII.

To calculate the change in $t$ for a given small change in $\delta$.

\begin{tabular}{|c|c|c|c|}
\hline$t^{\circ} \mathrm{C}$ & $\begin{array}{l}\text { Change in } t \text { for change } \\
\text { of }+0.01 \text { in } \delta \text {. }\end{array}$ & $t^{\circ} \mathrm{C}$ & $\begin{array}{l}\text { Change in } t \text { for change } \\
\text { of }+0.01 \text { in } \delta \text {. }\end{array}$ \\
\hline $\begin{array}{r}-40 \\
-20 \\
0 \\
20 \\
40 \\
60 \\
80 \\
100 \\
120 \\
140 \\
160 \\
180 \\
200 \\
250 \\
300 \\
350 \\
400\end{array}$ & $\begin{array}{l}+0.0056 \\
+0.0024 \\
+0.0000 \\
-0.0016 \\
-0.0024 \\
-0.0024 \\
-0.0016 \\
-0.0000 \\
+0.0024 \\
+0.0056 \\
+0.0096 \\
+0.0144 \\
+0.0200 \\
+0.0375 \\
+0.0600 \\
+0.0875 \\
+0.1200\end{array}$ & $\begin{array}{r}450 \\
500 \\
550 \\
600 \\
650 \\
700 \\
750 \\
800 \\
850 \\
900 \\
950 \\
1000 \\
1050 \\
1100 \\
1150 \\
1200\end{array}$ & $\begin{array}{c}+0.1575 \\
+0.200 \\
+0.247 \\
+0.300 \\
+0.357 \\
+0.420 \\
+0.487 \\
0.560 \\
0.637 \\
0.720 \\
0.807 \\
0.900 \\
0.997 \\
1.100 \\
1.207 \\
1.320\end{array}$ \\
\hline
\end{tabular}

Tables XLVII. and XLVIII. based on data given by Dr. J. A. Harker, Phil. Trans. Roy. Soc., Vol. 203, A. 369, p. 343 (1904). 



\section{N D E X}

Absorption devices, 117

Alumina, 147 of radiation, 103

Arc carbon, 158 tungsten, 155

Arsem, 146

Barus, 8

Bath salt, 26 water, 22

Bidwell, 131

Boiling-points, 8, 16, 72, 163

Bolometer, 84

Bridge resistance, 37

Brightness, total, 111

Brilliancy, intrinsic, 127

Bureau, International, 2

Calibration, mercury thermometers, 19 optical pyrometers, 125 radiation pyrometers, 94 resistance, 34

Callendar, 4 thermocouples, 77

Calorimetric thermometers, 34, 71

Carbon arc, 158 tube furnace, 126

Chromium oxide, 147

Cobalt, 147

Day and Sosman, 7, 9, 10

Deflection potentiometer, 66

Differential couples, 71

Direct reading indicators, 67

Distribution of energy, 106, 130

Emissivity metals, 102, 130-140 oxides, 95,102

Féry pyrometer, 89

Fixed points, 15

Foster pyrometer, 92

Fourth-power law, 81, 86

Fundamental scale, 1

Furnace, 165
Gas thermometer, 2, 3, 4

Glass thermometer, 28

Grey, 159

Griffiths, 7, 17, 31

Harker, 64, 165

Heating effect of current, 47

Henning, 12

High temperature thermometry, 8, 24

Holborn and Kurlbaum, 114

Valentiner, 9

Wien, 9,11

Hypsometer, 20

Ice point apparatus, 21

Indicators, 56, 67

Industrial pyrometers, 56

Ingersoll, 151

Insulation, 68

Iridium, 152

Kanolt, 145

Kelvin, 1

\section{Langmuir, 154}

Lime, 146

Low temperature measurement, 78

Lummer, 159 scale, 12

Luckey, 156 and Pringsheim, 82, 107, 112

Magnesia, 147

Manganese, 147

Melting-points, 145, 147

Mendenhall, 117

and Forsythe, 86

Mercury contacts, 38

Meyer, 52 thermometer, 18

Micropyrometer, 148

Morse, 114

Mueller, 44

Nernst glower, 151 
Nickel, 147 .

Nicol prism, $12 \sigma$

Optical pyrometers, 113

\section{Palladium, 74}

Perfect gas, 1

Pirani, 158

Planck, 110

Platinum, influence of purity, 33 melting-point, 150

Potentiometers, 60 thermometer, 4

Pouillet, 8, 56

Princeps, 8

Rasch, 128

Reich, 159

Resistance bridges, 37

Resistance thermometer, 4

Rossetti, 159

Ruthenium, 153

Scale, thermodynamic, 15

Schofield, 17

Siemens, 30

Silicon, 153

Smith difference bridge, 39
Spectrophotometer, 152

Spectroscopic eyepiece, 117

Standard temperatures, 15

Stefan, 81

Sulphur, 7, 8, 52, 54

Tantalum, 158

Temperature control; 47

Thermocouples, 59

Thermodynamic scale, 1

Thermoelectric effect, 49

Thwing pyrometer, 92

Titanium, 147

Total radiation, 89

Travers, 12

Tungsten, 158

Vanadium, 149

Varley, 63

Vernier potentiometers, 62

Verre dur, 2

Waidner, 159

Wartenberg, 158, 163

Wave-length transmitted, 117, 122

Welding vires, 71

Whipple, 92

Wien's law, 106, 112

Worthing, 157 


\section{CHARLES GRIFFIN \& COMPANY,}

L I M I TED.

A SUMMARISED LIST OF

THE

E N G I N E E R I N G, M I N I NG,

METALLURGICAL AND TECHNICAL

P U B L I CA T I O N S

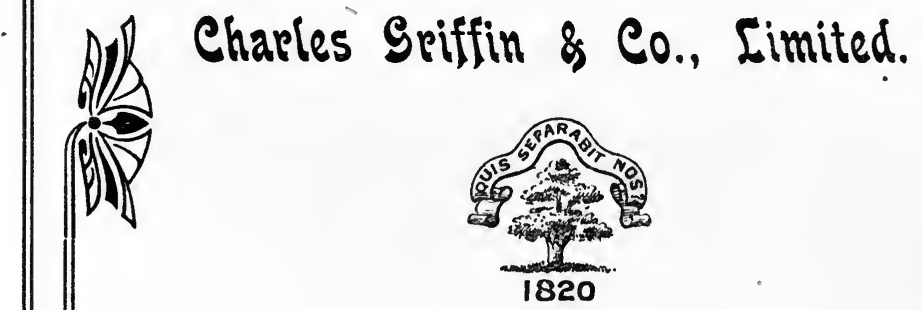

Trese Publications may be obtained through any Bookseller in the United Kingdom, or will be sent on receipt of a remittance to cover published price and postage. To prevent delay, Orders should be accompanied by a Cheque or Postal Order crossed "Union of London and Smith's Bank, Chancery Lane Branch."

Telephone- LONDON: "Telegrams3634 Gerpard. $L O N D$ : "Explanatus," London. $A$ 12 EXETER \&TREET, STRAND, W.C. 2. M. 8-pp., Sept., 1917. 


\section{GRIFFIN'S ENGINEERING PUBLICATIONS.}

THE DESIGN OF BEAMS, GIRDERS, AND COLUMNS in Machines and Structures. By W. H. ATHERTON,
BRIDGE CONSTRUCTION (Practical Treatise on). By Prof. C. FIDLER, M.Inst.C.E. FOURTH EDITION, Revised, CONSTRUCTIONAL STEELWORK. By A. W. FARNSWORTH, - - net. 10s 6d DOCK ENGINEERING. By BRYSSON CUNNINGHAM. SECOND EDITION. With Folding Plates and other Illustrations,

- net. $30 \mathrm{~s}$ od

HARBOUR ENGINEERING. By BRYSSON CUNNINGHAM. SECONI EDITION, Revised and Greatly Enlarged. In Large 8vo. Cloth. Profusely Illustrated.

DOCK AND HARBOUR ENGINEER'S REFERENCE BOOK. In Pocket Size, Leather. Fully Illustrated. BY BRYSSON CUNNINGHAM. - - - - net. 7s 6d HYDROGRAPHIC SURVEYING. By Commander S. MFSSUM, R.N., - - net. 12s od COAST EROSION AND PROTECTION. SECOND EIITION, Enlarged. By Prof. E. R. MATTHEWS, PR

THE CONSTRUCTION OF DAMS. By Prof. E. R. AlatThews, - At Press.

HYDRAULIC POWER AND HYDRAULIC MACHINERY. By Prof. H. ROBINSON, M.Inst.C.E. THIRD EDITION, Revised, - - - net. $25 \mathrm{~s}$ 0d MODERN PUMPING AND HYDRAULIC MACHINERY. By E. BUTLER, net. 18s od PUMPING MACHINERY (Steam and Water Pressure). By HENRY DAVEX, M.Inst.C.E. SECOND EDITION.

TEXT-BOOK OF PRACTICAL HYDRAÚLICS. Prof. J. PARK, - - net. 12s 6d

CENTRIFUGAL PUMPING MACHINERY. SECOND EDITION. By E. W. SARGEANT, P - - net. 10s 6d

WATER SUPPLY: Selection of Sources and Distribution. By R. E.

MIDDLETON, M.Inst.C.E., \&c. With Plates and other Illustrations, - net. $8 \mathrm{~s} 6 \mathrm{~d}$

SEA WATER DISTILLATION. By FRANK NORIANDY, - * - net. 6s od

THE THEORY OF THE STEAM TURBINE. By ALEX. JUde. SECOND EDITION, - - - - net. $18 \mathrm{~s}$ od

GAS, OIL, AND AIR ENGINES. By Donkin, Graves SMith, and Burstall.

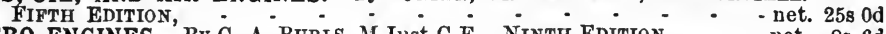

AERO ENGINES.' By $\dot{G}$. A. BURLS, M.Inst.C.E. NINTH EDiTION, $-\dot{-n}_{-}^{-}$net. $8 \mathrm{~s} 6 \mathrm{~d}$

INTERNAL COMBUSTION ENGINES. By C. W. ASKLING and E. RoESLER,

M.E.,

DIESEL' ENGINES, LAND AND MARINE. By Prof. SUPINO. Translated by A. G. BREMNER and A. RICHARDSON. SECOND EDITION, Revised, . - net. 12s 6d

EVOLUTION OF THE INTERNAL COMBUSTION ENGINE. By EDWARD

THE GAS TURBINE (Construction and Working of Two Actual $8 \mathrm{~s} 6 \mathrm{~d}$ Machines). By H. HOLZWARTH and A. P. CHALKLEY, - - net. is $6 \mathrm{~d}$

SUCTION GAS PLANTS. By Prof. C. A. SMITH. SECOND IMPRESSION, - net. 5s od

OIL MOTORS : Their Development, Construction, and Management. By G. LIEOKFELD. In Handsome Cloth. Fully Illustrated, - - net. 15s 0d

BOILERS, LAND AND MARINE. By T. W. TRAILL. FoURTH EnITION, net. 10s 6d

STEAM BOILERS : Their Defects, Management, and Construction. By

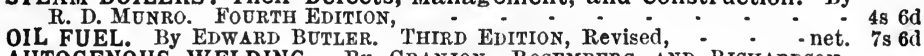

AUTOGENOUS WELDING. By GRANJON, ROSEMBERG AND RICHARDSON. FIFTH EDITION, - -

SMOKE ABATEMENT. By WM. NIOHOLSON. With 59 Illustrations, - net. 6s od LUBRICATION AND LUBRICANTS. By L. ARCHBUTT and R. M. DEELEY. THIRD EDITION, Thoroughly Revised, - - - - - - - net. 25s 0d

EMERY GRINDING MACHINERY. By R. B. HODGSON, A.M.Inst.C.E. - net. 5s od THE POWER REQUIRED IN ROLLING MILLS. By J. PUPPÉ, - - net. 12s $6 \mathrm{~d}$ LOCoMotive ENGINEERING. By W. F. PetTigrew, M.Inst.c.e. Third EDITION, Revised throughout. New Illustrations, - - - - - $21 \mathrm{~s}$ od

LOCOMOTIVE COMPOUNDING AND SUPERHEATING. By J. F. GAIRNS, net. $8 \mathrm{~s}$ 6d LIGHT RAILWAYS at Home and Abroad. By W. H. CoLE, M.Inst.C.E., - 16s od MECHANICAL DRAWING. By J. E. JAGGER, M.Sc. SECOND EDITION, - net. 7s 6d MECHANICAL ENGINEERING FOR BEGINNERS. By R. S. MCLAREN. Cloth. With 126 Illustrations. THIRD EDITION, - - - net. 5s od BONUS TABLES: for the Calculation of Wages on the Bonus System.

By H. A GOLDING, A.M.Inst.M.E.,
THE CALCULUS FOR ENGINEERS AND PHYSICISTS. By Prof. R. H.

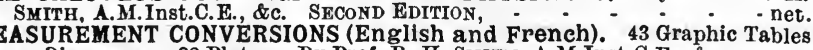
or Diagrams on 28 Plates. By Prof. R. H. SMITH, A.M.Inst.C.E., \&c., - - 7s 6d MATHEMATICS AND MECHANICS. By C. A. A. CAPITO, M.Sc., - - net. 12s 6d PRACTICAL SURVEYING AND FIELD-WORK. By V. G. SALMON, At Pres8.

PRACTICAL CALCULATIONS FOR ENGINEERS. By C. E. LARARD, A.M.Inst. C.E., \&c., and H. A. GOLDING, A.M.Inst.M.E. THIRD EDITION, - net. 3s 6d

ELEMENTARY GRAPHIC STATICS. By W. J. CRAWFORD, D.Sc., - net. 2s Gd

CALCULATIONS ON THE ENTROPY-TEMPERATURE CHART. By W.J. CRAWFORD,

THE EFFECTS OF ERRORS IN SURVEYING. By Hy. BRIGGs, M.Sc. In In
Crown 8vo. Cloth, 


\section{GRIFFIN'S ENGINEERING PÜBLICATIONS-Continued.}

TRANSMISSION GEARS. BY EDWARD BUTLER,

- net. $8 \mathrm{~s} 6 \mathrm{~d}$

VALVES AND VALVE GEARING. By Charles HuRst. SEVENTH EdTion,

With Important Appendix, - - - - • - • - - - net. 9s od

SCIENCE AND INDUSTRY: THEIR CO-OPERATION. By S. R. ILLING-

WORTH, A.R.C.Sc., \&c. In Pocket Size, - - - - - - - net. 1s 0d

THERMO-DYNAMIC PRINCIPLES OF ENGINE DESIGN. By L. HoBBs, net. 4s 6d

ENGINEERING DRAWING AND DESIGN. By S. H. WrLL, Wh.Sc., \&c.

Vol. I.-Practical Geometry, Plane, and Solid. SEventh EdITIon, - - is 6d

Vol. II.-Machine and Engine Drawing and Design. FIFTH EDITION, - : 4s 6d

HANDBOOK ON TOWN PLANNING. By J. JULIAN, - - - - - net. 5s Od REFUSE DISPOSAL. By Prof. E. R. MATTHEWS. Fully Illustrated, - net. 6s Od CIVIL ENGINEERING PRACTICE. By F. NOEL TAYLOR. 1,086 Illus., net. 25s od THE MAIN DRAINAGE OF TOWNS. By F. NOEL TAYLOR. Fully Illus., net. 12s $6 \mathrm{~d}$ MODERN DESTRUCTOR PRACTICE. By W. F. GOODRICH. Fully Illus., net. 15s od ROAD MAKING AND MAINTENANCE. By THOMAS AITKEN SECOND ED., net. 21s Od MODERN ROAD CONSTRUCTION. By FRANCIS WOOD, M.Inst.C.E., - net. 4s 6d PETROL MOTORS AND MOTOR CARS. BY F. STRICKLAND. SECOND ED., net. 18s Od MOTOR CAR MECHANISM AND MANAGEMENT. By W. P. ADAMS.

Part I.-The Petrol Car. ThIRD EDITION, - - - - - - net. 5s 0d Part II.-Electrical Cars, - - - - - - - - - - net. 5s 0d

THE VAPORIZING OF PARAFFIN FOR HIGH-SPEED MOTORS (Electric Ignition Type). By E. BUTLER, - - - - - net. 3s 6d CARBURETTORS, VAPORISERS, AND DISTRIBUTING VALVES. BY ED BUTLER - - - - - - - - - - - - net. SCIENCE IN SMITHY AND FORGE. By W. H. CATHCART. SECOND EDITION,

THE ATROPLANE By A. net. 4s 0d COMPENDIUM OF AVIATION. By Lieut.-Col. Hokrnes. "Pocket Size, - net. 2s 6d THE PROBLEM OF FLIGHT. By Prof. H. CHATLEY. ShCOND EDITION, net. 10s 6d THE FORCE OF THE WIND. By Prof. HERBERT CHATLEY, B.Sc., net. 3s 0d STRESSES IN MASONRY, By Prof. HeRbert ChATLEY, B.Sc., - - - net. 3s 6d BUILDING IN EARTHQUAKE COUNTRIES. By A. MONTEL, - - - net. $8 \mathrm{~s} 6 \mathrm{~d}$ CENTRAL ELECTRICAL STATIONS (Design, Organisation, and Management); By C. H. WORDINGHAM, A.K.C. SECOND EDITION, net. 24s od

ELECTRICITY METERS. By H. G. SOLOMON, - - - - - - net. 16s 0d TRANSFORMERS. By Prof. H. BOHLE and Prof. D. ROBERTson, - - - net. 21s Od ELECTRIC CRANE CONSTRUCTION. By C. W. HILL, A.M.I.C.E., - net. 25s Od ELECTRICAL PHOTOMETRY. By Prof. H. BOHLE, M.I.E.E. Fully Illus., net. 10s 6d ELECTRO-METALLURGY. By WALTER G. McMILlan, F.I.C., F.C.S. THIRD EDITION, Revised and Enlarged by W. R. COOPER. Demy 8vo., - - net. 12s 6d

ELECTRICAL PRACTICE IN COLlieries. By Prof. D.'Burns, M.E. Cloth. FOURTH EDITION, Revised. With numerous Illustrations. : . net, 7s 6d ELECTRICITY IN MINING. By SIEMENS BROS., Ltd., - - • - - net. 10s 6d WIRELESS TELEGRAPHY. By GUSTAV EICHHORN, Ph.D., - - - net. 8s 6d TELEGRAPHIC SYSTEMS, and Other Notes. By ARTHUR CROTCH, net. $5 \mathrm{~s}$ od ELECTRICAL RULES AND TABLES (A Pocket-book of). By JOHN MUNRO and Professor JAMIESON. TWENTIETH EDITION. Pocket size. Leather, - net. 6s od

ELECTRICAL THEORY AND THE PROBLEM OF THE UNIVERSE. By G. W. de TUNZELMANN, - . net. 15s od THE THEORY OF STATICS. By G. UDNY YULE. FodrTH EDITION, - net. 10s 6d

WORKS BY W. J. MACQUORN RANKINE, LL.D., \&C.

CIVIL ENGINEERING (A Manual of). TWENTY-FOURTH EDITION, - - 16s od

A MANUAL OF APPLIED MECHANICS. NINTEENTH EDITION, - • : 12s 6d

A MANUAL OF MACHINERY AND MILLWORK. SEVENTH EDITION, - $12 \mathrm{~s}$ 6d

A MANUAL OF THE STEAM ENGINE AND OTHER PRIME MOVERS.

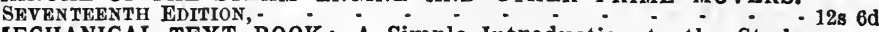

A MECHANICAL TEXT-BOOK: A Simple Introduction to the Study of Mechanies. By Prof. RANKINE and C. E. BAMBER. FIFTH EDITION, - 9s Od USEFUL RULES AND TABLES: For Arehitects, Builders, Engineers, Founders, Mechanics, Shipbullders, Surveyors, \&c. EIGHTH EDITION, 10s 6d

WORKS BY PROF. A. JAMIESON, M.InSt.C.E.

STEAM AND STEAM ENGINES (Advanced). SEVENTEENTH EDITION, - - 10s 6d APPLIED MECHANICS AND MECHANICAL ENGINEERING. Vol. I.Applied Mechanics, 6s, iet. Vol. II. - Strength of Materiais, 5s. Vol. III.-Theory of Structures, 5s. Vol. IV.-Hydraulics, 5s. net. Vol. V.Theory of Machines, $7 \mathrm{~s} 6 \mathrm{~d}$.

HEAT ENGINES: STEAM, GAS, AND OIL (Elementary Manual of). FourTRENTH EDITION, Revised by E. S. Andrews, B.Sc., - - - - net. 3s 0d

MAGNETISM AND ELECTRICITY (Practleal Elementary Manual of). NINTH EDITION, Revised by E. S. Andrews, B.Sc.

APPLIED MECHANICS (Elementary Manual of). ELEVENTH Edition, Revised by E. S. Andrews, B.Sc., 


\section{MARINE ENGINEERING AND NAVAL ARCHITECTURE.}

A MANUAL OF MARINE ENGINEERING. By A. E. SEATON, M.Inst.C.E., M.I.Mech.E., M.Iust.N.A. SEVhnthenth ED., Revised. net. 28s Od THE THEORY OF THE STEAM TURBINE. By ALEXANDER JUDE. ShCOND GDITION,
GRIFFIN'S NEW GUIDE TO THE B.o.T. EXAMINATIONS FंOR MARINE ENGINEERS. Vol. I.-Calculatious for Marine Engineers,. . . net. 8s 6d Vol. II.-Elementaries, Verbals, and Drawing, : . net. $8 \mathrm{~s} 6 \mathrm{~d}$

DIESEL ENGINES. By SUPINO, BREMNER, and RICHARDSON. SECOND EDITION,

EDITION, $\dot{0}$. net. 12s 6d HOBBS, R.N.,

ENGINE-ROOM' PRACTICE. 'By' JoH G. Liversidge, i.N.' NiNTH EDITION, Revised and Enlarged, . . * * . * . . . net. 6s od

SEA WATER DISTILLATION. By Frank NorMANDY. In Handsome cloth. Fully Illustrated, . . • . net. 6s od

MARINE ENGINEERING RULES AND TABLES. By A. E. SkATON and H. M. Rounthwaitk. Thirtentin Edition, Thoroughly Revised. Pocket

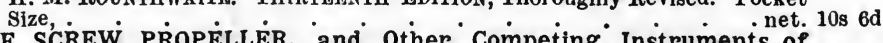

THE SCREW PROPELLER, and Other Competing Instruments of Marine Propulsion. By A. E. SkatoN, M.Inst.C.E. Fully Illustrated. net. 12s $6 \mathrm{~d}$

THE DESIGN AND CONSTRUCTION OF SHIPS. By Sir J. H. BILES, LL.D., \&c. Vol. I.-Calculations and Strength. With 36 Folding Plates and 245 other Illustrations. Complete in itself, with Index, . net. 25s od Vol. II.-Stability, Resistance, Propulsion, and Oscillations. Complete with

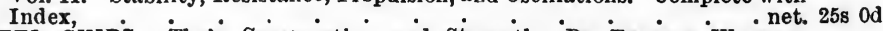

STEEL SHIPS. Their Constructioil and strength. By Thomas Waiton. FOURTH EDITION, Greatly Enlarged, . . . . . . . . net. 18s od

PRESENT DAY SHIPBUILDING. For Shipyard Students, Engineers, \&c. By THOMAS WALTON. Fully Illustrated,.

THE STABILITY OF SHIPS. By Sir EDWARD J. REED, 亡.C.B., F.R.S., M.P.

HYDROGRAPHIC SURVEYING. For the Use of Beginners, Amateurs, and Port and Harbour Masters. By Commander S. MEssum, of the R.N. College, Greenwich,

\section{GRIFFIN'S NAUTICAL SERIES.}

Elementary Seamanship. By D. WILSON-BARk ER. SEventh Edition, net. 6s Od Know Your Own Ship. By T. WALTON \& J. KING. FourTEENTh EdTTION, net. 7s 6d Trigonometry. By R. C. Buck. Fourth Edition, . • . • . . 3s 6d Practical Algebra. By R. C. Buck. SECOND EDITION, - • : • . 3s 6d Practical Mechanics. By T. MACKenzis. Fourth EDITION, - net. 3s 6d Navigation: Theoretical and Practical. By D. WILSON-BARKar and Marine Meteorology. By W. ALLINGHAM. SECond Edition, Revised, net, 7s 6d Latitude and Longitude. By W. J. MrLlar. SECOND EDITION, . . . is od The Legal Duties of Shipmasters. By B. W. GINsBURG. THIRD EdiTion, 5s Od A Medical and Surgical Help for Shipmasters. By W. JoHNson SMrTH. FouRTh EDITION, Revised by ARNOLD CHAPLIN of the P. \& O. Coy., . net. 5s Od

English-Spanish \& Spanish-English Sea Terms \& Phrases. By FleetPaymaster GrAHAM-HEWLETT. Pocket Size, . net. Definitions in Navigation \& Nautical Astronomy. By P.Groves-Show ELL,

The Practical Duties of Shipmasters. By Capt. W. HARrY Wrikrs.

Nature Notes for Ocean Voyagers. By Captains CARPENTER and WrisonBARKER, .

\section{PHYSICS.}

A TEXT-BOOK OF PHYSICS. By Prof. J. H. PoYnting and Sir J. J. THOMSON. Vol. I.-Properties of Matter. SIXTH EDITION, ..$\cdot^{*} .10 \mathrm{~s} 6 \mathrm{~d}$

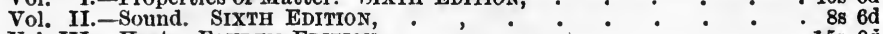

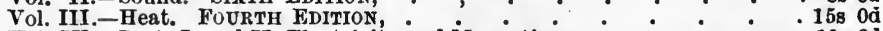
Vol. IV.-Parts I. and II. Electricity and Magnetism, . . . . . 10s 6d

ELEMENTARY TEXT-BOOK OF PHYSICS. By Dr. R. WALLACE STRWART. Vol. I.-General Physics, . . . . . . . . . . net. 4s 6d

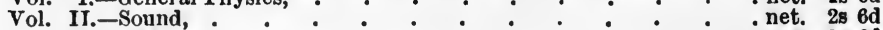
Vol. III.-Light, Vol. IV.-Heat, 


\section{GRIFFIN'S MINING AND GEOLOGICAL WORKS.}

ORE AND STONE MINING. By Sir C. LE Neve Foster, D.Sc., F.R.S. Sixth Edition, Revised by Prof. S. H. CoX, A.R.S.M., • • • net. 28s Od

THE ELEMENTS OF MINING AND QUARRYING. By Sir C. LE NEVE Foster, D.Sc. Revised by Prof. S. H. Cox. ThIRD Edition,. - - net. 7s 6d METHODS OF AIR ANALYSIS. By J. S. HALDANE, M.D., LL.D. In Crown

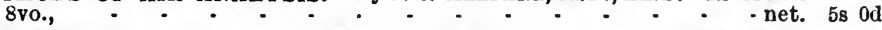

ThE AIR OF Mines. By Prof. J. Cadman and J. S. Haidane, M.D.,

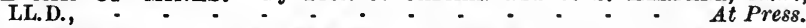

A TEXT-BOOK OF COAL-MINING. By H. W. HugheS, F.G.S. SIXTH EDITION, Revised and Enlarged. With 4 Plates and 670 Illustrations, - net. 24s 0d

PRACTICAL COAL-MINING. By GeORge L. KFrR, M.E. Fifth Edition, Rewritten and Greatly Enlarged, - • - • ? . ? . • net. $12 \mathrm{~s} 6 \mathrm{~d}$

ELEMENTARY COAL-MINING. By. GEORGE L. KERR, M.E. With 200 Illustrations. FOURTH EDITION, Revised, - $\cdot$ - ? • . - net. 3s 6d

MINE-SURVEYING. By BeNNETT H. BROUGH, F.G.S. FOURTEENTh Edition by H. DEAN, M.Sc., A.R.S.M., - - • • . - - • - net. 7s 6d

THEODOLITE SURVEYING AND LEVELling. 'By Prof. James Park, F.G.S. In Crown 8vo. Cloth. Illustrated. THIRD EDITION, - - net. 10s 6d

THE EFFECTS OF ERRORS IN SURVEYING. By HY. BRIGGS. With

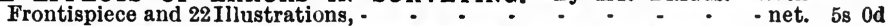

PRACTICAL SURVEYING AND FIELD-WORK. By V. G. SALMON, At Press.

MINING GEOLOGY. A Text-Book for Mining Students and Miners. By JAMES PARK, F.G.S., M.Inst.M.M.

PROSPECTING FOR MiNeRALS. By Prof. S. Herbert Cox. Sixth Edition, Revised,

MINING LAW OF THE BRITISH EMPIRE. By ChARLES J. ALFORD, F.G.S. Cloth, • - • - • - • • • • • - - - net. 8s 6d MODERN MINE VALUATION. By M. A. BURNhAM, B.Sc. Pp. $1-x i+160$.

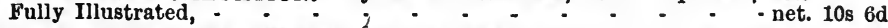
MINE ACCOUNTS AND MINING BOOK-KEEPING. By J. G. LAWN, Assoc.R.S.M. FIFTH IMPRESSION, - - • • • • - - - 10s 6d

THE MINING ENGINEER'S REPORT BOOK AND DIRECTORS' AND SHAREHOLDERS' GUIDE. By EDWIN R. FIELD. THIRD EDITION. Pocket Size. Leather, -

ELECTRICITY IN MINING. By SIEMENs BRos., Ltd. Very beautifully Illustrated. Printed on Art Paper, - - - - • - . - - net. 10s 6d

ELECTRICAL PRACTICE IN COLLIERIES. By Prof. D. BURNS, M.E., M.Inst. M.E. FOURTH EDITION, Revised and Enlarged, - $\cdot{ }^{-}$- net. 7s 6d

COMPRESSED AIR PRACTICE IN MINING. By D. PKNMAN, - - net. 5s 0d PRACTICAL HYDRAULICS FOR MINING STUDENTS. By Prof. J. PARK,

BRIQUETTING. By - net. 30s od BRIQUETTING. Vol. II. - $\cdot \cdot \cdot \cdot \cdot \cdot$ At Press.

SHAFT SINKING IN DIFFICULT CASES. By J. RIRMRR and J. W. BROUGH, - - • - • - • - * net. 108 6d

BLASTING: And the Use of Explosives. By 0 . GUTTMANN. SEOOND EDITION, TESTING EXPLOSIVES. By C. E. BICHEL and AXEL LARSEN. With many Plates, SPANISH-ENGLISH AND ENGLISH-SPANISH MINING, METALLURGICAL, AND ALLIED TERMS. By EDWARD HAISE, A.R.S.M. Cloth. SECOND EDITION, - • - - - - - - - • - - net. 10s 6d GETTING GOLD. A Gold-mining Handbook for Practical Men. By J. C. F. JOHNSON, F.G.S., A.I.M.E. FIFTH EDITION, - ? • - ? - net. 3s 6d GOLD-SEEKING IN SOUTH AFRICA. A Handbook of Hints. By THEO.

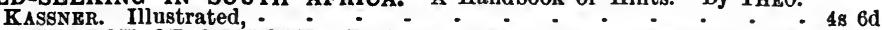

A TEXT-BOOK OF GEÓlogY. By Prof. James Park. Very fully Illus-

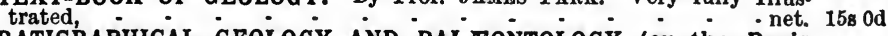
STRATIGRAPHICAL GEOLOGY AND PALEONTOLOGY (on the Basis of Phillips). By R. ETHERIDGB, F.R.S., - - - - - - - 34s 0d THE EARTH : ITS GENESIS AND EVOLUTION. By A. T. SWAINE. With 11 Plates and 53 other Illustrations, - $\bullet \cdot \cdot \cdot \cdot$ - net. $786 \mathrm{~d}$ AIDS. IN PRACTICAL GEOLOGY. By Prof. G. Cole, M.R.I.A. SixTH EDITION, FOR ENGINEERS. By Lieut.-Col. R. F. SorsBIE. Fully Illustrated, MINERAL WEALTH AND GEOLOGY OF CHINA. By C. Y. WANG, $\begin{array}{r}\text { - net. } \\ \text { 10s }\end{array}$ 


\section{GRIFFIN'S METALLƯRGICAL SERIES.}

AN INTRODUCTION TO METALLURGY. By Sir W. C. ROBERTS-AUSTEN, K.C.B., F.R.S., A.R.S.M. SIXTH EDITION, by F. W.HARBORD, A.R.S.M. net. 18s od

THE METALLURGY OF GOLD. By Sir T. KIRKE ROSE, D.Sc., Chemist and Assayer to the Royal Mint. SIXTH EDITION, Revised and re-written, - net. 22s 6d

THE METALLURGY OF SILVER. By H. F. COLLINS, Assoc.R.S.M., M.Inst.M.M. SECOND EDITION, - - - - - - In Preparation.

THE METALLURGY OF LEAD. An Exhaustive Treatise on the Manufac. ture of Lead. By H. F. Collins, Assoc.R.S.M., M.Inst.M.M. SECOND EDITION, Revisea ,

THE METALLURGY OF THE NON-FERROUS METALS. By WM. GOWLAND, F.R.S. SECOND EDITION, Revised and Enlarged, - - * - net.

THE METALLURGY OF STEEL. By F. W. HARBORD. Assoc. R.S.M., F.I.C. and J. W. HALL, A.M.Inst.C.E. SixTH EdiTion. In two volumes, - net. $36 \mathrm{~s}$ od

THE METALLURGY OF IRON. By THOMAS TURNER, Assoc.R.S.M., F.I.C., Prof. of Met., Birmingham Univ. FourTH EDIrION, Revised and Enlarged.

ALLOYS, AND THEIR INDUSTRIAL APPLICATIONS. By EDWARD F. LAW, 16s Od A.R.S.M. THIRD EDITION, - net.

SAMPLING AND ASSAY OF THE PRECIOUS METALS, By E. A. SMITH, 12s $6 \mathrm{~d}$ A.R.S.M., AS. - - - net.

ANTIMONY: Its History, Chemistry, Mineralogy, Geology, Metallurgy 15 s od Preparation, \&c. By C. Y. WANG. In Large 8vo. Cloth. Illustrated, net. 12s 6d

ROBERTS-AUSTEN : Addresses and Scientific Papers. By S. W. SMITH, - net. 21s 0d

OTHER METALLURGICAL WORKS.

GOLD DEPOSITS OF THE RAND. By C. B. HORWOOD, - - - - net. 15s Od RAND METALLURGICAL PRACTICE. In Two Volumes.

Vol. I. - SECOND EDITION, net. 21s. Vol. II. - SECOND EDITION, - - net. 21s 0d MODERN COPPER SMELTING, LECTURES ON. By D. M. LEVY, - net. 10s 6d RESEARCHES ON SPECIAL STEELS. By Sir R. A. HADFIELD, Bart.

CAST IRON IN THE LIGHT OF RECENT RESEARCH. By W. H. HATFIELD, D.Met. Profusely Illustrated. SECOND EDITION, Revised, - - - net. 10s 6d

PHYSICO-CHEMICAL PROPERTIES OF STEEL. By Prof. C. A. EDWARDS, $D$, Sc, -10 d

CYANIDING GOLD AND SILVER ORES. By H. FORBES JULIAN and EDGAR SMART, A.M.Inst.C.E. SEOOND EDITION, - - net. 21s 0d

THE CYANIDE PROCESS OF GOLD EXTRACTION. By Prof. JAMES PARK, F.G.S. FIFTH ENGLISH EDITION,

TEXT-BOOK OF ASSAYING. By J. J. BERINGER. F.I.C., F.C.S., and C. BERINGER, F.C.S. THIRTEENTH EDITION. Illustrated, - ? - - - 10s 6d

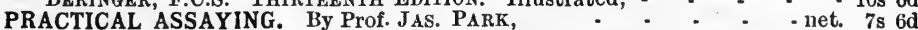

METALLURGICAL ANALYSIS AND ASSAYING. A Three Years' Course. By W. A. MACLEOD, B.A., B.SC., and CHAS. WALKER, F.C.S., - - - net. 12s 6d

MINERALOGY OF THE RARER METALS. By E. CAHEN and $w^{\circ} 0$. WOOTTON, - - - - - - os od

MICROSCOPIC ANALYSIS OF METALS. By FLORIS OSMOND and J. E. STEAD, F.R.S. SWOUND EDITION. By L. P. SIDNEY, - - - - ? - net. 8s 6d

METALLIC ALLOYS : Their Structure and Constitution. By G. $H$. GULLIVER, B.Sc., F.R.S.E. SECOND EDITION, Thoroughly Revised, - net. $10 \mathrm{~s} 6 \mathrm{~d}$ INTRODUCTION TO PRACTICAL METALLURGY. By Prof. T. TURNER, net. 3s Od ELEMENTARY METALLURGY. By A. H. SEXTON, F.I.C. FOURTH EDN., - 6s Od LECTURES ON IRONFOUNDING. By Prof. T. TURNER. SECOND EDITION, net. 3s 6d GENERAL FOUNDRY PRACTICE. By A. MCWILIIAM, A.R.S.M., and PERCY LONGMUIR. In Medium 8vo. SECOND EDITION, Revised, - ! - net. 15s 0d NOTES ON FOUNDRY PRACTICE. By J. J. MORGAN, F.C.S., - - - net. 2s 6d BLAST FURNACE PRACTICE. By J. J. MORGAN, F.C.S.." : - - net. 2s Od SMITHY AND FORGE, Science in. By W. H. CATHCART, SECOND ED., net. 4s Od TREATISE ON ELECTRO-METALLURGY. By W. G. McMillan and W. R. COOPER. THIRD EDITION, Revised, - . ? : - ? - net. 12s $6 \mathrm{~d}$

\section{WORKS ON PETROLEUM.}

PETROLEUM AND ITS PRODUCTS. By Sir BOVERTON REDWOOD, D.Sc. THIRD EDITION, Revised, A HANDBOOK ON PETROLEUM, for Inspectors under the Petroleum Acts. By Capt. J. H. THOMSON, Sir. B. REDWUOD, and Major COOPER-KeY.

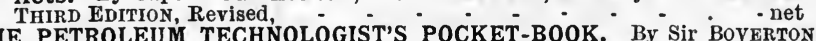
REDWOOD and ARTHUR EASTLAKE, - - • - • - • - net. 8s 6d THE STORAGE OF PETROLEUM. SPIRIT. By Major A. COOPER-KEY. - net. 2s 6d OIL FUEL. Its Supply, Composition, and Application. BY EDWARD BUTLER. M.I.Mech.E. THIRD EDITION, Revised and Enlarged, - - net.

LABORATORY HANDBOOK OF MINERAL OIL TESTING. BY J. A. HICKS. THIRD EDITION, Revised, - - : - - - - net. 2s 6d

LONDON : CHARLES GRIFFIN \& C0., LTD., EXETER ST., STRAND,W.C. 2. 


\section{GRIFFIN'S TECHNICAL PUBLICATIONS.}

Chemistry for Engineers and Manufacturers. By BERTRAM BLOUNT, F.I.C., and A. G. BLUXAM, F.I.C. Vol. I. SECOND EDITION, • • • $14 \mathrm{~s}$ od Vol. II. SECOND EDITION, - • • • - - - • • • • • . 16s 0d

Oils, Fats, Butters, and Waxes. By C. R. Aldor Wright, D.Sc. Revised by C. A. MITCHELL, B.A., F.I.C. SECOND EDITION. With 800 pages, - net. 25s od Aids In the Commercial Analysis of Oils, Fats, and their Manufactured Products. By G. F. PICKering, - - - - - net. 7s 6d Oils, Resins, and Paints : Analysis and Valuation. By H. INGLE, D.Sc., net. 3s $6 \mathrm{~d}$ Physico-Chemical Tables. By J. CASTkld-Evans, F.I.C. Vol. I.-Chemical Engineering, - - - - - - - - - * . - net. $24 \mathrm{~s}$ od

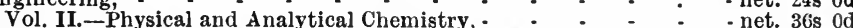

Quantitative Inorganic Analysis. By Dr. J. W. MeLLor. Very fully Illustrated throughout, Water Analysis for Sanitary and Technical Purposes. By H. B. STocks, F.I.C., F.C.S., - - - - - - - - - - - - - net. 4s 6d

Methods of Air Analysis. By J. S. HALDANe, M.D., LL.D., F.R.S. Fully Illustrated, - - : - - - net.

Foods: Their Composition and Analysis. By A. W. and M. W. BLYTH. Sixth EDITION, EDITION, - - - - • - - • - • • • • - net. 21s 0d

Flesh Foods: Chemical, Microscopical and Bacteriological Examination. By C. A. Mitchkl, - - - • - - - - - - 10s 6d

Dairy Chemistry. By H. DRoop RICHMOND, F.I.C., Analyst to the Aylesbury Dairy Co. SECOND EDITION, - - - - - - - - net. 15s 0d

Dairy Analysis. By H. DROOP RICHMOND, F.I.C. SECOND EDITION, Thoroughly Revised. Crown 8vo. Illustrated, - - - - - - - - net. 2s 6d

Milk: Its Production and Uses. By EdWARD F. WILloughBY, M.D. - net. 6s od

Elementary Agricultural Chemistry. By HerberT INGLe, B.Sc. SkCoND

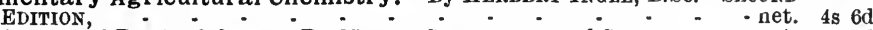

Agricultural Bacteriology. By LöHnIs, STEVENSon, and SMITH, - - net. 4s 6d

The Principles and Practice of Brewing. By Dr. W. J. SYKES. THIRD EDITION, Revised by A. R. LING, F.I.C., - - - - - * - net. $21 \mathrm{~s} 0 \mathrm{~d}$

Technical Mycology. Dr. F. LAFAr. SEcond EdITION. In Two Vols.

Vol. I., net. 15s 0d; Vol. II., net. $24 \mathrm{~s}$ od

Micro-Organisms and Fermentation. By ALFRED Jörgenskn. FourTH EdITION, Completely Revised. Translated by S. H. DAvirs, B.Sc, - net. 15s 0d

Ferments and Their Actions. By C. Oppenheimer. Translated by C. A MitcheLL, B.A., F.I.C. In Cloth, - - - - - - - - net. $7 \mathrm{~s} 6 \mathrm{~d}$

Vinegar: Its Manufacture and Examination. By C. A. Mrtchell, B.A., F.I.C. - - - - - - - - - - . - net

Peat: Its Use and Manufacture. By P. BJöRLING and F. Gissixg. net. Commereial Peat: Its Uses and Its Possibilities. By F. T. GIssing. In Crown 8vo. Cloth, - - - - - - net.

Paper Technology. By R. W. SINDAlL, F.C.S. In Medium 8vo. Handsonie Cloth. Illustrated. SECOND EDITION. Revised, - - - - net. 12s 6d

Stationery Testing. By H. A. BROMLEY. Fully Illustrated, - - net. 2s $6 \mathrm{~d}$

The Clayworkers' Handbook. By A. B. SEARLE. SkCOND Edition, Revised. In Cloth, - - - - - - - - - - net. $6 \mathrm{~s} 0 \mathrm{~d}$

Britlsh Clays, Shales, and Sands. By A. B. SEARLE. lllustrated, - net. 7s 6d

Refractory Materials. By A. B. SEARLF, - - - - - - - net. 15s 0d

Ceramic Literature. Compiled, Classifled, and Described by M. L. Solon, net. 42s 0d

Art of the Goldsmith and Jeweller. By T. B. WIGLEY. SECOND EDITION, Revised, and with 12 New Plates, - - - - - - - - net. 7s 6d

Modern Methods of Sewage Purification. By G. BERTRAM KERshaw. Fully Illustrated, - - - - - - • - - • - - net. $21 \mathrm{~s}$ od

The Principles of Sewage Treatment. By Prof. Dunbar of Hamburg. Translated by H. 1. CALVERT, M.Sc., - - * - * - net. 15s 0d

Trade Waste Waters. By H. WILSON, M.D., and H. T. CALVERT, Ph.D. With 22 Plates and many other Illustrations, - - - - - - net. 18s 0d

Trades' Waste: Its Treatment and Utilisation. By W. NAYLOR, F.C.S., - - net. $21 \mathrm{~s} 0 \mathrm{~d}$

Refuse Disposal. By Prof. E. R. Matriews, - - - - - - - net. 6s 0d

Fire and Explosion Risks. By Dr. VoN SchwarTz, - . - . - - net. 16s 0d

Smoke Abatement. By WM. NICHorson. With Illustrations, - - net. 6s od

Town Planning. By Julian JuliaN, B.E., - - - - - - - net 5s od

Calcareous Cements. By G. R. REDGrave and CharLes SPACKMAN, F.C.S.

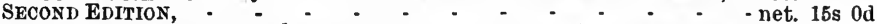

Handbook for Cement Works' Chemists. By Frank B. Gatrhouse, F.C.S. In Handsome Cloth. SECOND EDITION, Revised and Enlarged, - - net. 5s 0d

Calorific Power of Coal Gas. By J. H. CosTE, F.I.C. - • - - net. 6s 0d

Fuel : Gaseous, Liquid and Solid. By J. H. CoSTE and F. R. ANDREws, net. 6s Od Acetylene. By F. H. LEEDs and W. J. A. BuTTERFIELD. SECOND EDITION, net. $8 \mathrm{~s}$ 6d

Practical Sanitation. By GEo. REID, M.D. With Appendix on Sanitary Law. EighteENTH Edition, - net. $6 \mathrm{~s} 0 \mathrm{~d}$ 


\section{GRIFFIN'S TECHNICAL PUBLICATIONS.}

Lessons on Sanitation, By J. W. HARRISON, M.R.San.I., - . - net. 38 6d Sanitary Engineering. By FrancIS WOOD, A.M.Inst.C.E. THIRD EDITION,

Modern Destructor Practice. B w tor Practice. By W. F. GoODRICH. Illustrated, - net. 158 Od

Modern Road Construction. By Fraveis Wood,

Handbook on Town Planning. By J. Julis N, - . - . . - . net. 5s 0d

Enamelling on 1ron and Steel. By Julius GRüNwaLb. Cloth. Illustrated. net. 6s 0d Technology of Iron Enamelling and Tinning. By JULIUS GRüNWALD, net. 6s Od Raw Materials of the Enamel Industry. By J. GRüWALD, - - net. 8s 6d Treatise on Colour Manufacture. By GEORGK ZERR and Dr. RUBENCAMP. English Edition by Dr. C. MAYER, of Burgdorf. Profusely Illustrated, - net. 30s 0d Tests for Coal-Tar Colours in Aniline Lakes. By GEORGE ZERR. Translated by Dr. C. MAYER, - - net.

Painting and Decorating. A Complete Practical Manual. By W. J. Pearce. FOURTH EDITION, Revised and Enlarged, -

Painters' Colours, Olls, and Varnishes. G. H. HuRST, F.C.S. Frwth EDrTion, Revised and Enlarged. By NOEL HkatoN, B.Sc., • • - net. 10s 6d

Painters' Laboratory Guide. By G. H. HUlsT, F.C.S. In Cloth, : - - 5s 0d

The Chemistry of the Colloids. By Dr. V. Pöschl. Translated by Dr. H. - net. ne

Celluloid: Its Manufacture, Application, and Substitutes. From the French of MASSELON, ROBERTS, AND CILLARD. By Dr. H. H. HODGSON, - net. 25s Od

Chemistry of India Rubber. By C. O. WEBER, Ph.D. THIRD IMPRESSION. With many Illustrations, -

The Manufacture of Rubber Goods. By ADOLF Hril and Dr. W. Esch. Translated by E. W. LEWIS, A.C.G.I. In Cloth. Illustrated, - - net. 10s 6d

Rubber: Its Production, Chemistry, and Synthesis. By DUBOsc and LUTTRINGER. Translated by E. W. LewIs.

Glue, Gelatine, and Their Allied Products. By Thomas LAMBERT. In Large Crown 8vo. Fully Illustrated, - - . net. 5s 0d

Leather Trades Chemistry. By S. R. Troman, M.A., F.I.C. In Handsome

Cloth. Fully Illustrated, . - • • • • • • - net. 158 0 d

Ink Manufacture. By C. A. MrTCheli, B.A., F.I.C., and T. C. Hepworth. SFOOND EDITION, Revised. Re-set on Larger Page. In Cloth. With Plates

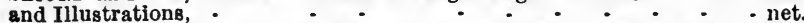

A Manual of Dyeing. By E. KNECHT, Ph.D., CHR. RAwson, F.I.C., and R. LOEWENTHAL, Ph.D. FourTh EDITION, - - • - . - net. 36s 0d

Synthetic Dyestuffs, and the Intermediate Products from which they are Derived. By J. C. CAIN, D.Sc., and J. F. THORPE, Ph.D. THIRD EDrmon, Revised, - * - - - - - - net.

The Analysis of Dyestufís. By ARTHor E. Green, M.Sc., F.R.S., F.I.C. Illustrated. SECOND EDITION, - - - : - - - net. 8s 6d

Dictionary of Dyes, Mordants, and Other Compounds. By CHR. RAwson, F.I.C.. W. M. GARDNRR, F.C.S., and W. F. LAYCOCK, Ph.D. In Large 8vo. Cloth, Library Style. SECOND EDITION, - - - - * • - net. 16s 0d

Spinning and Twisting of Long Vegetable Fibres (Flax, Hemp, Jute, Tow, and Ramie). By H. R. CARTER, - net. 16s 0d

The Cotton Weavers' Handbook. By H. B. HkYuIN. In Cloth, - - net. 6s 0d

Buyers and Sellers in the Cotton Trade. By H. B. HEYLrN. With Chronological and Statistical Chart, - - - - - • - - net. 8s 6d

Textlle Fibres of Commerce (Occurrence, Distribution, Preparation, and Uses). By W. I. HANNAN. In Cloth. With Illustrations, - - net. 9s od Bleaching and Finishing of Cotton. By S. R. TrotmaN, M.A., and E. L. THORP, M.I.Mech.E., - • • • • • • • net. 16s 0d

Textile Printing. By E. KNechr, Ph.D., and J. B. FoTHERGrLl. With 13 Plates and 86 Patterns in the Text, - - - - • - * - net. 36s.0d

Textile Printing. By C. F. S. RoTHweL, F.C.S. With Illustrations, : $21 \mathrm{~s}$ od Exraving for Calico-Printing. By WM. BLACKWOOD, • - net. 10s 6d Dyeing and Cleanine. By FRANK J. FARRELL, M.Sc. In Cloth. With 76 Illustrations. FourTH EDITION, Enlarged, Bleaching and Calico Printing. By G. DUERR \& WM. TURNBULL. - : - 12s 6d Text-Book of Inorganic Chemistry. Edited by J. NEwTON FrIEND, D.Sc. In IX Vols. (See General Catalogue, p. 97.)

Elementary Practical Chemistry. By J. E. MYers and J. B. FrrTH, - net. 4s 0d Inorganic Chemistry. By A. DUPRÉ and WILSON HAKE. ThIRD EdITIon, net. 6s Od Elements of Chemical Engineering. ByJ. Grossmann. SECOND EdrTion, net. 3s 6d Outlines of Quantitative Analysis. By A. H. SkXTon, F.I.C. FrFth Fidron, 3в 0d Outlines of Qualitative Analysis. By A. H. SEXTon, F.I.C. FodRTH EdiTion, 3s 6d 





\section{DAY USE \\ RETURN TO DESK FROM WHICH BORROWED LOAN DEPT.}

This book is due on the last date stamped below, or on the date to which renewed.

Renewed books are subject to immediate recall.

\begin{tabular}{|c|c|}
\hline : $180 \mathrm{coc}^{2} 55 \mathrm{~W}_{\text {: }}$ & $18 \mathrm{Nor} 158 \mathrm{GiH}$ \\
\hline RECD LD & \\
\hline$D E C_{4} \quad 1900$ & 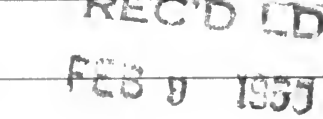 \\
\hline 2IAp55 8)Z & \\
\hline RECD D & \\
\hline APR 78903 & \\
\hline DAAPT58TS & \\
\hline & \\
\hline REC'D :D & \\
\hline APR 241958 & \\
\hline
\end{tabular}




$$
\text { YO } 11328
$$

THE UNIVERSITY OF CALIFORNIA LIBRARY 
